\title{
Regulation of FAT/CD 36-mediated long-chain fatty acid uptake by cardiac muscle : implications for diabetes and its treatment
}

Citation for published version (APA):

Coort, S. L. M. (2005). Regulation of FAT/CD 36-mediated long-chain fatty acid uptake by cardiac muscle : implications for diabetes and its treatment. [Doctoral Thesis, Maastricht University]. s.n.]. https://doi.org/10.26481/dis.20050630sc

Document status and date:

Published: 01/01/2005

DOI:

10.26481/dis.20050630sc

Document Version:

Publisher's PDF, also known as Version of record

Please check the document version of this publication:

- A submitted manuscript is the version of the article upon submission and before peer-review. There can be important differences between the submitted version and the official published version of record.

People interested in the research are advised to contact the author for the final version of the publication, or visit the DOI to the publisher's website.

- The final author version and the galley proof are versions of the publication after peer review.

- The final published version features the final layout of the paper including the volume, issue and page numbers.

Link to publication

\footnotetext{
General rights rights.

- You may freely distribute the URL identifying the publication in the public portal. please follow below link for the End User Agreement:

www.umlib.nl/taverne-license

Take down policy

If you believe that this document breaches copyright please contact us at:

repository@maastrichtuniversity.nl

providing details and we will investigate your claim.
}

Copyright and moral rights for the publications made accessible in the public portal are retained by the authors and/or other copyright owners and it is a condition of accessing publications that users recognise and abide by the legal requirements associated with these

- Users may download and print one copy of any publication from the public portal for the purpose of private study or research.

- You may not further distribute the material or use it for any profit-making activity or commercial gain

If the publication is distributed under the terms of Article $25 \mathrm{fa}$ of the Dutch Copyright Act, indicated by the "Taverne" license above, 


\title{
REGULATION OF FAT/CD36-MEDIATED LONG-CHAIN FATTY ACID UPTAKE BY CARDIAC MUSCLE:
}

\author{
Implications for diabetes and its treatment
}


The studies presented in this thesis were performed at the departments of Genetics \& Cell Biology and Physiology, Cardiovascular Research Institute Maastricht (CARIM), Maastricht University, the Netherlands.

Susan L.M. Coort, Maastricht 2005

ISBN $\quad: 90-8590-003-4$

Cover design,

Lay-out \& Illustrations : D\&L graphics - Eric Lemmens/John Derwall www.dlgraphics.nI

Printed by $\quad$ : Schrijen-Lippertz-Huntjens 


\title{
REGULATION OF FAT/CD36-MEDIATED LONG-CHAIN FATTY ACID UPTAKE BY CARDIAC MUSCLE:
}

\author{
Implications for diabetes and its treatment
}

\author{
PROEFSCHRIFT \\ ter verktijging van de graad van doctor aan de Universiteit Maastricht, \\ op gezag van de Rector Magnificus, Prof. mr. G.P.M.F Mols \\ wolgens het besluit van het College van Decanen, \\ in het openbaar te verdedigen \\ op donderdag 30 juni 2005 om 14:00 uur
}

door

Susan Leonie Marie Coort

geboren op 9 februari 1978 te Limbricht 


\section{Promotores:}

Prof. dr. J.F.C. Glatz

Prof. dr. G.J. van der Vusse

\section{Co-promotor:}

Dr. J.J.F.P. Luiken

\section{Beoordelingscommissie:}

Prof dr. H.A.]. Struijker Boudier (voorzitter)

Dr. M. Diamant (VUmc-Amsterdam)

Dr. A.J. Meijer (AMC-Amsterdam)

Prof. dr. A.M.W.J. Schols

Prof. dr. C.D.A Stehouwer

The studies presented in this thesis were supported by a grant of the Netherlands Heart Foundation (NHF-2000.159).

Financial support by the Netherlands Heart foundation and the Diabetes Foundation for the publication of this thesis were gratefully acknowledged. Printing of this thesis was also financially supported by the Dr. Ir. van der Laar Stichting, the J.E. Jurriaanse Stichting and Hope Farms / abdiets, Woerden. 
Voor mijn ouders en Erik 



\section{CONTENTS}

Chapter 1: General introduction

Chapter 2: Cardiac substrate uptake and metabolism in obesity and type-2 diabetes:

Role of substrate transport proteins

Chapter 3: Contraction-induced FAT/CD36 translocation in rat cardiac myocytes is mediated through AMP-activated protein kinase signalling

Chapter 4: Dipyridamole alters cardiac substrate preference by inducing translocation of FAT/CD36, but not that of GLUT4

Chapter 5: DAG-inducible PKC isoforms other than PKC $\alpha, \delta$ and $\varepsilon$ are involved in oligomycin-inducible palmitate uptake by cardiac myocytes

Chapter 6: Enhanced sarcolemmal FAT/CD36 content and triacylglycerol storage in cardiac myocytes from obese Zucker rats

Chapter 7: Divergent effects of rosiglitazone on protein-mediated fatty acid uptake in adipose and in muscle tissues of obese Zucker rats

Chapter 8: In vitro and in vivo application of sulfo- $N$-succinimidyl esters of long-chain fatty acids

Chapter 9: General discussion

Summary/Samenvatting

List of publications

Curriculum Vitae

Dankwoord 


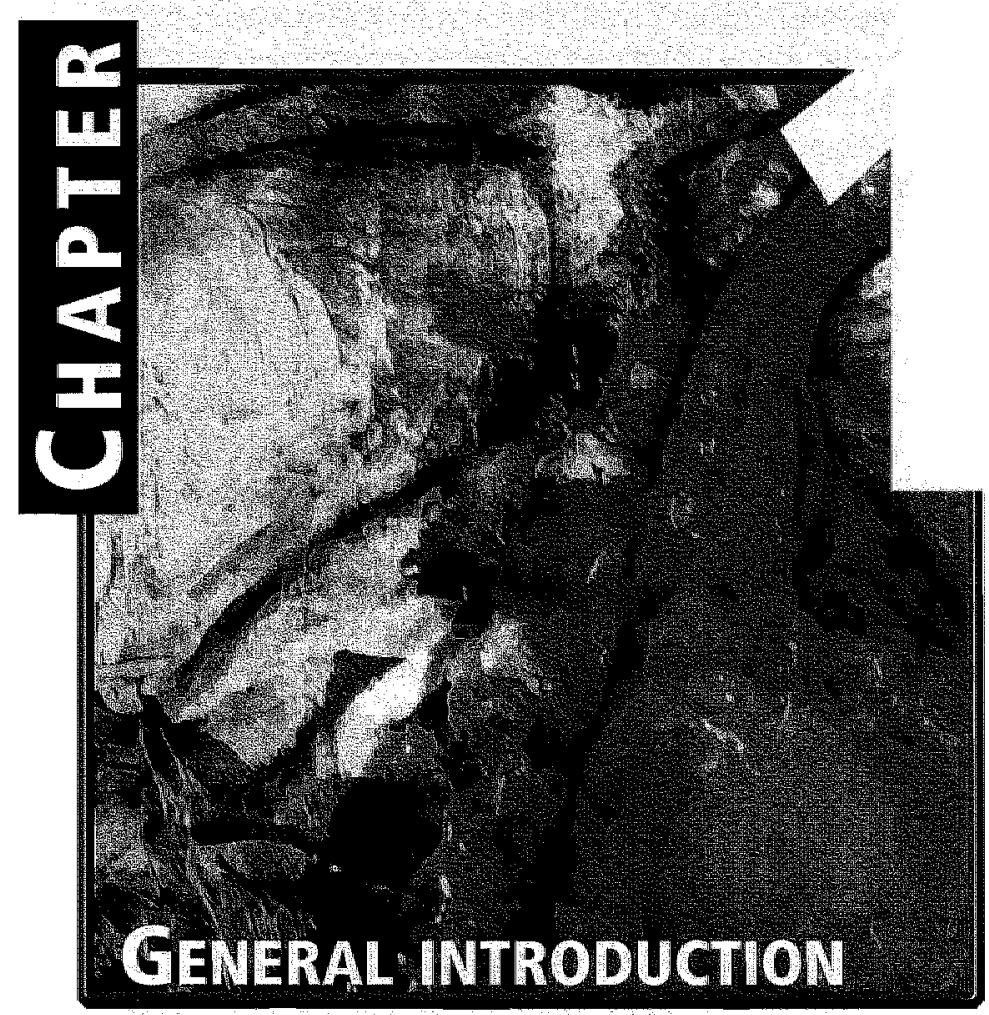




\section{INTRODUCTION}

The heart predominantly consists of specialized muscle cells, cardiac myocytes, which perform contractions in a coordinated manner. During the energy demanding contraction process ATP is generated by the oxidation of substrates. Under physiological conditions cardiac myocytes predominantly utilize long-chain fatty acids (LCFAs, 60-70\%) with the remainder being covered by carbohydrates, lie, glucose $(20 \%)$ and lactate $(10 \%)^{2,3}$. The uptake of both LCFAs and glucose is regulated by the sarcolemmal content of specific transport proteins, l.e., fatty acid translocase (FAT)/CD36 and GLUT4, respectively4,5. These transport proteins are not only present at the sarcolemma, but also in intracelluilar storage compartments 6,7 . The regulatory mechanisms involved in GLUT 4 -mediated glucose uptake by cardiac myocytes have been well described. Both an increased workload and the hormone insulin, via the activation of AMP-activated kinase (AMPK) and phosphatidylinositol-3 kinase $\left(\mathrm{Pl}_{3} \mathrm{~K}\right)$, respectively, acutely regulate glucose uptake by recruiting GLLT4 to the sarcolemma ${ }^{7} 10$. At present several putative LCFA transport proteins have been identified, i.e., FAT/CD36, plasmalemmal fatty acid binding protein (FABPpm) and fatty acid transport protein (FATP). Both the subcellular localization and the regulation by insulin of FAT/CD36 resemble that of GLUT44. However, whether an increased workload also affects FAT/CD 36 in the same manner as GLUT4 is uncertain. Studies presented in this thesis will contribute to the elucidation of the signalling pathway activated by an increased workload and modulating FAT/CD36-mediated LCFA uptake by cardiac myocytes.

The incidence of obesity and type-2 diabetes mellitus (T2DM) is drastically increasing worldwide ${ }^{1214}$. Heart disease is the leading cause of mortality and death in these patient populations 15,16 . The mechanism underlying cardiac dysfunction in T2DM is unknown, but alterations in the utilization of substrates by the heart have been proposed to contribute to the functional impairment. In this thesis, animal studies were performed to obtain new insights into substrate utilization by cardiac myocytes in the presence of insulin resistance.

\section{AIMS OF THIS THESIS}

The first aim of this thesis was to analyze the subcellular localization of FAT/CD36 in isolated rat: cardiac myocytes during cellular contractions. Moreover, components of the contractionsignalling pathway resulting in increased cardiac substrate uptake were to be unravelled. The second aim was to investigate in isolated cardiac myocytes from insulin resistant, obese Zucker rats, the content and subcellular localization of FAT/CD36. Moreover, in these cardiac myocytes the recruitability of FAT/CD3.6 upon insulin treatment or increased workload, and the consequences for LCFA utilization were investigated. The third aim was to determine whether the total amount and subcellular localization of FAT/CD36, and of other putative LCFA transport proteins, i.e., FABPpm and FATP1, in metabolically important tissues are affected in obese Zucker rats treated with a well-established oral insulin sensitizing agent, i.e., rosiglitazone. The final aim was to investigate the effects of possible new insulin sensitizing agents, i.e., sulfo- $N$-succinimidyl esters of LCFAs that specifically bind to FAT/CD36, on cellular LCFA uptake and utilization both in vitro and in vivo. 


\section{ISOLATED RAT CARDIAC MYOCYTES IN SUSPENSION FOR STUDYING CONTRACTION SIGNALLING}

Most studies presented in this thesis are based on measurements performed in isolated rat cardiac myocytes. By retrograde Langendorf perfusion cardiac myocytes were isolated from a rat heart and thereafter, were kept in suspension (Fig. 1.1). These single-cell suspensions are easily accessible by pharmacologically active compounds: In addition, the extracellular envitonment is well controlled and vascular factors are eliminated. Although cardiac myocytes contract constantly in vivo, in suspension the trigger for controlled contractions is not present resulting in a decline in metabolic rate. Therefore, Luiken et al. ${ }^{17}$ developed an experimental setup that induces contractions at $200 \mathrm{~V}$ with a frequency of $4 \cdot \mathrm{Hz}$ into cardiac myocytes in suspension. Moreover, in cardiac myocytes the contraction-signalling pathway can be pharmacologically induced by (i) 5-aminoimidazole-4-carboxamide-1- $\beta$-D-ribofuranoside (AICAR), which is intracellularly phosphorylated into AICAR monophosphate (ZMP), an AMP analog, and (ii) oligomycin, a mitochondrial $F_{1} / F_{0}$ ATPase inhibitor.

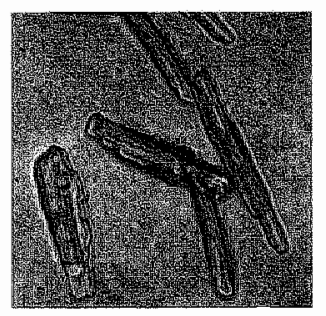

Figure 1.1: Isolated rat cardiac myocytes in suspension.

The cardiac myocytes possess a specialized contractile machinery which is composed of bundles of myofibrils containing myoflaments: The saromere, region of myoflament structures between two Z-lines, is the basic contractile device and is composed of myosin and actin filaments. Interactions between actir and myosin cause shortering of the sarcomere length making the cardac mocyte to contrat during the process of excitation contraction coupling?

\section{OUTLINE OF THESIS}

Following an overview of cardiac substrate uptake and utilization and membrane-associated substrate transport proteins under physiological conditions, Chapter 2 describes current insights on the regulation of substrate utilization by an increased workload and the hormone insulin. Moreover, alterations in substrate utilization by cardiac myocytes ith obesity progressing towards type-2 diabetes mellitus (T2DM), the aggravation of cardiac insulin resistance and possible manipulations that could prevent an impaired insulin-stimulated GLUT4 translocation are addressed in detail.

It is well documented that cellular contractions of cardiac myocytes increase the activity of AMPK resulting in translocation of GLUT4 to the sarcolemma thereby increasing inyocardial glucose uptake9. In Chapter 3 the involvement of AMPK in regulating LCFA uptake at the level of the sarcolemma through modulation of the subcellular distribution of FAT/CD36 is described. In cardiac myocytes, contractions increase the uptake of glucose and of LCFAs by a similar intracellular signalling pathway20,21. However, a pharmacological agent, i.e., dipyridamole, is able to alter cardiac substrate preference by inducing translocation of FAT/CD36, but not that of GLUT4, and is discussed in detail in Chapter 4. Moreover, in identifying other components of the contraction signalling pathway members of the protein kinase C (PKC) family are attractive candidates. In rat cardiac myocytes PKCs are activated during cellular contractions22:24 and in 
Chapter 5 the involvement of PKCs in myocardial LCFA uptake is presented. T2DM is a disease in which disturbances in substrate metabolism play a key role. One of the hallmarks of T2DM is muscle insulin resistance, which is defined as an impaired insulin-stimulated glucose uptake25,26. Moreover, the predominant cause of death in T2DM patients is cardiovascular disease, and alterations in substrate utilization are thought to underlie cardiac dysfunction 25 . In Chapter 6 alterations in glucose and LCFA uptake and LCFA utilization by cardiac myocytes from insulin resistant, obese Zucker rats are presented. The regulation of these metabolic processes by insulin or oligonycin, a contraction mimetic agent, is also discussed in detail in Chapter 6 .

A new class of oral insulin sensitizing agents are the thiazolidinediones (TZDS), which are potent peroxisome proliferator activated receptor (PPAR) $y$-agonists27,28. PPAR is known to influence lipid homeostasis in the body thereby improving the whole-body insulin resistance ${ }^{29,30}$. Chapter 7 addresses divergent effects of rosiglitazone, a member of the TZDs, on the cellular LCFA uptake capacity and transporter proteins in adipose tissue and muscle tissues of obese Zucker rats.

Current insulin sensitizing agents often have negative side effects. Therefore, we propose to ameliorate insulin sensitivity by inhibiting celiular LCFA transport. Effects of sulfo- $N$ succinimidyl esters of LCFAs, agents that specifically bind to FAT/CD36, on substrate uptake and metabolism in several cell types are presented in Chapter 8, Part 1. Moreover; in Chapter 8 , Part 2 kinetics of the sulfo- $N$-succinimidyl esters of LCFAs when applied intraperitoneally to rats were studied. Subsequently, in the addendum of Chapter 8 an approach for chronic intravenous application of these esters to rats is presented.

The new insights obtained by studies presented in this thesis will be discussed and placed in a broader perspective in Chapter 9 while a brief summary will conclude this thesis. 


\section{REFERENCES}

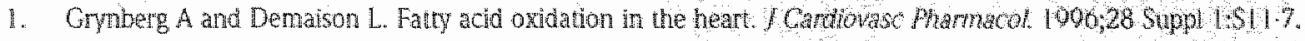

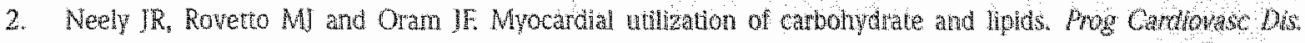
$1972 ; 15: 289 \cdot 329$.

3. wan der Vusse GI, Glatz JF, Stan HC and Reneman PS. Fatty acid honeostasis in the normoxic and ischemic heart. Physiol Rev. 1992,72,881.940.

4. Mueckler M. Facilitative glucose transporters. Eur f Biochent 1994/219:713-25.

5. Brinkmann JF, Abumrad NA, brahimi A, van der Vusse Gl and Glatz JF. New insights into longchain fatty acid uptake by heart muscle: a cacual tole for fatty acid translocase/0036. Brochem J 2002;367:561-70.

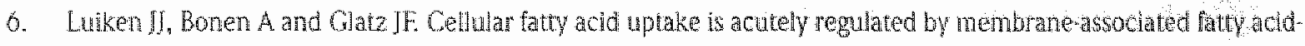
binding proteins. Prostaglandins Leukot Essent Faty Aclds. 2002;67:738.

7. Zorzano A, Sevilla L, Camps M, Becker C, Meyer J, Kammermeier H, Munoz P, Guma A, Jastar $X_{2}$ Palacin M, Blasi I and Fischer Y. Regulation of gucose transport, and glucose transporters expression and traficking in the heart: situdies in cardiac mocytes. Am / Cardiol 1997,80:65A76 A.

8. Till M, Kotter T and Eckel J. Molecular mechanisms of contraction-induced translocation of GLUT4 in isolated cardiomyocytes. Am / Cardiol 1997;80:85 A AA.

9. Russell RR, 3rd, Bergeron R, Shulman Gl and Young LH. Translocation of myocardial GLUT,4 and increased glucose uptake through activation of AMPK by AICAR. Am / Physiol 1999;277:4643\%.

10. Slor JW, Geuze HI, Gigengack $S_{1}$ James DE and Lienhard GE. Translocation of the glucose transporter OLUTA in cardiac myocytes of the rat. Proc Nall Acad SCI US A: 1991;88:7815.0.

11. Luiken JJ, Koonen DP, Wiliems J, Zarzano A, Becker C, Fscher Y, Tandon NN, Van Der Vusse GJ, Bonen A and Glatz IF: Insulin stimulates long chain fatty acid utilization by rat cardiac myocytes through cellulat redistribution of FAT rCD 30 . Diabetes. 2002,5131139.

12. Seidell JC. Prevalence and time trends of obesity in Europe. J Endocrinot invest 2002;25:816-22.

13. Passa P. Diabetes trends in Europe. Diabetes Metab Res Rev. 2002;18 Suppl 3\$33.

14. Strumpf $\mathrm{E}$. The obesity epidemic in the United States: causes and extent, risks and solutions. Issure Brief COMmonw Fund 2004; 100

15. Mensah GA. Mokdad AH, Ford E. Narayan KM, Gles WH, Vincor F and Deedwania PC. Obesly, metabolic syndrome, and tppe 2 diabees: emerging epidemics and their cardiovascular implications. Cardiof Cho 2004:22:485-504.

10. Fox CS, Coady S, Sorlie PD, LEvy D, Meigs 1B. DAgostino RB, St. Wilson PW and Sawage PI. Thends in cardiovascular complications of diabetes. Jama $2004 ; 292: 2495-9$.

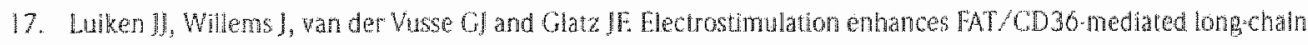
latty acid uptake by isolated rat cardac myocyles. Am S Physiol Endochinol Metab. 2001:281:5704-12.

18. Bers DM. Cardiac excitatun contraction coupling. Nature 2002;415:198:205.

10. Eisner DA, Isenberg $C$ and Sipido KR. Nomal ard pathological excitation-contraction coupling in the lieart - an overview. / Physiol $2003 ; 540 ; 34$.

20. Dyck D. Steinberg $\mathrm{G}$ and Bonen A. Insulin increases FA upake and esterification but reduces lipid utilization in isolated contracting muscle. Am / Physiol Endocrinol Metab. 2001;281;E600-7. 


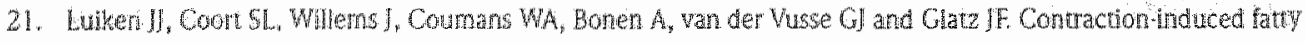

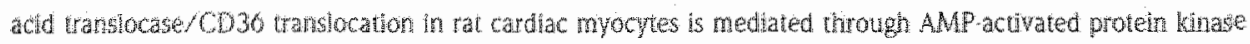
signaling Diabetes. 2003,52:1027.34.

22. Mahotra, $\mathrm{A}_{\text {, Kang }} \mathrm{BP}$, Opawumi D, Belizare W and Meggs LG. Molecular biology of protein kinase $\mathrm{C}$ signaing in cattiac myocyles. Mol Cell Biochem 2001,225:97-107.

23. Carson $L D$ anid Korzick DH. Dosedependent effects of acute exercise on PKC leweis in rat heart: is PKC the heart's prophylactic ACta Physiol Scand 2003:178:97100.

24. Braz JC, Gregon K, Pathak A, Zhan W, Sanh B, Kevisky R, Kimball TF, Lorenz IN, Nairm AC, Ligget SB, Bodi

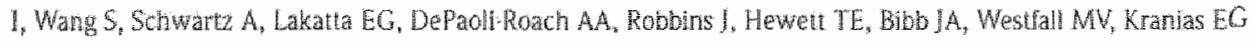
and Molkentin JD. PhCalpha regulates cardiac contractility and propensity toward heart falure. Nat Med. $2004: 10: 248 \cdot 54$

25. Zhou YT, Graburn P, Kanin A, Shimabukuro M, Higa M, Batetens D, Orci L and Unger RH. Lipotoxic heart disease in obese rats: implications for human obesity. Proc Natl Acad Sci U S A. 2000:97:1784-9.

26. Shumar GL Cellular mecharisms of insuin reststance. 1 Cin Invest 2000;106:1716.

27. Berger $\int$ and Moller DE. The mechanisms of action of PPARs. Annu Rev Med 2002,53:409.35.

28. Lehmatin JM, Moone LB, Snimolver TA, Wilkison WO, Willson TM and Kliewer SA. An antidiabetic thlazolidinedione is a high affinity ligand for peroxisome proliferatoractivated receptor gamma (PPAR gamma). I Bial Chem, 1995;270:12953-6.

29. Jucker BM, Schaeffer TR, Hambach RE, Mchosh TS, Chun D, Mayer M, Onistein DH, Davis HM, Smith SA, Cobitz AR and Sarkar SK. Momalizaiton of skeletal muscle glycogen synthesis and ghoolysis in rosiglitazonetreated Zucker fatty rats: an in vivo nuclear magnetic resonance study. Dlabetes. 2002;51:206073.

30. Murling M, Mensink RP, Pij H, Ronilin JA, Havekes LM and Voshol PI. Rosiglitazone improwes muscle insulin sensitivity, irrespectue of increased trighyeride content, in ob/ab mice. Metabolism, 2003,52:107883. 


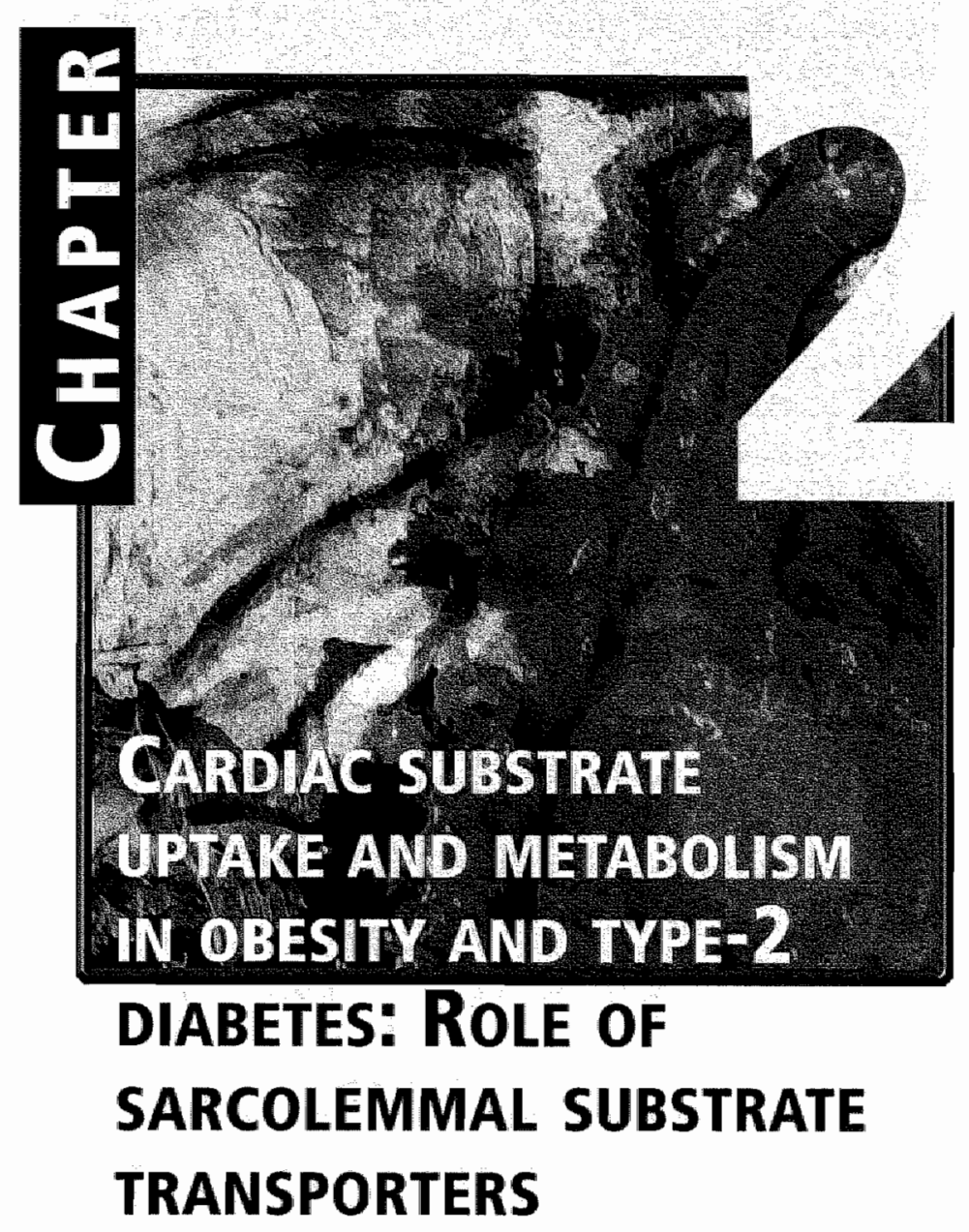

Susan L.M. Coort ${ }^{1}$, Arend Bonen ${ }^{2}$, Ger J. van der Vusse ${ }^{3}$, Jan F.C. Glatz' ${ }^{1}$, and Joost J.F.P. Luiken 1,4 .

Mol Cell Biochem. (accepted)

Departments of Molecular Genetics and sphysiology, Cardiovascular Research Institute Matstricht (CARIM], Maastricht University, Maastricht, the Netherlands.

2Department of Human Biology and Nutritional Sciences, Guelph University, Guelph, Ontario, Canada.

¿Department of Biochemical Physiology and Institute of Biomembitanes, Utrecht University, Utrecht, the Netheriands. 


\section{ABSTRACT}

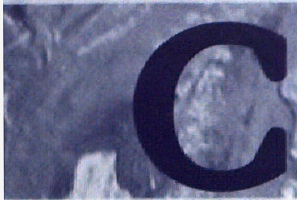

ardiovascular disease is the primary cause of death in obesity and type-2 diabetes mellitus (T2DM). Alterations in substrate metabolism are believed to be involved in the development of both cardiac dysfunction and insulin resistance in these conditions. Under physiological conditions the heart utilizes predominantly longchain fatty acids (LCFAs, $60-70 \%$ ), with the remainder being covered by carbohydrates, i.e., glucose $(20 \%)$ and lactate $(10 \%)$. The cellular uptake of both LCFAs and glucose is regulated by the sarcolemmal amount of specific transport proteins, i.e., fatty acid translocase (FAT)/ CD36 and GLUT4, respectively. These transport proteins are not only present at the sarcolemma, but also in intracellular storage compartments. Both an increased workload and the hormone insulin induce translocation of FAT/CD36 and GLUT4 to the sarcolemma. In this review, recent findings on the insulin and contraction signalling pathways involved in substrate uptake and utilization by cardiac myocytes under physiological conditions are discussed. New insights in alterations in substrate uptake and utilization during insulin resistance and its progression towards T2DM suggest a pivotal role for substrate transporters. In the early stages of T2DM, relocation of FAT/CD36 to the sarcolemma is associated with the myocardial accumulation of triacylglycerols (TAGs) eventually leading to an impaired insulin-stimulated GLUT4-translocation. These novel insights may result in new strategies for the prevention of development of cardiac dysfunction and insulin resistance in obesity and T2DM.

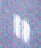

a.

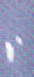

(6.) 


\section{INTRODUCTION}

In both Europe and the United States of America the incidence of obesity and type-2 diabetes mellitus (T2DM) is drastically increasing ${ }^{1-5}$. Obesity has been defined as having too much fat body mass compared to lean body mass. A western lifestyle and genetic factors play major roles in the development of obesity 6,7 . It is well known that obesity influences the total body metabolism of both lipids and carbohydrates, the regulation of blood pressure, and thrombotic and inflammatory reactions $s^{8,9}$. Most obese patients develop insulin resistance, which is characterized by impairment in the insulin-mediated glucose uptake by muscle and adipose tissue. Insulin resistance is also one of the key features of patients with T2DM. In T2DM insulin resistance occurs before the onset of hyperglycemia.

Although the heart plays a minor role in the development of whole-body insulin resistance, cardiovascular complications are one of the main causes of morbidity and death in insulin resistant obese and T2DM patients 10,11 . Obesity and T2DM are both independent risk factors for the development of cardiac dysfunction ${ }^{12-14}$. In T2DM patients who have no clinically manifested cardiovascular diseases, the left ventricular mass is increased, in combination with diastolic dysfunction, whereas in general systolic function is normal15,16. These structural and functional alterations in the hearts of T2DM patients are referred to as diabetic cardiomyopathy, and are even present in the absence of hypertension and coronary artery disease ${ }^{13,17}$. During the course of T2DM this cardiomyopathy can progress towards heart failure. Diabetic cardiomyopathy is the outcome of a multifactorial process and the following disturbances are believed to be involved in its development; alterations in the renin-angiotensin system, aldosterone-induced fibrosis, endothelial dysfunction, arterial stiffness, autonomic neuropathy, hyperglycemia and alterations in myocardial substrate utilization ${ }^{18,19}$.

In this review we will address recent findings on the role of sarcolemma-associated substrate transporters and their regulation in myocardial substrate utilization in obesity and T2DM. These findings lead us to hypothesize that disturbances in the regulation of cardiac long-chain fatty acid (LCFA) utilization play a role in the development of cardiac dysfunction and insulin resistance. First, we discuss various aspects of cardiac substrate metabolism under physiological conditions. Second, we will focus on the regulation of the cardiac substrate metabolism by both an increased workload and the hormone insulin. Third, alterations of cardiac substrate metabolism in obesity and T2DM will be discussed. Finally, possible therapeutic strategies aiming at correcting cardiac substrate metabolism are addressed.

\section{MeChanISM OF GLUCOSE AND LONG-CHAIN FATTY ACID UPTAKE AND METABOLISM IN THE HEART}

The heart predominantly consists of specialized muscle cells, cardiac myocytes, which perform a constant contraction and relaxation cycle in a coordinated fashion. To be able to contract cardiac myocytes need to generate energy, which is derived from adenosine triphosphate (ATP) hydrolysis 20 . ATP itself is generated during the oxidation of substrates. Cardiac myocytes behave like omnivores and can utilize fatty acids, carbohydrates, and ketone bodies 21 . Under physiological conditions these cells oxidize predominantly long-chain fatty acids (LCFAs, 
$60-70 \%)$, with the remainder covered by carbohydrates, i.e., glucose $[20 \%]$ and lactate $(10 \%)^{22,23}$. Before intracellular oxidation, these substrates have to enter the cardiac myocytes by crossing the sarcolemma.

The uptake of extracellular glucose by cardiac myocytes is regulated by the amount and activity of glucose transporters at the sacrolemma ${ }^{24}$. In the heart two glucose transport proteins, i.e., GLUT1 and GLUT4 are present, of which GLUT4 is most abundant25 (Fig. 2.1). Both GLUT1 and GLUT4 are not only located at the sarcolemma, but also in intracellular storage compartments ${ }^{20}$. Upon entering cardiac myocytes, glucose is rapidly phosphorylated into glucose-6-phosphate by hexokinase, resulting in intracellular trapping. Thereafter, glucose0-phosphate can either be stored as glycogen or enter the glycolytic pathway (Fig. 2.1). The end product of glycolysis, pyruvate, crosses the mitochondrial membranes and once present in the mitochondrial matrix is converted into acetyl-COA by the enzymatic action of pyruvate dehydrogenase (PDH) (Fig. 2.2). Acetyl-CoA undergoes further mitochondrial metabolism resulting in the synthesis of ATP by oxidative phosphorylation.

LCFAs destined for cardiac utilization are delivered in two different forms, (i) in complex with albumin and (ii) esterified in the lipid core of very-low density lipoproteins (VLDLs) and chylomicrons 27,28 . Whille albumin-bound LCFAs easily dissociated from albumin, the esterified LCFAs have to be hydrolyzed by the action of lipoprotein lipase at the luminal surface of the endothelium before they become available. Thereafter, LCFAs are transported across the endothelium, via a mechanism that is yet unclear. Once present in the interstitial space LCFAs are complexed with albumin, their transport vehicle through this aqueous compartment (Fig. 2.1). Prior to their transport across the sarcolemma, LCFAs dissociate again from albumin. Although it was originally believed that the transport of LCFAs across the sarcolemma into cardiac myocytes occurs solely by passive diffusion 29,30 , now it is generally accepted that the bulk of LCFAs are taken up via a protein-mediated (facilitated) transport system ${ }^{31,32}$.

Several putative LCFA transport proteins have been identified and are thought to act in concert to facilitate cardiac LCFA uptake. However, the molecular mechanism by which these transport proteins mediate LCFA transport across the sarcolemma is incompletely understood ${ }^{33}$. Evidence is accumulating that the $88 \mathrm{kDa}$ fatty acid translocase (FAT), a rat homologue of human $\mathrm{CD} 36$, is the main putative LCFA transport protein (reviewed by Brinkmann et al. ${ }^{34}$ ) (Fig. 2.1). FAT/CD 36, like GLUT4, is not only present at the sarcolemma, but also in intracellular storage compartments ${ }^{35}$. A strong positive correlation between the amount of FAT/CD36 present at the sarcolemma and the uptake of LCFAs has been observed in cardiac myocytes ${ }^{36}$. Moreover, by blocking FAT/CD 36 with sulfo- $N$-succinimidyl oleate [SSO], which specifically binds to FAT/CD36, myocardial LCFA uptake is markedly inhibited ${ }^{37}$. In addition to FAT/CD36, other proteins play a role in the sarcolemmal transport system, but they are believed to be non-regulating. First, at the outer leaflet of the sarcolemma a $43 \mathrm{kDa}$ fatty acid binding protein (FABPpm) is present ${ }^{38}$ (Fig. 2.1). By specifically inhibiting FABPpm with an anti.FABPpm antibody LCFA transport across the sarcolemmal membrane was decreased ${ }^{32}$. Interestingly, the inhibitory actions of SSO and anti-FABPpm were non-additive, suggesting the FAT/CD36 and FABPpm act together in the LCFA uptake process 32 . Second, two isoforms of the fatty acid transport protein (FATP) family, i.e., FATPL and FATP6, are 
present in cardiac myocytes and each exhibit acyl-CoA synthetase activity (reviewed by Stahl et al.39) (Fig. 2.1). FATPó is expressed exclusively in the heart, and also more abundant than FATP140,41. Since FATP is associated with the sarcolemma and colocalizes with FAT/CD36 it is suggested that these two LCFA transport proteins act in concert ${ }^{41}$.

Once inside the cardiac myocyte, LCFAs bind to $15 \mathrm{kDa}$ cytoplasmic heart type fatty acid binding protein (H-FABPc) (Fig. 2.1). Using this protein as a vehicle non-esterified LCFAs are transported inside the cardiac myocytes towards their site of metabolic conversion or action ${ }^{42,43}$. Subsequently, they are activated into acyl-CoAs by the enzyme acyl-CoA synthetase $(\mathrm{ACS})^{44}$. These acyl-CoAs can bind to the cytosplasmic acyl-CoA binding protein (ACBP) ${ }^{45}, 40$. Acyl-CoAs either enter the mitochondria or are incorporated into the intracellular lipid pools (Fig. 2.1). Transport of acyl-CoAs into the mitochondria is mediated by the concerted action of three carnitine-dependent enzymes ${ }^{47}$ (Fig. 2.2). At the outer mitochondrial membrane carnitine palmitoyl transferase [ (CPT-I] is present, catalyzing the formation of acylcarnitine. Thereafter, carnitime/acylcarnitine transferase (CACT) transports acylcarnitine into the mitochondria and at the inner mitochondrial membrane, CPT-II generates acyl-CoA. In the mitochondrial LCFA

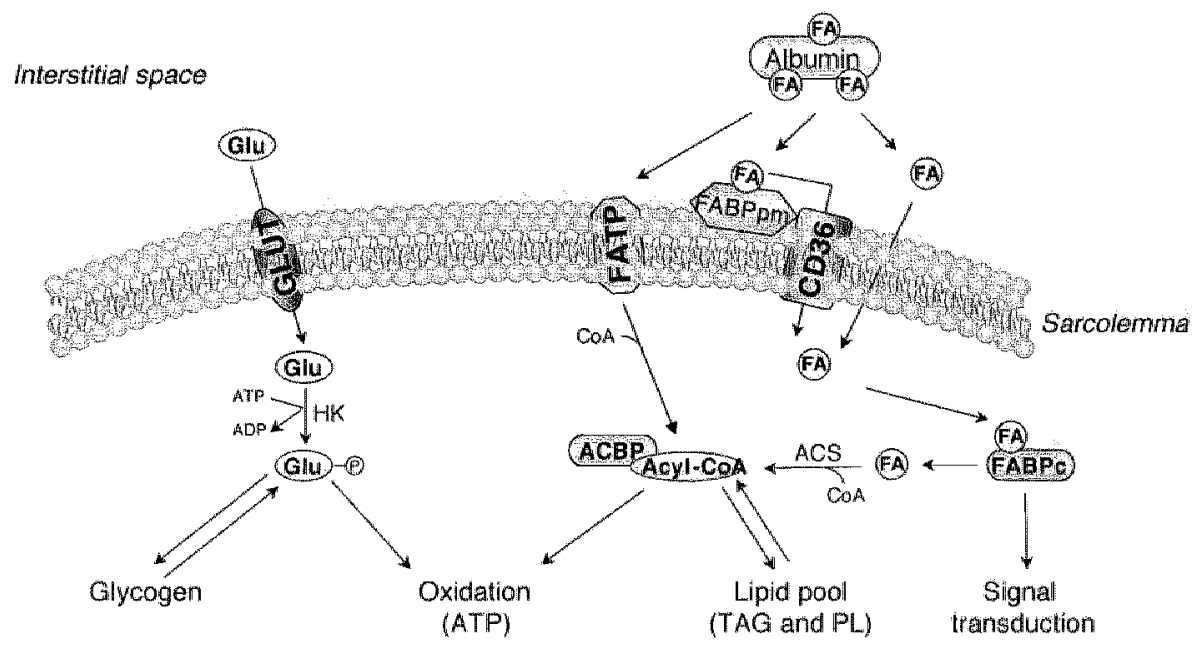

Cytoplasm

Figure 2.1: Glucose and long chain fatty acid uptake and metabolism in cardiac myocytes under physiological conditions.

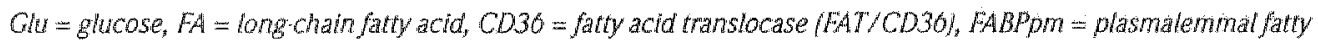
acia binding protein, FABPC =Cytoplasmic fatty acid binding procin, $F A T P=$ fatty acid transport protein, $A C B P=$ acylCOA binding protein, GLUT $=$ glucose transport protein either 1 or $4, H K=$ hexokinase, $A C S=$ acyl-COA synthetase, $T A C=$ triacylgycerol, and $P L=$ phospholipid, See text under Mechanism of stubstrate uptake and metabolism in the heart for a detailed description of this figure. 


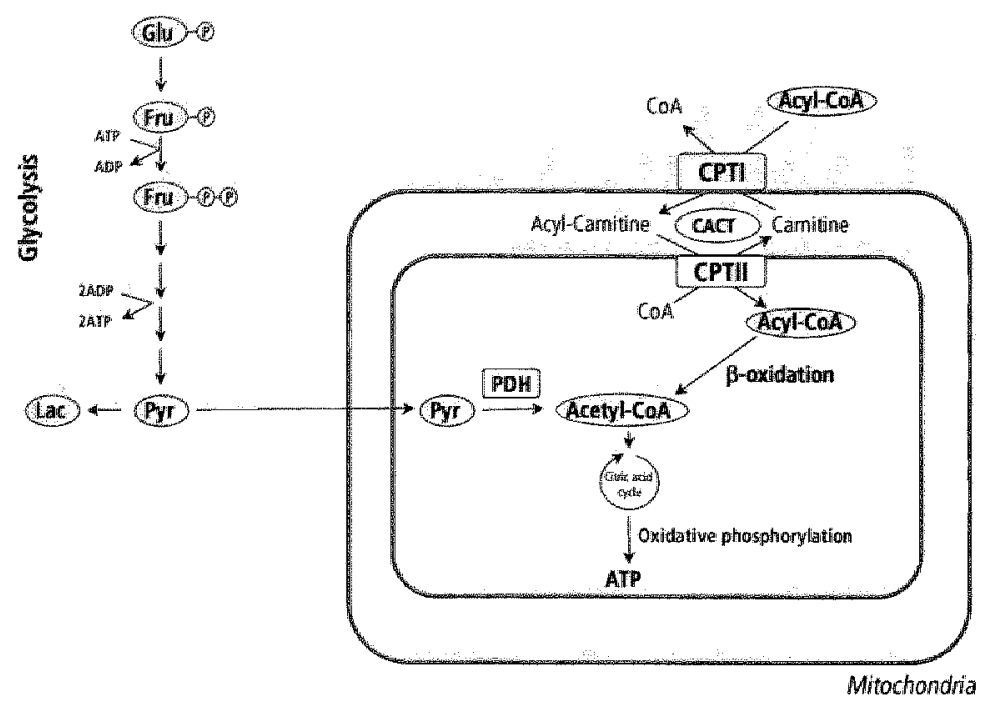

Figure 2.2: Substrate oxidation and ATP generation in cardiac myocytes under physiological conditions.

$G u=g l u c o s e, F r a=j r u c t o s e, B y=$ pyruwate, $L a C=$ lactate, $P D H=$ pyruvate dehydrogenase, $C P T I / I=$ carnitine palmitoyl transferase $1 / 11, C A C T=$ cartinine/acylcarnitine transferase. See text under Mechanism of substrate uptake and metabolism in the heart for a detalled description of this figure.

uptake process CPT-I is the key regulatory enzyme. Once inside the mitochondria acyl-CoAs are oxidized via $\beta$-oxidation and the endproduct, acetyl-CoA, is gradually degraded in the citric acid cyclest,49 (Fig. 2.2). At this point the pathways for giucose and LCFA oxidation merge.

Interestingly, whereas oxidation and esterification of LCFAs occur within minutes, within days intracellular LCFAs also exert effects on their awn utilization. These LCFAs induce the expression of genes involved in LCFA metabolism by activating a family of ligand-activated nuclear receptor, the peroxisome proliferator activated receptors (PPARs) that consists of three isoforms, i.e., $\alpha, \beta / \delta$ and $\gamma^{50,51}$. In cardiac myocytes, PPAR $\alpha$ and $\beta / \delta$ are the predominant isoforms and the abundance of PPARy is very low ${ }^{52}$. Gilde et al. ${ }^{52}$ demonstrated that in neonatal cardiac myocytes activation of PPAR $\alpha$ and $\beta / \delta$, but not that of PPAR $\gamma$, results in an increased expression of genes encoding for proteins involved in cardiac LCFA oxidation, including FAT/CD36 and CPT-I.

\section{CONTRACTION PATHWAY IN CARDIAC MYOCYTES}

Cardiac myocytes possess a specialized contractile machinery that enables them to contract and relax in a regular fashion ${ }^{53}$. The contraction process is an energy requiring process, which is accounted for by increased utilization of substrates by cardiac myocytes. It is demonstrated that in contracting isolated rat cardiac myocytes translocation of GLUT454,55 and FAT/CD3656 
from intracellular storage compartments towards the sarcolemma occurs, resulting in an increased glucose and LCFA uptake, respectively. Moreover, cellular contractions do not only induce FAT/CD36-mediated LCFA uptake, but also the LCFA oxidation rate, whereas the LCFA storage rate into TAGs remains unaltered (Fig. 2.4). Several proteins, l.e., protein kinase A (PKA), AMP-activated kinase (AMPK) and protein kinases C (PKCs), are potential candidates to be involved in the signalling pathway activated upon cellular contractions. These proteins and their role in the regulation of cardiac substrate utilization and substrate transport proteins localization are subject of intensive studies, the outcome of which will be discussed in detail below.

\section{Protein kinase A}

PKA is a serine/threonine kinase and activated by cyclic AMP (CAMP) 57,58 . In its inactive form, the enzyme consisting of two catalytic subunits and a regulatory dimer. Binding of CAMP to the regulatory dimer results in the dissociation of the dimer from the catalytic PKA subunits, resulting in the activation of PKA. Activated PKA phosphorylates other proteins containing specific serine/threonine residues (see for review5,58). Intramyocellular cAMP levels increase during acute exercise. Upon $\beta$-adrenergic receptor stimulation a sarcolemmal heterotrimeric GTP-binding protein is activated, which stimulates adenylyl cyclase to produce cAMP. Activation of PKA by CAMP results in the phosphorylation of several proteins involved in chronotropic and imotropic mechanisms in the cardiac myocytes, I.e., L-type-Ca ${ }^{2+}$ channels, and myosin binding protein 59,60 . Moreover, activation of PKA results in the phosphorylation of acetyl-CoA carboxylase (ACC) at Serine-77 (Ser77) and Ser120061,62 (Fig. 2.3). In the heart two isoforms of ACC with subunit sizes of $265(\alpha)$ and $280(\beta) \mathrm{kDa}$ have been identified. $A C C B$ is the major cardiac isoform and is involved in the regulation of LCFA metabolism63. Phosphorylation of ACC at critical sites, i.e., Ser 120064 , inhibits its activity, resulting in a fall of intramyocellular malonyl-CoA thereby deinhibiting the catalytic activity of CPT-I and accelerating $\beta$-oxidation 47 (Fig. 2.3). In contrast to the stimulatory effect of CAMP on LCFA oxidation, cardiac LCFA uptake is not regulated by intramyocellular CAMP levels and thus the activation of $\mathrm{PKA}^{65}$. In cardiac myocytes, in which CAMP levels are pharmacologically increased, LCFA uptake6 and subcellular distribution of FAT/CD3605 were unaltered. Collectively, these findings indicate that PKA directs intracellulat LCFAs towards mitochondrial Boxidation, whereas the subcellular localization of FAT/CD36 and hence cellular LCFA uptake remain unaltered.

\section{AMP kinase}

AMP kinase (AMPK) is a heterotrimeric protein consisting of one catalytic subunit, and two regulatory subunits. Activation of AMP kinase occurs through phosphorylation of threonine172 (Thr172) in the catalytic domain by one or more upstream AMPK kinases (AMPKKs), such as the recently discovered LKB 107, and allosterically by binding of AMP to one of the regulatory subunits ${ }^{68,69}$ (see in more detail Chapter 3 ). Coven and coworkers ${ }^{70}$ demonstrated that AMPK is activated in the rat heart during exercise, emphasizing the importance of AMPK in this organ. In muscle cells AMPK can be pharmacologically activated by 5 -aminoimidazole- 
4-carboxamide-1- $\beta$-Dribofuranoside (AICAR), which is intracellularly phosphorylated into AICAR monophosphate (ZMP) that closely resernbles the chemical structure of AMP71,72. It has been demonstrated that in both electrically stimulated and AICAR-treated cardiac myocytes GLUT4 translocates to the sarcolemma thereby increasing glucose uptake ${ }^{54,55}$. Since not only GLUT4-mediated glucose uptake, but also FAT/CD36-mediated LCFA uptake was induced in cardiac myocytes during celiular contractions (Fig. 2.4), we were interested in whether AMPK is involved in FAT/CD36 translocation. Subsequently, we were the first to demonstrate that in cardiac myocytes an increased AMPK activity is involved in translocation of FAT/CD36 from intracellular storage compartments to the sarcolemma ${ }^{73}$ (Fig. 2.3). Besides its role in the regulation of substrate transporter localization, AMPK activity directly influences cardiac LCFA oxidation. Activation of AMPK causes phosphorylation of ACC at Ser79, Ser 1200 and Ser 121574,75. Phosphorylation at Ser79 at ACC by AMPK results in the inhibition of ACC activity thereby lowering intracellular malonyl-CoA which eventualiy leads to an increased LCFA oxidation ${ }^{64}$. Collectively, these findings demonstrate that activation of AMPK is involved in inducing both FAT/CD36-mediated LCFA uptake and LCFA oxidation.

\section{Protein kinase $C$}

Protein kinases C (PKCs) are a family of serine/threonine kinases consisting of 12 members which are divided into three subfamilies based on their structure and ligand-binding domains, i.e., conventional (c), novel ( $\mathrm{n}$ ) and atypical (a) PKCs (see for review Newton et al ${ }^{76}$ ). $\mathrm{CPKCs}$ are activated by $\mathrm{Ca}^{2++}$ and diacylglycerols (DAGs), nPKCs are insensitive to $\mathrm{Ca}^{2+}$, but can be activated by DAGs and aPKCs are insensitive to both $\mathrm{Ca}^{2+}$ and $\mathrm{DAGs}{ }^{77,78}$. In the heart one CPKC, PKC $\alpha$, two $\mathrm{nPKCs}, \mathrm{PKC} \delta$ and $\varepsilon$ and one aPKC, PKC $\zeta$ have been detected 79 . It has been demonstrated that $\mathrm{PKCs}$ are involved in regulating contractile function by phosphorylating components of the cardiac contractile machinery ${ }^{80,81}$. Moreover, during cellular contractions intramyocellular $\mathrm{Ca}^{2+}$ levels increase through an increased uptake of $\mathrm{Ca}^{2+*}$ via sarcolemmal L-type $\mathrm{Ca}^{2+}$ channels by the cardiac myocyte, which then triggers the $\mathrm{Ca}^{2-1}$ release from the sarcoplasmatic reticulum ${ }^{82}$. This switches on the contractile machinery and relaxation is intitiated once $\mathrm{Ca}^{2+}$ is transported out of the cytoplasm 53,83 . Evidence is accumulating that activation of conventional and novel PKCs are involved in the contractioninduced substrate uptake by cardiac myocytes. Recently, we demonstrated that in cardiac myocytes treated with phorbol 12-myristate 13-acetate (PMA), a cell-permeable analog of DAG that induces PKC activity, both glucose and LCFA uptake are enhanced84. Moreover, in PMA-treated cardiac myocytes LCFA uptake can be inhibited by SSO to the same residual level as in non-treated cardiac myocytes, demonstrating the involvement of FAT/CD36 in the increase of LCFA uptake by PMA. Besides conventional and novel PKC, several studies in both rodent and human skeletal muscle demonstrated that upon exercise and electrical stimulation aPKCs translocate to the membrane ${ }^{85.87}$. These findings indicate a possible role for aPKCs in the effect of cellular contractions in cardiac myocytes. Taken together, activation of the PKC family is believed to be involved in contraction-induced substrate uptake by cardiac myocytes, although the specific PKC isoform and the molecular mechanism remains unknown. 


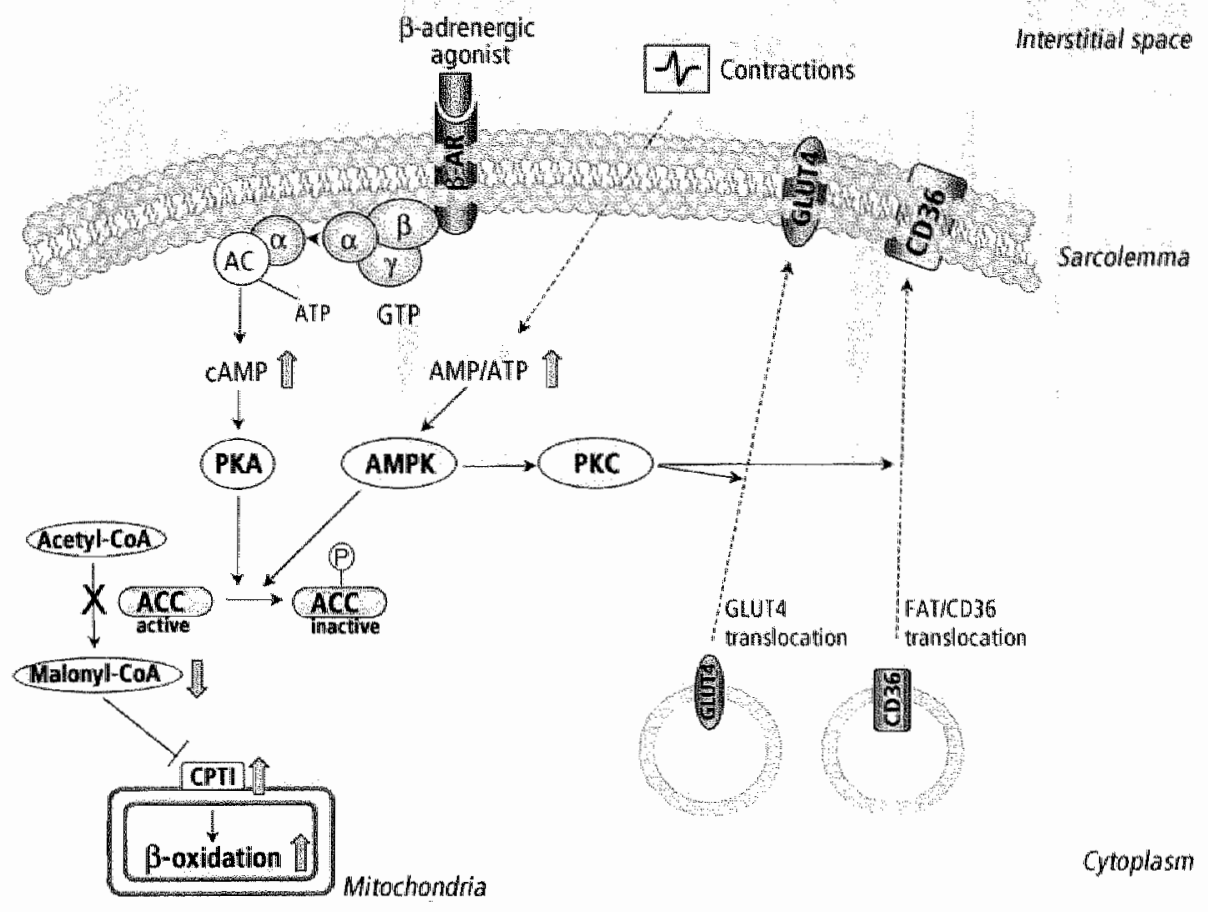

Figure 2.3 Components of the contraction pathway involwed in substrate utilization in cardiac myocytes. $\beta \cdot A R=\beta$-adrenergic receptor, $A C=$ adenylyl cyclase, $A C C=$ acetyl-COA carboxylase, FAT/CD30 = fatty acid translocase, $C A M P=$ cyclic $A M P, P K A=$ protein kinase $A, A M P K=A M P$ kinase, $P K C=$ protein kinase $C, C P T y=$ carnitine palmitoyt transferase I. See text under Contraction pathway of cardiac myocytes for a detalled description of this figure.

\section{INSULIN SIGNALLING PATHWAY IN CARDIAC MYOCYTES}

Similar to the effects of cellular mechanical activity, the hormone insulin regulates substrate utilization and localization of substrate transport proteins in muscle tissues ${ }^{89,90}$. Insulin is involved in the maintenance of normal plasma concentrations of glucose and lipids ${ }^{91}$. Upon binding of insulin to its $\alpha 2 / \beta 2$ tetrameric receptor at the sarcolemma of the cardiac myocyte the intracellular tyrosine kinase activity of this receptor is activated. This activation catalyzes phosphorylation of tyrosine residues at the insulin receptor interacting proteins, i.e., insulin receptor substrate 1 (IRS-1). The two major signalling pathways in cardiac myocytes subsequently activated by insulin are, (i) the phosphatidylinositol-3 kinase $\left(\mathrm{PI}_{3} \mathrm{~K}\right)$ pathway and (ii) the mitogen activated protein kinase (MAPK) pathway ${ }^{92}$. Whereas the MAPK pathway plays a prominent role in the transcriptional and mitogenic processes, such as alterations in growth, differentiation and regulation of gene expression, the $\mathrm{Pl}_{3} \mathrm{~K}$ pathway is involved in metabolic 
LCFA Uptake
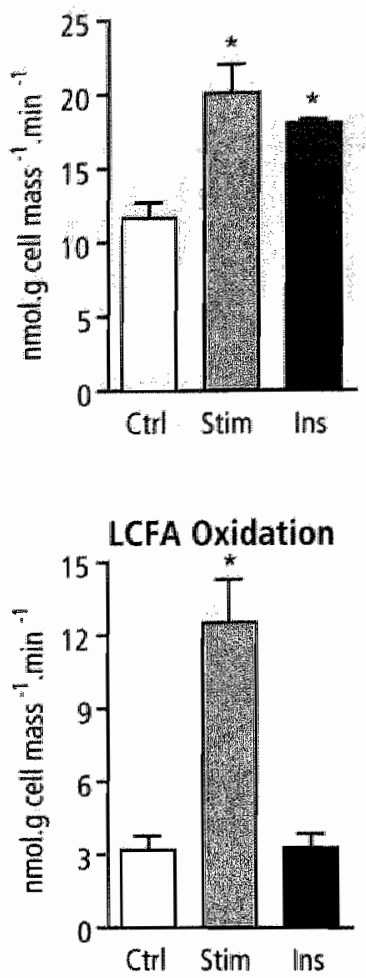

FAT/CD36
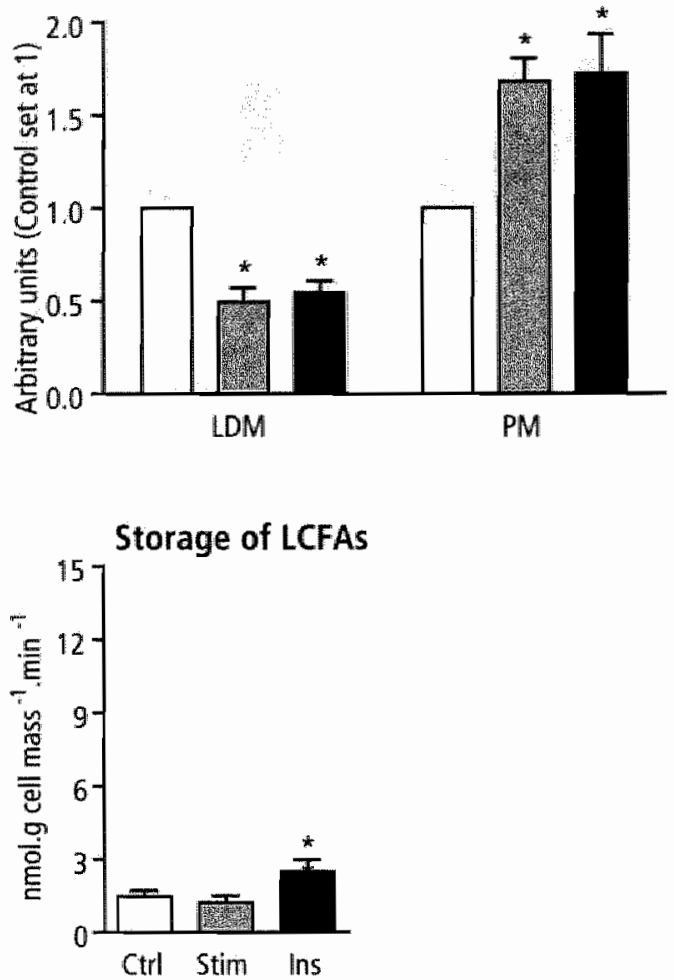

Figure 2.4 Overview of the effects of cellutar contractions and insulin on LCFA utilization and FAT/CD36 subcellular localization in cardiac myocytes.

1 solated cardac myoytes from lean Zucker rats were incubated for $15 \mathrm{~min}$ at $37^{\circ} \mathrm{C}$ under continuous shaking either

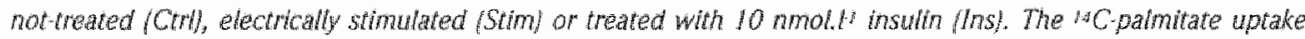
rate was measured in 3 min and the rates of oxidation and storage of 14 -palmitate were measured in 20 min. Moreover, the treated cardiar myockes were subcellular fractionated into low density microsomes (LDM) and plasma membrane (PMI fractons. By Western blotting using MO25, an antibody directed against. FAT/CD.30, the protein content of $A A T / C D 30$ was measured in these two fractions. Data on ${ }^{4} C$ palmitate utilization are expressed as means $\pm S$ EM. and presented as nmolg cell mass. min. The protein content of FAT/CD36 was expressed as percentage of control valtes (control set at 1). "Significantly different form control values, $P<0.05$.

signalling. Therefore, we will focus on the $\mathrm{PI}_{3} \mathrm{~K}$ pathway. An overview of recent insights in the regulation of substrate uptake and substrate transporter proteins in cardiac myocyte by insulin is given in Figure 2.5 .

$\mathrm{PI}_{3} \mathrm{~K}$ consists of two subunits, a $110 \mathrm{kDa}$ catalytic subunit and an $85 \mathrm{kDa}$ regulatory subunit. Once activated, $\mathrm{Pl}_{3} \mathrm{~K}$ translocates to the sarcolemma where it phosphorylates 
phosphatidylinositol phosphates (PIPs) at the 3 position. Especially the conversion of $\mathrm{PI}-4,5 \mathrm{P}_{2}$ to $\mathrm{PI}-3,4,5 \mathrm{P}_{3}$ is important for insulin signalling. $\mathrm{PI} \cdot 3,4,5 \mathrm{P}_{3}$ activates the phosphoinositidedependent kinase 1 , which phosphorylates and thereby activates the serine/threonine kinase, protein kinase $\mathrm{B}(\mathrm{PKB})^{93}$ and the atypical protein kinase $\mathrm{C}$ (aPKC) isoforms $\lambda$ and $\xi^{94}$.

It has been well documented that activation of the $\mathrm{PI}_{3} \mathrm{~K}$ pathway mediates translocation of the glucose transporter GLUT4 from intracellular storage compartments towards the sarcolemma, thereby increasing the myocardial glucose uptake rate ${ }^{26,95}$. The metabolic fate of glucose taken up into muscles exposed to elevated levels of insulin includes glycogen synthesis, glucose oxidation and lactate production. Recently is has been shown that insulin does not only induce glucose uptake, but also long-chain fatty acid (LCFA) uptake in cardiac myocytes ${ }^{96}$. Since FAT/CD36, an important regulatory LCFA transport protein, is just like GLUT4 present at the sarcolemma and in intracellular storage compartments, it was investigated whether insulin induces translocation of FAT/CD36. In adult rat cardiac myocytes, insulin indeed promotes FAT/CD36 translocation from intracellular sites to the sarcolemma depending on activation of $\mathrm{PI}_{3} \mathrm{~K}^{96}$ (Fig. 2.5). Moreover, the amount of FAT/CD36 present at the sarcolemma correlates with the myocardial LCFA uptake. Insulin induces not only the FAT/CD36-mediated LCFA uptake but

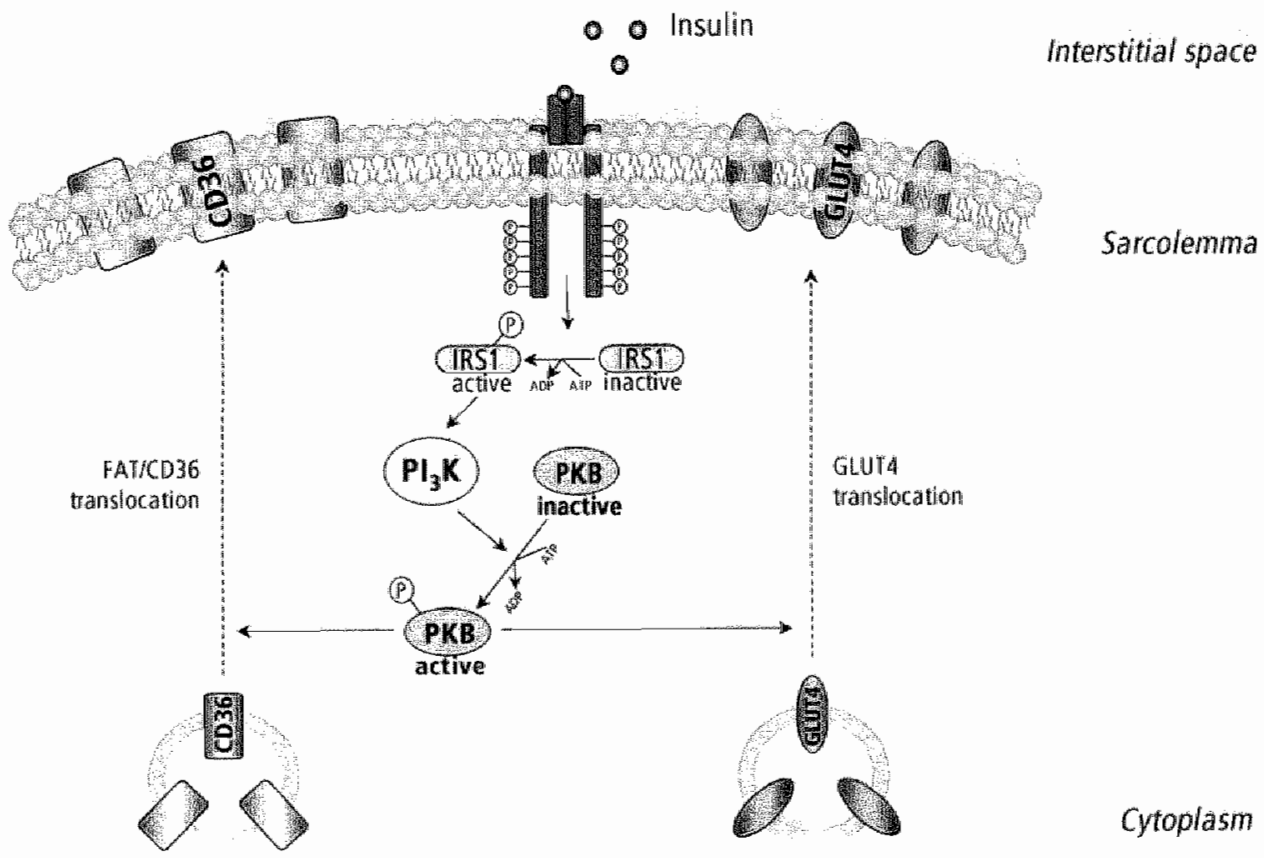

Figure 2.5: The insulin signalling pathway involved in substrate uptake by cardiac myocytes.

$I R S I=$ insulin receptor substrate $/, P I_{3} K=$ phosphatidylinositol 3 kinase, $P K B=$ protein kinase $B$ (See text under Insulin signaling pathway in cardiac myocytes for a detalled description of this figurel. 
influences also the intramyocellular channeling of LCFAs (Fig. 2.4). The additional amount of LCFAs entering the cardiac myocytes under the influence of insulin is predominantly stored into the intracellular lipid pool, whereas the LCFA oxidation rate remains unaltered ${ }^{97}$ (Fig. 2.4).

\section{CARDIAC SUBSTRATE UTILIZATION IN OBESITY AND TYPE-2 DIABETES MELLITUS}

Obesity and T2DM each are strongly associated with insulin resistance 98 . In the development towards full-blown T2DM compensatory hyperinsulinemia maintains normal plasma glucose levels. In most patients eventually pancreatic beta cells dysfunction and hyperglycemia will occur. Besides insulin resistance, T2DM is also strongly associated with the development of diabetic cardiomyopathy. Although, the mechanisms causing cardiac insulin resistance and diabetic cardiomyopathy are incompletely understood metabolic disturbances in the heart are thought to play an essential role. Because in the heart the expression, subcellular localization and functional regulation of GLUT4 and FAT/CD36 are important parameters determining the rates of substrate utilization. Therefore, it was of interest to study possible changes in the amount of substrate transport proteins in the insulin-resistant heart.

In rodent models of insulin-resistance 99,100 or early-onset T2DM101,102, basal cardiac glucose uptake has not been changed compared to controls. However, basal glucose uptake decreases in hearts of rodent models with full-blown T2DM, concomitant with a reduced total protein content of GLUT410!. In T2DM db/db mice also cardiac glycolysis and glucose oxidation are decreased. Belke and coworkersiol demonstrated that when overexpressing GLUT4 specifically in the heart of these rodents, changes in glucose utilization were completely normalized. These findings demonstrate that the reduced cardiac glycolytic state in T2DM rodents will likely be due to a reduced sarcolemmal GLUT 4 content. Not only the total amount of GLUT4 but also the induction of GLUT4 translocation by insulin and therefore the subcellular localization of GLUT4 is altered in T2DM. Since recruitment of GLUT4 to the sarcolemma upon insulin requires an intact $\mathrm{PI}_{3} \mathrm{~K}$ pathway, it is believed that alterations in this signalling pathway are responsible for an impaired GLUT 4 translocation. Indeed, several studies demonstrate that in the T2DM heart, insulin signalling in cardiac mycoytes is impaired. Insulin stimulated activity of the $\mathrm{LSS} / \mathrm{PI}_{3} \mathrm{~K} / \mathrm{PKB}$ pathway was reduced in (i) ventricular homogenates from rats that were exposed to a high fat diet and developed a T2DM phenotype ${ }^{103}$, (ii) perfused hearts and isolated ventricular cardiac myocytes from insulin resistant obese Zucker rats 99,104 and (iii) hearts from T2DM Goto Kakizaki rats 102 . At physiological insulin concentrations, insulin. stimulated GLUT 4 translocation and glucose uptake are reduced in insulin resistant obese rats 104,105 . If cardiac myocytes from obese Zucker rats are stimulated with maximal insulin concentrations, GLUT 4 translocation and glucose uptake are induced to the same extent as in control rats 100,104 . However, in hearts of $T 2 D M$ rodents even at maximal insulin concentrations GLUT4 translocation is impaired. These findings suggests that insulininduced GLUT4-mediated glucose uptake becomes impaired when progressing from obesity towards T2DM. 
While the impairment in myocardial glucose uptake occurs after the onset of T2DM, LCFA uptake in rodent hearts were altered already in the prediabetic state. It was demonstrated that in insulin resistant, obese Zucker rats myocardial LCFA uptake is increased ${ }^{18 \%}$, 100 . The increase in myocardial LCFA uptake coincided with an increased amount of FAT/CD36 at the sarcolenma, whereas the total cellular FAT/CD36 protein content was unaltered. Moreover; in these obese rats, the rate of cardiac LCFA oxidation was unaltered, whereas the cardiac TAG content and the incorporation rate of LCFAs into TAGs were increased. In T2DM rodents it: has been reported that cardiac LCFA oxidation and the activity of 3-hydroxyl-acyl-CoA dehydrogenase, a component of mitochondrial $\beta$-xidation pathway, increases $101,10 \%$. However, data obtained by human studies are contradictory to rodent models and do not give a clear view on the cardiac LCFA oxidation during impaired glucose tolerance. In patients with an impaired glucose tolerance no effect on myocardial "C-palmitate uptake and oxidation was observed 108, whereas in the same patient group the 123]-heptadecanoic acid (HAD) oxidation by the heart was reduced ${ }^{109}$. This discrepancy could be due to the difference in the fatty acid analog used to study oxidation. "23-HAD is, compared to $1 \mathrm{C}$-palmitate, limited for using it to quantitate myocardial LCFA axidation 110 .

In obese and T2DM subjects and in insulin-resistant, obese and T2DM rodent models $111: 113$ it has been well established that lipids accumulate in the heart. Young and coworkers 114 demonstrated that in obese rats a mismatch between LCFA uptake and oxidation leads to a deposition of the excess LCFAs taken up by the heart in the intracellular lipid pool. Recently, we showed that increased amounts of FAT/CD36 are present at the sarcolemma in cardiac myocytes from insulin-resistant vats, resulting in increased rates of LCFA deposition in TAGs and an increased intracellular LCFA content 88,100 (see for more detail Chapter 6). Moreover, Zhou and coworkers 11 demonstrated that the increased cardiac TAG content coincided with increased mRNA levels of glycerol-3-phosphate acyltransferase (GPAT), an enzyme known to direct exogenous LCFAs into TAGs 115 . Hence combined elevation of FAT/CD36 and GPAT provides a mechanism for increased LCFA channeling towards intracellular storage. The relation between FAT/CD36 and TAGs in the heart of obese Zucker was confirmed in human studies in skeletal muscle. Also in skeletal muscle of humans alterations in FAT/CD36 functioning are causally related to intramyocellular lipid accumulation. The plasmalemmal FAT/CD36 protein content, rates of palmitate transport and the tissue TAG content are increased in skeletal muscle from obese and T2DM subjects, compared to lean controls 110 .

\section{DEVELOPMENT OF LIPID-INDUCED CARDIAC INSULIN RESISTANCE}

In obesity and T2DM, the excess myocardial lipid accumulation is related to both myocardial dysfunction and the development of cardiac insulin resistance ${ }^{17}$. Initially it was believed that elevated intracellular levell of LCFAs result in an inhibition of glucose oxidation leading to a decreased glucose uptake, which is known as the Randle cycle. However, recent evidence demonstrated that rather than the Randle cycle, intracellular lipid metabolites result in an impaired insulin-stimulated GLUT4 translocation. 


\section{The Randle cycle}

Elevated plasma LCFAs levels, one of the main features in obesity and resulting in an increased cellular LCFA uptake, could play a role in the development of insulin resistance. In wiew to the Randle cycle, it is believed that an increased LCFA oxidation, due to increased availability of intracelluar LCFAs, contributes to the development of a decreased glucose uptake in cardiac myocytes ${ }^{118}$. By increasing LCFA oxidation the glycolytic pathway is inhibited due to an accumulation of intracellular acetyl-CoA and citrate leading to increased glucose-6-phosphate concentrations and decreased hexokinase activity 18,119 . Eventually cardiac glucose uptake and oxidation are reduced. An inverse relation between cardiac glucose uptake and plasma LCFAs in man has been demonstrated ${ }^{120}$. However, the mechanism proposed by Randle occurs under physiological conditions and it is unclear whether this mechanism can be extrapolated to pathophysiological conditions in which plasma LCFA concentrations are chronically elevated 121 .

\section{Intracellular lipid metabolites and insulin resistance}

A strong positive correlation between the accumulation of intramyocellular TAGs and cardiac insulin resistance has been demonstrated 11,114 . However, not TAGs directly but related lipid metabolites, i.e., acyl-CoAs, ceramides and DAGs are believed to be involved in the development of insulin resistance. Unfortunately, most studies addressing the effect of these lipid metabolites on insulin resistance are performed in skeletal muscle and not in heart muscle. However, findings in skeletal muscle usually can be extrapolated to the heart muscle due to the similarity in regulation of substrate utilization between skeletal muscle and heart.

\section{Triacylglycerols}

Intramyocellular TAGs are believed to directly affect cellular contractions by spatial hindrance of the contractile machinery making it more difficult to sustain contractions with appropriate amplitude in cardiac myocytes ${ }^{122}$. However, the precise mechanism has not been clarified yet. In addition, lipid metabolites such as acyl.CoAs, ceramides and DAGs originating from or in equilibrium with the intracellular TAG pool are believed to influence insulin-induced glucose uptake and GLUT4 translocation.

\section{Acy-CoAs and ceramides}

Acyl-CoAs are precursors for ceramides which are generated via de nowo synthesis or via degradation of sphingomyelin 123 . In skeletal muscle from human and rodent models of insulin resistance intracellular ceramide content was increased up to 2 -fold $124 \cdot 127$. In vitro treatment of sheletal muscle cell lines, i.e., L6 myotubes and $\mathrm{C} 2 \mathrm{C} 12$ myotubes with either a cellpermeable ceramide or palmitate increased the intracellular ceramide content $124,128.130$. In these ceramide-loaded skeletal muscle cells insulin-stimulated serine phosphorylation of PKB and its activation were reduced, whereas tyrosine phosphorylation of the insulin receptor and IRS! remained unaltered, suggesting that ceramides do not affect insulin signalling upstream of PKB 128, 130. Moreover, ceramide decreased insulin-stimulated glucose uptake and glycogen synthesis in skeletal muscle cells 124,131 . Whether ceramides affect GLUT4 translocation in 
skeletal muscle is unknown, however studies in $3 \mathrm{~T} 3$ adipocytes showed that ceramides fnhibit GLUT4 translocation leading to a decreased glucose uptake ${ }^{32}$.

\section{Diacylglycerols and protein kinase $C$}

Intracellular DAGs have been found to be markedly increased in skeletal muscle from insulin resistant rodents and humans 33137 . In skeletal muscle, the activity of conventional and novel PKCs is induced by DAGs. It has been demonstrated that activation of these PKCs leads to tyrosine phosphorylation of the insulin receptor and IRS1, thereby inhibiting their activity, which results in a decreased $\mathrm{PI}_{3} \mathrm{~K}$ stimulation ${ }^{138}$. Itani et al. ${ }^{139,140}$ showed that the activation of PKC $\theta$ is significantly increased in skeletal muscle from diabetic patients compared to muscle from non-diabetic controls. Whether DAGs are directly involved in the development of cardiac insulin resistance remains to be elucidated.

FAT/CD36 as a key player in the development of cardiac lipotoxicity; hypothetical model

Available data indicate that FAT/CD36 may have an important role in the etiology of diabetic cardiomyopathy. Abnormalities in the regulation of the sarcolemmal amount of FAT/CD 36 could

\section{Permanent relocation of FAT/CD36 to the sarcolemma}

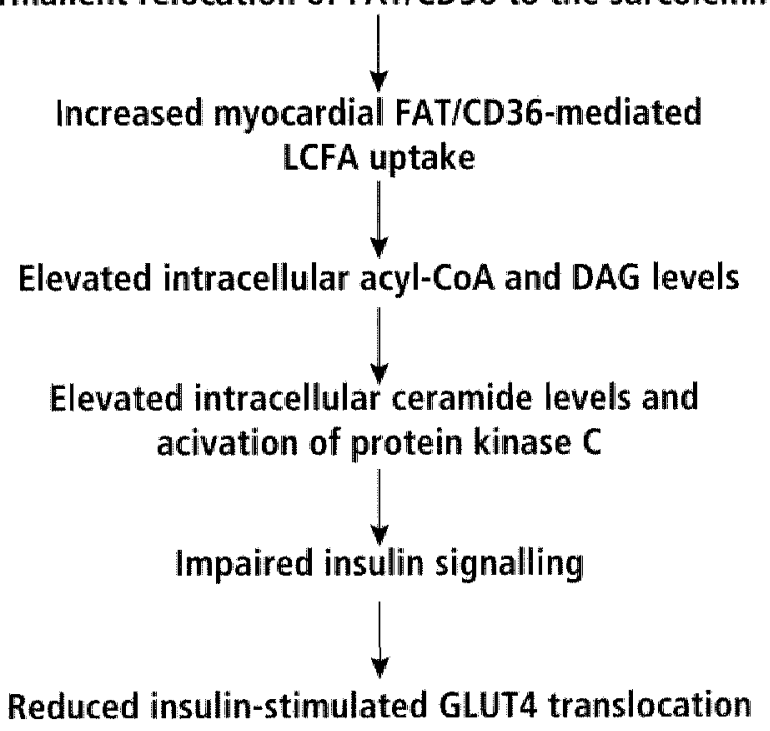

Figure 2.6 Hypothetical model for the development of an impaired insulin-stimulated CLUT4-translocation in cardiac myocytes.

$\angle C F A=$ long.chain fatty acid, FAT,$C D 30=$ fatty acid translocase and $D A C=$ diacylglycerol. 
contribute to both the development of cardiac lipotoxicity resulting in cardiac dysfunction and to a decreased insulin sensitivity of he heart. Based on animal studies, a hypothetical model is presented for the developmejt of impaired insulin-simulated GLUT4 translocation (Fig. 2.6).

Already under prediabetic conditions, LCFA uptake by cardiac myocytes is markedly increased, due to a permanent relocation of FAT/CD 36 to the sarcolemma. Moreover, it has been demonstrated that the total intracellular TAG and FA content and the incorporation rate of LCFAs into intracellular TAGs were increased in isolated cardiac myocytes from insulin resistant, obese rats. Interestingly, when sarcolemmal FAT/CD36 activity was inhibited by SSO in these cardiac myocytes both intracellular FAs and the incorporation rate of LCFAs into intracellular TAGs were normalized. The accumulation of TAGs, and its metabolites, i.e., acylCoAs, ceramides and DAGs are one of the first events in the development of cardiac insulin resistance. Both ceramides and DAG-activated PKCs will inhibit the insulin signalling pathway involved in translocation of GLUT4 from intracellular storage compartments to the sarcolemma, leading to a reduced GLUT4-mediated glucose uptake by cardiac myocytes. Interestingly, Bonen et al. "16 demonstrated in human skeletal muscle a strong positive correlation beween the amount of plasmalemmal FAT/CD36 and the amount of intramyocellular TAGs. Moreover both plasmalemmal FAT/CD36 and TAG content increased with the severity of the insulin resistance. Collectively, these data suggest a causal link between the activity of FAT/CD36 at the sarcolemma and the development of cardiac lipotoxicity, which eventually leads to cardiac insulin resistance. This model is based on animal studies performed in isolated cardiac myocytes and should be verified in humans.

\section{THERAPEUTIC APPROACHES}

During recent years several strategies were followed to normalize altered substrate preference to improve cardiac function and insullin sensitivity in T2DM. Classical and new strategies will be discussed in this paragraph.

First, since in full:blown T2DM cardiac glucose oxidation decreases it was thought that by inhibiting LCFA oxidation, glucose uptake and oxidation would be compensatory upregulated and thus normalized, resulting in an improved cardiac function. A manner to inhibit cardiac LCFA oxidation is by blocking the entry of acyl-CaA's into the mitochondria. Etomoxyril-CoA, the biologically active intracellular metabolite of etomoxir, inhibits the enzyme activity of CPT. $I$ in the same manner as its naturally occurring inhibitor, malonyl-CoA ${ }^{141}$. Studies in which T2DM patients were treated for three days with a high dose of etomoxir (100 mg.day-1) demonstrated that indeed overall insulin-stimulated glucose uptake increases, basal glucose oxidation increases and basal LCFA oxidation decreases 142,143. However, insulin-stimulated glucose oxidation was not altered ${ }^{143}$. One of the negative side effects of etomoxir-treatment is that lipids accumulate in non-adipose tissue such as the heart ${ }^{44}$. Etomoxir has no effect on FAT/CD 30-mediated LCFA uptake, thus LCFA taken up by cardiac myocytes can only be intracellularly stored 35 . On the long rum one would expect severe negative side effects when using etomoxir. Moreover, it has been demonstrated that cardiac hypertrophy occurs after etomoxir administration ${ }^{145}$. 
Second, manipulations of the AMPK signalling pathway could be an attractive approach to increase glucose uptake in heart and subsequently improve the functioning of the heart. Activating AMPK with exercise results in an increased LCFA oxidation which could eventually lead to a reduction in the accumulation of intracellular $\operatorname{TAGs}^{70}$. Since lipid intermediates of TAGs are believed to play a role in the impaired GLUT4 translocation in T2DM, inducing AMPK activity could be beneficial 146 . Because AMPK activation results not only in an enhanced LCFA oxidation but also LCFA uptake increases in cardiac myocytes ${ }^{73}$, short-term activation of AMPK may not result in an increased cardiac insulin sensitivity. However, recently it has been demonstrated that long-term AICAR administration and exercise, both activating AMPK, increases whole-body insulin sensitivity in Zucker diabetic fatty rats ${ }^{147}$.

Third, increasing the activity of PKA is another possibility to improve cardiac insulin sensitivity. Like AMPK, PKA is able to increase LCFA oxidation in cardiac mycoytes ${ }^{61.63}$. On the other hand, PKA has no effect on LCFA uptake, whereas AMPK enlances LCFA uptake 65 . Thus, by activating PKA the excess intracellular LCFAs are redistributed from esterfication towards $\beta$-oxidation, resulting in a decline in intracellular TAG content. Already a 3 fold elevation in intracellular cAMP was sufficient to maximally induce this redistribution 65 . However, a potential drawback of inducing the PKA activity is that this also elicits positive inotropic effects, which could lead to cardiac hypertrophy. This drawback could be partially circumvented by PKA stimulating agents that have relative small effects on cardiac hyperthrophy, but will sustain metabolic action.

Fourth, modulation of the expression of genes involved in substrate utilization by activating members of the PPAR family is one of the strategies recently followed to increase insullin sensitivity in T2DM. A new class of insulin-sensitizing agents that exert their action through activating PPAR $\gamma$, are the thiazolidinediones, such as rosiglitazone and troglitazone ${ }^{148,149}$. Rosiglitazone treatment of (i) insulin resistant obese Zucker rats ( 12 months old) for 14 days and of (ii] high-fat fed rats treated for 4 days, resulted in normalized insulin-stimulated glucose uptake and GLUT4 transporter expression in isolated cardiac myocytes ${ }^{99,150}$. Subsequently, treatment of Zucker diabetic fatty rats with a PPAR $\gamma$-agonist results in improved cardiac function ${ }^{15}$. The effects of TZDS seen in hearts of insulin resistant rodents are believed to be indirect, namely through shuttling of LCFAs towards adipose tissue (for more detail see Chapter 7).

Fifth, it is believed that by inhibiting the accumulation of intracellular TAGs, cardiac insulin-resistance will decline and its function will improve. The strong positive correlation between the intramyocellular amount of TAGs and the sarcolemmal FAT/CD36 content muscle of obese and T2DM patients, suggests that an inhibition of FAT/CD36 could result in an decreased TAG accumulation 88,116 . In vitro it has been demonstrated that FAT/CD36mediated cellular LCFA uptake can be inhibited by sulfo- $N$-succinimidyl oleate (SSO), which covalently binds to FAT/CD36. Therefore, SSO seems suitable to inhibit the accumulation of TAGs in the heart at an early stage of development of T2DM. However, FAT/CD36 is not only expressed in high amount in muscle tissue, but also in white adipose tissue ${ }^{30}$. It is expected that when SSO is administered in vivo, due to a decreased LCFA uptake by muscle tissues, plasma LCFA concentrations will rise. The increased plasma LCFA levels could be reduced if more LCFAs are taken up by adipose tissue, however, this is impossible since SSO will also 
block FAT/CD36 in adipose tissue. Ideally an agent should be developed that specifically inhibits FAT/CD36 in muscle tissue and that reaches the circulation after oral intake.

\section{Concluding remarks}

Chronically increased protein levels of FAT/CD 36 at the sarcolemma play a pivotal role in the development of T2DM, leading to enhanced LCFA uptake, accumulation of intracellular TAGs and inpaired insulin-stimulated GLUT4 translocation. The increased sarcolemmal abundance of EAT/CD36 is due an impairment of EAT/CD36 recycling between intracellular storage compartments and the sarcolemma. Pharmacological manipulations aimed at specific signalling processes, i.e., the contraction and insulin signalling pathways involved in substrate utilization, or trafficking steps that will result in selective recruitment of GLUT4 and/or internalization of FAT/CD36 are expected to inhibit the accumulation of TAGs and to reverse cardiac insulin resistant and prevent the development of cardiac dysfunction.

\section{ACKNOWLEDGEMENTS}

This work was supported by the Netherlands Heart Foundation, grant 2000.156, by the Heart \& Stroke Foundation of Ontario, and the Canadian Institutes of Health Research. Arend Bonen holds a Canada Research Chair in Metabolism and Health. Jan F.C. Glatz is Netherlands Heart. Foundation Professor of Cardiac Metabolism. Joost J.F.P. Luiken is the recipient of a VIDIInnovational Research grant from the Netherlands Organization for Scientific Research (NWOZonMw grant nr. 016.036.305). 


\section{References}

1. Seidell JC. Prevalence and time trends of obesily in Europe J Endownol intest $2002,25 \cdot 1022$.

2. Passa P. Diabetes trends in Europe. Duaberes Metab Res Rev 2002;18 Supp 333.8.

3. Riste L, khan $\mathbb{F}$ and Cruickshank $K$. High prevalence of twe 2 dabetes in all efinic groups, nduding Europeans, in

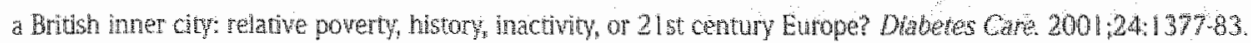

4. Engelga MM, Gess LS, Saadine JB, Boyle JP, Benjamin SM, Greg EW, Therney EF. Rios-Burrows M, Mokdad

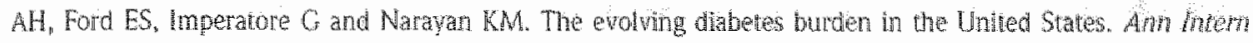
Med. $2004: 140: 945.50$.

5. Stumpt E. The obesing epidemto in the United States: causes and extent, risks and solutions. Fstue brtef ICommonw Fund. $2004 ; 1.6$.

6. Pery II. Heatthy diet and lifescyle clustering and glucose intolerance. Proc Nutr Soc 2002,61:543-51.

7. Perusse $\mathrm{L}$. Chagnon $\mathrm{YC}$ and Bouchard C. Etougg of massive obesity: role of genetic factors. Worta / Surg. $1098222907-12$.

8. Remacle C, Bieswal F and Reusens B. Programming of obesity and cardiowascuiar disease. Int j Obes Retat Metab Drord. 2004;285 Suppl 3:546-53.

9. Aneja A. El-Atat F, McFarlane SI and Sowers IR. Hypertension and obesity. Recent Prog Horn Res 2004:59:100. 205.

10. Mensah GA, Mokdad AH, Ford E, Narayan KM, Gile WH, Yinicor Fand Deedwania PC, Obesity, metabohic syndrome, and type 2 diabetes: emerging epidemics and their cardiovasculai implications. Cardiol Chn. $2004: 22: 485-504$

11. Fox Cs, Coady S, Sorlie PD, Levy D, Meigs JP, DAgostino RB, Sr, Wilson PW and Savage Pl. Thends in cardiowascualar complications of diabetes. Jama. 2004;202:2405-9.

12. Grundy SM. What is the contribution of obesity to the metabolic shindrone? Endocrino Metab Chin North Am. $2004,33: 267-82$, table of contents.

13. Tang WH and Young, JB. Cardiomyopathy and heart balure in diabetes. Endocrinol Metab Clin Nonth An. $2001 ; 30: 1031 \cdot 46$.

14. Bertoni AG, Trai $A$, Kasper EK and Brancati FL. Diabetes and idopathic cardionyopathy: a natonwide case. control study. Diabetes Cate 2003,20:2791-5.

15. Diamant M, Lamb HI, Groeneveld Y, Lndert EL, Snit WW, Bax JI, Romin JA, de Roos A and Radder JK. Dascolic dysfunction associated wh altered myocardial metabolism in asymptomatic nomotensive patents with wetl. controlled type 2 diabetes nellitus. I Am Coll Camdiol 2003;4232835.

16. Varminen E, Mustonen \, Vamio P, Lansimies E and Uustupa M, Left venticular function and dmensions in newly diagrosed non insulin dependent diabetes mellitus. Am / Cardiol 1092,70,371.8.

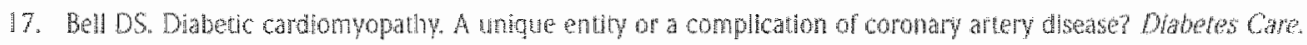
$1905 ; 18: 708.14$

18. Hayat $S A$, Patel B, Khatar KS and Malik RA. Diaberc cardiomyopathy: mechanisms, diagnosis and treatmeni. Clin Sci $2004: 107539.57$.

19. Taegtreyer $H$, McNuly $\mathrm{P}$ and Young ME Adaplation and maladaptation of the hean in dabetes: Part 1 generat concepts. Crovation. 2002;105:172733.

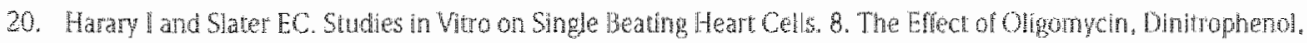
and Ouabain on the Beating Rate. Brochim Brophys Acta. 1965;09:227.33. 
21. Wan der Wusge Gl and de Groo M. Interelatonshp bewwen lactate and cardiac faty acid metabolism. Mol Cel Biochent 1992:116:11.7

22. Glat If, Borchers $T$, spener $F$ and wan der Vusse of. Faty acids in cell signaling: modulation by lipid binding

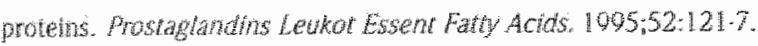

23. van der usse Of, Grat JF, Stam HC and Reneman RS. Fatty acid homeostasis in the normuxic and ischemic heart. Physiol her 1902;72:881.940.

24. Muecher M. Fachtotive glucose transporters. Eut / Btomen 1904:219:71325.

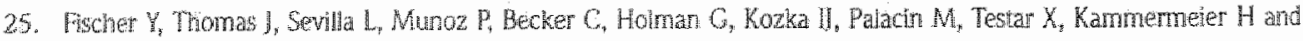
Zorzano A. Insulin-nduced recuiment of gucose transporter 4 (GLUT 4) and GUTT 1 in isolated tat cartiac mocytes. Endence of the eximence of diferent intracelluar GUTA vesicle populations. I Bol Chem 1997,2727085.92.

20. Zorzano A, Sevila L, Camps M, Becker C. Meyer I. Kammemejer H, Munoz P, Guma A, Testar X, Palacin M, Btas! ) and Fischer $Y$. Regulation of glucose transport, and gluchse transporters expression and trafficking irs the heart studies in cardac myocytes. Am / Cardiod 1997,8006 A.76A.

27. Spector AA. Piasma lipid tunspont. Chn Physiol Btochem. 1984;2:123-34.

20. van der Vusse Gl, wan Bisen M and Glatz. JF. Cardiac fatry acid uptake and transport in health and disease. Cardiovasic Res. 2000;45:270.93

29. Hamiton JA and Karnp F. How are free fatly acids tramsported in mernbranes? is th by proteins or by free diffusion through the lipids? Diatetes, 1999:48:2255-69.

30. Powinall $\mathrm{HJ}$ and Harnilton $\mathrm{A}$. Energy translocation across cell nembranes and membrane nodels. Acta Physio Scand. $2003 ; 178.357 .65$.

31. Luken J), van Nieuwenhoven FA, America $\mathrm{C}$, van der Vusse GI and Glatz JF Uptake and metabolism of pamitate br isdated cardiac myochtes from adult tas: involvement of sarcolenmal proteins. JLipid Res. 1907;38:745-58.

32. Luiken II, Schaap FG, van Nieuwenhowen FA, wan der Wusse GJ, Boner $A$ and Glatz JF. Celluar faity acid transport in heart and skeletal nuscle as facllitated by proteins. Lipids. 1999;34 Suppl:5160.75.

33. Bonen $A$, Luiken IJ and Glaz JF. Regultition of fatry acid transport and nembrane transporters in health and disease. Mol Cell Biochem, 2002;230:181-92

34. Brimkmant JF, Abumad NA, Ibrahimi $A$, van der Vusse $\mathrm{G}$ and Clatz IE New insights into longechain fatty acid uptake by heart muscle: a cucial role for fatty acid transhocase CD 36 . Bochem / 2002:367.561-70.

35. Gava JF: Luken If and Bonen A. Inolvement of membrane-associated proteins in the acute regulation of cellular latiy acid uptake. J Mol Neurosci, 2001:16:123.32, discussion 51.7 .

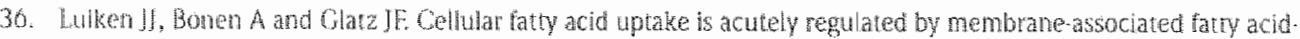
binding proteins. Prostagkandins He tukot Essent Fady Acids. 2002,67.73-8.

37. Coot SL, Wiliens I, Coumans WA, van der Vusse G], Bonen A, Glate If and Luiken II. Sulfon-succinimidy! esters of long chan fally acids spechically inhibit faty acid translocase [FAT/CD36/-mediated cellular fatty acid uptake. Mol Cell Bhochem. 2002;239;2139.

38. Stremme W, Strohnever $G$. Borchard $\mathrm{F}$, Kochwa $S$ and Berk PD. Eolation and partial characterization of a fatty acid binding protein in at liver plasma membrames. Hoc Nat Acad SE US A. 1085;82:A8.

39. Stah A. A current review of fatty acid transpot proteins $6 L \mathrm{C} 27$. Pfhgers Arch 2004:447:722.7.

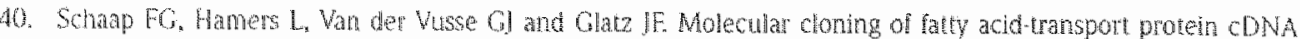
From att. Bochm Bophy Acra. 1007;1354:2034.

41. Gimeno RE, Oferon AM, Patel S, Punreddy S, Ge P, Sun Y, Lodish HF and Stan A. Characterization of a hear. specific faty acid transport protein. / Biol Chem. 2003:278:1603044. 


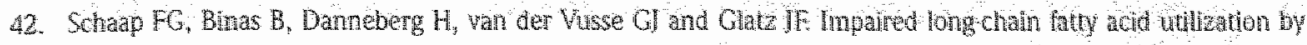
cardiac mpocytes isolated fron mice lacking the hearttype faty acid binding proten gene. Oinc Res. $1090 ; 85: 329 ; 37$.

43. Glatz Jf and Storch I. Unaveling the significance of cellular fatty acidbinding proteins. Curr Opin Lipdot. 2001;12:267-74.

44. Gargitlo GE, Stuhlsatzkrouper SM and Schaffer JE Localization of adpocyte longechain fatry achl CoA synhetase at the plasma membrane. J Lipid Res, 1999:40:881-02.

45. Knudsen J, Neergaard TB, Gaigg B, lensen MV and Hansen IR. Role of acyl CoA binding protein in acylCoA metabolism and acyl-CoAmediated cell signalng. 1 Nutr: 2000,1302045.8S.

46. Faergeman $\mathrm{N}$ and Krudsen I. Acy $\mathrm{COA}$ binding protein is an essential protein in mammaltan cell lines Btochem J. $2002 ; 308: 670-82$.

47. Eaton S. Control of mitochondrial betaxidation flux. Prog Lipid Res. 2002;41:197.239.

48. Schulz H. Regulation of fatty acid oxidation in heart. / Wutt 1994;124:105.71.

49. Ghisla S. Beta-oxidation of fatty acids. A century of discovery. Eur J Biochen. 2004;271:450-61.

50. Taegtmeyer H. Genetics of energetics: transcriptional responses in cardiac metabolism. Ann Bromed Ent: $2000 ; 28: 8716$.

51. van Bilsen $M$, van der Vusse $G$, Gilde A), Lindhout $M$ and wan der Lee KA. Peroxisome proliferatoractivated receptors: lipid binding proteins controling gene expression. Mol Cell Biochert 2002;230:131-8.

52. Gilde $\mathrm{Al}$ and Van Bilsen M. Peroxisome proliferatoractwated receptors [PPARSi: regulators of gene expression in heart and skeletal muscle. Acta Physiol Scand. 2003;178:425-34.

53. Bers DM. Cardiac excitation-contraction coupling. Nature 2002;415:198.205.

54. Till M, Kolter T and Eckel J. Molecular mechanisms of contraction induced transtocation of GLUT4 in tsolared cardionyocytes. Am / Cardol. 1997;80:85 A-9A.

55. Russell RR, 3rd, Bergeton R, Shulman GI and Young LH. Translocation of myocardial GLUT-4 and increased glucose uptake through activation of AMPK by ACAR. An / Physiot. 1999;277: Hod3-9.

56. Luiken J, Willems J, van der Vusse GI and Glate JF. Flectrosimulation enhances FAT/CD30 mediated long whain fatty acid uptake by isolated rat cardiac myocyles. Am / Physiol Endochol Metab. 2001;281:E704-12.

57. Doskeland $5 O$, Maronde E and Gertsen BT. The genetic subtype of CAM dependent protein knase functonally different on redundant? Brochim Biophys Acta. $1993,11782,240.58$.

58. Beebe S. The CAMP dependent protein kinases and CAMP signal transduction. Semh Cancer Bol 1904:5285.44.

59. Gerharasten BL, Pur TS, Chien Al and Hosey MM Identilication of the sites phospholyated by cyclic AMP demendent proten kimase on the beta 2 subunit of L type wollage dependent caldum channess. Biochemisty, 1990,38:1036170.

60. Tong CW, Gaffin RD. Zawiefa DC and Muthuchamy M. Roles of phosphowlaton of myosin binding protein-C. and troponin I in mouse cardiac muscle twitch dymamics. J Physiot 2004:558:027.41.

61. Boone AN, Rodrigues $\mathrm{B}$ and Brownsey RW. Multiple-site phosphorylaton of the $280 \mathrm{kDa}$ isoform of aceyl CoA carboxylase in rat cardiac myocytes; evidence that CAMPdependent protein knase medates eflecs of beta. adrenergic stimulation. Biochem /. 1099,341 (Pr 21347.54.

62. Dyck IR, Kuco N, Barr AI, Davtes SP, Hardie DG and Lopaschuk GD. Phosphorylation control of cardiac acely. CoA carboxylase by CAMPdependent protein kinase and 5 -AMP actuated protein kinase. Eur / Biochem. $1990: 202: 18400$.

63. Bimchi $\mathrm{A}$, Evans $\mathrm{L}$, Iverson $\mathrm{A}$, Nordind $\mathrm{AC}$, Wats $\mathrm{TD}$ and witters $\mathrm{LA}$, Identification of an isozymic form of acetyl.CoA carbowlase. J Biol Chem. 1990,265:15029. 


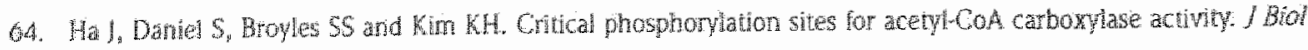
Chem. 1904,269:221028.

65. Luthen J), Whems J, Coont SL, Coumans WA, Bonen A, Van Der Vusse Gl and Giatz JF Effects of CAMP modulators on long tham faty.acid uptake and utilization by electrically stimulated rat cardiac myocytes. Biochem f. 2002;367:881.7.

60. Abdel.Ateern $S$, Bady $M$ and Frangakis $C$. Stimulation of fary acid oxidation in myocytes by phosphodiesterase inhubtors and adenowine andogues. Life Scl. 1901;48:P1.97.102

67. Woods $A$, Johnstone $\$$ R, Dickerson $K$, Leiper FC, Fryer LG, Neumam D, Schlatuer U, Walliman T, Carlson M

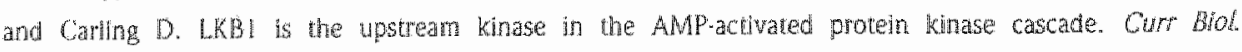
$2003 ; 13: 20048.8$

68. Scot JW, Hawey SA, Green KA, Anis M, Stewart G, Scullion GA, Noman DG and Hardie DG. CBS domans form energy-sensing modules whose binding of adenosine ligands is distupted by disease mutations. / Cin hnvest. $2004: 13: 274.84$.

69. Hardie DC. AMp ucivated proten kinase: a master swith in gucose and lipid metabolism. Rev Endocr Metab Disord 2004:5:119-25.

70. Coven DL., HuX, Cong L, Betgeron R, Shuman GI, Hardie DG and Young LH. Physiological role of AMP. activated protein kimase in the heart: graded activation duing exercise. Am I Physiol Endocrinol Metab. $2003 ; 285: 5629 \cdot 36$

71. Merrill CF, Kuth E, Hardie DG and Winder WW. AICA riboside increases AMP-activated protein kinase, fatiy acid oxidaton, and gucose uptake in rat muscle. Am J Physiol 1097273:E1107-12.

72. Bergeron R, Russeil RR, 3rd, Young LH, Ren MM, Marcuci M, Lee A and Shuman Gl. Effect of AMPK activation

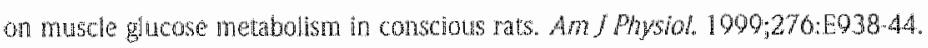

73. Luiken 1, Coon SL, Whlems, Counans WA, Bonen A, van der Wusse GI and Glatz JF, Contraction-nduced fatcy acid Iranslocase/CD36 translocation in mat Cardiac nyocytes is mediated through AMP. activated protein kinase signaling, Diabetes, 2003;52:1027-34.

74. Kudo N, Barr A, Barr RL, Desal S and Lopaschuk GD. High rates of tatty acid oxidation during repertusion of ischemic hearts are associated with a decrease in malonyl.CoA levels due to an increase in 5 'AMP.activated protein kinase inbibtion of acetyl CoA carboxylase. I Blol Chem. 1905;270:1751320.

75. Kauhlk Vk, Voung ME, Dean DI, Kurowsk TO, Saha AK and Rudeman NB. Regulation of farty acid oxidation and

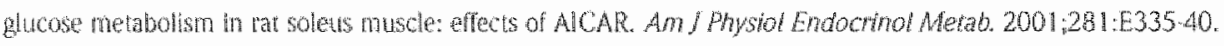

76. Nevtor AC. Protein kinase C. structure, function, and reguhation. IBiol Chem. 1905:270:28495-8.

7\%. Mochly-kosen D and Gordon AS. Anchoring proteins for protein kinase C: a means for isozyme selectiwly. Faseb 1. 1998:12:35.42.

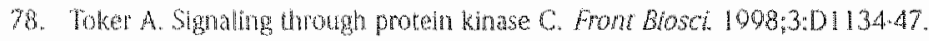

70. Puceat M, Hitat Dandan R, Strulowti B, Bruntoh LL and Brown JH. Differential regulation of protein kinase C

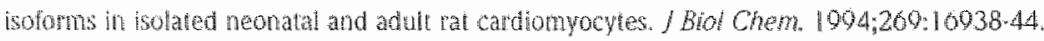

80. Steinberg SF, Goldberg $M$ and Rybin Vo. Ploten kinase $C$ isoform diversicy in the heat. $/ \mathrm{Mol}$ Cell Cardot. $1005 ; 2 \%: 141,53$

81. Mahona A, Kang BP, Opawumi D, Beilzatre W and Meggs LG. Molecular biology of protein kinase C signaling In candiac nuocytes. Mol Cest Biochem. 2001,225:97-107.

82. Schab MC and Kunz B. Regulation of contraction in cardiac and smooth muscles / Cardovasc Pharmacol. 1080,8 Suppl 8511723. 
83. Korzick DH. Regulation of cardiac excitation contuacion coupling a cellular update: Aw Phyou Lduc. $2003 ; 27: 1922000$.

84. Luken J], Coort SL, Koonen DP, Bonen A and Glatz JF Signaling components involved in contradon-nducble substrate uptake into cardiac mocytes. Proc Nutr $500.2004 ; 03: 251.8$.

85. Rose A, Michell B. Remp BE and Hargreaves M. Effect of exercise on protehn kinase C activity and localration in human skeletal muscle. I Physiol 2004,561:86170.

86. Richter EA, Vistisen B, Maarbjerg S1, Sajan M, farese RV and kiens B. Differential effect of bicycling exercise intensity on activity and phosphorylation of ahpical protein kinase $\mathrm{C}$ and extracellular signalregulated proten kinase in skeletal muscle / Physiol. 2004;560:900\%18.

87. Permin S, Hentiksson J, Zlerath IR and Widegnen U. Exercise-induced protein kinase C isoform-speciflc actuation in human steletal muscie. Diabetes. 2004:53:21:4.

88. Coort SL, Hasselbaink DM, Koonen DP, Wilems J, Coumans WA, Chabowsk A, wan tet Vusse GI, Bonen A, GlaIz JF and Luiken IJ. Enhanced sarcolenmal FAT/CD36 content and triacylglycerol storage in cardiac myocytes from obese zucker rats. Diabetes. $2004 ; 53: 1655 \cdot 63$.

89. Brownsey RW, Boone AN and Allard MF. Actions of insulin on the mammalian heart: metabolism, pathology and biochemical mechanisms. Cardiovasc Res. 1907,34:324.

90. Hiraoka M. A movel action of insulin on cardiac membrane. Circ Res. 2003;:92:707-9.

91. Pirola L, Johnsion AM and Van Obberghen E. Modulation of insulin action. Diabetologua. 2004:47:170.84.

92. Saltiel AR and Kahn CR. Insulin signalling and the regulation of gucose and lipid metabolism. Nature. $2001: 414: 790,800$.

93. Taha $C$ and Klip A. The insulin signaling pathway. Membr Btol 1999;100:1-12.

94. Bandyopadhyay G, Sajan MP, Kanoh Y, Standaer ML, Quon MI, Lea-Currie R, Sen A and Farese RV, PKC.zeta mediates insulin effects on glucose transport in cultured preadipocyte-derived human adipocytes, / Clin Endocrinol Metab. 2002;87:710.23.

95. Slot IW, Genze HJ, Gigengack S, James DE and Lienhard GE. Transiocation of the glucose transporter GLUT4 in Cardiac myocytes of the rat. Proc Nat Acad Sci US A. 1091;88:78159.

Q0. Luiken II, Koonen DP, Willems J, Zorzano A, Becker C, Fischer Y, Tandon NN, Van Der Wusse GI, Bonen A and

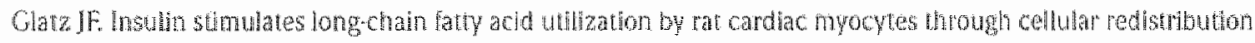
of FAT/CD30. Diaberes. 2002:51:31139.

97. Dyck DJ, Steinberg $G$ and Bonen A. Insulm incteases FA uptake and esterificalion but reduces lipid utilization in isolated contracting muscle. Am I Physiol Endochiol Metat. 2001;281:E0007.

98. Bonadona RC, Groop L, Kraemer N, Ferramini E, Del Prato $S$ and DeFronzo RA. Obesily and insulin resistance in humans: a doseresponse study. Metabolism. 1990;39:4520.

99. Sidell R, Cole MA, Draper N], Desrois M, Buckinghan RE and Clarke K. Thiazolidinedione treatment normalizes insulin resistance and ischemic infury in the zucker Fanty tat heart. Diaberes. $2002 ; 51: 1110 \%$.

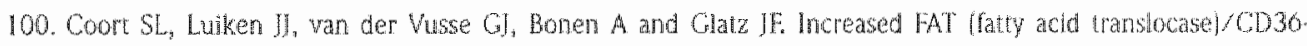
mediated longchain fatty acid uptake in cardiac myocytes from obese Zucker rats. Bochem Soc Trans. $2004 ; 32: 83 \cdot 5$

101. Beike DD. Larsen TS, Gibbs EM and Severson DL. Altered metabolism causes cardiac dystunction in perfused heats from diabetic lob/db] mice. Am J Physiol Endorinol Metab. 2000;279:E1 104.13.

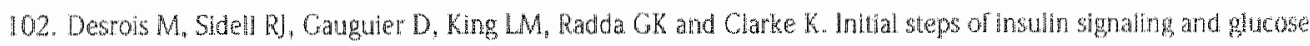
transport are defective in the type 2 diabetic rat heart. Cardionasc Res, 2004;61:288-96. 


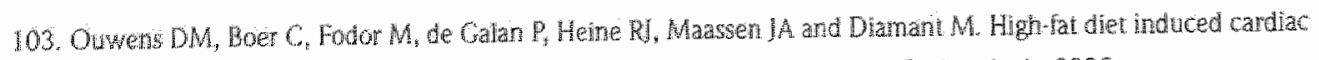
dysfunction is associated wh altered myocardial insulin signalling in rats. Diabctologia 2005;

104. Kolter $T$, Uphues I and Eckel I. Moleculat analysis of inswilin resistance in isolated ventricular cardiomyochtes of obere Zucker rats. Am / Physiol 1997;273:55907.

105. Uphues $I$, Chern $Y$ and Eckel $J$. Insulindependerst transiocation of the smaf GTP.binding protein rab3C in cardic muscle: studies on insulntesstant Zucker rats. FEBS Let. 1995; 377:109.12.

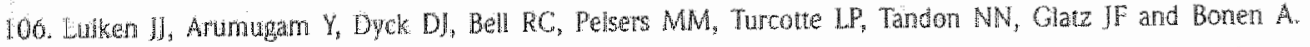
thciedsed rates of faty acid uptake and plasmalemmal fatry acid transporters in obese Zucker rats. $/$ Bol Chem. $2001,276.40507 .73$

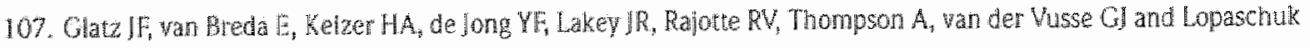
CD. Rat heart fatty actubinding protein content is increased in experimentai diabetes. Blochem Biophys Res Commun. 1094:100:039-46.

108. Knutut J, Takala TO, Nagten K, Sipila $H_{2}$, Turpeinen AK, Uusitupa MI and Nutuda P. Myocardial fatry acid oxddation in patients with irnpared glucose tolerance. Diabetologia $2001 ; 44: 184-7$.

109. Turpethen AK, Kukka IT, Waminen E and Uusitupa Ml. Abnormal myocardial kinetics of 123 l heptadecanok acid in subiects with impared glucose tolerance. Diabetologia. 1997,40:541-9.

110. Schon HR. I. 23 heptadecanoic acld value and limitations in comparison with C. I / palmilate. Eur / Nucl Med. 1986,12 Suppl:510.9.

111. Zhou YT, Graybum P, Karm A, Shmabukuro M, Higa M, Baetens D, Ore L and Unger RH. Lipotoxic heart disease in obese rats implicatons for thumen obesity. Proc Nail ACad SCl U S.A. 2000;07:1784.9.

112. Christoftersen C, Bollano E, Lindegaard ML, Bartels ED, Goeze IP, Andersen CB and Nielsen LB. Cardiac lipid accumulation associated wh diastolic dysfunction in obese mice. Endocrinolog/ 2003;144:3483.90.

113. Atkinson LL. Kozak R, Kelly SE, Onay Besikci A, Russell JC and Lopaschuk CD. Potential mechanisms and consequences of cardiac triacyglycerol accumuation in insulin-resistant rats. Am I Physiol Endocrinol Metab. $2003: 284: 5923-30$.

114. Young ME, Guthre PH, Razeghi P, Leighton B, Abbasi S, Patil S, Youker KA and Taegtmeyer H. Impaired Iong chain faty acid oxidation and contractie dystunction in the obese Zucker rat heat. Dhabetes. 2002;51:2587-95.

115. Igal RA, Wang S, Conzalez ban $M$ and Colenan RA. Mitochondrial gycerol phosphate acyltransferase directs the inconporation of exogenous faty acto ino triacylycerol. I Bol Chem. 2001;270:42205.12.

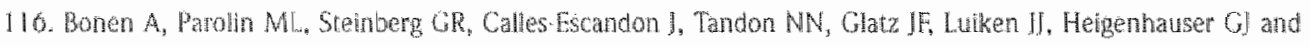
Dyck D. Triachgyctral accumulation in human obesify and type 2 diabetes is associated wilh increased fates of sketetal muscle fatty acid ranspont and increased sarcolemmal FAT/CD36. Faseb/.2004:18:1144-6.

117. Unger RH. Lpolowic disedses. Anm Rev Med 2002:53:310-30.

18. Rande P], Kerbey Al. and Espinal J. Mechanisms decreasing glucose oxidation in diabetes and staryation: role of lipid Tuels and homones. Diabetes Metab Rev 1988;4:023-33.

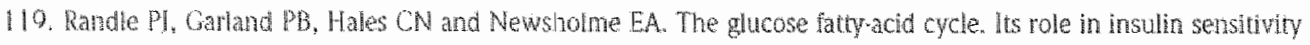
and the netabolic disintbances of diabetes mellitus. Lancet 1963:1:785-9.

120. Mututa P, Knenti MU, Raikakan M, Ruotsalanen U, Teras M, Voipio Pükki LM, Haaparanta M, Solin O, Wegelius U and Thi Jarvinen H. Effect of antilipolysis on heart and skeletal muscle givcose uptake in oyernight fasted humans. Am / Physiol 1094;267.6941-6.

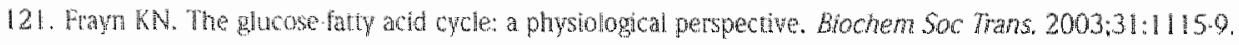


122. Unger RH and Orci L. Diseases of liporegulation: new perspeoive on obesily and related disorders fasebt. 2001;15:312.21.

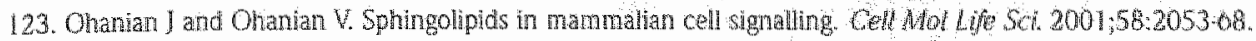

124. Adarns IM, 2nd, Pratipanawar T, Berria R, Wang E. Defronzo RA, Sultards MC and Mandarino L. Cerantide content is increased in skeletal muscle from obese instlinuresistant humans. Dabetes. 2004;5325-31.

125. Straczkowski M, Kowalska I, Nikolijuk $A_{2}$ Dzienis-Straczkowska $S$, Kinalkka I, Baranowski M, ZendzanPiorowsska $M, B$ zezinske $Z$ and Gorsi J. Relationship between insulin sensitivity and sphingomyelin signaling pathway in human skeletal muscle. Diabertes. 2004;53:1215-21.

120. Itani $S$, Ruderman NB, Schmeder $F$ and Boden $G$. Lipid-Induced insulin resistance in human muscle is associated with changes in diacylglycerd, protein kinase $\mathrm{C}$, and Ikappa Balpha. Ditaters. 2002;51:2005-11.

127. Turinsicy I, O Sullivan DM and Bayly BP. 1,2. Diacylgycerol and ceramide levels in insulingreststant dissues of the rat in vivo. J Bol Chem. 1900;205:16880-5.

128. Powell DI, Turban $S$, Gray $A$, Hajduch $E$ and Hundal HS. Intracellular ceramide synthesis and protein kiase Czeta activation play an essential role in paimitate induced insulin resistance in tat Lo skeletal muscle cells. Biochent /. 2004:382:619.29.

120. Chavez JA and Summers SA. Characterizing the effects of saturated fatty acids on insilin signaling and ceramide and diacylgycerol accumulation in 3T3H... adpocytes and C2C12 myoubes. Arch Bochem Biophys 2003:410:101.9.

130. Schmitz Peiffer C, Craig DL and Biden TJ. Ceramide generation is sufficient to account lor the inhibition of the insulinstimulated PKB pathway in $\mathrm{C} 2 \mathrm{C} 12$ skeletal muscle celis pretreated with palmitate. J Biol Chem. 1999;274:2420210.

131. Hajduch E, Balendram A, Baty H, Litherland Cl, Blair AS, Downes CP and Hundal HS. Ceramide impairs the insulin-dependent membrane rechument of protein kinase $B$ leading to a loss in downstream signalling in $\mathrm{L} .6$ skeletal muscle cells. Diabetologia. 2001;44:17383.

132. Summers SA, Garza LA, Zhou H and Bimbaum MI. Regulation of insulinstimulated glucose transporter GiUTA translocation and Akt kinase activity by ceramide. Mol Cell Blol. 1908;18:5457-04,

133. Heydrick SJ, Ruderman NB, Kurowski TC, Adams HB and Chen. KS. Enkanced stimulation of diacylglycerol and lipid synthesis by insulin in denervated muscle. Altered protein kinase $C$ activity and possible link to insulin resistance. Diabetes 1091;40:170711.

134. Avignon A, Yamada K, Zhou X, Spencer B, Cardona O, Saba-Siddique S, Calloway L, Siandaen ML and Farme RV. Chronic activation of proten knase Citn soleus muscles and other tissues of mavin-resistant type ll diabetic Gotokakizaki IGK, obese/aged, and obege/Zucker rats. A mechanism for inhbiting glycogen synthesis. Diabetes. 1990;45:1396-404.

135. Schmitz-Peifer C, Browne CL, Oakes ND, Watkinson A, Chisholm DJ, Kraegen EW and Biden TJ. Alterations in he expression and cellular localization of protein kinase $C$ isozymes epsion and theta are associated with insulin resishance in skeletal muscle of the high fat fed rat. Diaberes. $1997 ; 40: 169.78$.

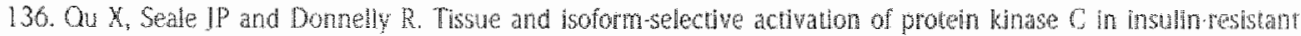
obese Zucker rats effecs of feeding. / Endocrinol. 1909;162207/14.

137. Cooper DR, Wetson JE and Dao ML Decreased expression of protein kinase Calpha, beta, and epsion in soleup muscle of Zucker obese (fa/fa) ras. Endocrinology 1093:133:22417.

138. Chin $\mathbb{E}$, Liu $F$ and Roth RA. Activation of protein kinase $C$ alpha inhibits insulinstimulated tyosine phosphorylation of insulin receptor substrate-1. Mol Endochinol 1994:8:51-8.

139. Itani SI, Zhou Q, Pories WJ, MacDonald KG and Dohm OL. Involvernent of protein kinase Cin human skeletal muscle insulin resistance and obesity. Diabetes. 2000;49:1353.8. 


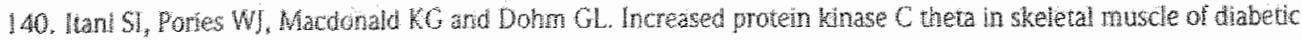
parterity. Merabolism 2001;50:5537.

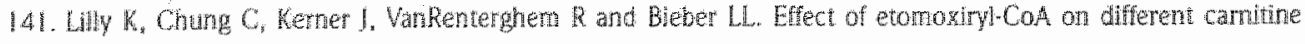
achiransferases. Biochem Pharnacol, 1902;43:353.61.

142. Hubnger $A$, Wekert $G$, Wol HP and Gries FA The effect of etomoxir on insuln sensitwity in thpe 2 diabetic patients. Horm Metalo Res. 1092:24:115.8.

143. Hubinger $A_{1}$ Knode $O$, Susanto $F$ Reindue Hand $C$ wes FA. Effecs of the camitine-acyltransferse inhibitor etomoxir on insultn sensituty, energy expenditure and substrate oxidaton in NDDDM. Hom Metab Res. 1097;29:436-9.

144. Schmilz H, Rosen $\mathrm{P}$ and Reinauer H. Improvement of myocardial function and metabolism in diabetic rats by the carnitue paimitow transierase inhibtor Etonoxir. Hom Melab Res. 1995:27:51522.

145. Rupp H and lacob R. Metabolically-modulated growth and phenotppe of the rat heart. Eur Hearl J. 1092:13 Suppl D.50-01.

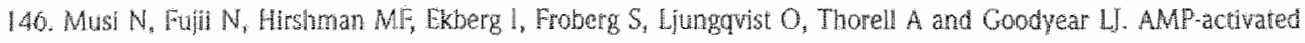
protein kinase (AMPK) is activated in muscle of subjects with type 2 diabetes during exercise Dabetes. $2001 ; 50: 921.7$.

147. Pold $\mathrm{R}$, Jensen LS, Jessen $\mathbb{N}$, Buh ES, Schmiz O, Flyblerg A, Fuji N, Goodyear LJ, Gotredsen CF, Brand Cl. and Lund S. Longterm AICAR administration and exercise prevents diabetes in $2 D F$ rats. Diabetes. 2005;54:928-34.

148. Rramer D, Shapiro R, Adter $A$, Bush E and Rondinone CM. Insulin-sensitizing effect of rosiglitazone (BRL 49653) by regulation of glucose transponters in muscle and fat of Zucker tats. Metabohism 2001;50:1204-300.

140. Oakes ND. Thaten PG, facinto SM and Lung B. Thiazolidinediones increase plasma-akipose tissue FA exchange Capacty and enhance insulin mediated control of systemic FA avallability. Diabetes 2001:50:1158.65.

150. Oakes ND, Kennedy CJ, Jenkins AB, Laybutt DR, Chisholm DI and Kraegen EW. A new antidabeuc agent, BRL 40653, reduces lipid availability and improves insalin action and gitcoregulation in the rat. Biabetes. 1994:43:1203-10.

151. Golman LS, Wilson CR, Sharma S, Burgmaier M, Young ME, Guthrie PH, Van Ardall M, Adrogue NV, Brown KK, Taegtmeyer $\mathrm{H}$. Activation of PPAkgamma enhances myocardial glucose oxidation and improves contractile furction in isolated waking hearts of ZDF rats. An / Physiot. $2005 ; 20$ 


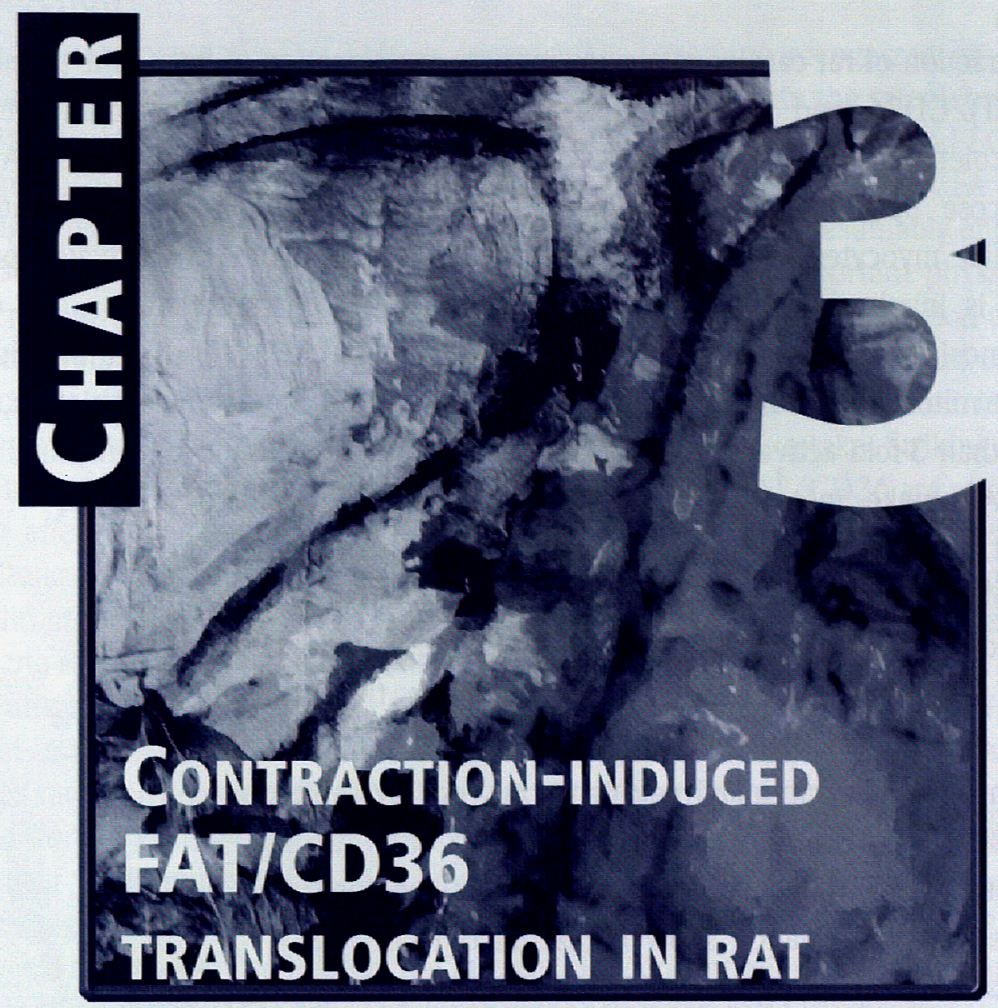

\section{CARDIAC MYOCYTES IS MEDIATED THROUGH AMP-ACTIVATED PROTEIN KINASE SIGNALLING}

Joost J.F.P. Luiken ${ }^{1}$, Susan L.M. Coort ${ }^{1}$, Jodil Willems ${ }^{1}$, Will A. Coumans ${ }^{1}$, Arend Bonen ${ }^{2}$, Ger J. van der Vusse', and Jan F.C. Glatz ${ }^{1}$.

Diabetes 2003:52;1627-34.

IDepartment of Physiology, CARIM, Maastricht University, Maastricht, the Netherlands.

2Department of Kinesiology, Waterloo University, Waterloo, Ontario, Canada. 


\section{INTRODUCTION}

Fatty acid translocase (FAT)/CD36 is increasingly becoming recognized as a physiological important long-chain fatty acid (LCFA) transport facilitator within the sarcolemma of muscular tissues $^{1-3}$. We have gathered convincing evidence that FAT/CD36-mediated LCFA uptake is a rate-limiting step in LCFA use by heart and skeletal muscle ${ }^{2}$. Moreover, LCFA uptake appears to be regulated by translocation of FAT/CD36 from intracellular, presumably endosomal, stores to the sarcolemma. Insulin and cellular contractions are two important physiological factors able to recruit FAT/CD36 to the sarcolemma ${ }^{4 \cdot 7}$. Interestingly, the stimulation of LCFA uptake by contractions was additive to that of insulin, indicating that both stimuli operate through independent mechanisms. Furthermore, wortmannin completely blocked insulin-inducible LCFA uptake, but had no effect on contraction-inducible LCFA uptake. Strikingly, the effects of insulin and contractions on LCFA uptake by translocation of FAT/CD36 are remarkably similar to their effects on glucose uptake by translocation of the glucose transporter GLUT4 from intracellular storage compartments to the sarcolemma ${ }^{7}$. Whereas the wortmannin sensitivity of insulin-inducible LCFA uptake indicates an involvement of phosphatidylinositol-3 kinase $\left(\mathrm{PI}_{3} \mathrm{~K}\right)$, the signalling pathway responsible for contraction-inducible FAT/CD36 translocation is largely unknown. Recently, we have established that cAMP-dependent protein kinase A is not involved in regulation of LCFA uptake $e^{8}$. Another likely candidate-signalling enzyme could be AMP-activated protein kinase (AMPK), which has been firmly established to be involved in translocation of GLUT4 during an increase in contractility9,10. During such an increase in mechanical performance, the high constitutive activity of adenylate kinase in the heart prevents a drastic fall in ATP via the conversion of two molecules of ADP into ATP and AMP11,12. This process also renders the intracellular concentration of AMP, a sensitive indicator of the metabolic state of the cell. The subsequent activation of AMPK has now been established to play an important role in the cellular response to an increase in mechanical activity.

AMPK is a heterotrimeric protein consisting of 3 different subunits, the catalytic $\alpha$ subunit, and the regulatory $\beta$ - and $\gamma$-subunits (Fig. 3.1, left panel). Each subunit has two or more different isoforms ( $\alpha 1$ and $2, \beta 1$ and 2 and $\gamma 1,2$ and 3 ). The different $\alpha \beta \gamma$ combinations exhibit differences in their properties, for example in their response to AMP and in their subcellular localization. The $\alpha 2$-isoform of AMPK is predominantly expressed in heart and skeletal muscle. Activation of AMPK occurs through phosphorylation of threonine-172 (Thr172) in the catalytic domain by one or more upstream AMPK kinases (AMPKKs), such as the recently discovered LKB1 ${ }^{13}$, and allosterically by binding of AMP to the $\gamma$-subunit (Fig. 3.1) ${ }^{14}$. Not only via direct allosteric activation, but also through the stimulation of the phosphorylation of Thr172 and the inhibition of its dephosphorylation by phosphatases regulates intracellular AMP activation of AMPK (Fig. 3.1, right panel). These effects of AMP are antagonized by high intracellular concentrations of ATP15. In resting muscle, AMPK can be pharmacologically activated by 5 -aminoimidazole-4-carboxamide-1- $\beta$-D-ribofuranoside (AICAR) 16-18. After being readily taken up by the muscle cell, AICAR is phosphorylated by the catalytic action of adenosine kinase to form AICAR monophosphate (ZMP), which closely resembles the chemical structure of AMP. ZMP in turn is known the activate AMPK, and in this it mimics the effect of contraction on muscle metabolism. 

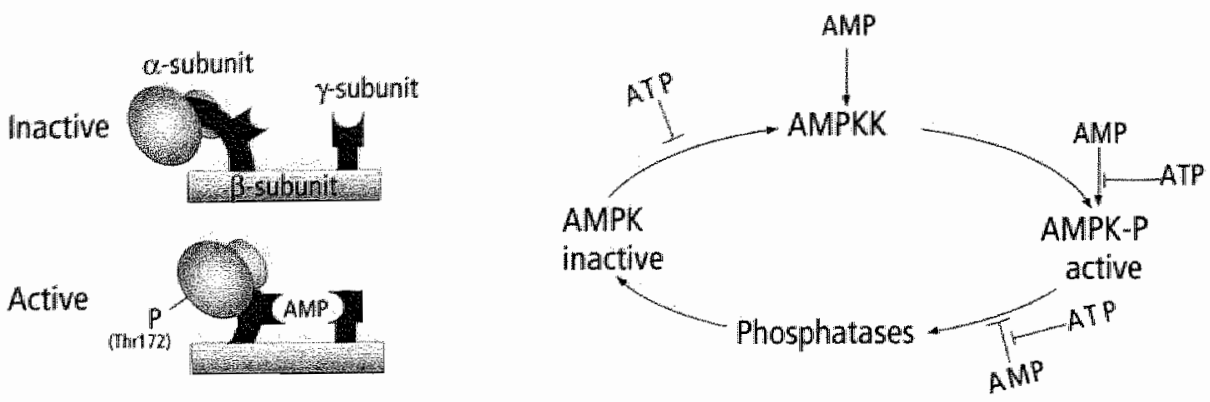

Figure 3.1: Regulation of AMP kinase activation.

The structure of the inactive and active AMP kinase molecule is given in the left panel. The manner in which the intramyocellular AMP and ATP Concentrations infuence AMPK activity is shown in the right panel.

It thas been widely accepted that AMPK activation has a great impact on substrate metabolism in heart and skeletal muscle, perhaps most notably by stimulating glucose utilization via induction of GLUT4 translocation to the sarcolemma:10. Furthermore, AMPK has also been recognized to be involved in LCFA utilization by heart and skeletal muscle. In these tissues, activation of AMPK causes an inhibition of acetyl-CoA carboxylase activity concomitant with lowering intracellular levels of malonyl-CoA $16,10-21$. This results in an enhancement of mitochondrial LCFA oxidation, because the decline in cytoplasmic malonyl-CoA concentration relieves the inhibition on carnitine palmitoyl transferase I (CPT.1).

The present study explores the possibility that there is another level of regulation of LCFA. utilization by AMPK, i.e., at the level of the sarcolemmal uptake process through modulating the subcellular distribution of FAT/CD36. To this end, we investigated whether activation of AMPK is able to stimulate LCFA uptake. For this purpose, we applied the two following pharmacological manipulations, (1) the adenosine analog AICAR leading to activation of AMPK by ZMP, and (ii) the mitochondrial inhibitor oligomycin to elevate the intracellular levels of AMP. Both AICAR and oligomycin were added to quiescent cardiac myocytes as well as to cardiac myocytes electrically stimulated to contract at $4 \cdot \mathrm{H} z$ to study the degree of convergence of theil potential effects with contraction-inducible LCFA uptake. Subsequently, it was determined whether FAT/CD36 and its translocation to the sarcolemma were involved in stimulation of L.CFA uptake by AMPK.

\section{RESEARCH DESIGN AND METHODS}

\section{Materials}

${ }^{14} \mathrm{C}$-palmitic acid and $3 \mathrm{H}$ deoxyglucose were obtained from Amersham Life Science (Little Chalfont, United Kingdom). Bovine serum albumin (BSA, fraction $V$, essentially fatty acid free), 
phloretin, AICAR, oligomycin, adenosine, dimethyl sulfoxide (DMSO), insulin and wortmannin were all obtained from Sigma (St. Louis, MO, USA). 5-Iodotubercidin was purchased from Biomol (Plumouth Meeting, PA, USA). Collagenase type 2 was purchased from Worthington (Lakewood, NJ, USA). Antibody MO25 was a gift from Dr. N.N. Tandon, Thrombosis and Vascular Biology Laboratory, Otsuka America Pharmaceutical (Rockville, MD, USA). The antibody directed against GLUT4 was obtained from Sanvertech (Heerhugowaard, the Netherlands). Anti phospho-acetylCoA carboxylase was obtained from Brunschwig Chemie (Amsterdam, the Netherlands). Sulfo- $N$ succinimidyl palmitate (SSP) is routinely synthesized in our laboratory, as has been previously described 22 . Purity of this compound was confirmed with infrared spectroscopy lperformed by Dr. van Genderen, Technical University, Eindhoven, the Netherlands].

\section{Isolation of cardiac myocytes}

Cardiac myocytes were isolated from male Lewis rats (200-250g) using a Langendorff perfusion system and a Krebs Henseleit bicarbonate medium which is equilibrated with a $95 \%$ $\mathrm{O}_{2} / 5 \% \mathrm{CO}_{2}$ gas phase (medium $\mathrm{A}$ ) at $37^{\circ} \mathrm{C}$, according to Fisher and coworkers and as previously described 24 . After isolation, the cells were washed twice with medium A supplemented with 1.0 mmol. $1^{-1} \mathrm{CaCl}_{2}$ and $2 \%$ (wt/vol) BSA (medium $\mathrm{B}$ ) and then suspended in $15 \mathrm{ml}$ medium $\mathrm{B}$. The isolated cells were allowed to recover for approximately $2 \mathrm{~h}$ at room temperature. At the end of the recovery period, cells were washed and suspended in medium B. Only when $>80 \%$ of these cells had a rod-shaped appearance and excluded trypan blue were they used for subsequent tracer uptake studies.

\section{Electrical stimulation of cardiac myocytes in suspension}

As described in detail elsewhere ${ }^{5}$, cell suspensions were subjected to an electric field via two platinum electrodes that were connected to a pulse generator capable of generating biphasic pulses up to $250 \mathrm{~V}$. The monophasic components before exhibited a block profile. The duration of a monophasic pulse was set at $100 \mu$, and the time interval between the monophasic components before reversal of the voltage was fixed at $10 \mu \mathrm{s}$. The voltage was set at $200 \mathrm{~V}$ and the frequency at $4 \cdot \mathrm{Hz}$.

\section{Measurement of palmitate and deoxyglucose uptake by cardiac myocytes}

Cells (2.0 ml, $5.8 \mathrm{mg}$ wet mass. $\left.\mathrm{ml}^{-1}\right)$, suspended in medium $B$, were preincubated in capped $20 \mathrm{ml}$ incubation vials for $15 \mathrm{~min}$ at $37^{\circ} \mathrm{C}$ under continuous shaking. To study palmitate uptake, $0.5 \mathrm{ml}$ of the ${ }^{14} \mathrm{C}$-palmitate/BSA complex was added at the start of the incubations so that the final concentration of palmitate amounted to $100 \mu$ mol..$^{-1}$ with a corresponding palmitate/BSA ratio of 0.3 . This palmitate/BSA complex was prepared as previously described ${ }^{24}$. To study deoxyglucose uptake, ${ }^{3} \mathrm{H}$-deoxyglucose was added to the palmitate/BSA complex to a final concentration of $100 \mu \mathrm{mol} . .^{1}$. Palmitate and deoxyglucose uptake were simultaneously determined ( 3 min incubation). The uptake process was stopped upon washing the cells three times for $2 \mathrm{~min}$ at $100 \mathrm{~g}$ in an ice-cold stop solution containing $0.2 \mathrm{mmol.1}$ phloretin as previously described ${ }^{24}$. The washing procedure did not affect cellular integrity as evaluated by microscopical evaluation. 
AICAR (1.0 mmol..1-1), oligomycin ( $30 \mu$ mol.1.1), insulin (10 nmol.1.1), wartmannin (200 nmol..1), and adenosine $\left(\leq 1.0 \mathrm{mmol} \cdot \mathrm{I}^{-1}\right)$ were added to cell incubations $15 \mathrm{~min}$ prior to addition of the radiolabeled substrates. 5-Iodotubercidin $\left(20 \mu \mathrm{mol} . \mathrm{I}^{-1}\right)$ was added $90 \mathrm{~min}$ prior to any other addition. Cell suspensions were incubated with sulfo- $N$-succinimidyl palmitate (SSP, 400 umol.11) for $30 \mathrm{~min}$, and subsequentiy washed to remove unbound SSP, and resuspended in medium $B$ before addition of radiolabeled substrates. Stock solutions of oligomycin, wortmannin, SSP and 5-iodotubercidin were prepared in DMSO, which never exceeded a final concentration of $0.5 \%$ in the cell suspension. At this concentration DMSO did not affect cellular substrate utilization. None of the agents, alone or in combination with SSP, were found to affect the percentage of cells that (i) were rod-shaped, and (ii) excluded trypan blue as parameters of cellular integrity.

\section{Measurement of adenosine phosphates and ZMP in cardiac myocytes}

Cardiac myocytes (12-15 mg wet mass. $\mathrm{ml}^{-1}$ ) were incubated in medium $B$ in the absence or presence of addition for $15 \mathrm{~min}$. Thereafter, the cells were centrifuged in a microcentrifuge at $2,000 \mathrm{rpm}$. Upon removal of the supernatant, the cell pellet was extracted with $250 \mu 13 \mathrm{~mol}^{-1} \mathrm{l}^{-1}$ perchloric acid and neutralized with 1 mol. $1^{-1} \mathrm{KHCO}_{3}$. Hereafter, the intracellular content of adenosine phosphates and ZMP were determined by high-performance liquid chromatography according to a variation of the procedure of Wynants and Van Belle ${ }^{25}$, as described earlier ${ }^{26}$.

\section{Measurement of the activation of AMP kinase}

Cardiac myocytes (8-1.2 mg wet mass.ml. 1 ) were incubated in medium B in the absence or presence of addition for $15 \mathrm{~min}$. At the end of the incubation, an aliquot was quickly transferred to one-third volume of sampled buffer containing 62.5 mmol. $1^{-1}$ Tris- $\mathrm{HCl}$ ( $\mathrm{pH} 6.8$ ), 2 mmol..$^{-1}$ EDTA, 20 mmol..$^{-1}$ dithiothreitol and $7.5 \%$ (wt/vol) SDS and used for SDS-PAGE. Subsequently, Western blotting was performed with an antibody directed against the serine-79 phosphorylated acetyl.CoA carboxylase according to manufacturer's instructions.

\section{Subcellular fractionation of cardiac myocytes}

Cardiac myocytes (2.0 $\mathrm{ml}, 20-25 \mathrm{mg}$ wet mass. $\mathrm{ml}^{-1}$ ) were incubated in medium B without further additions or with $10 \mathrm{nmol.1} \mathrm{H}^{-1}$ insulin or $30 \mu \mathrm{mol} .1 .1$ oligomycin for $15 \mathrm{~min}$. At the end of the incubation, the total volume of cell incubations was immediately transferred to a tightfitting 5 -ml Potter-Elvejhem glass homogenizer on ice containing $1 \mathrm{ml}$ ice-cold $\mathrm{dH}_{2} \mathrm{O}$, after which $\mathrm{NaN}_{3}$ was added to a final concentration of 5 mmol. . $^{-1}$ to stop ATP-dependent vesicular trafficking events such as GLUT4 translocation 27 . Thereafter, cell suspensions were homogenized with 10 strokes. Subsequently, fractionation was carried out according to Fisher et al.2. For determination of GLUT4 and FAT/CD36 protein content in the plasma membrane (PM) and the low-density microsomes (LDM) fractions, aliquots of the membrane fractions were separated with SDS.PAGE and Western blotting, as we have described recently ${ }^{4}$. To detect FAT/CD36, we used a monoclonal antibody (MO25), directed against human CD36, and to detect GLUT4 a polyclonal IgG antserum was applied. Signals obtained by Western Blotting were quantified by densitometry. 


\section{Other procedures}

Cellular wet mass was obtained from cell samples taken during the incubation period and determined after centrifugation for 23 s at maximal speed in a microcentrifuge and subsequent removal of the supernatant fraction. Protein was quantified with the bicinchoninic acid protein assay (Pierce, Rockford, IL, USA) according to manufacturer's instructions.

\section{Data presentation and statistics}

All data are presented as means \pm SE.M. for the indicated number of cardiac myocyte suspensions. Statistical difference between groups of observations were tested with a paired Students's $t$ test. P values $\leq 0.05$ were considered significant.

\section{REsULTS}

\section{Dose-dependent effects of AICAR and oligomycin on LCFA uptake}

AICAR has been frequently used to activate AMPK1:12,16. Its phosphorylated product, i.e., ZMP, has been abserved to gradually accumulate in hepatocyte incubations up to $60 \mathrm{~min}$. However, ongoing accumulation of ZMP beyond an optimal level can be rather inhibitory to $\mathrm{AMPK}^{29}$. Therefore, we tested in cardiac myocytes the optimal AICAR concentration that Would, in combination with 15 min preincubation, exert the maximal effect on LCFA uptake, the process under study. Indeed we found an optimal concentration of AICAR, which was determined to be $1.0 \mathrm{mmol}^{-1}$ (Fig. 3.2).

Inhibition of mitochondrial ATP production will result in an increase in the intracellular AMP concentration and hence activation of AMPK. The drop in intracellular ATP acts synergistically,
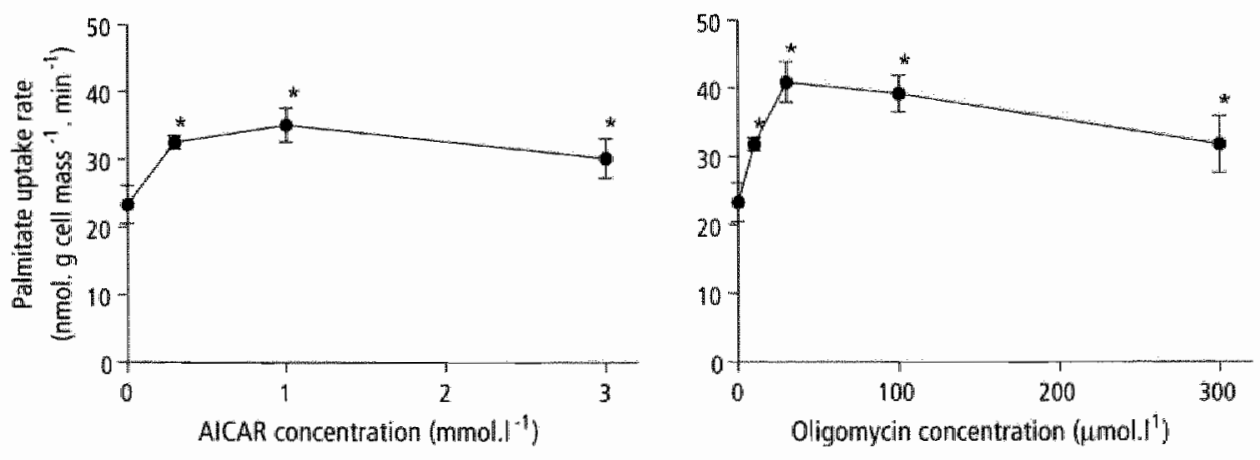

Figure 3.2: Dose dependent effects of AlCAR and ollgomycin on the palmitate uptake rate in cardlac myocytes. Cardiac myochtes were incubated for $15 \mathrm{~min}$ with various concentrations of AlCAR or oligomycin. Datia are presented as means \pm S.EM. of three experiments carried out with different cardiac myocyte preparations. "Significantly different from myocytes without additions, $p<0.05$. 
because the AMP-driven activation is inhibited by high ATP, making the AMP/ATP ratio the

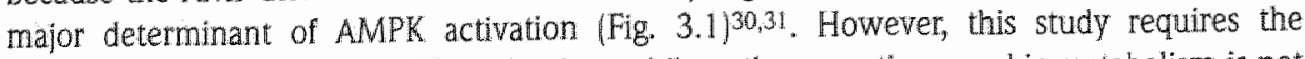
inhibition of mitochondrial ATP production, while at the same time aerobic metabolism is not inhibited. Notably, LCFA uptake depends highly on aerobic metabolism, because we previously observed that a complete block in rnitochondrial $\beta$-oxidation upon addition of the CPT-I inhibitor etomoxir was able to markedly inhibit LCFA uptake by cardiac myocytes 24 . Oligomycin, a potent inhibitor of mitochondrial $F_{1} / F_{0}$ ATPase, has long been used to inhibit state 3 respiration in isolated mitochondria. However, recent observations by Ylitalo and coworkers $^{3 i}$ showed that the concentration of oligomycin required for $50 \%$ inhibition of the mitochondrial $\mathrm{F}_{1} / \mathrm{F}_{0}$-ATPase was 5 -fold lower than its concentration required for $50 \%$ inhibition of electron flux through the respiratory chain, and hence, oxygen consumption. This leaves open a window of oligomycin concentrations at which intracellular AMP is elevated whille simultaneously oxygen consumption is not inhibited. Based on these observations, we studied LCFA uptake as a function of the oligomycin concentration and found it to be maximally stimulated at $30 \mu$ mol.1.1. oligomycin (Fig. 3.2).

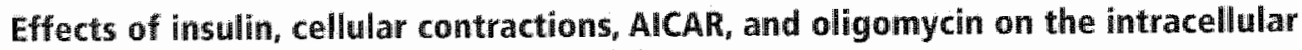 levels of adenosine phosphates and ZMP in cardiac myocytes}

We have compared the effects of $1.0 \mathrm{mmol}^{-1-1}$ AICAR and $30 \mu \mathrm{mol} . \mathrm{I}^{-1}$ oligomycin with that of $4 \cdot \mathrm{Hz}$ contractions on intracellular adenosine phosphates. A comparison with insulin is also relevant to explore a possible convergence between insulin and contraction signalling at the level of AMP. In non-stimulated cardiac myocytes, the AMP/ATP ratio was 0.041. None of the selected manipulations significantly affected the ATP levels, although electrical stimulation and oligomycin had a small lowering effect (Fig. 3.3). Insulin and AICAR did not affect the intracellular levels of AMP nor the AMP/ATP ratio (Fig. 3.3). In cardiac myocytes contracting at $4 \cdot \mathrm{Hz}$, the AMP/ATP ratio was increased by 1.9-fold (Fig. 3.3). Oligomycin enhanced the AMP/ATP ratio by 2.5 -fold. Only in AICAR-treated cardiac myocytes was the formation of ZMP observed, which greatly exceeded the intracellular concentration of AMP (ZMP/AMP ratio: $20.9 \pm 2.4, n=6$; Fig. 3.3).

\section{Effects of insulin, contractions, AICAR, and oligomycin on activation of AMP kinase in cardiac myocytes}

Activation of AMPK was assessed by determining its ability to phosphorylate acetyl-COA. carboxylase, one of its major downstream targets. The heart expresses predominantly a $280-\mathrm{kDa}$ (Bi) isoform and to a lesser extent a $265 \mathrm{kDa}(\alpha)$ isoform ${ }^{19}$, and both can be phosphorylated by $A M P K 32$. This phosphorylation decreases the activity of both isoforms of aceiyl-CoA carboxylase and results in a drop in the intracellular malonyl-CoA concentration. A fall in intramyocellular malonyl-CoA deinhibits the enzyme activity of CPT-I, resulting in an increased mitochondrial LCFA oxidation ${ }^{33}$. The only other signalling enzyme known to be able to phosphorylate acetylCoA carboxylase, i.e., CAMP-dependent protein kinase $\mathrm{A}^{32}$, is likely not activated by, AICAR or oligomycin. Notably, intracellular levels of CAMP do not increase by AICAR treatment 29,34 . In addition, mitochondrial inhibitors, such as oligomycin, are expected to decrease rather than 

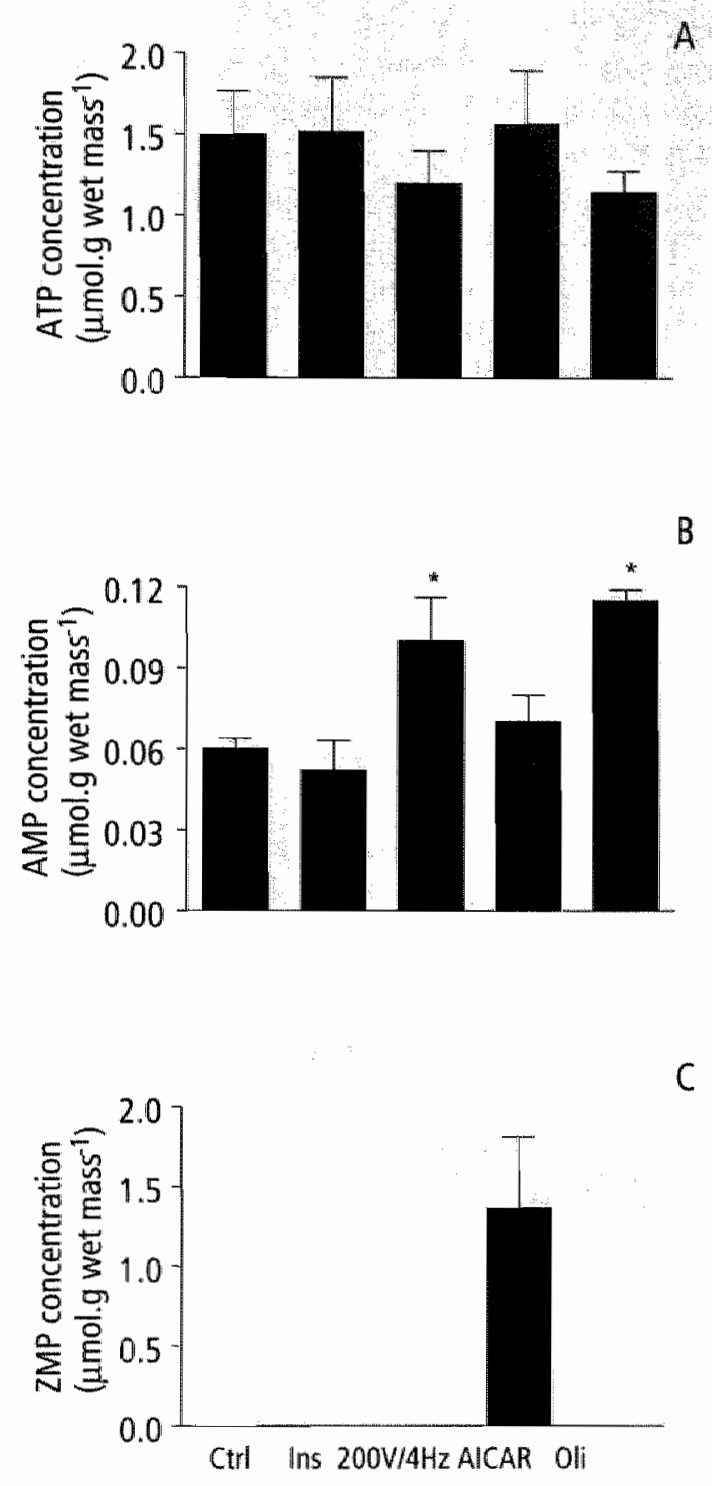

Figure 3.3: Influence of insulin, electrical stimutation, AVAR and oligomycin on intracellular nucleoside phosphates in cardiac myocytes.

Cardiac myocyles were incubated for $15 \mathrm{~min}$ in the absence (Ctrl) or presence of 10 nmoll. insulin (Ins), electrical

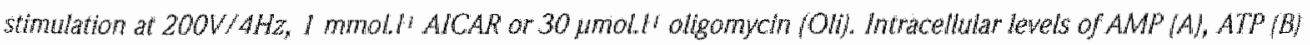
and $Z M P(C)$ were determined as described in research design and methods. Data are presented as means \pm S.EN. of three to six experiments carried out with different cardiompocyte preparations. "Signiffantly different from myocytes without additions (Ct.rl), p<0.05 
increase CAMP as a result of decreased availability of ATP, the substrate of adenyly cyclase. Furthermore, recent studies in electrically stimulated skeletal muscle have convincingly shown that there is a direct link between AMPK activation and phosphorylation of the muscle-specific acetyl-CoA carboxylase $\beta$ isoform ${ }^{35}$.

Under basal conditions, we observed a low level of phosphorylation of the predominant 280 . $\mathrm{kDa}$ isoform of acetyl-COA carboxylase. Insulin did not stimulate phosphorylation of acetyl. CoA carboxylase. In contrast, cellular contractions at $4 \mathrm{~Hz}$ and preincubation with oligomycin and AICAR increased this phosphorylation by 3.3-,5.5- and 8.7-fold, respectively (Fig. 3.4). In the case of AICAR- and oligomycin-treated cardiac myocytes, a second lower band appears, which likely corresponds to phosphorylation of the $265 \mathrm{kDa}$ isoform. The effect of AICAR on phosphorylation of acetyl-CoA carboxylase could be blocked in the presence of 5-iodotubercidin, a potent inhibitor of adenosine kinase ${ }^{36}$.

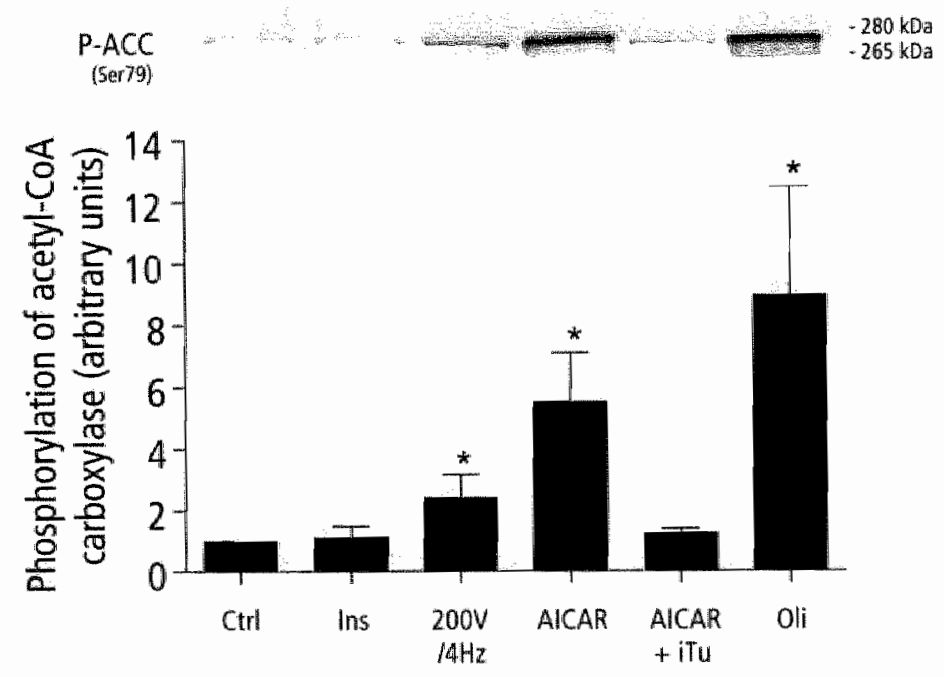

Figure 3.4: Infuence of insulin, electrical stimulation, AICAR and oligomycin on the phosphorylation of acetylCOA carboxylase.

Cardiac myocytes were incubated for $15 \mathrm{~mm}$ in the absence (Cull or presence of 10 nmol." insulin (Ins), electrical

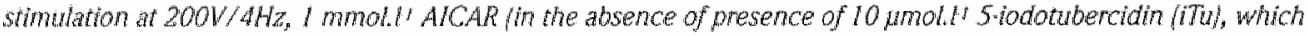
was added 90 min before ALCAR, or 30 umoth oligomycin (Oli). Phosphorylation of acetyl CoA carboxylase at Serne 70 was detected at $280 \mathrm{kDa}$, i.e, the major isoform of this enzmme in the heart. However, in AlCAR and oligonycin-treated cardiac mycoytes a second lower band is apparent, corresponding to the $265 \mathrm{kD}$ a tsoforn. Data are presented as means \pm S.E.M. of three experiments carried out with different cardiac myacyte preparations. "Significantly different from mocytes without additions (Ctrl), $p<0.05$. 


\section{Effects of AICAR and oligomycin on deoxyglucose uptake by cardiac myocytes}

Uptake of deoxyglucose into cardiac myocytes was markedly elevated by $4 \mathrm{~Hz}$ stimulation (1.5-fold). In addition, AICAR (1.4-fold) and oligomycin (2.0-fold) substantially stimulated the deoxyglucose uptake rate (Fig. 3.5, right panel). These findings verify that manipulations that activate AMPK exert an expected metabolic response?.

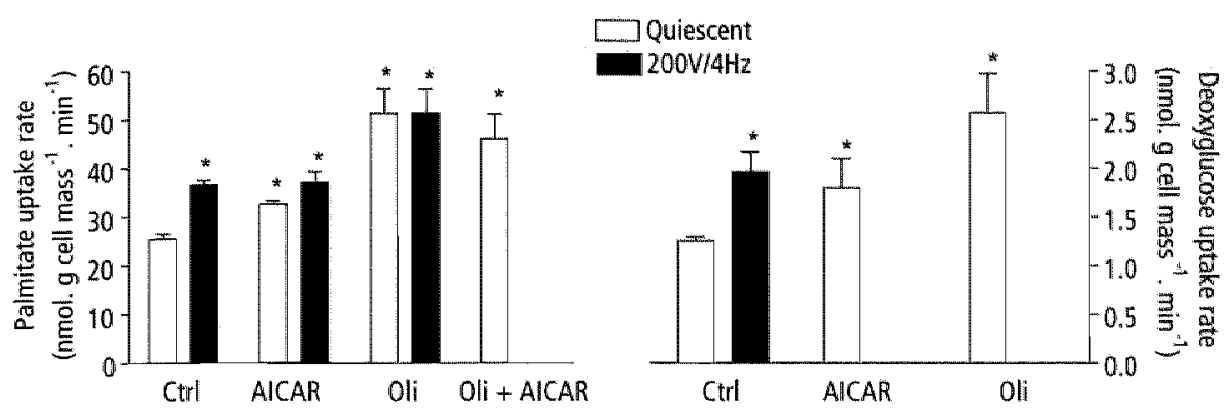

Figure 3.5: Effects of AICAR and oligomycin in the absence pr presence of electrical stimulation on the palmitate and deoxyglucose uptake rate in cardiac myacytes.

Cardiac myocytes were incubated in the absence of additions (Ctrly or presence of 1 mmollt AlCAR and/or 30 umol." oligomycin (Oli) for 15 min before determining the uptake rate of palmitate (left panell and deoxyghcose (right panell in 3 min, with or without electrical field stimulation at $200 \mathrm{~V}$ and $4 \mathrm{~Hz}$ (200V/4Hz). Data are presented as means \pm S.E.M. of four to six experiments carried out with different cardiac myocyte preparations. "Significantly different from myocytes without additions ( $C t r)$, and in the absence of electricat stimutation, $p<0.05$.

\section{Mechanism of the effects of AICAR and oligomycin on LCFA uptake by cardiac myocytes}

Electrical stimulation of cardiac myocytes at $4-\mathrm{Hz}$ resulted in an 1.5 -fold increased LCFA uptake rate, in agreement with our previous findings5. LCFA uptake into quiescent cardiac myocytes was markedly enhanced by AICAR (1.4-fold) or oligomycin (2.1.fold) (Fig. 3.5). Electrical stimulation at $4 \cdot \mathrm{Hz}$ had no significant additional effect on LCFA uptake by cardiac myocytes treated with either AICAR or oligomycin. Similarly, when AICAR was added together with oligonycin, LCFA uptake could not be stimulated further (Fig. 3.5), suggesting that these agents, as well as cellular contractions, exert their action through the same pathway.

To study the involvement of FAT/CD36, we applied its inhibitor SSP, for which we earlier collected evidence that it specifically inhibits FAT/CD36 without affecting $43-\mathrm{kDa}$ plasmalemmal fatty acid binding protein (FABPpm) and $02-\mathrm{kDa}$ a fatty acid transport proteins (FATPs) ${ }^{37}$. In addition, mammalian cells are impermeable for the sulfo- $N$ succinimidyl molety ${ }^{30}$, excluding possible effects of SSP on intracellular LCFA metabolizing enzymes. Preincubation 


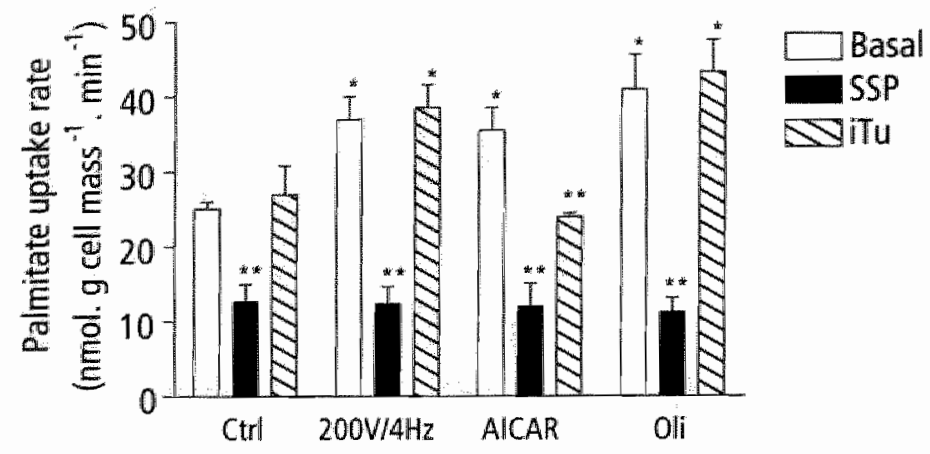

Figure 3.6: Modulation of the stimulatory effects of electrical stimulation, AICAR, and oltgomycin on the palmitate uptake rate by SSP and S-iodotubercidin.

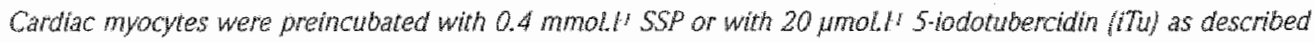
in research design and methods. In the case of SSP, cardiac myocytes were centrifuged at the end of the incubation period, washed twice, and resuspended in medium B. The SSP matched basal incubation did not display an LCFA uptake rate significantly different from the ifu-matched basal. Subsequently, cardiac myacytes were incubated in the absence of additions (Corl) or in the presence of electrical stmulation at $200 \mathrm{~V} / 4 \mathrm{Kz}$ or in the presence of I mmot/ ANCAR or 30 umoll" aligomycin (Oli) or 15 min before deternination of palmitate uptake in 3 min. Data are presented as means it S.E.M. of four to eight experiments carried out with different cardiac myocyte preparations. * Significantly different from cardiac myocytes without additions /Ctrll, p<0.05. "Significantly different from corresponding basal cardiac myocytes $\{B a s a l l, p<0.05$.

of cardiac myocytes with SSP reduced palmitate uptake by $47 \%$ (Fig. 3.6). In the presence of this LCFA transport inhibitor, cellular LCFA uptake is not enhanced by cellular contractions or by AICAR or oligomycin (Fig. 3.6). Hence, inhibition of FAT/CD36 completely abolishes the stimulatory effects of all these manipulations on myocardial LCFA uptake.

Inclusion of the adenosine kinase inhibitor 5-iodotubercidin had no effect on basal LCFA uptake by cardiac myocytes, but caused a complete blockade of the stimulatory action effect of AICAR on cellular LCFA uptake (Fig. 3.6). However, 5-iodotubercidin did not affect stimulation of LCFA uptake by cellular contractions or by oligomycin (Fig. 3.6).

The $\mathrm{Pl}_{3} \mathrm{~K}$-inhibitor wortmannin had no effect on palmitate uptake by quiescent cardiac myocytes and was also noneffective on LCFA uptake by cardiac myocytes stimulated at $4 . \mathrm{Hz}$ or" treated with AICAR or oligomycin. Insulin further enhanced LCFA uptake by cardiac myocytes stimulated at $4 \mathrm{~Hz}(1.5$ fold $)$ or treated with AICAR 11.3 fold $)$ of oligomycin $(1.4$. fold) (Fig. 3.7).

\section{Effects of insulin and oligomycin on subcellular distribution of FAT/CD36}

Incubation of cardiac myocytes in the presence of insulin or oligomycin for 15 min before subcellular fractionation decreased the content of FAT/CD 36 in the low-density mircosomes 


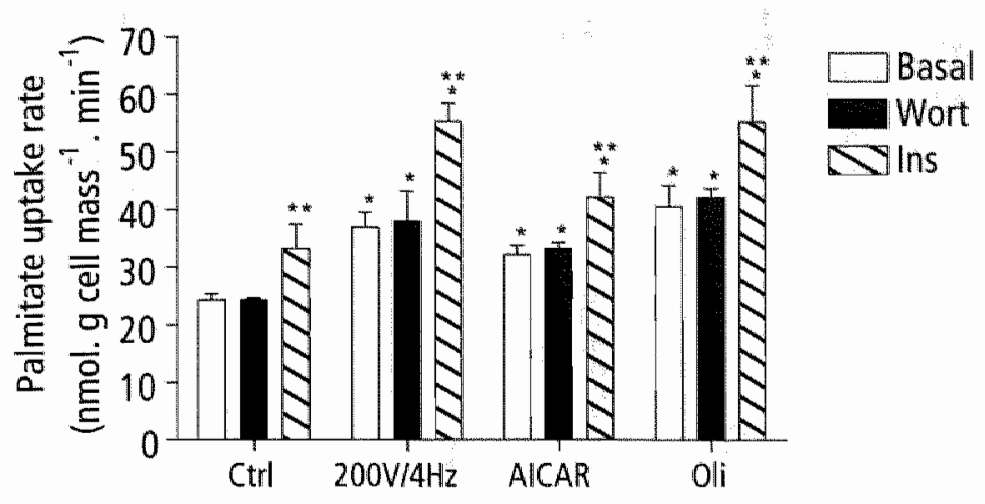

Figure 3.7: Effects of $\mathrm{Pl}_{3} K$ inhibition and insulin on stimulation of the palnitate uptake rate by electrical stimulation, AICAR and oligonycin.

Cardiac myoctes were incubated for 15 min before the measurement of palmitate uptake in 3 min, under basal conditions "Crnl, in the presence of electrical field stimulation at $200 \mathrm{~V} / \mathrm{AHZ}$, of in the presence of I mmol.t AICAR, 30 umol." oligomycin (Oli, 10 nmoll" insulin (Ins) or 200 hmol.t wortmannin (Wowt. Data are presented as means \pm S.E.M. of four to six experiments carried out with different cardiac myocyte preparations. "Significantly different from myocytes without additions (Cthl, p<0.05. * Significantly different from corresponding control cardiac myocytes (Basal), $p<0.05$.

(LDM) fraction by 49 and $42 \%$, respectively. Simultaneously, these agents increased the content of FAT/CD36 in the plasma membrane (PM) fraction to a similar magnitude of 1.5 fold (Fig. 3.8). Both insulin and oligomycin had comparable effects on subcellular distribution of GLUT4. Moreover, these effects of both agents were very similar in magnitude, i.e., a decrease in GLUT4 content in the LDM fraction by 57 and $56 \%$, respectively, and a concomitant increase in the PM fraction by 1.8 - and 1.7 -fold, respectively.

\section{Discussion}

The primary goal of this study was to delineate the signalling process involved in contractioninducible LCFA uptake in cardiac myocytes. Using the cell-permeable AMPK activator AICAR and the mitochondrial inhibitor oligomycin, we found strong evidence that contractioninducible LCFA uptake is mediated by elevated intracellular AMP and subsequent activation of AMPK, resulting in translocation of FAT/CD36 from intracellular stores to the sarcolemma of cardiac myocytes. These data reveal another level of regulation of cardiac substrate utilization by AMPK.

\section{Central role for AMP kinase}

The ability of AICAR to induce LCFA uptake by cardiac myocytes is a completely novel 


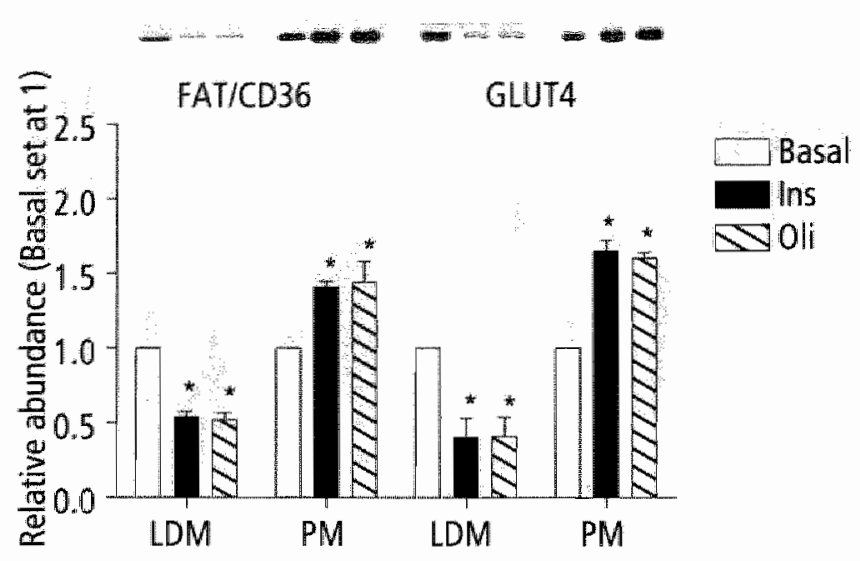

Figure 3.8: Effects of insulin and oligomycin on subcellutar distibution of FAT/CD36 and GLUTA in cardiac myocytes.

Cardiac mwocytes were incubated for 15 min in the absence (Basal), or presence of 10 nmolth insulin (Ins) or 30 whol. I oligomycin (ONi), after which $\mathrm{NaN}_{3}$ was added to a final concentration of 5 mmollt to stop ATP demanaing processes. Thereafter, cardiac myocytes were frozen in liquid nitrogen and, upon thawing, subjected to subcellular fractionation. In the obtaned low density membrane (LDM) and plasma membrane (PM) fractions, the protein content of FAT/CD36 and OLUTA was determined by Western blotting. Signals were quantified by densitometry. The protein content of the transport proteins was expressed as multiple of control (Basall in the corresponding fraction. Data are presented as means \& S.E.M. of four experiments cartied out with different cardiac myocyte preparations. Represented Western btots are shown. *Significantly different from myocyes under basat conditions (Basal), $p<0.05$.

observation and suggests involvement of AMPK in the regulation of LCFA uptake. While the consensus is that AJCAR acts mainly through activation of $\mathrm{AMPK} 9,10,29$, it has been occasionally reported in cardiac myocyte studies that AICAR does not cause accumulation of ZMP39 and does not activate AMPK ${ }^{40}$. Therefore, it was important to verify whether AICAR in the present study indeed would exert these effects. Measurement of nucleoside phosphates in AICAR-treated cardiac myocytes demonstrated an accumulation of ZMP to a concentration of $1.38 \pm 0.36 \mu \mathrm{mol} . \mathrm{g}$ wet mass ${ }^{-1}$ (Fig. 3.3). This is a concentration very near to the optimal concentration of ZMP to stimulate AMPK in rat adipocytes 29 . With respect to AMPK activation, AICAR treatment clearly resulted in a 5.5.fold increase in phosphorylation of acetylCoA calboxylase at Ser79, which indicates that there is a marked increase in AMPK activity.

The adenosine kinase inhibitor 5-iodotubercidin inhibits the conversion of AICAR to ZMP and therefore blocks the effects of AICAR that are mediated through AMPK. The ability of 5 iodotubercidin to completely inhibit the AICAR-induced increase in phoshorylation of acety. COA carboxylase as well as the AICAR-induced increase in LCFA uptake by cardiac mycoytes indicates that ZMP formation is necessary for AICAR to stimulate both AMPK activity and 
LCFA uptake. However, it could be argued that these effects of 5-iodotubercidin are mediated via high local endogenous adenosine concentrations, which are also a consequence of inhibition of adenosine kinase. To investigate this issue, cardiac myocytes were incubated in the presence of adenosine. It was found that adenosine in concentrations up to $1.0 \mathrm{mmol} . \mathrm{I}^{1}$ was without effect on LCFA uptake (data not shown), thus excluding that the effects of 5 iodotubercidin are mediated via adenosine. Therefore, the present findings strongly favour the notion that AICAR stimulates LCFA uptake by cardiac myocytes through its phosphorylated product, $2 M P$, and thereafter through activation of AMPK.

Besides direct activation of AMPK by AICAR, elevation of the intracellular AMP/ATP ratio by using oligomycin was found to enhance myocardial LCFA uptake. The ability of oligomycin to strongly augment the phosphorylation of acetyl-COA carboxylase is in favour of an important role of AMPK in oligomycin-induced LCFA uptake. The nonadditivety of the effects of oligomycin and AICAR further indicates that these agonists operate via a similar mechanism involving AMPK. In contrast to AICAR, the stimulatory effect of oligomycin was insensitive to the inhibition of 5-iodotubercidin. This is line with the notion that AMP formation in the presence of this mitochondrial inhibitor is due to hydrolysis of mitochondrial produced ATP rather than phosphorylation of adenosine.

Contractile activity appeared to markedly (1.9-fold) elevate the intracellular AMP/ATP ratio, which is, however, less effective than the stimulating effect of oligomycin on this ratio (2.5-fold stimulation). In line with this, $4-\mathrm{Hz}$ contractions substantially (3.3-fold) increased the activity of AMPK, as evidenced by measurement of phosphorylation of acetyl-CaA carboxylase. This increase is also of a lesser magnitude than that of oligomycin (8.7-fold stimulation). Thus, when considering these two different stimuli, there appears to be a positive correlation between the AMP/ATP ratio and the degree of AMPK activation. These findings also show that electrically stimulated cardiac myocytes are a suitable system to study the role of AMPK in cardiac substrate utilization. It is of interest to note that increasing workload in Langendorffperfused hearts did not induce activation of AMPK 41,42 . The discrepancy between these latter studies and the present study must be attributed to the different model used. However, Coven et al. ${ }^{33}$ demonstrated that in rats cardiac AMPK activity progressively increases with exercise intensity, suggesting that AMPK has a physiological role in the heart.

In contrast to the stimulatory effect of AICAR and oligomycin on LCFA uptake in quiescent cardiac myocytes, neither agents were effective in stimulating LCFA uptake in electrically stimulated cardiac myocytes. This lack in additivity is regarded as evidence that both agonists increase myocardial LCFA uptake via a similar mechanism, including activation of AMPK. Similar to oligomycin, contractile activity maintains its ability to stimulated LCFA uptake in the presence of 5 -iodotubercidin-imposed blockade in adenosine kinase activity. Hence, contraction-induced AMP accumulation occurs at the expense of intracellular ATP levels and does not depend on phosphorylation of adenosine.

\section{Involvement of FAT/CD36 translocation}

Treatment of cardiac myocytes with SSP resulted in a complete block of the stimulation of LCFA uptake by oligomycin and AICAR, powerfully indicating that increased involvement of 
FAT/CD36 is causally linked to the increase in LCFA uptake in the presence of AMPK activation. Subsequent subcellular fractionation demonstrated that oligomycin was able to mobilize FAT/CD36 from intracellular membrane stores to the sarcolemma. Because both oligomycin and AICAR activate AMPK and because the effects of oligomycin and AICAR on LCFA uptake are nonadditive and sensitive to inhibition of SSP, it can also be deduced that AlCAR induces translocation of FAT/CD36. Interestingly, the oligomycin-induced increase in sarcolemnal abundance of FAT/CD36, amounting to 1.5 -fold, is in the same order of magnitude as the increase in myocardial LCFA uptake in the presence of this mitochondrial inhibitor. It can therefore be concluded that activation of AMPK stimulates LCFA uptake through translocation of FAT/CD36 to the sarcolemma.

The stimulatory effect of AMPK activation on LCFA uptake by cardiac myocytes was found to be independent of insulin's stimulation of LCFA uptake, because insulin stimulated LCFA uptake to a similar extent whether in the absence or presence of contractions, oligomycin or AiCAR. Furthermore, when $\mathrm{PI}_{3} \mathrm{~K}$, a key enzyme in insulin-signalling events, is inhibited by wortmannin, the stimulatory effects of contractions, oligomycin or AICAR on myocardial LCFA uptake are maintained. Taken together, these findings implicate that in the presence of an increase in mechanical activity, FAT/CD36 is translocated from its contraction-inducible intracellular storage compartment upon activation of AMPK and independent of insulin signalling. Vice versa, insulin is not able to mobilize FAT/CD36 from the contraction-inducible storage compartment because the intracellular AMP/ATP ratio is not altered by insulin, nor is AMPK activated.

\section{Comparison between LCFA and glucose uptake by cardiac myocytes}

In addition to stimulating LCFA uptake and FAT/CD36 translocation, the present study indicates that AICAR and oligomycin also stimulate glucose uptake as well as GLUT4 translocation. These findings are in line with recent studies by Russell et al.9 and KurthKraczek et al.44 showing that AMPK activation increases cardiac muscle glucose uptake through translocation of GLUT4 via a pathway that is independent of $\mathrm{PI}_{3} \mathrm{~K}$. The stimulating effect of AICAR, added at an optimal concentration of 1 mmol. $1^{-1}$, on both deoxyglucose and LCFA uptake, however, is markedly smaller than that of oligomycin, which corresponds to an earlier report in which potassium cyanide was found to be more effective than AICAR to induce glucose uptake 17. Furthermore, the conformation of GLUT4 translocation in response to insulin-and contraction-signalling validates the suitability of isolated cardiac myocytes as an experimental model to study signalling and vesicular trafficking processes.

\section{Concluding remarks}

AMPK is known as a stress and exercise-induced multisubstrate enzyme. It precludes ATP utilization for anabolic purposes, and it switches on catabolic processes for meeting increased energy demands 45,46 . Among these latter processes are translocation of GLUT4 and LCFA oxidation. Based on the present study, AMPK is now also shown to upregulate FAT/CD36mediated sarcolemmal LCFA transport. In light of the accumulating evidence that LCFA uptake into myocytes of heart and skeletal muscle is a rate-governing step 2,5 , the combined induction 
of EAT/CD36 mobilization and of CPT-I activity through AMPK activation is metabolically efficient, because this allows the extra incoming LCFAs to be preferentially channelled into mitochondrial $\beta$-oxidation. It remains to be established whether AMPK activation is fully responsible for the increase in LCFA uptake in the presence of myocardial contractions or that AMPK-independent mechanisms are necessary to mobilize FAT/CD36 from contractionsensitive intracellular stores.

\section{ACKNOWLEDGEMENTS}

This study was supported by the Netherlands Heart Foundation, grants D98.012 and 2000.156 , and by the Heart \& Stroke foundation of Ontario. Dr. JJ.F.P. Luiken was the recipient of a VIDI-Innovational Research Grant from the Netherlands Organization of Scientific Research (NOW-ZonMw grant number 016.036.305). Antibody MO25 was provided by Dr. N.N. Tandon, Thrombosis and Vascular Blology Laboratory, Otsuka America Pharmaceuticals, Rockville, MD, USA. 


\section{REFERENCES}

1. Abumrad N, Cobum $\mathrm{C}$ and lbrahimi A. Membrane proteins tmplicated in longthain raty acid uptake by

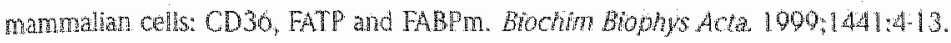

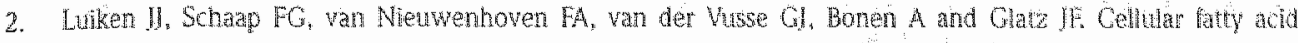
transport in heart and skeletal muscle as facilitated by proteins. Lipids. 1909;34 \$uppls 16075.

3. Brinkmann JF, Abumrad NA, Ibrahmi A, wan der Vusse Cf and Glatz IF Now insights unto longechain faty acid uptake by heart muscle: a crucial role for fatty acid translocase, CD30. Blochem I. 2002;367561-70.

4. Bonen A, Luiken J), Arumugan Y, Glatz IF and Tandon NN. Acute regulation of fatcy acid uptake involves the cellular redistribution of falty acid transtocase. / Biol Chem 2000;275:14501-8.

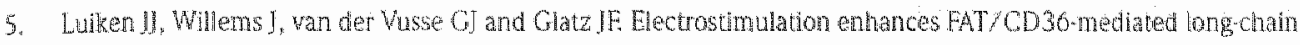
fary acid uptake by isolated rat cardiac myocytes. Am / Physiol Endocinol Metab. 2001,281:E704-12.

6. Luiken IJ, Dyck DJ, Han XX, Tandon NM, Arumugam Y, GlatX JF and Bonen A. Insulin induces the translocation of the fatry acid transpoter FAT CD36 to the plasma membrane Am / Physol Endocrinol Metab 2002;282:L4915.

7. Luiken I], Koonen DF, Willems ], Zorzano A, Becker C, Fischer Y, Tandon NN, Van Der Vusse OI, Banen A and Gatz IF. Insulin stimulates long chain fatty acid utilzation by rat cardiac myocytes through cellular redistribution of FAT/CD36. Diabetes 2002:51:31139.

8. Lulken J, Willems J, Coont SL. Coumans WA, Bonen A, Van Der Vusse Gf and Giatz If laffects of cAMP modulators on longchain Fatwacid uptake and utilization by electricaly stimulated rat catliac myocytes. Biochem/. 2002.367:881-7.

r. Russell RR, 3rd, Bergeron R, Shuiman GI and Young LH. Jransiocation of myocaldial GLUT.4 and increased glucose uptake through actwation of AMPK by AlCAR. Am / Physof 1009;277: H1043-9

10. Buhi ES, Jessen N, Schmtz O, Pedersen SB, Pedersen O, Holman GD and Lund S. Chronic treatment with 5 . aminomidazole-4-carboxamide-1-beta-D-ribofuranoside increases insulin-stimuated glucose uptake and CLUT translocation in rat skeletal muscles in a fiber type-specific manner. Diabetes, 2001;50:12-7.

11. Curtin NA and Woledge RC. Energy changes and muscular contraction. Physiol Rev 1978;58:600701.

12. Ingrwall IS. Phosphorus nuclear magnetic resonance spectroscopy of cardiac and skeletal muscles. An / Physol. $1082,242: 4720.44$

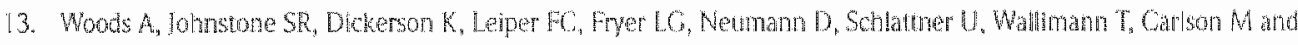

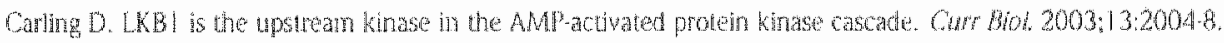

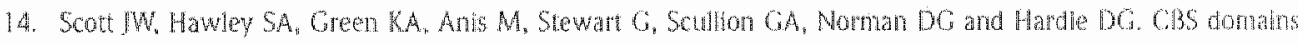
form energy sensing modules whose birding of adenosine ligands is distupted by disese mutations. J Chm Mnest. 2004:113:274:84.

15. Hardie DC. AMPartivated proten knase: a master switch in glucose and lipid metabolism. Rev findow Metat Disord. 2004:5:11925.

10. Merril GF, Kurth EJ, Harde DG and Winder WW. AlCA riboside Increases AMPactivated proten kinase, haty acid oxidation, and gluoose uptake in rat muscle. Am / Physiol. 1007,273:E1 107-12.

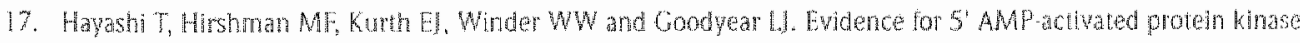
mediation of the effect of muscle contraction on gucose transport. Diabetes. 1998,47:1369.73.

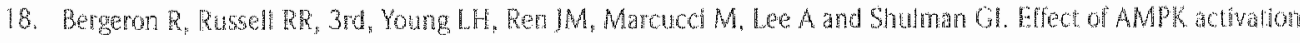
on muscle glucose metabolism in conecious rass. Am / Physol 1909;270.E038-4h.

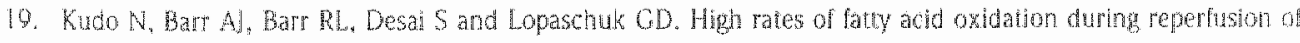




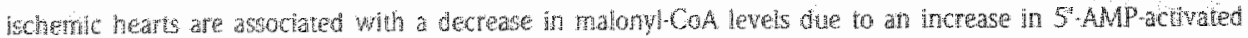

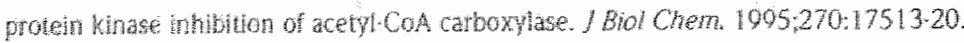

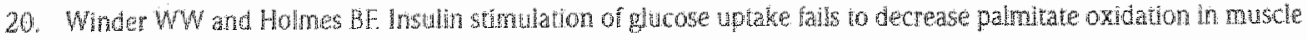

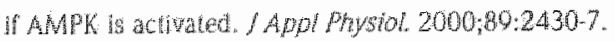

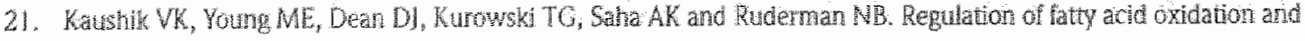

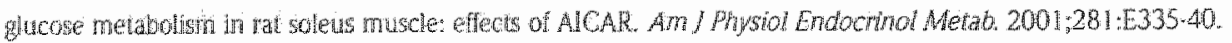

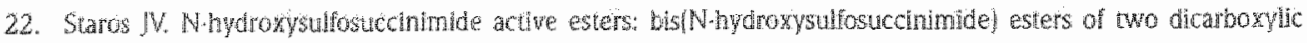

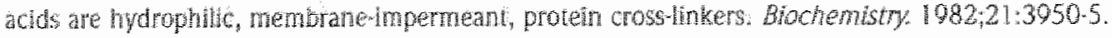

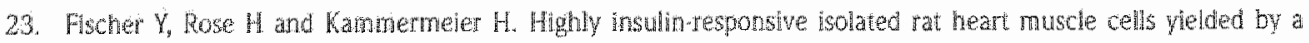

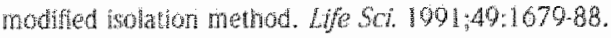

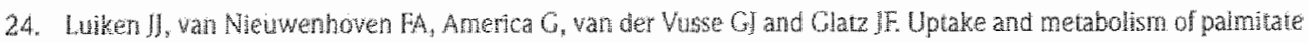

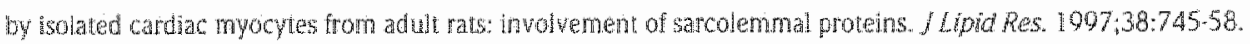

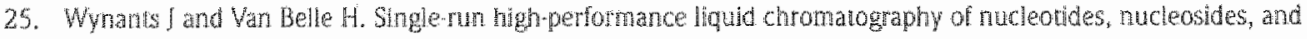

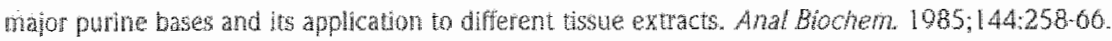

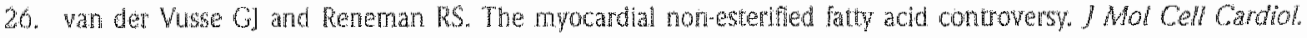
$198 \%, 10.677 .32$

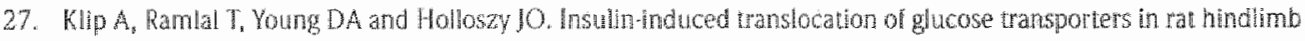
muscles. FeBS Let. $1987,224: 224-30$

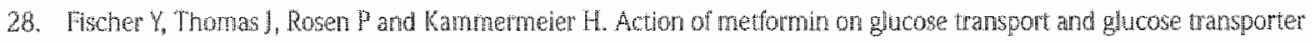

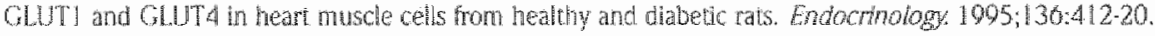

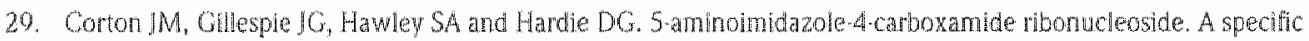

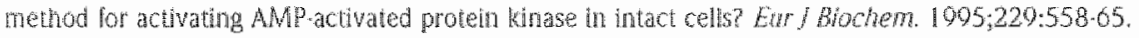

30. Groen AK, Wanders R, Westerhof HW, van der Meer $\mathrm{R}$ and Tager JM. Ouantification of the contubution of

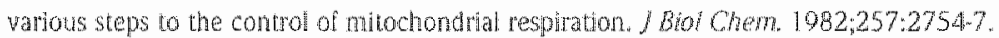

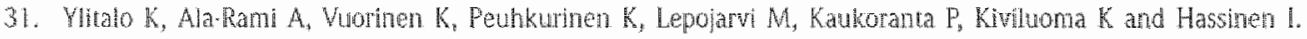

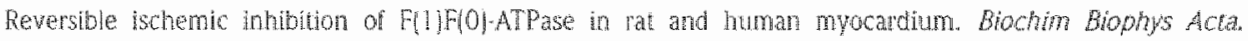
$2001 ; 1504320-30$

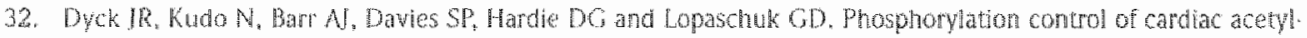

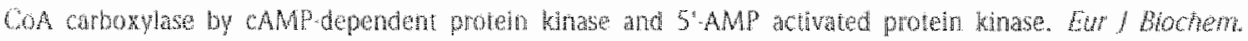
$1009202: 80.00$

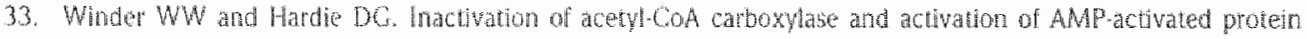
kinase in muscle during exercise. An / Physot 1906,270:E209-304.

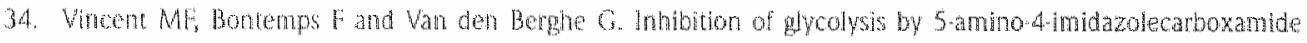

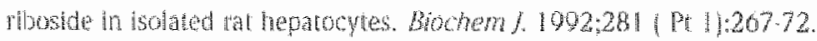

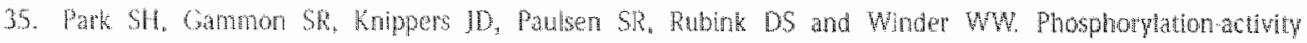

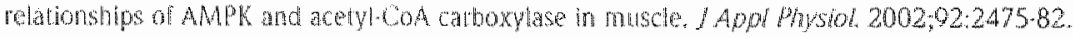

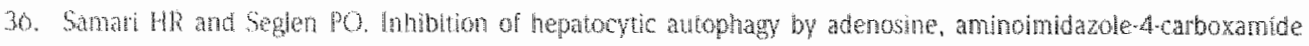

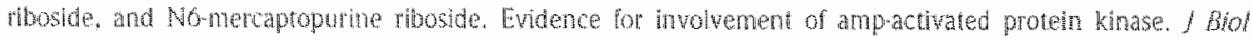
Gym. $100 \mathrm{~g} \cdot 27323758 \cdot 63$

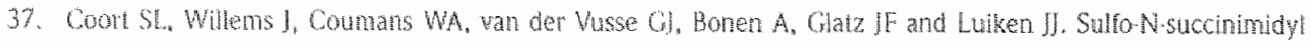

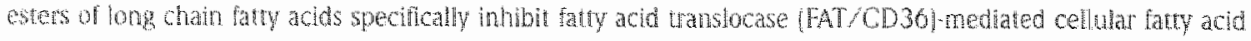
uphase. Mol Cell Bochem, 2002,230213\%. 


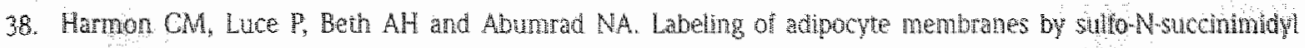

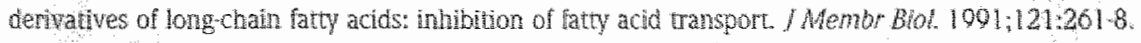

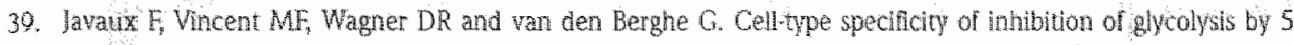
amino-4imidazolecarboxamide riboside. Lack of effect in rabbil cardiomyochtes and human exythrocytes, and inhibition in FTO2B rat hepatoma celis. Biochem f. 1905;305 (Pt 31:9139.

40. Marsin AS, Bertrand L, Ride: MH, Deprez ], Beauloye C, Vincent MF, Van den Berghe $\mathrm{C}$, Carling $\mathrm{D}$ and Hue $L$. Phosphorylation and activation of hear PFK 2 by AMPK has a role in the stimulation of glycolysis duing inchaemia. Cun Biol 2000,10:124755.

41. Coodwin GW and Taegumeyer H. Regulation of fatty acid oxidation of the heart by MCD and $\mathrm{ACC}$ during contractile stimulation. Am I Physiol 1990;277:57727.

42. Beauloye C, Marsin AS, Bertrand L, Wanoverschelde JL, Rider MH and Hue L. The stinulation of heart glycolysis by increased workload does not require AMPractivated protein kinase but a wortmaminsensitive mechanism. FERS Lett. 2002;531:324.8.

43. Coven DL, Hu X, Cong L, Bergeron R, Shulman GI, Hardie DG and Young LH, Physiological role of AMP-activated protein kinase in the heart: graded activation during exercise. Am / Physiol Endocrinol Metab 2003:285:E620-30.

44. Kurth-Kraczek EI, Hirshman MF, Goodyear IJ and Winder WW. 5' AMPactivated protein kinase activaton causes GLUT4 translocation in skeletal muscle. Diabetes. 1999;48:1607.71.

45. Hardie DG, Carling D and Carlson M. The AMPractivated/SNF1 protein kinase subfamily: melabolic sensors of the eukaryotic cell? Annu Rev Blochem. 1998;67:821.55.

40. Kernp BE, Mitchelhill K1, Stapleton D, Michell B], Chen ZP and Witters LA. Dealling with energy demand: the AMPactuated protein kinase. Trends Biochem Sci. 1990,24:225. 


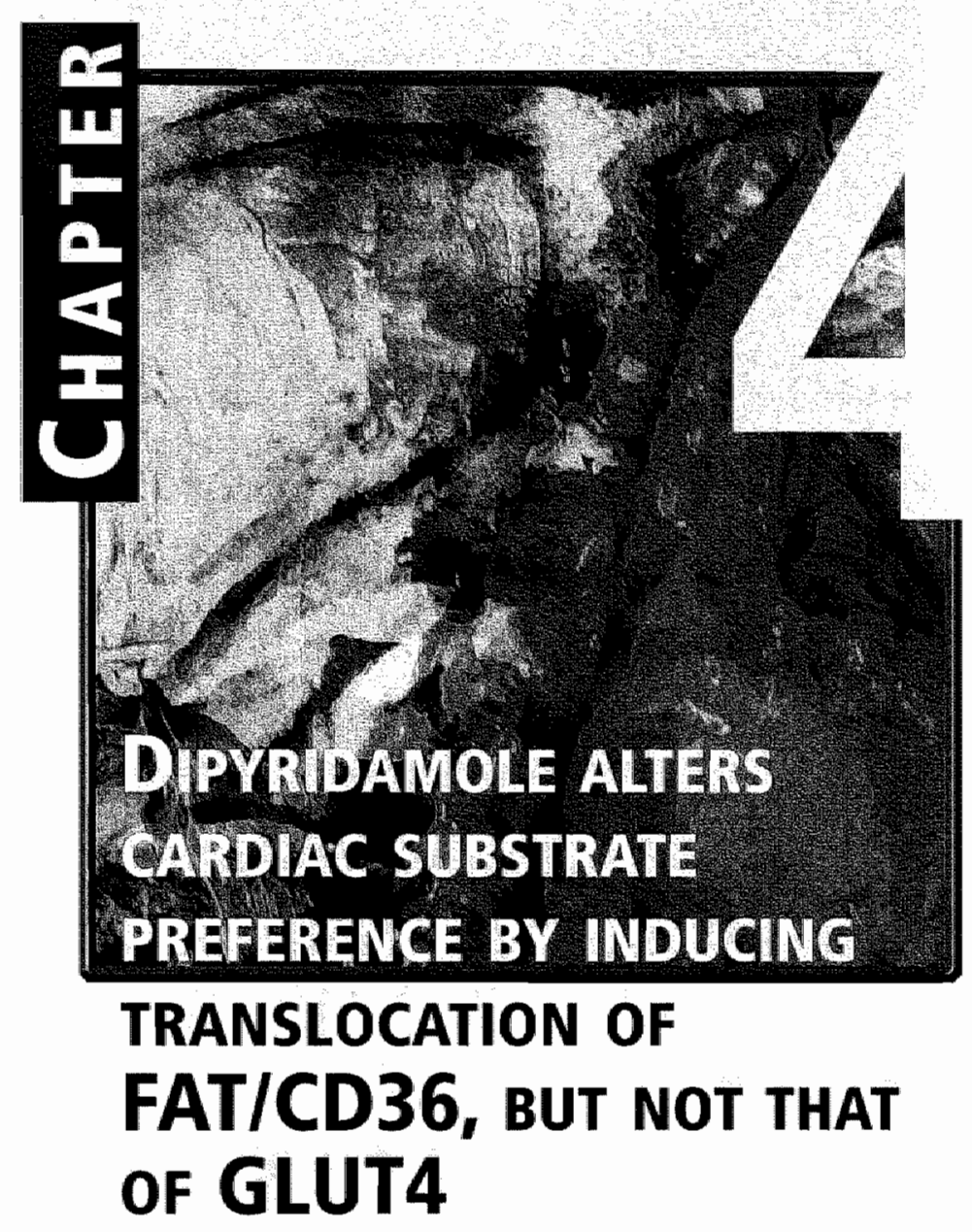

Joost J.F.P. Luiken', Susan L.M. Coort", Jodil Willems', Will A. Coumans', Arend Bonen², and Jan F.C. Glatz ${ }^{1}$

Mol Pharmacol. 2004;65:639-45.

IDepartment of Molecular Genetics, CARIM, Maastricht Universiry, Maastricht, the Netherlands.

aDepartment of Human Biology and Nutritional Sciences, Guelph University, Guelpla, Ontario, Canada 


\section{ABSTRACT}

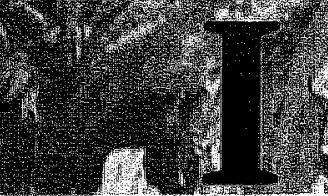

n cardiac myocytes, uptake rates of glucose and long chain fatty acids (LCFAs) are regulated by translocation of GLUT4 and fatty acid translocase (FAT)/CD36, respectively, from intracellular stores to the sarcolemma. Insulin and contractions are two physiological stimuli able to induce translocation of GLUT4 and FAT/CD 36 and therefore enhance the uptake of glucose and LCEAs, respectively. Interestingly, the cardiovascular drug dipyridamole was able to enhance LCFA uptake, but had no effect: on glicose uptake. The selective stimulatory effect of dipyridamole on LCFA uptake was unrelated to its effects on phosphodiesterase inhibition and on nucleoside transport inhibition. However, dipyridamole-stimulated LCFA uptake was abolished in the presence of sulfo- $N$-succinimidyl palmitate, which indicated that FAT/CD36 is involved in the uptake process. Furthermore, the effect was additive to that of insulin, but not to that of the AMP-elevating agent oligomycin, indicating that dipyridamole stimulates FAT/CD36-mediated LCFA uptake by activating the AMPractivated protein kinase (AMPK). Finally, dipyridamole was able to induce FAT/CD36 translocation from intracellular storage compartments to the sarcolemma, but had no effect on the subcellular distribution of GLUT4. It is concluded that beyond AMPK the contraction-induced and AMPK-mediated signal branches off into separate mobilization of GLUT4 and of FAT/CD36, and that dipyridamole activates a yet unidentified target in the FAT/CD36 mobilizing branch. 


\section{INTRODUCTION}

Dipyridamole (DPY) is a cardiovascular drug that is currently being used in the clinic because of (i) its coronary dilatory properties and (ii) its ability to inhibit platelet aggregation 1-4. This is based, at least partly, on some interesting pharmacological effects elicited by DPY on cardiac myocytes and other mammalian cells. It is recognized to be (i) an inhibitor of phosphodiesterase V and VI, thereby increasing intracellular levels of cyclic AMP (CAMP), and even more potently cyclic GMP (cGMP)5,6, and (ii) an inhibitor of the nucleoside transport?. When not inhibited phosphodiestersases (PDEs), a large group of structurally related enzymes, regulate intracellular CAMP and CGMP levels. Until now, seven gene families of mammalian PDE have been identified and they for example differ in their affinity to CAMP and CGMP, and sensitivity to specific inhibitors.

Furthermore, DPY is known to alter cardiac utilization of long-chain fatty acids (LCFAs). Its main action in this respect is the stimulation of LCFA uptake by cardiac myocytes,9. The molecular mechanism by which DPY stimulates LCFA uptake involves a translocation of the fatty acid translocase (FAT)/CD36 to the sarcolemma ${ }^{10}$. In contrast, the effect of DPY on glucose uptake, the other main substrate of cardiac myocytes, is less clear. It has been reported that DPY inhibits glucose uptake 1 , stimulates glucose uptakel2, or does not affect glucose uptake ${ }^{13}$. At the level of GLUT4, the main cardiac glucose transporter, DPY has been found to inhibit its intrinsic activity via a direct interaction with the transporter at the sarcolemmal!.

For the maintenance of mechanical activity, the heart is depending on the uptake of both glucose and LCFAs. Glucose uptake by cardiac myocytes is completely accounted for by the facilitative action of bath GLUT1 and GLUT4. Of these glucose transporters, GLUT4 is the predominant cardiac isoform since it is three times more abundantly expressed in the heart than is GLUT1 14. LCFA uptake by cardiac myocytes is mainly mediated by the facilitative action of FAT/CD3615,16. In non-stimulated cardiac myocytes, a substantial portion of FAT/CD36 is stored in intracellular membrane compartments. Insulin, which is known to translocate GLUT4 from intracellular compartments to the cell surface ${ }^{17}$, has recently been shown to induce also the translocation of FAT/CD36 to the sarcolemma in muscle tissues $10_{*} 18$. This insulin-induced translocation is sensitive to inhibition by wortmarnin and IY.294002, indicating a dependence on phosphatidylionisol-3 kinase $\left(\mathrm{Pl}_{3} \mathrm{~K}\right)$. Other factors, such as hypoxia/ischemia, mitochondrial inhibitors, and an increase in contractile activity, known to induce GLUT4 translocation, have all been found to activate a $\mathrm{Pl}_{3} \mathrm{~K}$-independent pathway involving AMP-activated protein kinase (AMPK)19-21. The involvement of AMPK in the translocation of GLUT4 has been further substantiated by using the cell-permeable adenosine analog AICAR. AICAR's phosphorylated product (ZMP) has been recognized as a suitable activator of AMPK. Consequently, AMPK has been shown to induce GLUT4 translocation that is insensitive to inhibitors of adenosine kinase ${ }^{19,22}$. Recently, we have demonstrated that contractions, AICAR and the mitochondrial inhibitor oligomycin all stimulate LCFA uptake via FAT/CD36 translocation independently of $\mathrm{PI}_{3} \mathrm{~K}^{23}$. Clearly, $\mathrm{FAT} / \mathrm{CD} 36$ can be mobilized from intracellular stores by two independent pathways, one inducible by $\mathrm{Pl}_{3} \mathrm{~K}$ and the other by AMPK. Thus, regulation of LCFA uptake and regulation of glucose uptake share, (i) a common mechanism, i.e., transporter translocation, (ii) induction by the same physiological stimuli, and (iii) common signalling components. 
The ability of DPY to stimulate FAT/CD36 translocation in combination with the fact that it has not been documented that DPY influences GLUT4 recycling makes it a potentially interesting compound to separate FAT/CD36 translocation from that of GLUT4. For this we investigated the parallel effects of DPY on LCFA uptake/FAT/CD 36 translocation and on glucose uptake/GLUT4 translocation in the absence or presence of physiological and pharmalogical modulators of PI $I_{3}$ and AMPK signalling. We also included the inhibitory action of DPY on nucleoside transport in these studies, because it has been shown that adenosine accumulates inside cardiac myocytes in the presence of this compound. Adenosine, through conversion into AMP by adenosine kinase, could theoretically activate AMPK, thereby offering a potential action mechanism for DPY. The results show that DPY stimulates FAT/CD36-mediated LCFA uptake by activating the AMPK signalling pathway without increasing GLUT4-mediated glucose uptake. These observations make DPY an interesting tool to identify the molecular components uniquely involved in FAT/CD36 trafficking.

\section{RESEARCH DESIGN AND METHOdS}

\section{Materials}

${ }^{14} \mathrm{C}$-palmitic acid was obtained from Amersham Biosciences (Little Chalfont, Buckinghamshire, UK). Bovine serum albumin (BSA, fraction V, essentially FA rree) phloretin, dipyridamole, nitrobenzylthioinosine, oligomycin, adenosine, dimethyl sulfoxide (DMSO), insulin, and wortmannin were all obtained from Sigma (St. Louis, MO). 5-Iodotubercidin was purchased from Biomol (Plymouth Meeting, PA). Collagenase type 2 was purchased from Worthington (Lakewood, N). BCA protein assay reagent kit was from Pierce (Rockford, IL). Antibody MO25 was a gift from Dr. N. N. Tandon (Thrombosis and Vascular Biology Laboratory, Otsuka America Pharmaceutical, Inc., Rackville, MDI. Antibodies directed against GLUT4 were obtained from Sanver Tech (Heerhugowaard, the Netherlands). Anti-phospho acetyl-CoA carboxylase was obtained from Brunschwig Chemle (Amsterdam, the Netherlands). SSP is routinely synthesized in our laboratory, as has been described previously24. Its purity was confirmed with infrared spectroscopy lkindly performed by Dr. van Genderen, Eindhoven Tecknical University).

\section{Isolation of cardiac myocytes}

Cardiac myocytes were isolated from male Lewis lats (200-250 g) using a Langendorff perfusion system and a Krebs-Henseleit bicarbonate medium equilibrated with a $95 \% \quad \mathrm{O}_{2} / 5 \% \quad \mathrm{CO}_{2}$ gas phase (medium A) at $37^{\circ} \mathrm{C}$ as described previously 25 . After isolation, the cells were washed twice with medium A supplemented with 1.0 mmol. $1 \mathrm{CaCl}_{2}$ and $2 \%$ (W/V) BSA (medium B) and then suspended in $15 \mathrm{ml}$ of medium $B$. The isolated cells were allowed to recover for approximately $2 \mathrm{~h}$ at room temperature. At the end of the recovery period, cells were washed and suspended in medium B. Only when $>80 \%$ of the cells had a rod-shaped appearance and excluded trypan blue were they used for subsequent studies. 


\section{Measurement of palmitate and deoxyglucose uptake by cardiac myocytes}

Cardiac myocytes ( $2.0 \mathrm{ml} ; 5-8 \mathrm{mg}$ wet mass. $\mathrm{ml}$ ), suspended in medium $B$, were preincubated in capped $20-\mathrm{ml}$ incubation vials for $15 \mathrm{~min}$ at $37^{\circ} \mathrm{C}$ under continuous shaking. To study palmitate uptake, $0.5 \mathrm{ml}$ of the ${ }^{14} \mathrm{C}$-palmitate/BSA complex was added at the start of the incubations so that the final concentration of palmitate amounted to $100 \mu \mathrm{mol.} \mathrm{I}^{-1}$ with a corresponding palmitate/BSA ratio of 0.3. This palmitate/BSA complex was prepared as

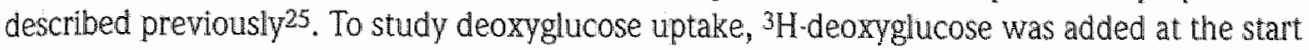
of the incubations to the palmitate/BSA complex to a final concentration of $100 \mu \mathrm{mol.1} . \mathrm{l}$. Palmitate and deoxyglucose uptake (3-min incubation) were simultaneously determined. The uptake process was stopped upon washing the cells three times for $2 \mathrm{~min}$ at $1.00 \mathrm{~g}$ in an icecold stop solution containing $0.2 \mathrm{mmol}^{-1} \mathrm{I}^{-1}$ phloretin as described previousiy 25 . The washing procedure did not affect cellular integrity as evaluated by microscopic inspection.

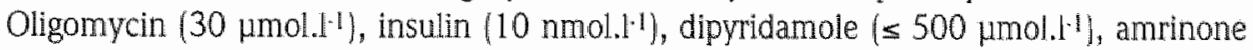

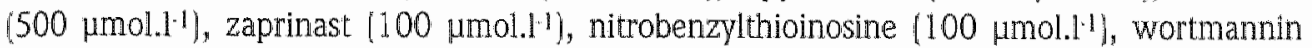
(200 nmol. $\left.\mathrm{I}^{-1}\right)$, and adenosine $\left(\leq 1.0 \mathrm{mmol} . \mathrm{l}^{-1}\right)$ were added to the cell incubations $15 \mathrm{~min}$ before addition of radiolabeled substrate. 5-Iodotubercidin $\left(20 \mu \mathrm{mol} . \mathrm{l}^{1}\right)$ was added $90 \mathrm{~min}$ before any other addition. Cell suspensions were incubated with sulfo- $N$ succinimidylpalmitate (SSP; $400 \mu \mathrm{mol}^{-1}$ ) for $15 \mathrm{~min}$, washed to remove unbound SSP, and resuspended in medium $B$ before addition of radiolabel. Stock solutions of oligomycin, dipyridamole, amrinone, zaprinast, nitrobenzylthioinosine, wortmannin, SSP, and 5-iodotubercidin were prepared in DMSO, which never exceeded a final concentration of $0.5 \%$ in the cell suspensions. At this concentration, DMSO did not affect cellular substrate utilization. None of these agents, alone or in combination and including SSP, were found to affect the percentage of cells that (i) were rod-shaped and (ii) excluded trypan blue, as parameters of cellular integrity.

\section{Measurement of adenosine phosphates in cardiac myocytes}

Cardiac myocytes (12-15 mg wet mass. $\mathrm{ml}^{-1}$ ) were incubated in medium $B$ in the absence or presence of additions for $15 \mathrm{~min}$. Then, they were centrifuged in a microcentrifuge at 2000 rpm. Upon removal of the supernatant, the cell pellet was extracted with $250 \mu \mathrm{l}$ of 3 mol.1. perchioric acid and neutralized with 1 mol.1.1 $\mathrm{KHCO}_{3}$. Thereafter, the cellular content of adenosine phosphates was determined by high-performance liquid chromatography as described previously20.

\section{Measurement of AMP kinase activation}

Cardiac myocytes (8-12 mg wet mass.ml" ") were incubated in medium B in the absence and presence of additions for $15 \mathrm{~min}$. At the end of the incubation, an aliquot was quickly transferred to one third volume of sample buffer containing 62.5 mmol. ${ }^{3}$ Tris. $\mathrm{HCl}, \mathrm{pH} 0.8,2$ mmol.1.1 EDTA, 20 mmol..$^{11}$ dithiothreitol, and $7.5 \%$ (W/v) SDS, and used for SDSpolyacrylamide gel electrophoresis. Subsequently, Western blotting was performed with an antibody directed against the serine79-phosphorylated acetyl-CoA carboxylase according to the manufacturer's instructions. 


\section{Subcellular fractionation of cardiac myocytes}

Cardiac myocytes (2.25 m; $20.25 \mathrm{mg}$ wet mass. $\mathrm{ml}^{-1}$ ) were incubated for 15 min in medium $B$ in the absence or presence of additions. At the end of the incubation, the total volume of cell incubations was quickly transferred to a tightly fitting $5-\mathrm{ml}$ Potter-Elvejhem glass homogenizer on ice containing $1 \mathrm{ml}$ of ice-cold $\mathrm{H}_{2} \mathrm{O}$, after which $\mathrm{NaN}_{3}$ was added to a final concentration of 5 mmol. $\mathrm{I}^{\text {t }}$ to stop ATP-dependent vesicular trafficking events. Immediately thereafter, cell suspensions were homogenized with 10 strokes. Subsequently, fractionation was carried out as described previously10,27. For determination of the GLUT4 and FAT/CD36 content in the plasma membrane (PM) and in low-density microsomes (LDM), aliquots of the membrane fractions were separated with SDS-polyacrylamide gel electrophoresis and Western blottinglo. To detect FAT/CD30, we used a monoclonal antibody (MO25) directed against human CD36 and to detect GLUT4, a polyclonal IgG antiserum was applied. Signals obtained by Western blotting were quantified by densitometry.

\section{other procedures}

Cellular wet mass was obtained from cell samples taken during the incubation period and determined after centrifugation for 2 to $3 \mathrm{~s}$ at maximal speed in a microcentrifuge and subsequent removal of the supernatant. Protein was quantified with the bicinchoninic acid protein assay (Pierce, Rockford, IL) according to manufacturer's instructions.

\section{Data presentation and statistics}

All data are presented as means \pm S.E.M. for the indicated number of cardiac myocyte

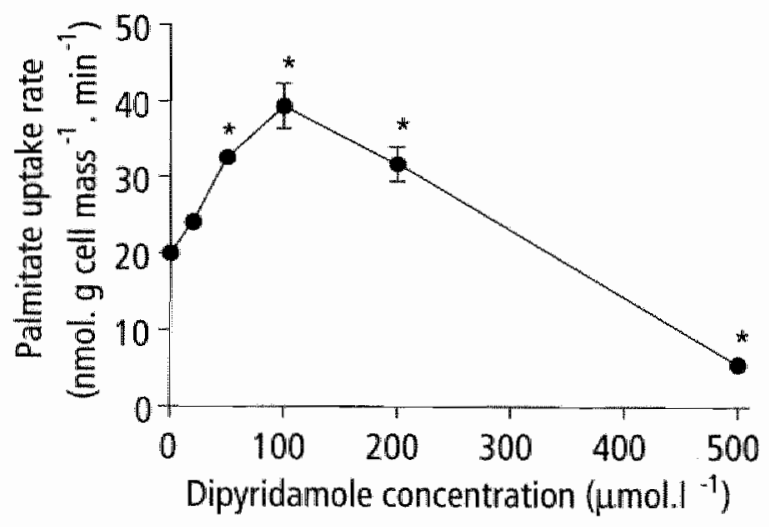

Figure 4.1: Dose-dependent effect of dipyridamole on the palmitate uptake rate in cardiac myocytes.

Cardiac myocytes were incubated for $15 \mathrm{~min}$ with warious concentrations of dipyridamole. Data are presented" as means \pm S.EM. of three experiments carried out with different cardiac myocyte preparations. "Significantly" different from non-treated cardiac mpocytes, $p<0.05$. 
preparations. Statistical difference between groups of observations was tested with a paired Student's t test. P values $\leq 0.05$ were considered significant.

\section{RESULTS}

\section{Effects of dipyridamole on substrate uptake}

DPY has previously been shown to enhance LCFA uptake by cardiac myocytes.9. We have applied DPY to cardiac myocytes at a variety of concentrations up to 500 umol. $\mathrm{l}^{1}$. Within this concentration range, DPY did not alter the number of cardiac myocytes that were rod shaped or excluded trypan blue, indicating that cellular integrity was not affected (see research design and methods). When studying LCFA uptake as a function of the concentration of DPY, this compound seemed to be optimally increasing LCFA uptake at 100 umol. ${ }^{-1}$ (Fig. 4.1). At this concentration of DPY, the intracellular ATP concentration was measured to be $1.25 \pm 0.35$ umol.g wet mass ${ }^{1}$, which was not significantly different form non-treated myocytes (ATP concentration, $1.47 \pm 0.27 \mu \mathrm{mol}$. gwet mass ${ }^{1}$ ), indicating that cell viability remained unchanged.

At $100 \mu \mathrm{mol} . \mathrm{I}^{1}$, the stimulatory effect of DPY on LCFA uptake arnounted to 2.0-fold, whereas simultaneous uptake of deoxyglucose was slightly (32\%) inhibited (Fig. 4.2). In contrast, other mamipulations to stimulate LCFA uptake also stimulated deoxyglucose uptake. In this respect, oligomycin stimulated LCFA and deoxyglucose uptake to the same extent $(2,0$. fold], whereas insulin had a greater stimulatory effect on deoxyglucose uptake $(2.7$-fold stimulation) than on LCFA uptake (1.6-fold stimulation).

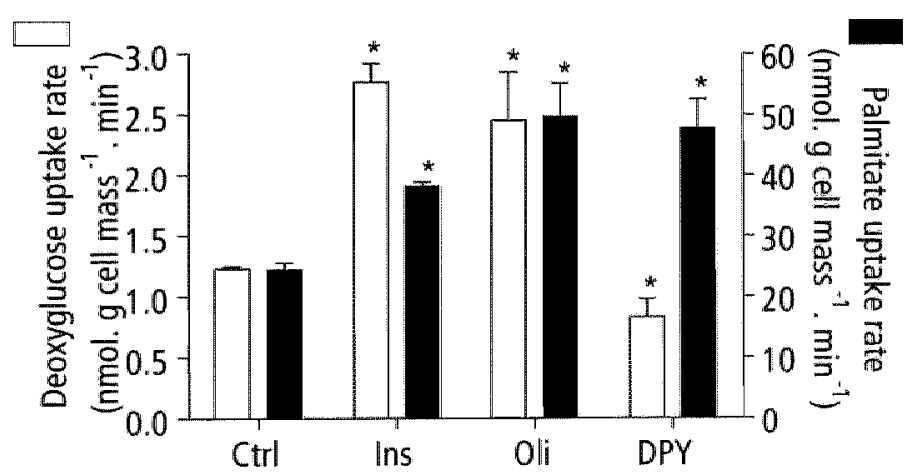

Figure 4.2: Effects of insulin, oligomycin and dipyridamole on substrate uptake by cardiac myocytes.

Cardac myocytes were incubated in the absence of additons (Ctrl) or presence of 10 mmoll" insulin (Ins), 30

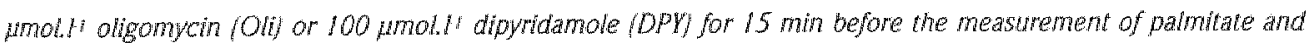
deoxyglucose uptake in 3 min. Data are presented as means \pm S. E.M. of four to six experiments carried out with different cardiac myocyte preparations. *Significantly different from non-treated cardiac myocytes, $p<0.05$. 


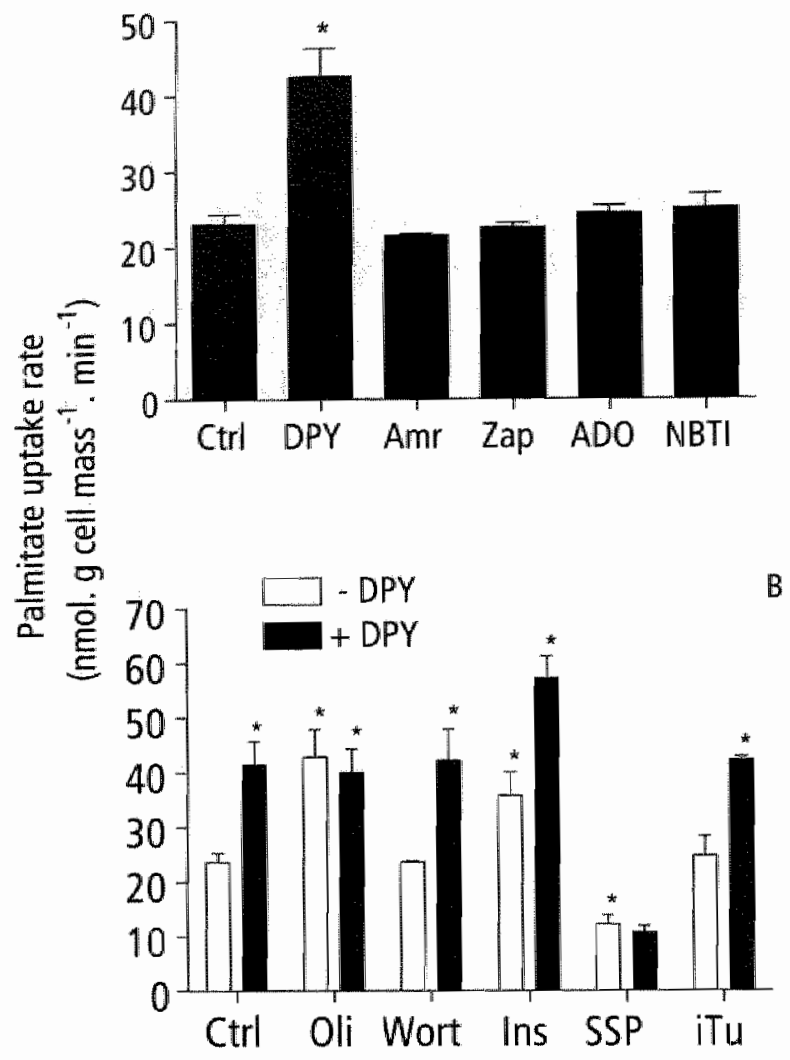

Figure 4.3: Onto the wiechantsm of the effect of dipyridamole on LCFA uptake into cardiac myocytes.

A) Effect of phosphodiesterase inhibitors, adenosine and nucleoside transpont inhibitor on LCA uptake by cardiaC mpocytes. Before determination of palmitate uptake in 3 min, cardiac mocytes were incubated for 15 min in the

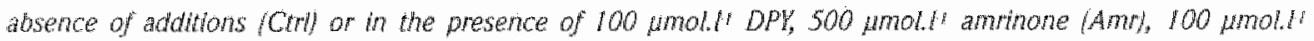

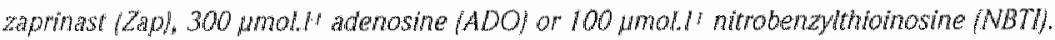

B) Modulaton of the stmulatory effect of dipyrdamole on LCFA uptake by insulin, oligomych and protein inhibitors. In the case of SSP, catdiac mocytes were preincubated with DMSO (Basall or with 400 umollt SSP labsotved in DMSO, after which the cardiac myocyes were washed twice with medium B. In the case of 5 iodoluberdin "WTu, cardiac myacytes were suspended in DMSO Basall or 10 umoll iTh (dissolved in DMSO), for Q0 min betore preicubation with 100 wholl: DPY. In the case of the other compounds used in combination with dipyridamole, ie, 30 umol." olgompcin (OH), 200 umolls wortmannin (Wort) or 10 nmol.t" insulin (Ins), cardiac mpocytes were incubated in the absence or presence of DPY before determination of patmitate uptake in 3 min. Data ate presented as meats \pm S.EM. of fou" to eight experiments carried out with different cardiac myocyte preparations. "Significantly different from cardiac myocytes without additions $/$ Ctrl), $0<0.05$. 


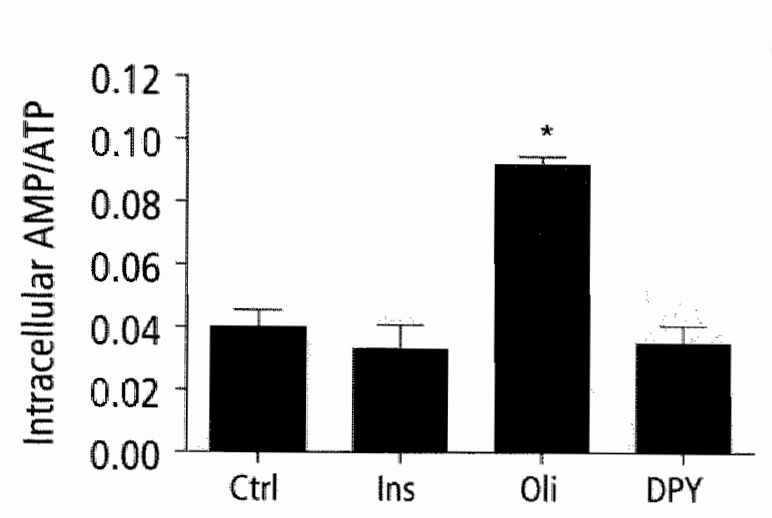

B

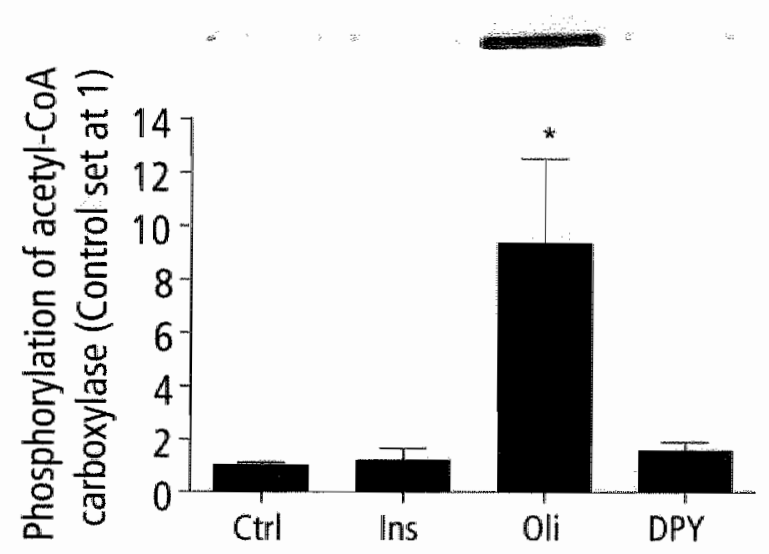

Figure 4.4: Infuence of insulin, oligomycin and dipyridamole on the AMP/ATP ratio and phosphorylation of aceryl-COA carboxylase in cardiac myocytes.

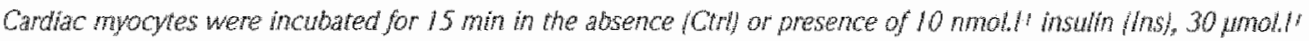

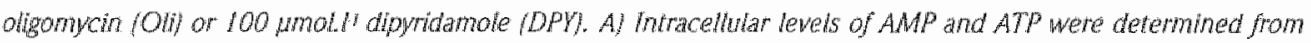
Which the AMP/ATP ratio was calculated. BS Phosphorylation of acetyl CoA carboxylase at Ser 70 was detected at 280 $\mathrm{KD}$ a, i.e., the major isoform of this enayme in the heart. However, in oflgomycin treated cardiac mocytes a second lower band is apparent, corresponding with the $265 \mathrm{kD}$ a isoform. Data are presented as means is 5 . M. M of three to six experiments carried out with different cardiac myocyte preparations. "Significantly different from cardiac myocytes without additions (Ctri), $p<0.05$. 
To explore the possibility that the stimulatory effect of DPY on LCFA uptake was caused by its inhibitory action on phosphodiesterases and on nucleoside transport, it was determined whether amrinone (phosphodiesterase III inhibitor resulting in the accumulation of $\mathrm{CAMP}^{28}$ ), zaprinast (phosphodiesterase $V$ inhibitor resulting in the accumulation of cGMP29), adenosine (theoretical substrate for AMP fomation resulting in AMPK activation), and nitrobenzylthioinosine (nucleoside transport inhibitor ${ }^{7}$ ) were able to influence LCFA uptake by cardiac myocytes (Fig. 4.3A). However, none of these agents had an effect on LCFA uptake.

A further attempt to unravel the mechanism of DPY's stimulatory action on LCFA uptake was carried out by investigating its effect in combination with other compounds that influence FAT/CD36-mediated LCFA uptake (Fig. 4.3B). Addition of the specific FAT/CD36 inhibitor SSP completely prevented the stimulatory effect of DPY on LCFA uptake. Phamacological activation of AMPK signaling by oligomycin, a potent inhibitor of mitochondrial $F_{1} / F_{0}$-ATPase, resulted in a 2.0-fold increase in LCFA uptake, but the addition of DPY did not further increase LCFA uptake. In contrast, whereas insulin stimulated LCFA uptake (1.5-fold), the addition of DPY stimulated LCFA uptake further by 1.6 fold. In fact, the absolute stimulatory action of DPY on LCFA uptake was similar in absence $\left[18.6\right.$ nmol.g cell mass ${ }^{-1}$. min $\left.^{-1}\right)$ and presence (22.5 nmol.g cell mass ${ }^{-1}$. min-1) of insulin (Fig. 4.3B). Blockade of $\mathrm{PI}_{3} \mathrm{~K}$ activity upon the addition of wortmannin neither affected LCFA uptake into cardiac myocytes under nonstimulated conditions not inhibited the stimulatory action of DPY (Fig. 4.3B). The adenosine kinase inhibitor 5-iodotubercidin neither influenced LCFA uptake under nonstimulated conditions nor inhibited that stimulatory action of DPY (Fig. 4.3B].

\section{Effects of dipyridamole on intracellular AMP/ATP ratio and on AMPK activation}

The nonadditivity of the effect of DPY with aligomycin on LCFA uptake into cardiac myocytes indicates that DPY acts on a component in the AMPK signaling pathway. Therefore, we tested the ability of DPY to alter the intracellular AMP/ATP ratio and to induce phosphorylation of acetyl-CoA carboxylase, which is a sensitive marker of activation of AMPK 30 . Similar to insulin (but in contrast to oligomycin, which enhanced the AMP/ATP ratio by 2.4 -fold and the phosphorylation of acetyl-CoA carboxylase by 8.6 -fold\}, DPY had no effect on both parameters of contraction signalling (Fig. 4.4).

\section{Effects of dipyridamole on transporter translocation}

Despite the fact that DPY does not induce the activation of AMPK, the nonadditivity of the effects of DPY and oligomycin on LCFA uptake into cardiac myocytes, suggests that DPY, just like oligomycin ${ }^{23}$, induces translocation of FAT/CD36 from an intracellular storage compartment to the sarcolemma. Incubation of cardiac myocytes for $15 \mathrm{~min}$ in the presence of oligomycin or DPY decreased the content of FAT/CD36 in the low density microsome (LDM) fraction by 42 and $46 \%$, respectively. These agents simultaneously increased the content of EAT/CD36 in the plasmalemmal (PM) fraction to a similar magnitude of 1.5 -fold (Fig. 4.5). Oligomycin had comparable effects on subcellular distribution of GLUT4, i.e, a decrease by $54 \%$ in the LDM fraction and an increase by 1.7-fold in the PM fraction. However, DPY, unlike its stimulation of FAT/CD36 translocation to the sarcolemma, was unable to modulate the subcellular distribution of GLUT4 (Fig. 4.5). 


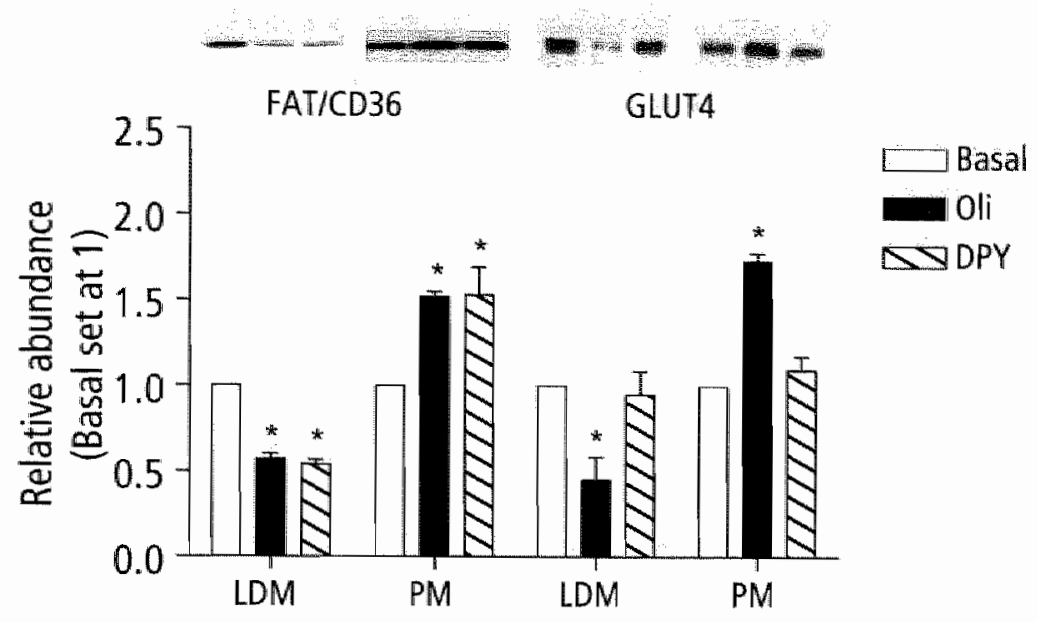

Figure 4.5: Effect of oligomycin and dipyridamole on the subcellular distribution of FAT/CD 36 and GLUT4 in cardiac myocytes.

Cardiac myocytes were incubated for 15 min in the absence (Basall or presence of 30 jumal. oligomycin or 100

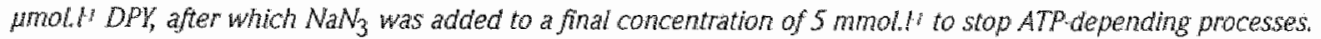
Thereafter, cardiac myocytes were frozen in liquid nitrogen, and upon thawing were subjected to subcellular fractionation. The collected fractions were analysed on the relative contents of FAT/CD30 188 kDal and GLUTA 445 kDay. Transporter content was expressed as multiple of control (Basal) in the corresponding fraction. Data are presented as means \pm S. E.M. of four experiments carried out with different cardiac myocyte preparations. Representative Western blots are presented. *Significantly different from cardiac myocytes without adiditions (Basal), $p<0.05$.

\section{Discussion}

The main purpose of this study was to asses the use of DPY as a tool to examine the regulation of FAT/CD36 translocation and its relationship with GLUT4 translocation. The novel findings of this study are that (i) DPY stimulates LCFA uptake by influencing contraction-inducible, but not insulin-inducible, FAT/CD36 translocation, and (ii) DPY is able to divorce FAT/CD36 translocation from GLUT4 translocation. These findings indicate the potential of DPY to study the regulation of cardiac substrate preference at the level of trafficking of substrate transporters.

\section{Action of dipyridamole on contraction-inducible FAT/CD36 translocation}

To unravel the molecular mechanism by which DPY stimulates LCFA uptake, we investigated whether the known ability of DPY to block phosphodiesterases and nucleoside transporters was involved in stimulating LCFA uptake. CAMP elevation by amrinone and CGMP elevation by zaprinast did not influence LCFA uptake into cardiac myocytes, indicating that the stimulatory action of DPY on LCFA uptake is not related to the inhibition of phosphodiesterases. Inhibition 
of nucleoside transpont and concomitant intracelluar accumulation of adenosine was ruled out as a contributing factor to the DPY-induced LCFA uptake on basis of three lines of evidence, (i) the well-established nucleoside transport inhibitor nitrobenzylthioinosine, which, like DPY, causes adenosine accumulation in cardiac myocytes ${ }^{31}$, did not influence LCFA uptake, (ii) adenosine added at concentrations up to 1 mmol..' did not stimulate LCFA uptake, and (iin) inhibition of adenosine conversion into AMP by inclusion of the adenosine kinase inhibitor 5 iodotubercidin did not inhibit DPYinduced LCFA uptake.

The stimulatory action of DPY on LCFA uptake occurred at the level of FAT/CD36, based on the ability of the specific FAT/CD36 inhibitor SSP (see in more detail Chapter 8) to block

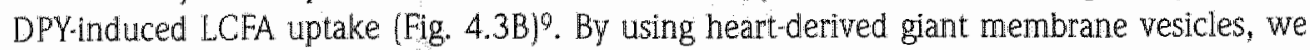
were previously able to exclude a direct interaction of DPY with FAT/CD36. In this preparation, in which the amount of FAT/CD36 at the surface is fixed and not subject to regulation, LCFA. uptake was not inducible by DPY\%.

The following observations were instrumental in pinpointing the effect of DPY on LCFA uptake to its ability to induce translocation of FAT/CD36 from intracellular storage compartments, (i) in the presence of oligomycin (Fig. 4.3B) or AICAR (data not shown), DPY was able to further induce LCFA uptake, indicating that this compound is activating AMPK silgnalling, (ii) DPY, like oligomycin and insulin, is able to decrease the FAT/CD36 content in intracellular membrane compartments and simultaneously increase its content at the sarcolemma, indicating that this compound operates through induction of FAT/CD36 translocation. A possible interaction of DPY with the insulin-inducible FAT/CD 30 translocation was excluded by the observation that, (i) DPY retained its full stimulatory effect on LCFA uptake in the presence of insulin, and [il] inhibition of $\mathrm{PI}_{3} \mathrm{~K}$, a key enzyme in the insulin signalling pathway, did not block DPY-inducible LCFA uptake.

The next goal was to locate the action of DPY along the AMPK signalling pathway. The observations that DPY neither" elevated the intracellular AMP/ATP ratio nor enhanced the phosphorylation of acetyl-CoA carboxylase, indicated that the action of DPY on contraction signaling is downstrearn of AMPK. However, the signalling events downstream of AMPK leading to translocation of FAT/CD36 are at present unknown.

\section{Mechanism of separation of FAT/CD36 translocation from that of GLUT4 by dipyridamole}

Unlike its stimulatory action on LCFA uptake and FAT/CD36 transiocation, DPY neither stimulates glucose uptake nor induces GLUT4 translocation. The slight inhibitory effect of DPY on glucose uptake is in line with an earlier observation made in adipocytes that DPY is directly interacting with glucose transporters, thereby decreasing their intrinsic activity 1 . The selective recruitment of FAT/CD36 suggests that (i) FAT/CD36 and GLUT4 are stored in distinct intracellular compartments or, on the other hand, that (ii) FAT/CD36 and GLUT4 are stored in the same compartment, but recruited by different signalling mechanisms. In the latter case, there must be a sorting mechanism present that is able to excise either EAT/CD36-and GLUT4. containing transport vesicles from the storage compartment shared by FAT/CD36 and GLUTA. Because DPY is believed to act downstream of AMPK and at the same time is selective for 
FAT/CD36 recruitment, it follows that downstream of AMPK the signal branches off into two pathways. One of these pathways leading to mobilization of intracellularly stored GLUT4 and the other to mobilization of intracellularly stored FAT/CD36. It also pinpoints the in tracellular target of DPY not only downstream of AMPK but also downstream of this branch point in AMPK signalling, i.e., at the pathway specifically leading to FAT/CD36 translocation. These novel insights are schematically depicted in Fig. 4.6.

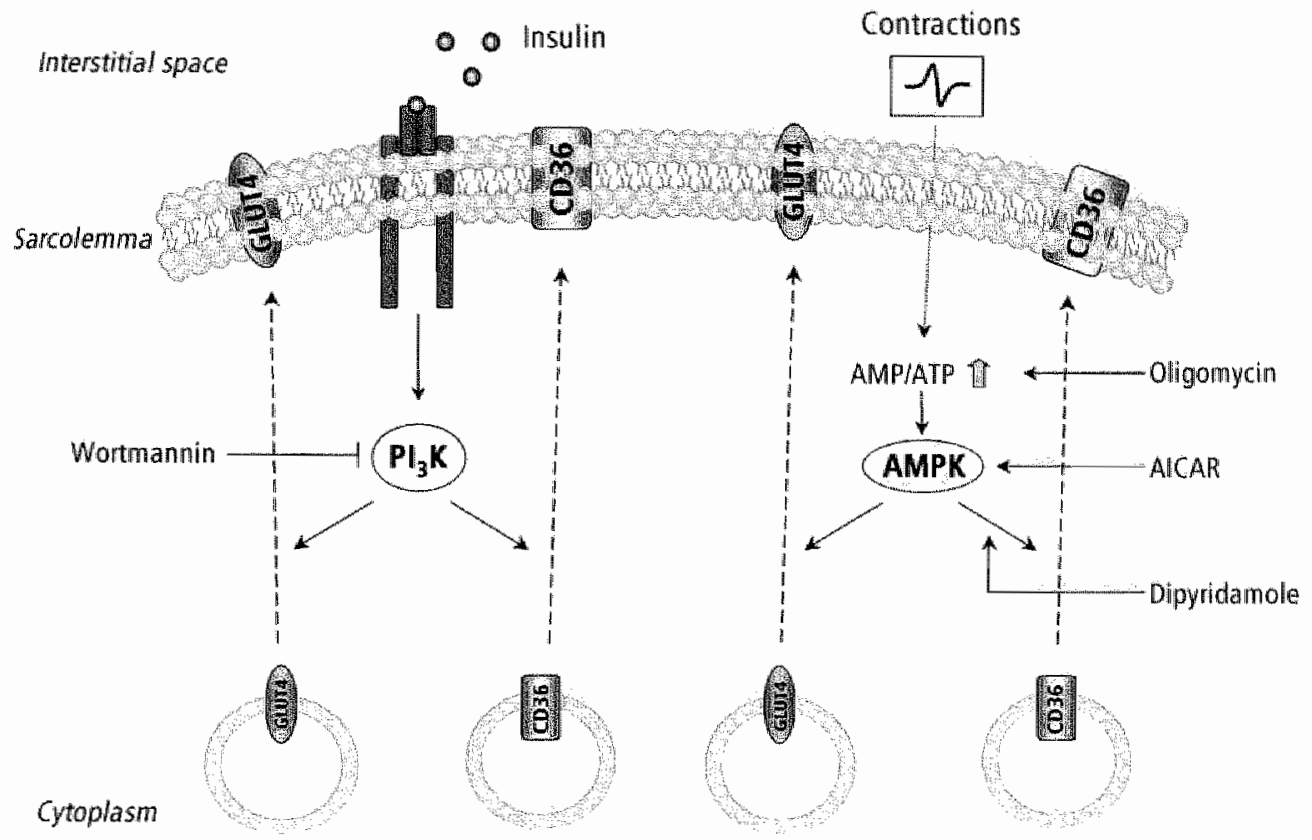

Figure 4.6. Schematic presentation of signaling pathways inwolved in mobilization of FAT, CD36 and GLUT4 in cardiac myocytes.

Intracelluar FATYCD36 and GLUT4 car be mobilized by both insulin and celluar contractions. Insulin activates its

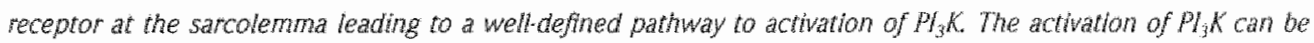
spectically intibited by wortmannin. The sequence of events downstream of Pl,k is not completely elucldated, but leads to mobilization of FAT/CD30 and CLUT4 from intracelluhar stores. Celluar contractons induced ATP utilization concomitant with an elevation of intracellular AMP, which causes activation of AMPk thadditon to Pl, signalling downstream of AMPK is not well defined, but moblized both FAT/CD36 and OLUTA. Contraction.

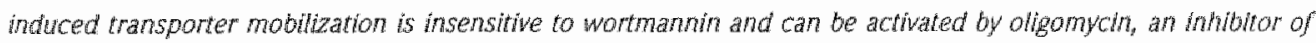
mitochondrial ATPase. Contractiontinduced transporter mobilization can also be activated by the cell-permeable AMP anatog, ACAR, which drectly activated AMPK. Dipyriamole also moblizes HAT/CD30 via the contiction pathway but does not affect CLUTA moblization. The site of action of DPV is not yer identiled, but it is believed to be dowhstrean of AMP kihase. 


\section{Concluding remarks}

The ability of DPY to selectiwely recruit FAT/CD36 to the sarcolemma may help to uniavel signalling proteins downstream of AMPK that are solely dedicated to FAT/CD36 trafficking without affecting CLUT4. Furthermore, this ability may make DPY of potential clinical interest.

\section{ACKNOWLEDGementS}

Aritibody MO25 was kindly provided by Dr. N.N. Tandon, Thrombosis and Vascular Blology Laboratory, Otsuka America Pharamceutical, Rockville, MD, USA. 


\section{REFERENCES}

1. Humphreys DM, Street I, Sohmacher H, Bertand-Hardy IM and Paluk R. Dipyridanole mat be used safey in patients with ischaemic heart disease. In J Cin Pract 2002;56:121.7.

2. MacWalter RS and Shirley CP. A betefitrisk assessment of agents used in the secondary prevention of stroke. Dirg Saf. $2002 ; 25: 94363$.

3. Petigrew $\mathrm{LC}$ and Whilams SC. Antithrombotic drugs for preventon of recurrent stroke. $/ \mathrm{Ky} / \mathrm{Med}$ Assoc. $2002: 100: 184.03$.

4. De Schryer EL. Dipyridanole in stroke prevention effect of dipyridamole on blood pressure. Stroke. $2003 ; 34: 2339-42$.

5. Konas $\mathbb{N}$, Le Bec A, Stoclet JC and Lugnier C. Cardiac COMP-stimulated cyclic mucleotide phosphodiesterases: effects of cGMP analogues and drugs. Aur Phamacol 1091200:5-13.

6. Beavo J. Cyclic nucieotide phosphodiesterases: functional implications of multiple isofoms. physiof hew $1995 ; 75: 725.48$.

7. Hammond JR, Willams EF and Clanachan AS. Affinty of calcium channel inhibitors, benzodiazepines, and other wasoactive compounds for the nucleoside transport system. Can / Physiol Pharmacol 1085:63:1302-7.

8. Abdel-aleem S, EI-Guindy N, Sallam TI, Hughes GC and Lowe JE, Stmulation of long-chain falty acid uplake by dipyridamole in isolated myocyles. J Cardiovasc Phamacol. 1090;33:43-8.

9. Luiken JJ, Willems J, Coort SL, Coumans WA, Bonen A, Wan Der Vusse Gl and Glatz If grfects of cAMP modulators on longchain fatcyacid uptake and utiliation by electrically stimuiated rat cardac myocytes. Biochem. 2002;367:881.7.

10. Luiken J, Koonen DP, Willems J, Zorzano A, Becker C, Fischer Y, Tandon NW, Van Der Vusse G, Bonen A and Glatz JF Insulin stimulates long chain faty acid utilization by rat cardiac nyocytes through celluar redistribution of FAT/CD36. Diabetes. 2002;51:3113-9.

11. Stainfelder $\mathrm{HJ}$ and Joosi $\mathrm{HG}$. Inhibition of insulin-stimulated glucose transport in rat adipocytes by mucleoside transport inhibitors. FEBS Lett. 1988;2272159.

12. Mainwaring FO and Mentzer RM, It Effects of dipyridanole on mocardial glucose uptate in the newborn tamb. J Surg hes. 1986,40:528-33.

13. Prasad RK, Behrooz A and Ismail-Beigl F. LY.83583 stimulates glucose transporter tnedlated ghucose transpont independent of changes in CGMP levels. Eur J phamacot $1900,300: 101-9$.

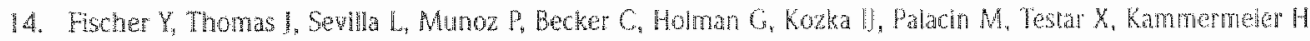
and Zorzano A Insulin induced recutment of glucose transporter 4 (GLUT4) and CLIT in isolated fat cardiac myocytes. Evidence of the existence of different intracellalar Ciut4 vesicle populations f Brol Chem. $1097: 272.708592$.

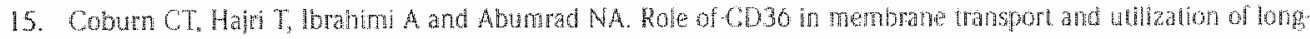
chain faty acids by different ussues. $/$ Mol Newosci. 2001;10:11721; discussion 51.7.

16. Brinkmann IF, Abumrad WA, lbrahimi $A$, van der Vusse $\mathrm{O}$ and Clata IF New insights into long chain fally acld

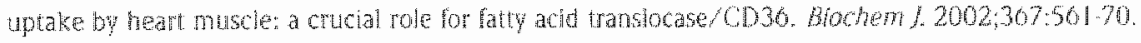

17. Kandror WV and Pich PF. Compartmentalization of protein traffic in insulnsensitue cels. Am / Physiol. $1090: 271: E 1-14$

18. Luiken II, Dyck DI, Han XX, Tandon WN, Arumigam Y, Glatz JF and Fonen A. Insulin induces the transtoction of

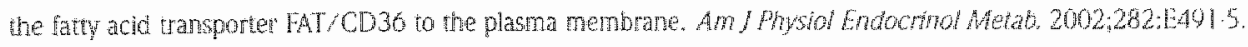




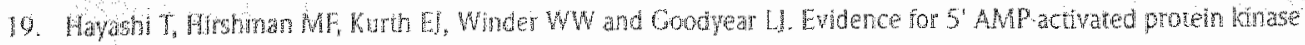

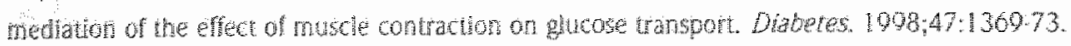

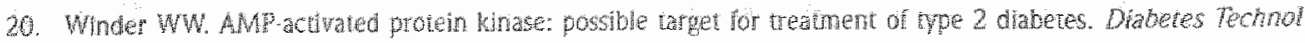
The $2000 ; 2: 4418$

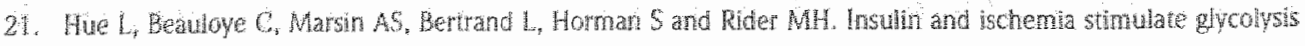

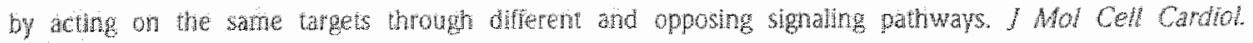
$2002,341091 \%$

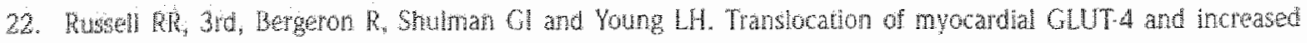

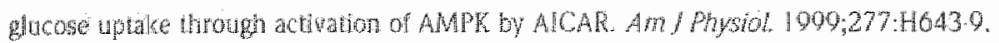

23. Luken J, Coori SL, Whemg, Coumans WA, Bonen A, van der Vusse Gl and Gatz IF Contracion induced faty

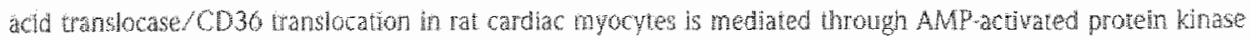
sighaling. Diabetes. $2003552: 1027-34$.

24. Coort St, Whlems I, Coumans Wh, vara der Wusse GJ, Bonen A, Gatz IF and Luken IJ. SuloN-succinmidyl

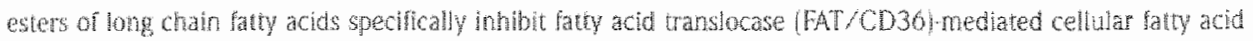
uptake. Mol Gill Blochem. 2002;230:213-9

25. Luken, J, van Wleuwenhoven FA, America G, van der Vusse $\mathrm{Cl}$ and Glatz IF Uptake and metabolism of palmiats

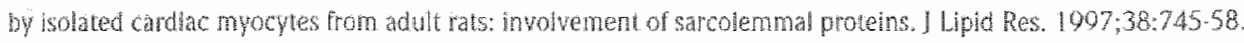

20. Wan der Wusse $\mathrm{O}$ and Reneman RS. The myocardial nonesterified fatty acid controversy. I Mol Cell Comblot. $1084: 1067782$.

27. Fscher $Y$, Thomas 1 , Rosen $P$ and Kammermeier H. Acton of metormin on glucose transport and glucose transporter CLUT and GLUTA in heart muscle cells from healthy and diabetic rats. Endocrinobgy $1995: 130: 412,20$

20. Endoh $M$, Yamashita $S$ and Taira $N$. Postive inotropic effect of ammone in relation to cyclic nucleotide metabohism in the canine venticular muscle, / Phatmacol Exp Then 1982,221:775.83.

29. Gong CX, Weis HR, Tse and Scholz PM. Cyclo GMP decreases cardia myoche axygen consumprion to a greater extent under conditions of increased merabolism. Jardrowas phamacol. 1097;30537-43.

30. Park SH, Gammon SR, Knippers ID, Pausen SR, Rubink DS and Winder WW. Phosphorylaionactivty

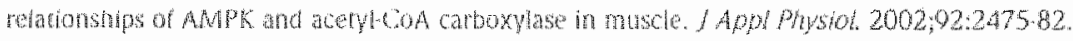

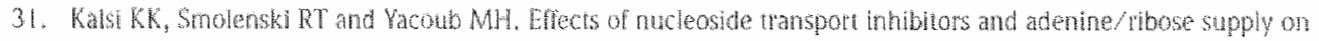

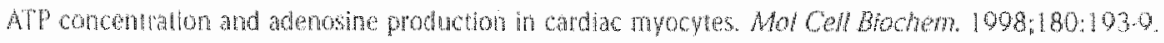




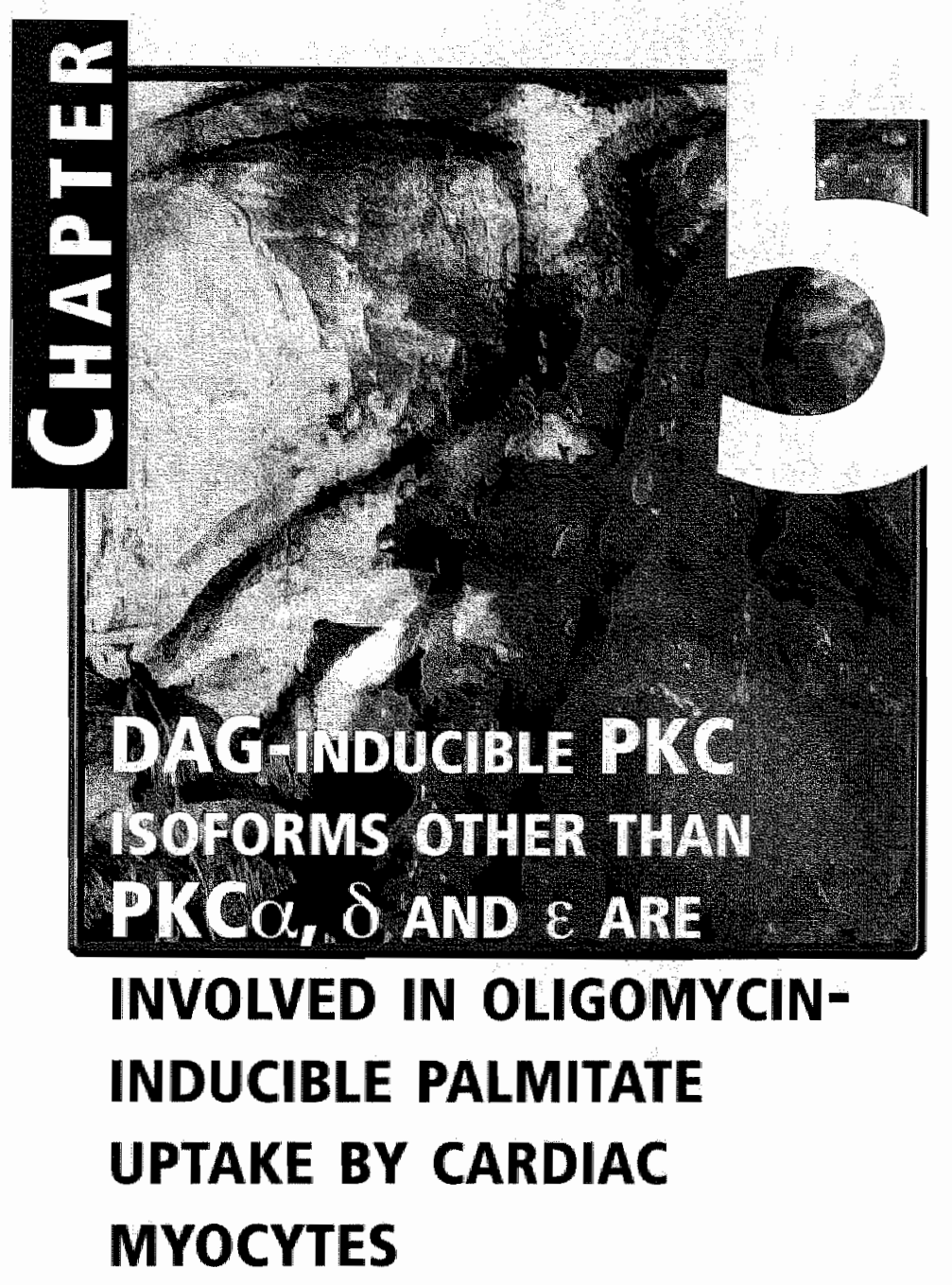

Susan L.M. Coort ${ }^{1}$, Jodil Willems ${ }^{1}$, Will A. Coumans', Maurice M.A.L. Pelsers', Arend Bonen $^{2}$, Ger J. van der Vusse ${ }^{3}$, Jan F.C. Glatz', and Joost J.F.P. Luiken ${ }^{1,4}$

Department of Molecular Genetics and 3Physiology, CARIM, Maastricht University, Maastricht, the Netherlands. 2Department of Human Biology and Nutritional Sciences, Guelph University, Guelph, Ontario, Canada.

Department of Biochemical Physiology and Institute of Biomembranes, Utrecht University, Utrecht, the Netherlands. 


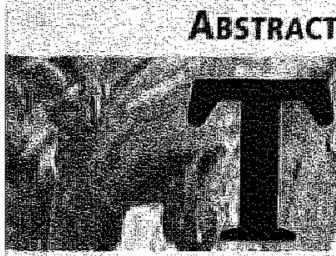

o reach the energy production required for electromechanical activity in cardiac myocytes, the uptake rate of metabolic substrates, like long-chain faty acids (LCFAs), should match the need for energy. Upon electrical stimulation of cardiac myocytes the rate of LCFA uptake increases due to the translocation of the main LCFA transport protein, fatty acid translocase (EAT)/CD36, from intracellular stores to the sacrolemma. Recenty, it is established that activation of AMP activated kinase (AMPK) is Involved in the contraction mediated. CFA uptake by cardiac myocytes. In identifying the signalling kinases involved in contraction-indicible palmitate uptake members of the protein knase C (PKC) family are attractue candidates, In the present study we will explore the possible role of the most abundant novel and conventional PKCs present In casdiac myocytes, 1.e, PKCo, 0 and $\mathrm{e}$, in palmitate uptake induced by oligomyicn, a contraction-mimetic agent. In addilion, the positioning of PKCs relative to AMPK in the contraction signalling pathway was investigated. Three lines of evidence indicate the involvement of PKCs that contain a DAG binding domain in oligomycin induced palmitate uptake by cardiac myocytes. First: phorbol 12-myristate 13-acetate (PMA), a diacylglycerol (DAG) analog activating both conventional and novel PKCs, induced the palmitate uptake rate. Second, the effect of PMA was non addituve to the stimulatory effect of oligomycin on palmitate uptake. Third, the oligomycin-induced palmitate uptake rate was inhlbited by the PKC inhibitor, staurosporine. Interestingly staurosporine was able to block AMPK activity suggesting that PKCs are positioned upstream of AMPK in contraction signalling leading to FAT/CD36 translocation. However, activation of PKCo, 8 and $e$ measured by transiocation was only induced by PMA and not by oligomycin. In addition, the phosphorylation of PKCa (Thr638) and PKCo (Ser643) was not affected by oligomycin, whereas PMA induced only the latter phosphorylation. In conclusion, DAGinducible PKC isoforms other than PKCo, o and e are involved $\mathrm{n}$ oligomycin-inducible palmitate uptake and are possibly positioned upstream of AMPK. 


\section{INTRODUCTION}

The heart predominantly consists of specialized muscle cells, cardiac myocytes, which perform contractions in a coordinated fashion. During the energy demanding contraction process, ATP is generated by the oxidation of substrates 1 . Under physiological conditions cardiac myocytes predominantly utilize long-chain fatty acids (LCFAs), mainly palmitate and oleate, to generate energy for a proper electro-mechanical activity 2,3 . In rat cardiac myocytes it was demonstrated that electrically-induced contractions increase the rate of palmitate uptake, coinciding with the translocation of fatty acid translocase (FAT)/CD36, i.e., the main putative LCFA transport protein, from intracellular storage compartments to the sarcolemma ${ }^{4}$. Contraction-inducible FAT/CD36-mediated LCFA uptake by cardiac myocytes can be mimicked by oligomycin, a well known inhibitor of the mitochondrial $F_{1} / F_{0}$ ATPases. In addition, we demonstrated that in electrically-stimulated and oligomycin-treated cardiac myocytes the intracellular AMP/ATP ratio increases, resulting in activation of AMPK5. The activity of AMPK is not only regulated by the intracellular AMP/ATP ratio, but also by phosphorylation at Thr 172 by an AMPK kinase $\left(\right.$ AMPKK $^{\circ}$. Activation of AMPK is involved in the induction of FAT/CD36 translocation upon an increased workload (see in more detail Chapter 3). Furthermore, AMPK has been recognized to be involved in mitochondrial LCFA oxidation. Once activated AMPK inhibits acetyl-CoA carboxylase (ACC) activity through phosphorylation at Serine.79 (Ser79), leading to a lowering of the intracellular malonyl-CoA concentration?. A decline in malonyl-CoA relieves, in turn, the inhibition of carnitine palmitoyl transferase I (CPT-I) resulting in enhanced LCFA oxidation". The simultaneous activation of FAT/CD36 translocation and of CPT-I activity allows an efficient intracellular channelling of the extra LCFA take up into mitochondrial LCFA oxidation.

In identifying signalling kinases involved in the induction of FAT/CD36-mediated LCFA uptake during cellular contractions, members of the protein kinase $C(P K C)$ family are attractive candidates. PKCs, a family of serine/threonine kinases ${ }^{9}$, have been demonstrated to be activated during contractions and once activated phosphorylate components of the contractile machinery $10 \cdot 12$. The PKC family consists of three subfamilies, i.e., conventional $(\alpha, \beta \mathrm{I}, \beta \mathrm{II}$ and $\gamma$, novel $(\delta, \varepsilon, \eta$ and $\theta)$ and atypical $(\zeta$ and $\lambda)$, which are separated based on their structure and ligand-binding domains (for detail see review by Newton et at.13). All PKC isoforms are characterized by a highly conserved catalytic domain, i.e., the ATP binding (C3) and substrate binding (C4) domains and they each have a N-terminal pseudosubstrate (PS) domain (Fig. 5.1). This PS domain autoinhibits the PKC enzyme activity by binding to the C-terminal substrate binding domain. Binding of co-factors, like phosphatidyl-L-serine (PtdSer), induces the release of the PS domain from the substrate binding domain ${ }^{14}$. Conventional PKC also require diacylgiycerols (DAGs) and $\mathrm{Ca}^{2 *}$ for their activation, whereas novel PKCs do require DAGs, but are $\mathrm{Ca}^{2+}$-independent. The activation of atypical PKCs is independent of both DAGs and $\mathrm{Ca}^{2+}$, but requires besides PtdSer also other lipids. In rat cardiac myocytes the most prominent PKC isoforms are $\alpha, \delta, \varepsilon$, and $\zeta,\left(\mathrm{Fig} .5 .1\right.$ ), whereas also $\beta \mathrm{IL} / \beta \mathrm{II}, \theta, \eta$ and $\mu$ are present although less abundant ${ }^{15}$.

PKCs are activated via (i) binding of DAG and/or PtdSer to the protein thereby inducing translocation from a soluble form present in the cytoplasm to a membrane bound form and/or via (ii) phosphorylation at distinct regions in the catalytic domain 16 . PKC translocation is traditionally used as a hallimark of PKC activation and applied in the present study. Phosphorylation 

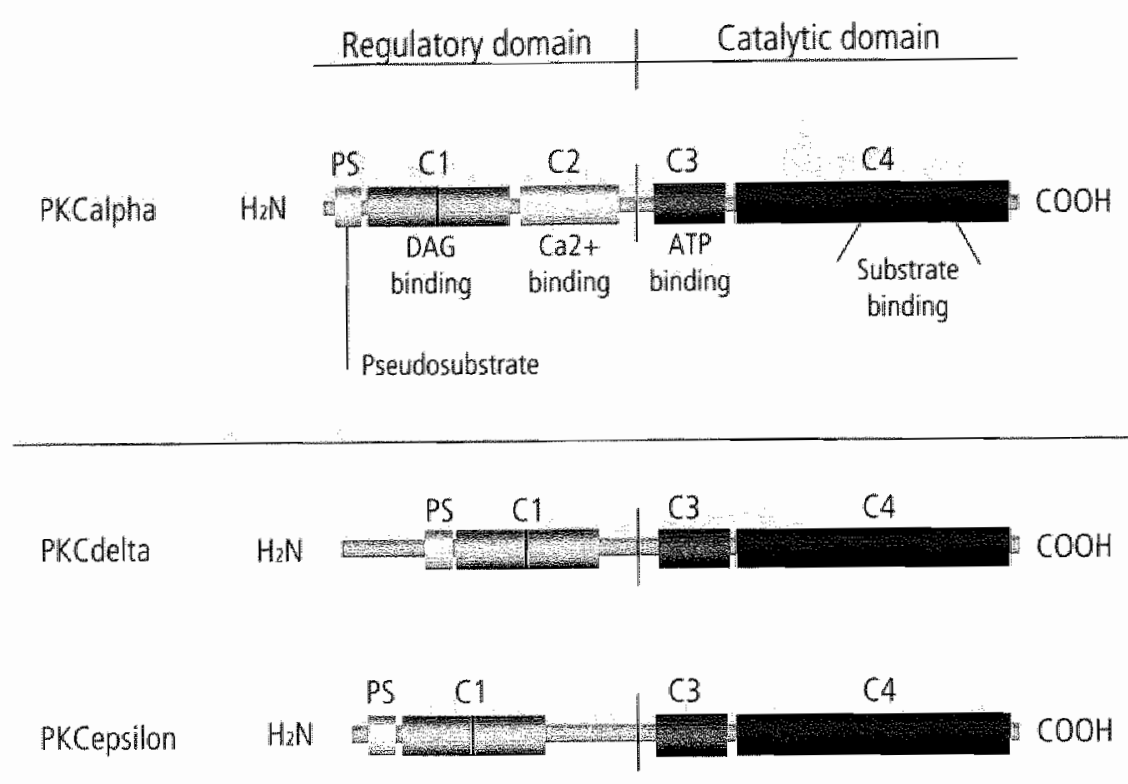

PKCzeta

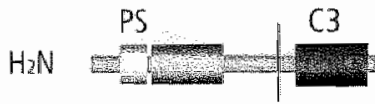

$\mathrm{C4}$

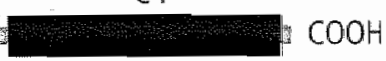

Figure 5.1: Domain structure of the predominant PKC isoforms known to be present in cardiac myocytes.

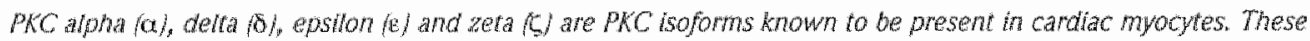

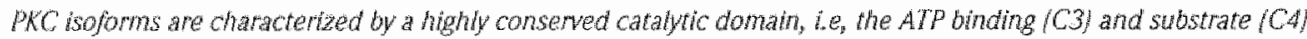
binding domain, whereas except for the pseudosubstrate (PS) donain, the regulatory domains differ. PKCo exhibits

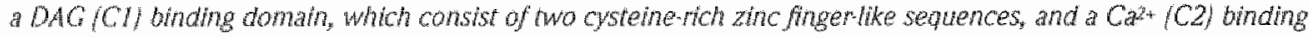
doman. PKOS and a aso contain the DAG binding domain, wut the Ca² binding domain is absent. In PKCE the Cakt binding domain is aiso absent and only one cysteinerich ainc finger-like sequences is present. Adapted from Mochly Rosen er al. sis.

of PKC at the activation loop, present within the catalytic domain, plays an essential role in its activation and causes a conformational change at the enzyme allowing autophosphorylation at the C-terminal region, which is characterized as hierarchical phosphorylation. It has been demonstrated that phosphoinositide-dependent kinase 1 phosphorylates the activation loops of conventional, novel, and atypical PKCs ${ }^{17}$.

The aim of the present study was to investigate the role of the most prominent novel and conventional PKC present in cardiac myocytes, i.e., $\mathrm{PKC} \alpha, \delta$ and $\varepsilon$, in the oligomycin-induced 
palmitate uptake. In addition, the positioning of PKCs relative to AMPK in the contraction signalling pathway was investigated. In isolated rat cardiac myocytes in which either PKCs are activated or inhibited the effect of oligomycin on palmitate uptake and AMPK activity was investigated. Phorbol 12 -myristate 13-acetate (PMA), a cell-permeable DAG analog, was used to activate $\mathrm{PKC} \alpha, \varepsilon$ and $\delta$ and staurosporine, an inhibitor of serine/threonine kinases, was used to inhibit these PKC isoforms. Activation of the PKC isoforms was determined by translocation of $\mathrm{PKC} \alpha, \delta$ and $\varepsilon$ and the phosphorylation state of PKCa and $\delta$. The activity of AMPK was indirectly determined by measuring phosphorylation of one of the main downstream targets of AMPK, i.e., ACC. To investigate whether PKC activation influences the amount of FAT/CD36 at the sarcolemma a specific inhibitor of FAT/CD36, i.e., sulfo- $N$ succinimidyl oleate (SSO) was used.

The present study indicates that DAG-inducible PKC isoforms other than PKC $\alpha, \delta$ and $\varepsilon$ are involved in oligomycin-inducible palmitate uptake by cardiac myocytes and that they are possibly positioned upstream of AMPK.

\section{EXPERIMENTAL DESIGN AND METHODS}

\section{Materials}

${ }^{14} \mathrm{C}$-palmitic acid was obtained from Amersham Life Science (Little Chalfont, United Kingdom). Bovine serum albumin (BSA, fraction $V$, essentially fatty acid free), phloretin, oligomycin, dimethyl sulfoxide (DMSO), phorbol 12-acetate 13-myristate (PMA), and staurosporine each were obtained from Sigma-Aldrich (St. Louis, MO, USA). Collagenase type-2 was purchased from Worthington (Lakewood, N], USA). Anti phospho acetyl-CoA carboxylase (ACC) was obtained from Upstate (Dundee, UK]. Sulfo- $N$-succinimidyl oleate (SSO) is routinely synthesized in our laboratory, as has been previously described ${ }^{19}$. Purity of this compound was confirmed with infrared spectroscopy (performed by Dr. van Genderen, Technical University, Eindhoven, the Netherlands).

\section{Isollation of cardiac myocytes}

Cardiac myocytes were isolated from male Lewis rats $(200-250 \mathrm{~g})$ using a Langendorff perfusion system and a Krebs Henseleit bicarbonate medium which is equilibrated with a $95 \%$ $\mathrm{O}_{2} / 5 \% \mathrm{CO}_{2}$ gas phase (medium A) at $37^{\circ} \mathrm{C}$, according to Fisher et al.20 and as previously described 21 . After isolation, the cells were washed twice with medium A supplemented with 1 mmol. ${ }^{1} \mathrm{CaCl}_{2}$ and $2 \%$ (wt/wol) BSA (medium B) and then suspended in $15 \mathrm{ml}$ medium B. The isolated cells were allowed to recover for approximately $2 \mathrm{~h}$ at room temperature. At the end of the recovery period, cells were washed and suspended in medium $B$. Only when more than $80 \%$ of these cells has a rod-shaped appearance and excluded trypan blue, they were used for subsequent studies.

\section{${ }^{14} \mathrm{C}$-palmitate uptake rate in cardiac myocytes}

lsolated rat cardiac myocytes ( $2 \mathrm{ml}, 5-8 \mathrm{mg}$ wet mass. $\left.\mathrm{ml}^{1}\right)$, suspended in medium $B$, were 
preincubated in capped $20 \cdot \mathrm{ml}$ incubation vials for $15 \mathrm{~min}$ at $37^{\circ} \mathrm{C}$ under continuous shaking. To study palmitate uptake, $0.5 \mathrm{ml}$ of a ${ }^{4} \mathrm{C}$ palmitate/BSA complex was added at the start of the incubations so that the final concentration of palmitate amounted to 100 Hmol. ${ }^{-1}$ with a corresponding palmitate/BSA ratio of 0.3 . This palmitate/BSA complex was prepared as: previously described 21 . Cellular uptake of palmitate in 3 min after addition of 14 C-palmitate was determined upon washing the cells three times for $2 \mathrm{~min}$ at $100 \mathrm{~g}$ in an icecold stop solution containing 0.2 mmol.11 phloretin as previously described 21 . The washing procedure did not affect cellular integrity as evaluated microscopically.

\section{Fractionation of carthac myocytes into membrane and cytosolic fractions}

Isolated cardiac myocytes (2 $\mathrm{ml}, 12-1.5 \mathrm{mg}$ wet mass. $\mathrm{ml} / 1)$ were incubated for $15 \mathrm{~min}$ at $37^{\circ} \mathrm{C}$ either nontreated or treated with $30 \mu \mathrm{mol} \mathrm{I}^{-1}$ oligomycin or $0.1 \mathrm{mmol.1}$ PMA under continuous shaking. After the incubation period, cardiac myocytes were separated into two parts, a small part $(0.5 \mathrm{ml})$ for the total protein fraction and a large part $(1.5 \mathrm{ml})$ for fractionation into membrane and cytosolic fractions. After separation both parts were immediately centrifuged at $4,000 \mathrm{rpm}$ for 4 min at $4^{\circ} \mathrm{C}$. The pellets were resuspended in icecold homogenizing buffer $\left(20\right.$ mmol. ${ }^{1}$ Tris. HCl, 0.33 mol..$^{-1}$ sucrose, 5 mmol. ${ }^{-1}$ EDTA, 0.5 mmol.' EGTA, 1 mmol. " PMSF, 0.005\% Aprotinin, pH set at 7.4), $0.3 \mathrm{ml}$ for the total protein fraction, which was frozen in liquid nitrogen and stored at $-80^{\circ} \mathrm{C}$, and $0.5 \mathrm{ml}$ for fractionation. Thereafter, the latter cardiac myocyte solutions were immediately frozen in liquid nitrogen and thoroughly homogenized by three cycles of freeze/thawing. Homogenates were then centrifuged at $18,000 \mathrm{xg}$ lo $20 \mathrm{~min}$ at $4^{\circ} \mathrm{C}$ to collect membrane (pellet) and cytosolic (supernatant) fractions. The pellet was resuspended in $0.3 \mathrm{ml}$ ice-cold homogenizing buffer. Both fractions were stored at $-80^{\circ} \mathrm{C}$.

\section{Determination of the PKC $\alpha, 8$ and $\mathrm{e}$ protein content in total homogenates, membrane and cytosolic fractions}

In $20 \mu \mathrm{g}$ total homogenates, membrane and cytosolic fractions, protein content of PKC $\alpha, \delta$ and $\varepsilon$ was determined by Western Blotting. Rabbit anti-protein kinases $C$ directed against $P K C \alpha, \delta$ or : 11:2,500, Sigma.Aldrich, St. Louis, USA, product number P4334, P8333 and P8458, respectively| were used to detect the different $\mathrm{PKC}$ isoforms. Protein bands were visualized by enhanced chemiluminescence (ECL) and immunoblot intensities were analyzed by densitometry using the computer program Scion Image.

\section{Determination of phosphorylated ACC (Ser 79), PKCa (Thr638) and PKCS (Ser643)}

In $20 \mu g$ cardiac myocyte homogenates, phosphorylated ACC (Ser79), PKCo (Thr638) and PKCO (Ser643) were determined by Western blotting. Rabbit anti-phospho ACC directed against Ser79 (Upstate, Dundee, UK, 07-303) was used to detect phosphorylated ACC. Rabbit anti-phospho PKC directed against Thr638 and Ser643 [Cell Signalling, Beverly, MA, USA, product number 9375 and 9376 , respectively) were used to detect phosphorylated PKCo and PKCD, respectively. Protein bands were visualized by ECL and immunoblot intensities were analyzed by densitometry using the computer program Scion Image. 


\section{Statistics}

Data are presented as means \pm S.E.M. Differences between cardiac myocyte preparations were tested by the non-parametric Mann-Whitney U-test. The paired ttest was used to define differences between treatments within a cardiac myocyte preparation. $\mathrm{P}<0.05$ indicates a statistical significance.

\section{RESULTS}

\section{Effects of oligomycin and sulfo- $\mathrm{N}$-succinimidyl oleate on the palmitate uptake rate in cardiac myocytes either non-treated or PMA-treated}

In isolated rat cardiac myocytes oligomycin as well as PMA significantly stimulated the palmitate uptake rate by 1.96 and 1.63-fold, respectively (Fig. 5.2). Oligomycin had no additional effect on the PMA-stimulated myocardial palmitate uptake rate (Fig. 5.2). However, sulfo- $N$-succinimidyl oleate $(\mathrm{SSO})$ reduced the palmitate uptake rate in both non-treated and PMA-treated cardiac myocytes to the same level of approximately 13 nmol.g cell mass ${ }^{-1}$ min $^{-1}$ (Fig. 5.2)

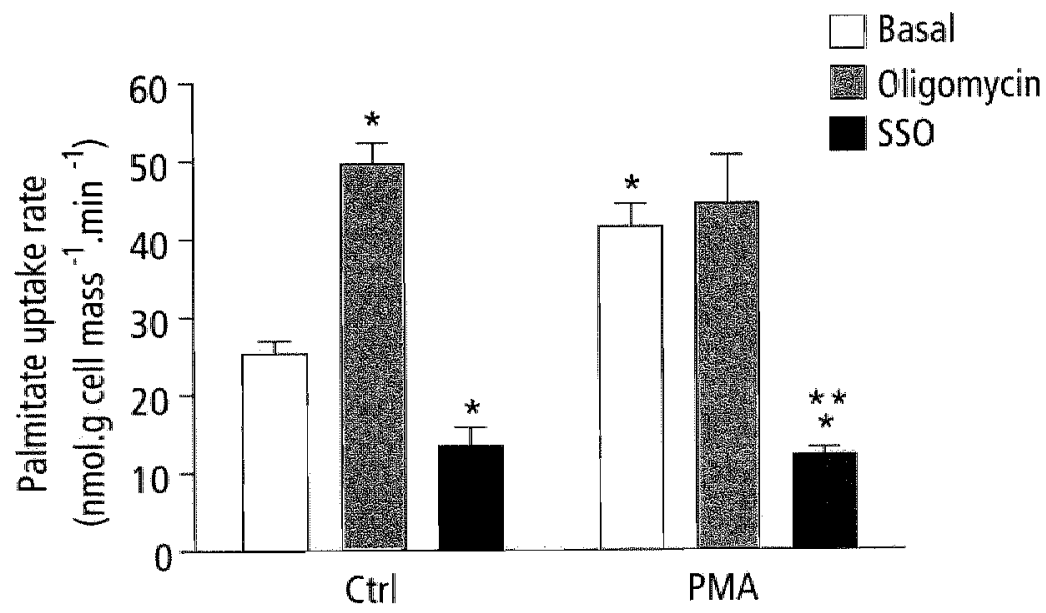

Figure 5.2: Effects of oligomycin and SSO on the palmitate uptake rate in cardiac myocytes either non-treated or PMA-treated.

Isolated rat cardiac myocytes were preincubated for /i $15 \mathrm{~min}$ at $37^{\circ} \mathrm{C}$ either non treated / Basal/ or reated with 30

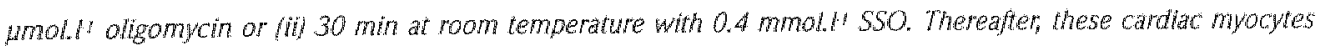

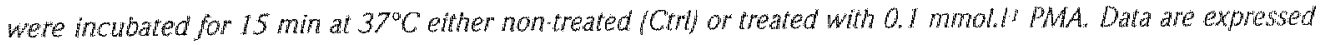
a.s nwolg cell mass' "min" and presented as means \pm . E.M., $n=3$. "Significancly different from control /Basal" cardiac myocytes, $p<0.05$ and * Significantly different from PMA-theated controt cardiac myocytes, $p<0.05$. 


\section{Dose dependent effect of staurosporine on the oligomycin-induced palmitate uptake rate in cardiac myocytes}

To inhibit the kinase activity of PKCs staurosporine was used. Staurosporine is a bacterial alkaloid with an inhibitory activity against several serine/threonine kinases ${ }^{22}$. In cardiac myocytes staurosporine inhibited the oligomycin-induced palmitate uptake rate in a dosedependent manner (Fig. 5.3). At 0.01 umol..$^{-1}$ staurosporine inhibited the palmitate uptake rate by $16 \%$, whereas at 0.1 and $1 \mu$ mol..$^{1}$ staurosporine completely blunted the stimulatory effect of oligomycin (Fig. 5.3).

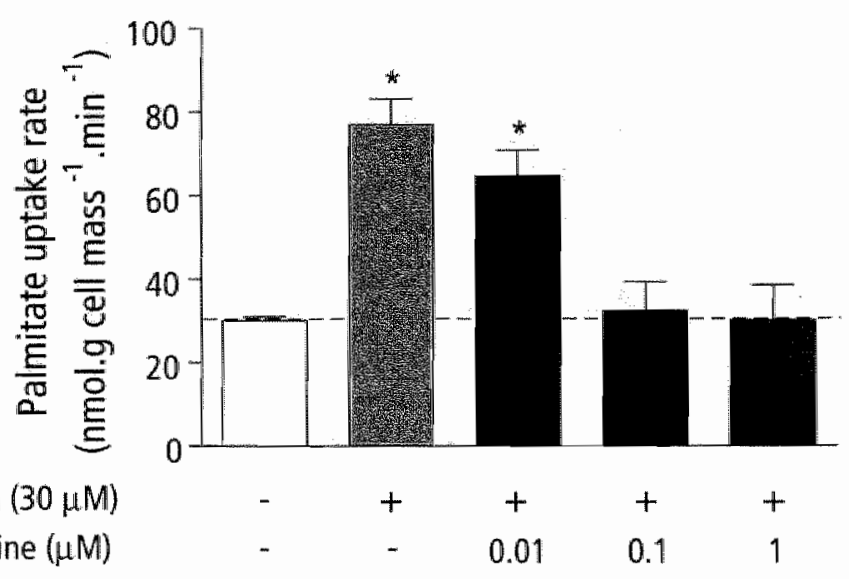

Figure 5.3: Effect of staurosporine on the ollgomycin induced palmitate uptake rate by cardiac myocytes. I.solated rat cardiac myochtes were preincubated for 15 min at $37^{\circ} \mathrm{C}$ either non treated or treated with various concentrations $10.01,0.1$ and / umol.14 of staturasporine, Thereafter, these cardiac myochtes were incubated for 15 min at $37^{\circ} \mathrm{C}$ either montreared or treated with 30 umol.h digomycin. Data are presented as molg cell mass.

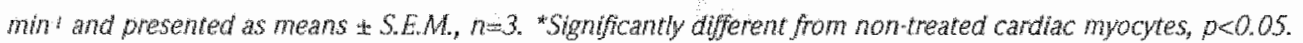

\section{Effect of oligomycin and staurosporine on phosphorylation of acetyl-CoA carboxylase}

To investigate the position of PKC relative to AMPK we determined AMPK activity in cardiac myocytes in which the PKC activation is inhibited by staurosporine. AMPK activity was indirectly determined by measuring phosphorylation of ACC at Ser79, one of the main downstream targets of AMPK. Phosphorylation of ACC at Ser79 was significantly increased in oligomycin-treated cardiac myocytes (Figs. 5.4). When pre-treated with the PKC inhibitor staurosporine, phosphorylation of ACC induced by oligomycin was inhibited in cardiac myocytes (Fig. 5.4). 


\section{Phospho-ACC (Ser79)}

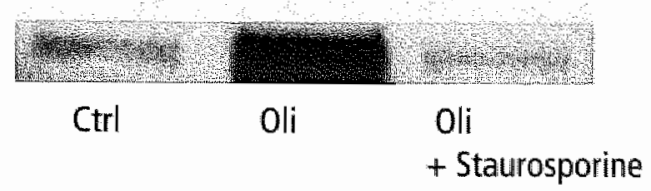

Figure 5.4: Effect of staurosporine on oligonycin-induced phosphorylation of acetyl-CoA carboxylase.

Isolated rat cardiac myocytes were preincubated for $15 \mathrm{~min}$ at $37^{\circ} \mathrm{C}$ either non-treated (Ctri) or treated with 1 umols staurosporine, thereafter these cardiac myocytes were incubated for $15 \mathrm{~min}$ at $37^{\circ} \mathrm{C}$ with 30 , wholl ollgomycin 1Oll. In $20 \mathrm{\mu g}$ of total homogenates of these cardiac myocyles protein content of phosphorylated ACC was measured by Westem bloting using an antibody directed against the phosphorylated Ser79. A representatwe Western biat is presented.

\section{Effect of oligomycin and PMA on translocation of PKC $\alpha, \delta$ and $\varepsilon$}

Total PKC $\alpha, \delta$ and $\mathrm{e}$ protein content was not altered in cardiac myocytes treated with eithel" oligomycin or PMA compared to non-treated cardiac myocytes (Fig. 5.5). Oligomycin had no effect on the protein content of $\mathrm{PKC} \alpha, \delta$ and $\varepsilon$ in membrane and cytosolic fractions (Fig. 5.5). However, PMA markedly decreased PKC $\alpha, \delta$ and $s$ protein content in the cytosolic fraction, whereas in the membrane fraction the protein content of these PKCs was markedly increased (Fig. 5.5).

\section{PKC alpha}

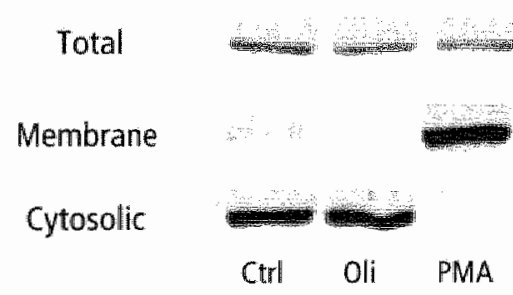

PKC delta

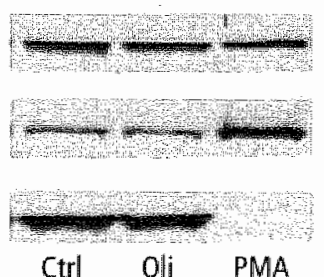

PKC epsillon

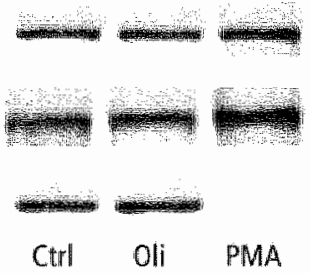

Figure 5.5: Effect of oligomycin and PMA on the translacation of PKCa, $\delta$ and $\mathrm{E}$ in cardiac myocytes.

Isolated rat cardiac myocytes were inculated for 15 min at $37^{\circ} \mathrm{C}$ either non-treated (Ctrl) or treated with 30 umol. oligomycin (Oti) or 0.1 mmol." PMA. A small part of these cardiac myocytes were used for total homogenates and the remaining part was fractionated in membrane and cytasolic fractions /see expertmental design and methods/. in $20 \mathrm{Hg}$ of total homogerates, membrane and cytosolic fractions protein content of $\mathrm{PKCO}$, of and $\mathrm{E}$ was measured by Westem bothing using antibodies directed against the different PKC isoforms. Representative Western blots are presented. 


\section{Effect of oligomycin and PMA on phosphorylation of PKCa (Thr638) and PKC8 (Ser643)}

Activation of PKC occurs not only upon translocation from the cytosol to the plasma membrane, but also by phosphorylation. Therefore, we determined in the present study the phosphorylation of PKCa and 8. Phosphorylation of PKCa at Thr638 and PKCO at Sero 43 in cardiac nyocytes was not influenced by oligomycin (Fig. 5.6). PMA had also no effect on the phosphorylation of PKC $\alpha$ at Thr638, whereas it induced phosphorylation of PKCS at Ser643 in cardiac myocytes (Fig. 5.6).

\section{Phospho-PKC alpha}

\section{Thr638}

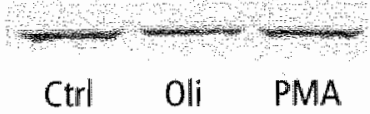

\section{Phospho-PKC delta}

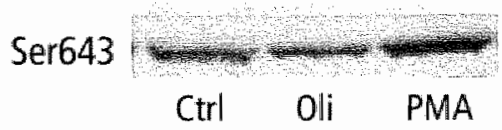

Figure 5.6: Effect of oligomycin and PMA on phosphorylation of PKCO. (Thr638) and PKCS. (Ser643) in candiac myocytes:

Isolated rat cardiac myocytes were incubated for $15 \mathrm{~min}$ at $37^{\circ} \mathrm{C}$ either non-treated /Ctrl/ or treated with 30 pincl th aligomycin (Oli) or 0.1 mmolt PMA. Fotal homogenates were prepared from these cardac myocytes. In $20 \mathrm{ug}$ of these homogenates protein content of phosphorylated PKCa and 8 was measured by Western blotting using antibodies directed against the phosphoryled Thro38 at PKCO and the phosphorylated Serb43 at PKCO. Representative Western blots are presented.

\section{Discussion}

In the present study the following observations were made, (i) PMA induced the palmitate uptake rate in isolated rat cardiac myocytes and the effect was not additive to the oligomycininduced palmitate uptake rate, (1i) staurosporine reduced the myocardial paimitate uptake rate to basal levels and inhibited oligomycin-induced ACC phosphorylation, (iii) PMA induced the transislocation of $\mathrm{PKC \alpha}, \delta$ and $\varepsilon$ from the cytoplasm to the sarcolemma, whereas oligomycin had no effect on the translocation of these PKC isoforms, (iv) PMA induced phosphorylation of PKCO (Ser643), but not of PKCQ (Thro38), in cardiac myocytes, and (v) oligomycin had no effect on phosphorylation of both PKCa (Thro38) and PKCo (Ser643).

\section{Involvement of PKCs in the oligonycin-induced palmitate uptake rate by cardiac myorytes}

To investigate whether PKGs are involved in oligomycin-induced palmitate uptake we either stinulated or inhibited PKC activation in cardiac myocytes and determined if the palmitate uptake rate is still inducible by oligomycin. To translocate and thereby activate conventional and novel PKCs, PMA, a cell-permeable DAG analog, was used. PMA induced the myocardial palmitate uptake rate in the same manner as oligomycin. Interestingly, the effect of oligonycin on the 
palmitate uptake rate was not additive to the effect of PMA, strongly suggesting the involvement of one (or more) of the PKC isoforms. When inhibiting PKC activation with staurosporine, the oligomycin-induced palmitate uptake rate was reduced to basal levels. It is well known that staurosporine inhibits not only the activity of $\mathrm{PKC}$, but also that of cyclic-adenosine monophosphate (CAMP)-dependent protein kinases (PKA)23-25. However, earlier we demonstrated that changes in intracellular CAMP concentrations have no influence on the FAT/CD36-mediated palmitate uptake by cardiac myocytes26, suggesting that PKA is not involved in the regulation of palmitate uptake. Therefore, the inhibitory action of staurosporine also points towards the involvement of one (or more) PKC isoforms in the oligomycin-induced palmitate uptake.

The involvement of FAT/CD36 in the PMA induced myocardial palmitate uptake rate was investigated with SSO. SSO binds covalently to FAT/CD36 thereby specifically blocking its activity, which results in a decreased uptake rate of palmitate27 (see Chapter 8). Since SSO inhibited palmitate uptake to the same residual level in both non-treated and PMA-treated cardiac myocytes is it believed that FAT/CD36 is involved in the effect of PMA on palmitate uptake. Collectively, these data indicate that PKC activation is indeed involved in the intracellular signalling pathway induced by oligomycin leading to FAT/CD36-mediated palmitate uptake by cardiac myocytes.

\section{Positioning of PKCS relative to AMPK in the contraction-signalling pathway}

A first set of experiments was performed to investigate the positioning of PKCs relative to AMPK in the contraction-signalling pathway in cardiac myocytes was investigated. We inhibited PKC activity in cardiac myocytes with staurosporine and thereafter it was investigated whether oligomycin is still able to induce AMPK activity.

AMPK has been characterized as a "metabolic master switch" that regulates substrate utilization. Both phosphorylation at Thr172 by an upstream AMPK kinase (AMPKK) and the intracellular AMP/ATP ratio regulate the activity of AMPK 0,28 (see for more detail Chapter 3). Cardiac AMPK is activated by exercise ${ }^{29}$, myocardial ischemia ${ }^{30,31}$ and pharmacologically by oligomycin (a $\mathrm{F}_{1} / \mathrm{F}_{0}$ ATPase that indirectly activates AMPK by elevating the AMP/ATP ratio) ${ }^{5}$ and AICAR, which is phosphorylated into ZMP (an AMP analog that directly activates AMPK ${ }^{32}$. Recently, it has been shown that LKB1, a tumor suppressor, can phosphorylate and activate $\mathrm{AMPK}^{33}$. However, exercise, $\mathrm{AICAR}^{34}$ and myocardial ischemia ${ }^{31}$, all activating AMPK, had no effect on LKB1 activity. We speculate that members of the PKC family are possible candidate upstream AMPKKs. This is in line with recent findings of Nishino and coworkers $^{35}$ who showed that ischemic preconditioning of cardiac myocytes against myocardial stunning activated AMPK in a PKC-dependent manner.

In the present study we measured the activity of AMPK indirectly by the phosphorylation at Ser79 of ACC, one of the main downstream targets of AMPK 36,37 . Here, we confirmed that phosphorylation of A.CC was induced in cardiac myocytes treated with oligomcyin, indicating that AMPK activity increases. When using staurosporine, which inlibits PKC phosphorylation the oligomycin-induced ACC phosphorylation is markedly reduced. Taken together, these data implicate that PKCs may be upstream targets of AMPK (Fig. 5.7), however additional studies, such as in vitro kinase assays, are needed to further elucidate this. 


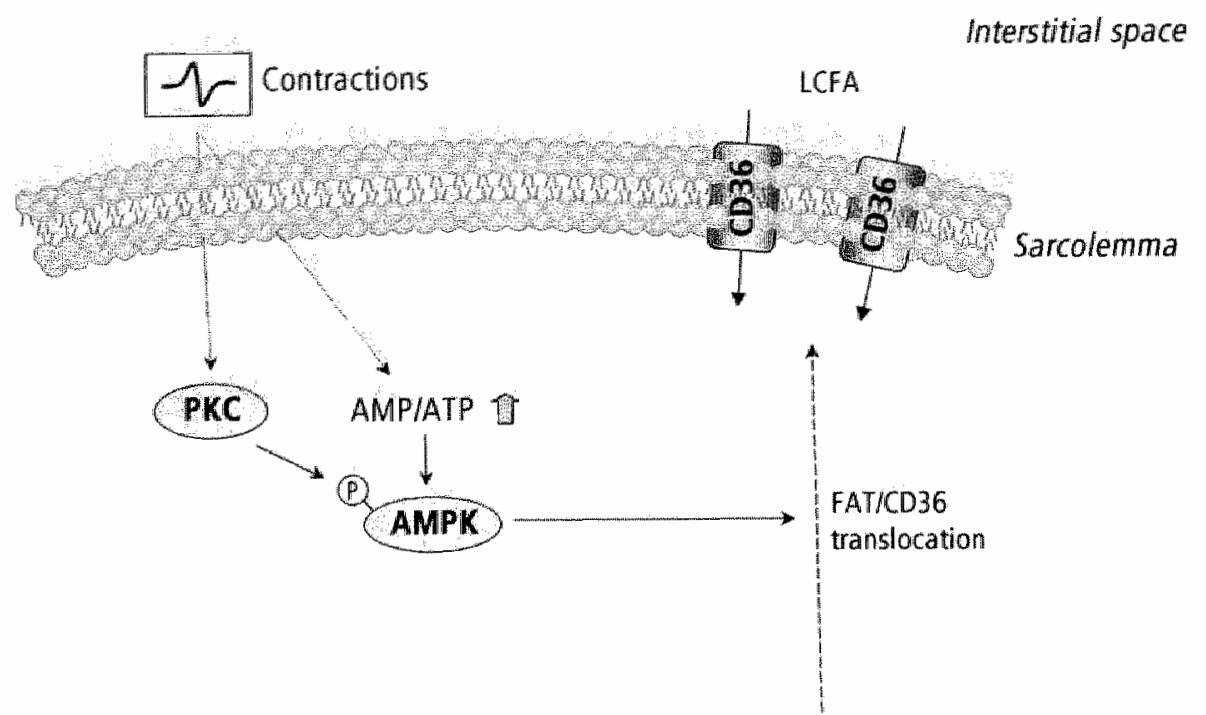

Cytoplasm

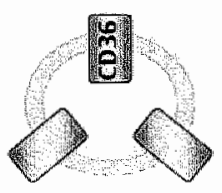

Figure 5.7: Hypothettcal model of the signalling pathway inwolved in contraction-induced FAT/CD36 translocation and LCFA uptake.

Upon cellular contractions the intracellular. AMP/ATP ratio increases and it is believed that one for morel PKC isoform/s/ is/are/ activated. Both effects result in an induction of the AMPK activity leading to the transtocation of FATYCD36 from an intracellular storage compatment to the sarcolenma. Due to an increased sarcolemmal amount of FAT/CD 30 present at the sarcolemma more LCFAs are transported across the sarcolemma into the cytoplasm of the cardiac mooyte.

\section{PKC $\alpha_{4} 8$ and $\varepsilon$ are not translocated by aligomycin in cardiac myocytes}

Since PKC activation is likely to be inwolved in oligomycin-induced paimitate uptake, we were interested in which PKC isoforms are activated by oligomycin. Here, we focussed on PKCa, $\delta$ and $\varepsilon$, the major conventional and novel PKC isoforms present in cardiac myacytes. Processes leading to the activation of PKC are (i) translocation from an inactive soluble form to an active membrane bound form and/or (ii) phosphorylation of distinct sites at the activation loop and the C-terminal region. The present study confirms that in cardiac myocytes PMA is able to translocate PKCa, $\delta$ and $\varepsilon$ from the cytosolic fraction to a membrane fraction 15 . However, oligomcyin had no effect on the subcellular distribution of $\mathrm{PKCa}, \delta$ and $\varepsilon$ in the cardiac myocytes. These data suggest that the PKC isoforms $\alpha, \delta$ and $\varepsilon$ are not translocated and hence 
activated upon oligomycin-induced AMPK activity. However, activation of these PKC isoforms via phosphorylation could still be involved in the signalling pathway induced by oligomycin and resulting in FAT/CD36-mediated palmitate uptake. In contrast to these findings is a study by Tsouka and coworkers 38 who demonstrated that in adult rat cardiac myocytes subjected to ischemia, a condition known to activate AMPK, PKCa and $\mathrm{E}$ were translocated to the membrane, whereas the subcellular distribution of PKC $\delta$ was unaltered.

\section{Effect of PMA and oligomycin on phosphorylation of PKC $\alpha$ (Thr638) and PKC\& (Ser643) in cardiac myocytes}

Traditionally, PKC translocation is considered as a hallmark for determination of PKC activation. However, when investigating PKC activity, studies in which only PKC translocation is determined and not PKC phosphorylation, are incomplete. We measured phosphorylation of different PKC isoforms by Western blotting using antibodies directed against the specific phosphorylation sites of the various PKC isoforms. The PKC isoforms contain multiple phosphorylation sites, however not all phosphorylation sites are involved in PKC activation. In the present study we determined two phosphorylation sites, i.e., Thr638 at PKC $\alpha$ and Ser643 at PKC 8 . We will integrate the effect of PMA and oligomycin on phosphorylation of these sites with current ideas on phosphorylation events leading to the activation of each specific isoform.

\section{Phosphorylation of PKCQ}

Until now three distinct sites at the PKCa molecule are known to be phosphorylated, i.e., Thr497, Thr638 and Ser657. The Thr638 is present at the catalytic domain of PKC $\alpha$ and is not required for the activation of $\mathrm{PKC} \alpha$, but serves to control the duration of the activation by regulating the rate of dephosphorylation and inactivation of this PKC isoform ${ }^{39}$. This is achieved through the cooperative interaction between Thro 38 and the catalytic core site, Thr497. We demonstrated that neither oligomycin nor PMA had an effect on phosphorylation of PKC $\alpha$ at Thr638 in cardiac myocytes, which does not exclude that other sites at the PKC $\alpha$ molecule can be phosphorylated upon oligomycin treatment. It has been shown that phosphorylation at Thr497 plays a dominant role in the regulation of PKC $\alpha$ activity ${ }^{40}$. Replacement of the Thr 497 phosphorylation site by an alanine resulted in a kinase that could not be activated ${ }^{40}$. The third phosphorylation site of PKCa is Ser657, which is located near the C. terminal region of the molecule ${ }^{41}$. The replacement of Ser 657 by alanine caused a $70 \% 10$ ss of the catalytic activity as well as a drastically increased downregulation upon translocation of this isoform to the membrane when induced by phorbol esters ${ }^{42}$. Moreover, it was demonstrated that phosphorylation at Ser657 controls the duration of PKC $\alpha$ activation upon agonist-induced translocation by protecting the protein from dephosphorylation ${ }^{43}$. To investigate whether PKC $\alpha$ is activated by phosphorylation the study should be extended with experiments that determine the phosphorylation of Thr497 and Ser657 in oligomycin-treated cardiac myocytes.

\section{Phosphorylation of PKCS}

At the PKC $\delta$ molecule there are two distinct serine/threonine phosphorylation sites identified, i.e., Thr505 and Ser643. The Ser643 at PKCo is an autophosphorylation site at the C-terminal 
region that plays an important role in controlling the enzymatic activityad, but it is not essential for the kinase activity of PKC845. Here, we demonstrated that in cardiac myocytes PMA increased the phosphorylation of PKC 8 at Ser643, whereas oligomycin has no effect on this. phosphorylation site. In accordance with this effect of PMA is the PMA-induced Ser643 phosphorylation at PKC 8 in NH 3 T3 cels demonstrated by Srivastava and coworkers ${ }^{46}$. The other identified phosphorylation site, Thr505, which is located at the activation loop of PKCO. is also not essential for obtaining a catalytically competent conformation of $\mathrm{PKC} \mathrm{S}^{47}$. Another interesting effect of PMA is that it leads to phosphorylation of multiple tyrosine residues in the regulatory domain of the PKCS molecular thereby influencing its activity 48.49 . To investigate whether PKC8 is activated upon oligomycin treatment via phosphorylation it should first be clear which phosphorylation sites are involved in $\mathrm{PKC \&}$ regulation and whether oligomycin modulates tyrosine phosphorylation of PKCO.

\section{Phosphorylation of PKCE}

At the molecule of PKCe three distinct phosphorylation site, i.e., Thr566, Thr710 and Ser729, are identifed. Thr566 is present at the activation loop and can be transphosphorylated 17 . Both Thr710 and Ser729 are autophosphorylation sites and present at the C-terminal region ${ }^{17}$. It has been demonstrated in human embryonic 293 cells that PDK1 induces phosphorylation of Thr560 and Ser72950. It is unknown whether phosphorylation of PKCE is induced in aligomycin-treated cardiac myocytes.

Phosphorylation of PKCs is believed to be important for their activation. However, for most PKC isoforms it is incompletely understood which phosphorylation sites are crucial for their activation and regulation. Thus, from data presented in this study we cannot determine whether oligomycin affects the activity of $\mathrm{PKC} \alpha, \delta$ and $\varepsilon$ via alterations in the phosphorylation pattern of these isoforms.

\section{Cowchuling remarks and whther perspectives}

The present study strongly suggests that PKC isoforms are involved in the oligomycin-induced palmitate uptake by cardiac myocytes. However it still remains obscure which isoforms are activated and whether activation occurs wa translocation and/or phosphorylation. It is clear that in activating palmitate uptake with oligomcyin translocation of $P K C \alpha, \delta$ and $x$ did not occur. Morecver, we demonstrated that the PKC isoform involved in the oligomycin-induced palmitate uptake should have a DAGbinding domain, since the increase of pamitate uptake by PMA is not additive to the one mediated by oligomycin.

In the present study the role of atypical PKCs in oligomycin-induced palmitate uptake was not investigated, because this PKC sublamily is not activated by PMA. However, studies in both rodent and human skeletal muscle demonstrated that upon exercise and electrical stimulation aPKCs translocate to the membrane, whereas the subcellular distribution of $\mathrm{PKC} \alpha, \delta$ and $\varepsilon$ remained unaltered 5.53 . These findings suggest that aPKCs could play a role in the effect of oligomycin.

Since we are interested in the contraction-pathway resulting in FAT/CD36-mediated LCFA uptake by cardiac myocytes the involvement of PKC isoforms in electrically-stimulated 
cardiac myocytes should be investigated. Both oligomycin and electrical stimulation elicit similar stimulatory effects on ACC phosphorylation and FAT/CD36-mediated palmitate uptake, however electrical stimulation resembles the physiological situation better than oligomycin.

In identifying whether PKCs are upstream targets of AMPK some unresolved issues should be addressed. First, the PKC isoform(s) that is (are) activated by oligomycin in cardiac myocytes should be identified. Second, in vitro kinase assays should demonstrate that the oligomycininducible PKC(s) can activate AMPK. Third, ideally specific activation of PKCs possibly involved in palmitate uptake during contractions should be investigated in cardiac myocytes lacking AMPK. 


\section{REFERENCES}

1. Gryberg A and Demasson L. Fatty acid oxidation in the heart. $/$ Cardowase Phamacol 1096283 Supp 1:5117.

2. Neely JR, Rovetio MI and Oram JE. Mrocardial utilization of carbohydrate and lipids. Prog Cardiowasc Dis. $1972 ; 15: 289.329$.

3. van der vusse GJ, Glatz JF, Stam HC and Reneman RS. Faty acid honeostasis in the nomoxic and ischenic heart. Physiol Rey 1902;72:881,040.

4. Luken I, Willens I, van der Wusse GJ and Glatz JF Electrosimulation enhances FAT/CD36-mediated Iong chain faty acid uptake by isolated rat cardiac myocytes. Am / Physol Endocinol Metab. 2001;281:1:704-12.

5. Luiken JI, Coort SL. Willems I, Coumans WA, Bonen A, van der Vusse Gll and Glatz JE Contaction-induced fatty acid transtocase/CD36 translocation in rat cardiac myocytes is mediated through AMP-activated protein kinase signaling. Diatetes. 2003:52:1627-34.

6. Hardie DG. AMPactivated protein kinase: a master switch in glucose and lipid mekabolism. Rev Endoc Metab Disord. 2004:5:110.25.

7. Ha J, Danied S, Broyles SS and Kim KH. Critical phosphorylation sites Ior acetyl-CoA carboxylase acivity. / Bto Chen2. 1904;260:22162.8.

8. Eaton S. Control of mitochondrial beta-oxidation flux. Prog Lipid Res. 2002;41:197-239.

9. Toker A. Signaling through protein kinase C. Front Biosci. 19983:D1134-47.

10. Malhotra A, Kang BP, Opawumi D, Belizaire W and Meggs LG. Molecular biology of protein kinase $C$ signaling un cardiac myocytes. Mol Cell Biochem, 2001;225:97-107.

11. Carson LD and Korzick DH. Dose-dependent effects of acute exencise on PKC levels in rat heart: is PKC the heart's prophylactic? Acta Physiof Scand. 2003;178:97-100.

12. Braz JC, Gregory K, Pathak A, Zhao wh, Sahn B, Klewisky R, Kimball TF, Lorenz IN, Naim AC, Ligget SB, Bodi I, Wang S, Schwartz A, Lakatta EG, DePaolirRoach AA, Robbins. I, Heweti TE, Bibb IA, Westrall MV, Kranias EG and Mokentin JD. PKC-alpha regulates cardiac contractility and propensity toward heart fallure. Nat Med. $2004 ; 10: 248 \cdot 54$

13. Newton AC. Protein knase $\mathrm{C}$ structure, Function, and regulation. J Biol Chem. 1995;27028495.8.

14. Huang KP. The meclyanism of protein kinase C acivation. Trends Newrow 1089;12:425-32.

15. Puceat M, Hial-Dandan $R$, Strulovici B, Brumton LL and Brown JH. Diferental regulation of protedin kinase C Swoforms in isolated neonatal and adult rat cardiomyocytes. I Brol Chem. 1994:260:16938-44.

16. Keranen LM, Dutil EM and Newton AC. Protein kinase $C$ is regulated in vivo by three funclionaly distinct phosphorylations. Curr Biol 1995:5:1304.403.

17. Parekh D, Legler W, Yonezawa K, Hara $K$ and Parker PJ. Mammalian IOR controls one of two knase pathways acting upon nPKCdelta and nPKCepsilon. / Biol Chem. 1999;274:34758-64.

18. Mochly-Rosen D and Gordon AS. Anchoring proteins for protein kinase C: a means for isozyme selectivity. Faseb 1. $1998 ; 12: 3542$.

19. Staros N. Mhydroxysuffosuccinimide active esters: bis (Nhydroxysulfosuccinimidel esters of two dicarboxylic actids are hydrophilic, membrane mperneant, pratein cros sinkers. Bochemistry. 1982;21:39505.

20. Fischer $\mathrm{Y}$, Rose $\mathrm{H}$ and Kammetmeter H. Highly insuin responswe isolated rat heart muscle cells ylelded by a modiffed isolation method. Life Sc. 1091:40:1079.88.

21. Luken II, van Nienwemhoven FA, America $G$, van der Vusse GI and Glanz IE. Uphake and metaholism of palmitate by isolated cardiac myocytes from adult rats: involvement of satcolemnal proteins. J Lipid Res. 1997,38:745.58. 


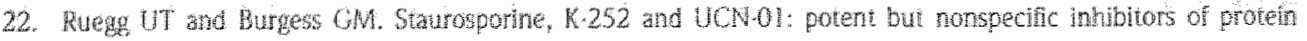
kinges. Tends phamacol Sel $1989 ; 1021820$.

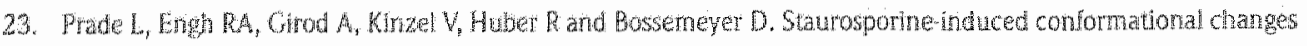

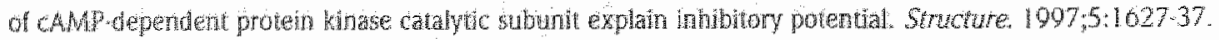

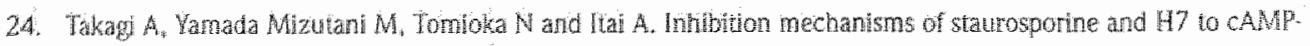
dependent protein wase though docking study. Chem Pham Bull Tokol. 1996,44,61820.

25. Budworth and Gescher A. Differental whibiton of chtosolic and membranederwed protein knase $\mathrm{C}$ actwity by statrosporine and other kinase inhtotors. FEBS Let. 1905;362:130-42.

20. Luken I. Wiltens I. Coor SL, Coumans WA, Bonen A, Van Der Vusse Gl and Gatz IF Effects of cAMP modutariors on longchain tatty-acid uptake and utilization by elecricaly stimulated tat cardiac myocyces Biochem 1. 2002;367:881.7.

27. Coor SL, Willems J, Coumans WA, van der Wusse GJ, Bonen A, Glatz JF and Luiken JJ. Sulto N-succinimidyl esters of long chain faty adds specticaly inhbit faty acid transiocase (FAT/CD36) mediated cellular fatry acid uptoke. Mol Cell Bochem. 2002,239:2139.

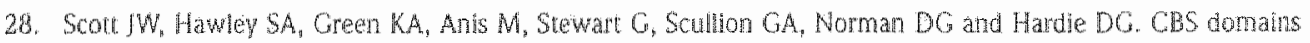
form energy-sensing modules whose binding of adenowine ligands is distupted by disease mutations. / Clin Invest $2004 ; 113: 27484$.

29. Coven DL Hu $X$, Cong $L$, Bergeron R, Shalman GI, Harde DG and Young LH. Prysiological role of AMP.

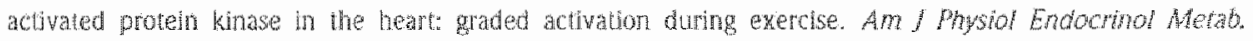
$2003 ; 285: 1029 \cdot 30$

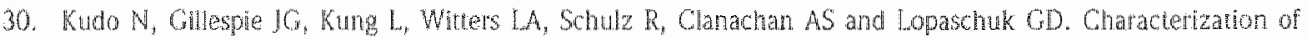
5AMPactiwated protein kinase activity in the heat and its role in inhibiting acety-CoA caboxylase during reperfusion following ischema. Biochin Bophys Acta. 1900;1301:67.75.

31. Altarejos YY, Taniguch M, Clanachan AS and Lopaschuk OD. Myocardial Ischemia Differentialy Regulates LKBI and an Alternate 5".AMPactivated Protein Kinase Kinase. J Bol Chem. 2005;280:183-90.

32. Sullwan If, Brockehurst KI, Mafley AE, Carey F, Canting D and Ber RR. Inhibition of lipolysis and ipogenesis in isolated rat adpocytes with ACAR, a cellpermeable activator of AMP-activated protein kinase. FEBS Let. 190, 353333.6 .

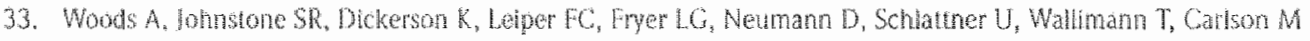

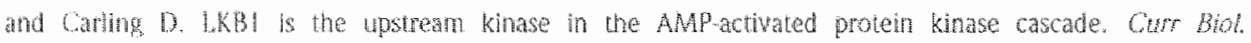
$2003 ; 13: 20048$.

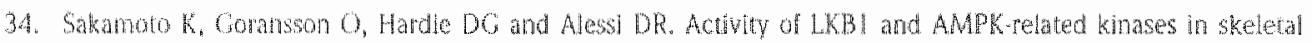

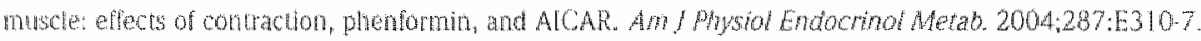

35. Nishina Y. Mura T. Miki T, Sakamoto J. Nakamura $\psi$, Keda $Y$, Kobayashi $H$ and Shimamoto $K$. Ischenic precondinoning adtuates. AMPK in a PKC dependen manner and induces GLUTA up-Eegulaton in the late phase of cardiopotection. Cardionase hes. $2004,610109$.

36. Winder WW, Mitson HA, Hardie DG, Rasmussen EB, Huther CA, Cal GR, Clayton RD, Contey LM, Yoon Sand

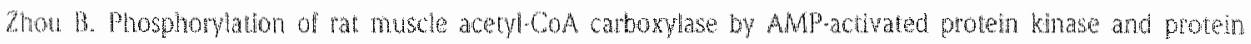
kinase A. J Appl Physiod 1097:82:21925.

37. Murdal MR Regulaton of manmalian acetwl CoA carboxylase. Btochem Son Trans. 2002;30: 1059-64.

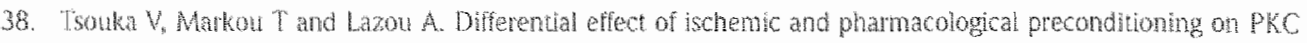

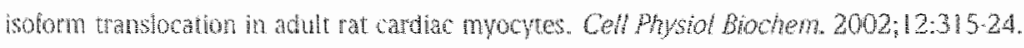


39. Bomancin F and Parker Pl. Phosphoryation of threonine 638 critically controls the dephosphorytation and macrivation of proten kinase Calpha. Curr Brot 1990;0:111423.

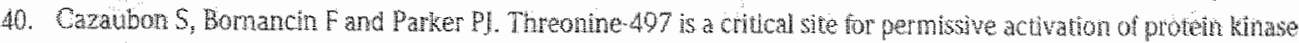
Calpha. Biochem ). 1094;301 ( Pt 21:443-8.

41. Bomancin F and Parker P1. Phosphorylation of protein kinase G alpha on serine 657 controls the accumbutaton of active enzyme and contributes to is phosphataseresistant sate. / bol Chem. 1997272,35449.

42. Gysin S and Imber R. Replacement of Ser657 of protein kinase Calpha by abmine leads to premature down

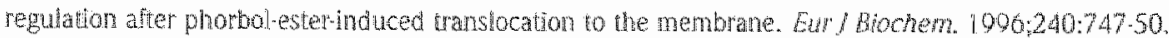

43. Gysin $S$ and tmber R. Phorbolesteractiwated protein knase Calpha lacking phosphorylation at Sero57 is downregulated by a mechanism inwowng dephosphorytaton. Eup / Brochem. 1097249:15060.

44. Li W, Zhang I, Bottaro DP and Pierce JH. Identification of serine 043 of protein kinase Cdelta as an mpotant autophosphorylation site for its enzymatic activity. I Btol Chen. 1907:272:24550-5.

45. Stempka L, Schnolzer M, Radke S, Rincke G, Marks F and Gschwendt M. Reguirements of protetn knate colta for catalytic function. Role of glutanic acia 500 and autophophorylation on seme 643 . I Bol Chem. $1099 \cdot 274: 8980.92$

46. Srivastava J, Procyk KJ, Jurrioz $X$ and Patker PI. Phosphorylation is reçured for PMA and celloyde induced degradation of protein kinase Cdelta. Biochent /. 2002,308:34055.

47. Stempka L, Girod A, Muller HI, Rincke G, Marks F, Gschwend M and Bossemwer D. Phosphontiation of protein kinase Cdelta [PKCdela] at threonine 505 is not a prerequisite for enzmatic activity. Expression of at PKCdetta and an alanine 505 mutant in bacteria in a functional form. / Bto Chen 1997,272,6805-11.

48. Brodte C. Bogi K, Acs P, Lorenzo PS, Baskin L and Blumberg PM. Protein kinase C delta (PKCdelan inhibits the expression of glutamine synthetase in ginal cells wia the PKCdelta regulatory domain and its tyrasine phosphorylation. I Biol Chem. 1998;273:307138.

49. Kronted I, Kazmirsky G, Lorenzo PS, Garfied SH, Blumberg PM and Brodie C. Phosphorytation of protein kinase Cdelta on distinct tyrosine residues regulates specific cellual functions. J Biol Chen. 2000,27535491-8.

50. Cenni $V$ Doppler H, Somnenburg ED, Maraldi N, Newton AC and Toker A. Regulation of novel protein kinase Cepsion by phosphorytation. Biochem /. 2002,363,53\%45.

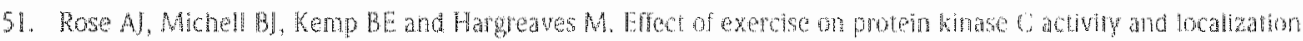

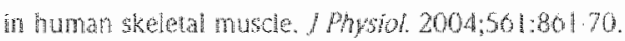

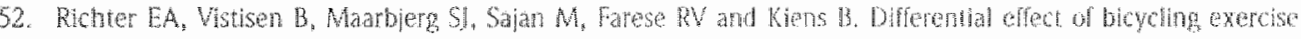

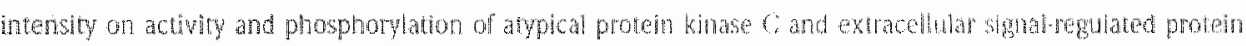
kinase in skeletal muscle. I Phwsio 2004,56090918.

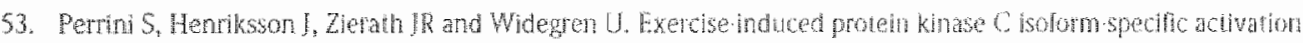
in thuman skeletal muscle. Dabetes. 2004,53.21-4. 


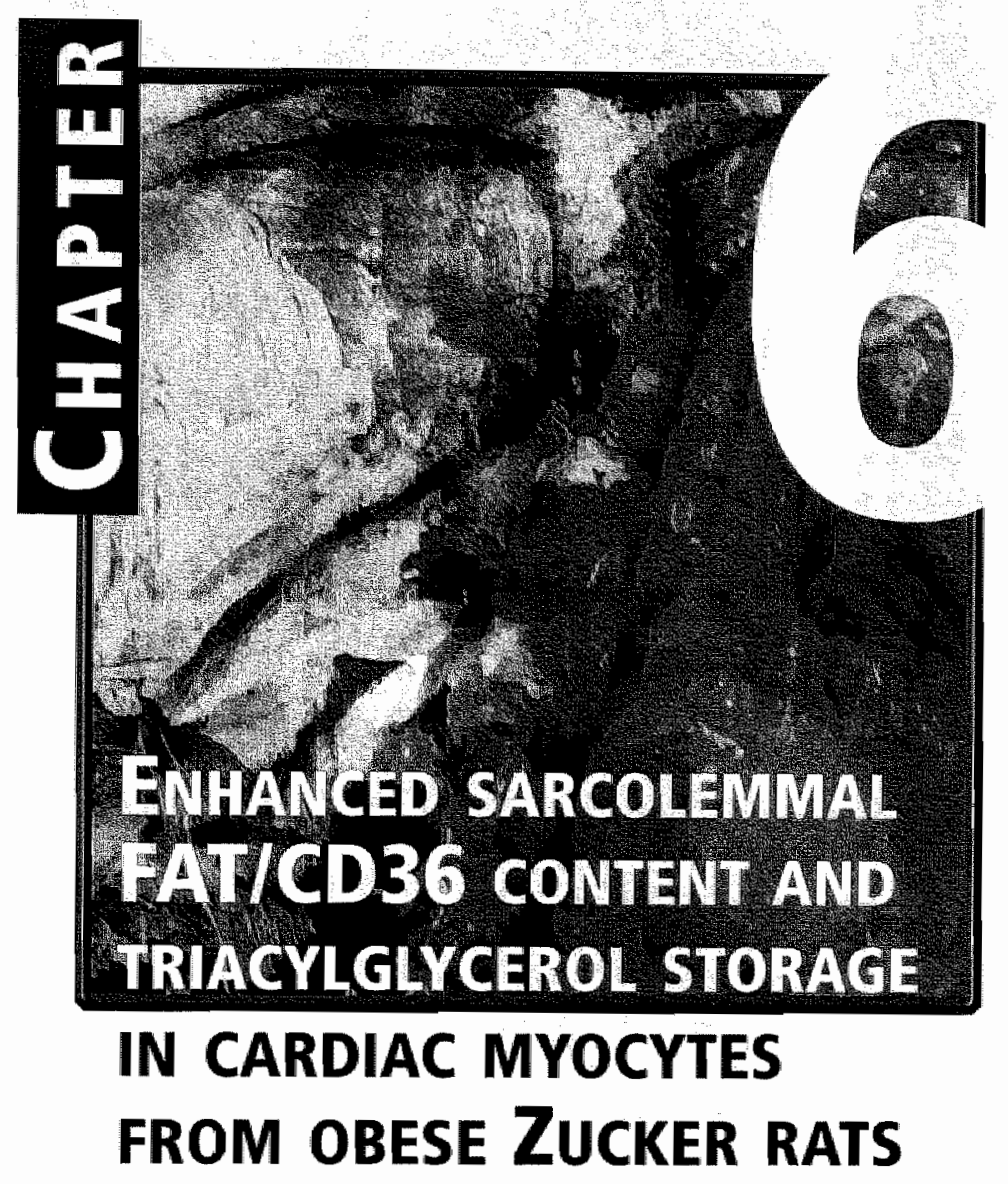

Susan L.M. Coort'1, Danny M. Hasselbaink2, Debby P.Y. Koonen ', Jodil Willems ${ }^{1}$, Will A. Coumans ${ }^{1}$, Adrian Chabowski ${ }^{3}$, Ger J. van der Vusse ${ }^{2}$, Arend Bonen ${ }^{3}$, Jan F.C. Glatz ${ }^{1}$, and Joost J.F.P. Luiken 1,4

Diabetes 2004:53;1655-63.

Biochem Soc Trans. 2004:32;83-5.

"Departments of Molecular Gesetics and 2Physiology, Cardiovascular Research Institute Maastricht (CARIM)" Maastricht University, Maastricht, the Netherllands.

Department of Human Biology and Nutritional Sciences, Guelph University, Guelph, Ontario, Canada.

¿Department of Biochemical Physiology and Institute of Biomembranes, Utrech University, Utrechi, the Netherlands. 


\section{ABSTRACT}

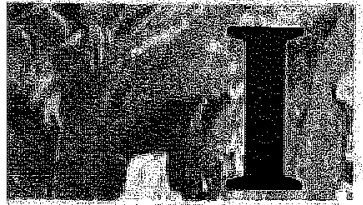

n obesity, the development of cardiac dysfunction is associated with the accumulation of myocardial triacylgycerols (TAGs), possibly stemming from elevation of myocardial long chain fatty acid ( CFA) uptake, Because LCEA uptake is regulated by insulin and by contractions, we examined in cardiac myocytes from lean and obese Zucker rats he effects of (i) insulin, and lif the contraction-mimetic agent oligomycin on (a) initual rates of LCFA and deoxyglucose 10 take, (b) subcellular distribution of FAT/CD36, and (C) LCFA metabolism. In cardiac nyocytes from obese 2 ucker rats, under basal conditions, FAT/CD 36 was relocated to the sarcolemma at the expense of intracellular storage compartments. In addtion, the LCFA uptake rate, the LCFA esterification rate into TAGs, and the intracellular unesterified LCFA concentration each were significantly increased. All these metabolic processes were normalzed by the FAT/CD 36 inhibitor sulfo-Nstccinimidyl oleate, indicating its antidiabetic potential. In cardiac myocytes isolated from lean rats, in vitro administration of insulin induced the translocation of FAT/CD 36 to the sarcolemma, and stimulated initial rates of LCFA uptake and TAG esterification. In contrast, in myocytes from obese rats insulin falled to alter the subcellular localization of FAT/CD 36, and the rates of LGFA uptake and TAC esterification. In cardiac myocytes from lean and obese animals aligomycin stimulated the initial rates of LCFA uptake and oxidation, although oligomycin only induced in lean rats the translocation of FAT/CD36 to the sarcolemma. The present study indicates that in cardiac myocytes from obese Zucker rats, a permanent relocation of FAT/CD 36 to the sarco. lemma is responsible for myocardial TAG accumulation. Fulthermore, in vitro these cardiac myocytes, while sensitive to contraction-like stimulation, are eompletely insenstive to insulin, since the basal conditions in hyperinsulinemic, obese animals resemble the insulin-stimulated condition in lean littermates. 


\section{INTRODUCTION}

Cardiovascular disease is the most serious complication of obesity!. A common feature of obesity is insulin resistance, which is characterized by a diminished ability of insulin sensitive tissues, such as heart, to take up and metabolize glucose in response to insulin ${ }^{1 \cdot 3}$. There is a strong relationship between the development of insulin resistance and the accumulation of intracellular triacylglycerols (TAGs) in skeletal muscle from both rodents and humans 0 . Several studies demonstrated that in an insulin resistant state, TAGs not only accumulate in skeletal muscle, but also in the heart 2,7 . This cardiac accumulation of TAGs could be stemming from an increased myocardial long-chain fatty acid (LCFA) uptake. Rodent models in which myocardial LCFA uptake is elevated, such as mice overexpressing peroxisome proliferatoractivated receptor alpha (PPARa) or acyl-COA synthetase [ACS), indeed showed markedly increased cardiac TAG levels ${ }^{3,9}$. Interestingly, it has been shown, in hearts from obese Zucker rats that lipid accumulation is associated with an impaired cardiac function 2,7 .

Evidence is accumulating that cellular LCFA uptake is a rate-governing step in LCFA utilization ${ }^{10}$. Using heart giant membrane vesicles, a model to investigate cardiac LCFA uptake dissected from LCFA metabolism", and cardiac myocytes, in which LCFA uptake is closely linked to metabolism ${ }^{12}$, we previously showed that about half of the myocardial LCFA uptake is mediated by the $88 \mathrm{kDa}$ putative LCFA transport protein, i.e., fatty acid translocase [FA'T)/CD36. Under physiological conditions, both insulin ${ }^{13.15}$ and cellular contractions ${ }^{16}$ are able to elevate LCFA uptake into cardiac myocytes. We recently demonstrated that insulin induces translocation of FAT/CD36 from an intracellular pool towards the plasma membrane, leading to an 1.5-fold increase of LCFA uptake by cardiac myocytes, both in vivo and in vitrol ${ }^{3}$. 15. Moreover, in electrically-stimulated cardiac myocytes, FAT/CD36 is translocated towards. the plasma membrane, which is accompanied by an 1.6-fold increase in LCFA uptakelo. Despite the fact that both insulin and cellular contractions induce FAT/CD36-mediated LCFA uptake to the same magnitude, their effects are additive and different signalling pathways are involved. Notably, insulin activates phosphatidylinositol-3 kinase $\left(\mathrm{Pl}_{3} \mathrm{~K}\right)^{15}$, whereas cellular contractions activate AMP-activated kinase (AMPK) 17,18.

Upon their transport into the cytoplasm of the cardiac myocyte, LCFAs are directed towards different target sites, i.e., mitochondrial $\beta$-oxidation, esterification into TAGs and phospholipids (PLs), and signal transduction pathways 19,20 . Insulin predominantly directs intracellular LCFAs towards esterification ${ }^{21}$, whereas during cellular contractions LCFAs are efficiently used for energy production via mitochondrial $\beta$-oxidation 22 . Recently, we unmasked a pivotal role of FAT/CD36 in the altered myocardial LCFA uptake in obese Zucker rats $^{23}$. It appeared that in giant membrane vesicles isolated from the heart of obese Zucker rats LCFA uptake was elevated, whereas neither the total abundance of FAT/CD36 mRNA. nor the total amount of protein was different in the heart of obese compared to that of lean Zucker rats. Notably, an increased amount of FAT/CD36 was detectable at the sarcolemma of the obese rat heart. These findings indicate that in cardiac myocytes from obese Zucker rats a portion of the intracellular FAT/CD36 pool is permanently relocated to the sarcolemma 23 . However, it is not known whether this permanent relocation is due to an impaired FAT/CD30 translocation from intracellular pools towards the sarcolemma in response to insulin or to 
cellular contractions. Moreover, it remains unclear whether the regulation of LCFA uptake and utilization by insulin and cellular contractions is impaired in cardiac myocytes from obese Zucker rats.

We hypothesize that in obesity the regulation of myocardial FAT/CD36-mediated LCEA uptake and utilization by the hormone insulin and by cellular contractions are altered. Isolated, quiescent cardiac myocytes were used to investigate the direct regulation of myocardial glucose uptake, LCFA uptake and utilization under well-controlled conditions in which vascular factors are eliminated. The effect of cellular contractions on myocardial LCFA utilization was studied by means of oligomycin, a compound that inhibits $F_{1} / F_{0}$ ATPase activity at relatively low concentrations. Oligomycin, at an optimal concentration $\left(30 \mu \mathrm{mol} . \mathrm{H}^{-1}\right)$, increased the AMPK activity in cardiac myocytes by elevating the intracellular AMP/ATP ratio to approximately the same extent as observed with cellular contractions ${ }^{18}$. To investigate the role of FAT/CD36 in myocardial LCFA uptake and utilization in lean and obese Zucker rats, cardiac myocytes were treated with sulfo- $N$-succinimidyl oleate [SSO], which inactivates FAT/CD 36 by covalently binding to its LCFA binding site 24,25 .

\section{RESEARCH DESIGN AND METHODS}

\section{Animals}

Eleven-week old female lean and obese Zucker rats were obtained from the Harlan laboratory, kept on a 12 -h light/12 h dark cycle and fed a standard laboratory diet and water ad libitum. Before any surgical interference, these rats, in the fed state, were anesthetized with an intraperitoneal injection of sodium pentobarbital. In blood plasma, collected from anesthetized lean and obese Zucker rats, glucose (hexokinase method), and triacylglycerols (glycerol kinaselipase method) were analyzed on a COBAS BIO analyzer, and insulin was determined by using a radio immunoassay kit 23 . The Experimental Animal Committee of Maastricht University gave approval for all experiments involving animals.

\section{Treatment of isolated cardiac myocytes}

Cardiac myocytes were isolated from lean and obese Zucker rats, with use of a Langendorff perfusion system and a modified Krebs-Henseleit bicarbonate medium which is equilibrated with a $95 \% \mathrm{O}_{2} / 5 \% \mathrm{CO}_{2}$ gas phase at $37^{\circ} \mathrm{Cl}^{12,26}$. After isolation, cardiac myocytes were washed and treated with either $0.5 \%$ dimethyl sulfoxide (DMSO) or with 0.4 mmol. $\mathrm{I}^{-1}$ sulfo- $\mathrm{N}$. succinimidyl oleate (SSO) in DMSO for 30 min at room temperature. SSO is routinely synthesized in our laboratory according to Staros and coworkers ${ }^{27}$. Both the DMSO- and SSOtreated cardiac myocytes were, after a washing step, incubated for $15 \mathrm{~min}$ at $37^{\circ} \mathrm{C}$ under continuous shaking. Thereafter, the DMSO-treated myocytes were incubated for $15 \mathrm{~min}$ under continuous shaking at $37^{\circ} \mathrm{C}$, either non-treated (basal) or treated with 10 mol.1.1 insulin or $30 \mu$ mol. $1 \%$ oligomycin. Subsequently, these cardiac myocytes were used for further investigations, but only when more than $80 \%$ of the cells had a rod-shaped appearance, which was determined by a trypan blue staining. 


\section{${ }^{14} \mathrm{C}$-paimitate and ${ }^{3 \mathrm{H}}$-deoxyglucose uptake and ${ }^{14} \mathrm{C}$-palmitate oxidation and incorporation into intracellular lipid pools}

At the start of the incubation a ${ }^{14} \mathrm{C}$-palmitate/BSA complex (molar ratio 0.3) was added to non(basal), SSO-, insulin- and oligomycin-treated cardiac myocytes so that the final concentration of 14C-palmitate amounted to $100 \mu \mathrm{mol} .1 \%$. This palmitate concentration, which is below the $\mathrm{km}$ of $435 \mu \mathrm{mol} . \mathrm{I}^{-1}$ (corresponding to a "free" palmitate concentration of 6 nmol..$^{1 \cdot 128}$ ) allows to study unidirectional LCFA uptake in the absence of saturation of transporters. To study deoxyglucose uptake, ${ }^{3} \mathrm{H} \times$ deoxyglucose was added at the start of the incubations to the palmitate/BSA complex. to a final concentration of 100 umol..$^{-1}$. Cellular uptake of palmitate and deoxyglucose was simultaneously determined after 3 min as previously described 12 "In other experiments rates of ${ }^{14} \mathrm{C}$-palmitate oxidation (measured as production of $14 \mathrm{CO}_{2}$ after $20 \mathrm{~min}$ of incubation) ${ }^{29}$ and esterification (measured as incorporation of the ${ }^{14} \mathrm{C}$-label into intracellular phospholipids, triacylglycerols and unesterified LCFAs after $20 \mathrm{~min}$ of incubation) $)^{30}$ were determined.

\section{Subcellular fractionation of cardiac myocytes and determination of FAT/CD36}

Non- (basal), insulin - and oligomycin-treated cardiac myocyte suspensions from lean and obese Zucker rats were diluted with $\mathrm{H}_{2} \mathrm{O}$, and $\mathrm{NaN}_{3}$ was added to a final concentration of 5 mmol. to stop ATP-dependent vesicular trafficking events 31 . Immediately thereafter, cardiac myocyte suspensions were homogenized and frozen in liquid nitrogen. Subsequently, fractionation was carried out according to a modification of a procedure of Euller ${ }^{32}$, as previously described ${ }^{22}$. For the determination of the FAT/CD36 protein content in the total heart homogenates, and in the sarcolemmal. (SL) and low-density mircosomal (LDM) fractions, SDS-PAGE and Western blotting were performed. A monoclonal antibody (MO25) directed against human CD36 was used to detect FAT/CD36. The immunoblot intensities were analyzed by densitometry using the computer program Quantity One (BioRad).

\section{Cardiac triacylglycerol content}

Total triacylglycerol (TAG) content was determined in heart homogenates from lean and obese Zucker rats. Lipids were extracted and separated by high-performance thin layer chromatography (HPTLC) as previously described ${ }^{33}$ "Ouantification was performed scaming plates and integrating the density areas using Quantity One software (Biorad).

\section{Statistical analysis}

Data are presented as means \pm S.E.M. Differences between lean and obese animals were tested by ANOVA and the nonparametric Mann-Whitney U test. The paired sample test was used to define difference between treatments within a group. $\mathrm{P}<0.05$ indicates statistical significance.

\section{REsULTS}

\section{Characteristics of lean and obese Zucker rats}

The body and heart mass of eleven week old obese Zucker rats were significantly higher than 
those of their agematched lean littermates (Table 6.1). The obese Zucker rats, compared to their lean controls, had significantly elevated TAG plasma concentrations. In addition, the obese rats were euglycemic and markedly hyperinsulinemic, demonstrating the presence of systemic insulin resistance (Table 6.1).

Body mass (9)

Heart mass (g)

Glucoseplasina (mmol.1.1)

Insulinglasm (nmol: / li)

Tracylglycerolsplasma (molit 1$)$
Lean

$184 \pm 18$

$0.98 \pm 0.08$

$11.5+1.3$

$0.44 \pm 0.29$

$0.36 \pm 0.07$
Obese

$333 \pm 35$

$130 \pm 0.12$

$13.5 \pm 2.3$

$3.14+0,65^{*}$

$2.06 \pm 1.43^{*}$

Table 6.1: Characteristics of lean and obese Zucker rats.

Data are presented as means \pm S.E.M. for 810 rats. "Significantly different from lean Zucker rats, $p<0.05$.

\section{Inithial rates of myocardial LCFA and deoxyglucose uptake}

The initial rates of basal myocardial LCFA uptake were 1.4 -fold higher $(p<0.05)$ in obese Zucker rats compared to theil" lean littermates (Fig. 6.1). The imhibitor 550 reduced initial, basal myocardial LCFA uptake rates in both lean $(-34 \%, p<0.05)$ and obese $(-46 \%, 0<0.05)$ rats [Fig. 6.1). Notably, in SSO-treated cardiac myocytes, initial rates of LCFA uptake were not significantly different in lean and obese rats (Fig. 6.1).

Insulin stimulated initial rates of LCFA uptake into cardiac myocytes from lean rats up to 1.3-fold $(p<0.05)$. In contrast, in myocytes isolated from obese rats in vitro treatment with. insulin failed to stimulate LCFA uptake (Fig. 6.1). The contraction-mimetic agent oligomycin increased the initial rates of myocardial LCFA uptake by $1.7-$ fold $(p<0.05)$ in lean and by 1.8 . fold $(p<0.05)$ in obese rats (Fig. 6.1). In oligomycin stimulated cardiac myocytes, initial LCFA uptake rates were greater $(p<0.05)$ in obese than in lean animals (Fig. 6.1).

Under basal and SSO-treated conditions, myocardial deoxyglucose uptake rates were not different between lean and abese rats (Fig. 6.1). Insulin was able to induce deoxyglucose uptake rates in cardiac myocytes from both lean and obese rats by 2.0 -fold and 1.7 -fold $(p<0.05)$, respectively (Fig. 6.1). Oligomycin also induced in both lean and obese cardiac myocytes deoxyglucose uptake rates by 2.5-fold and 2.2-fold, respectively (Fig. 6.1).

\section{Sarcolemmal and intracellular FAT/CD 36 protein content}

The total protein amount of EAT/CD36 in the heart of obese Zucker rats was not significantly different from that in lean rats (Fig. 6.2A). However, under basal conditions the sarcolemmal FAT/CD36 protein content was elevated by $74 \%(\mathrm{p}<0.05)$ in cardiac myocytes from obese rats, compared to cardiac myocytes from lean rats. Concomitantly, the intracellular FAT/CD36 protein content was reduced by $50 \%(p<0.05)$ in obese Zucker rats (Fig. 6.2B). 

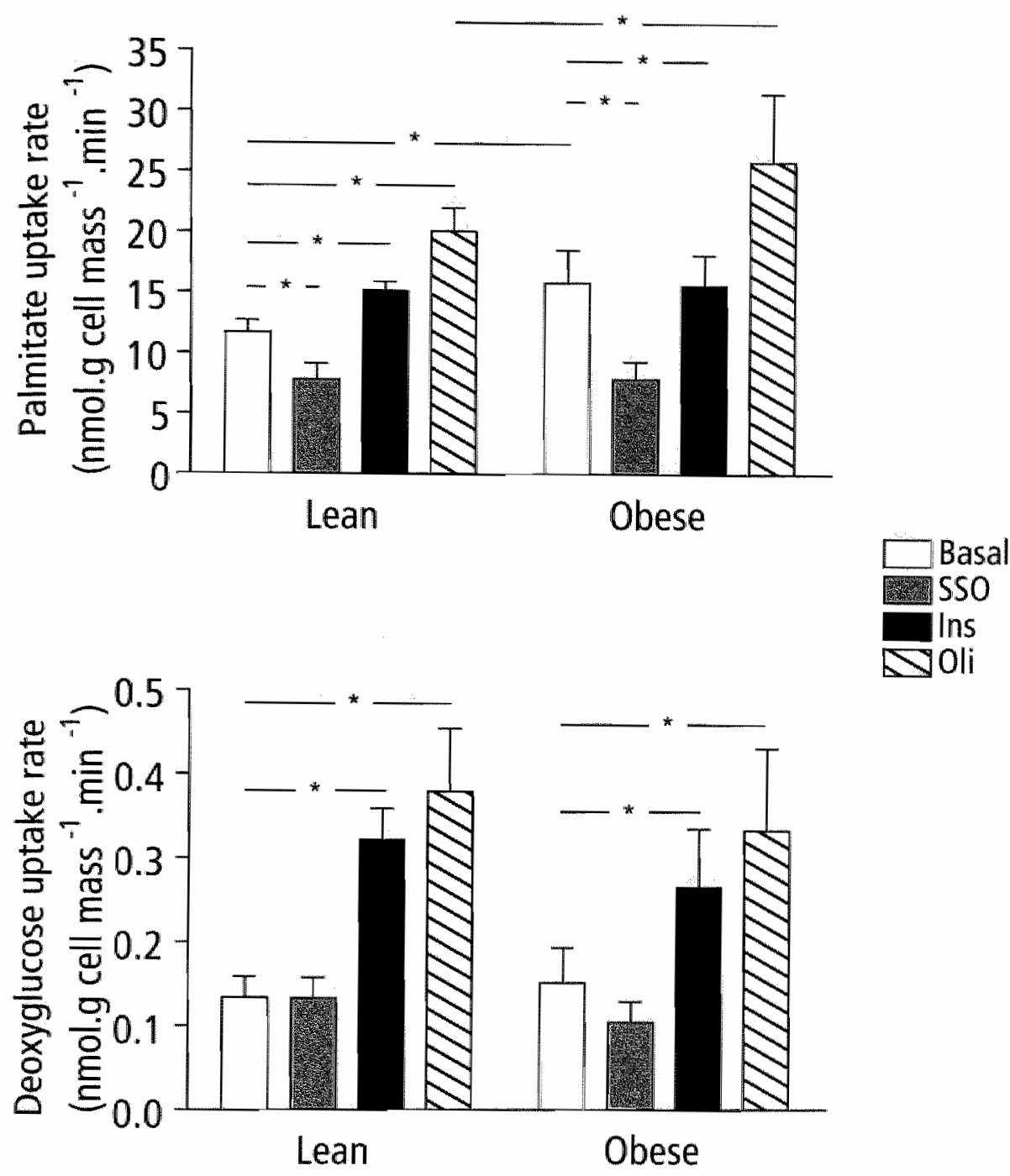

Figure 6.1: Influence of 550 , insulin and oligomycin on the initial paimitate and deoxyglucose uptake rate in cardiac myocytes from tean and obese Zucker rats.

${ }^{14} \mathrm{C}$ palmitate and $3 H$ deoxyglucose uptake in 3 min was simultaneousty determined in candac nyocytes from tean and obese Zucker rats. These cardiac myocytes were either non treated (Basall or treated with 0.4 mmol 11550,10 nmall" insulin (Ins) or 30 pmol.t oligomycin folt). Data are expressed as nmalg cell mass, min and presented as means \pm S. E.M., n=8. *Significantly different from each other, $0<0.05$. 
In isolated cardiac myocytes from lean rats, in vitro administration of insulin and oligomycin increased the total sarcolemmal protein amount of FAT/CD 36 by $73 \%$ and $86 \%(\mathrm{p}<0.05)$, respectively. This coincides with a decrease in intracellular FAT/CD36 protein content of $-46 \%$ and $51 \%(\mathrm{p}<0.05)$, respectively (Fig. 6.2B). In contrast, in isolated myocytes from obese rats both in vitro administration of insulin and oligomycin failed to increase sarcolemmal FAT/CD36 beyond the increase observed in the basal state (Fig. 6.2B). Concurrently, in isolated myocytes from obese rats, insulin and oligomycin also failed to decrease the intracellular depot of FAT/CD36 beyond the reduction observed in the basal state (Fig. 6.2B).

A

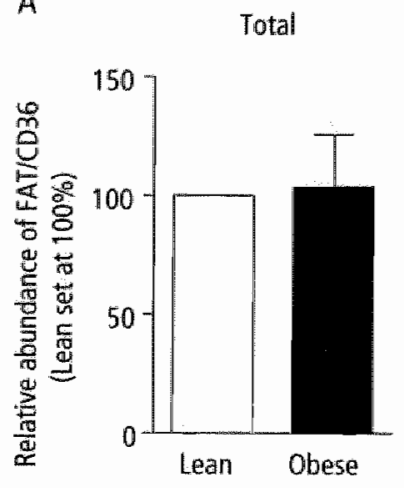

B

LDM

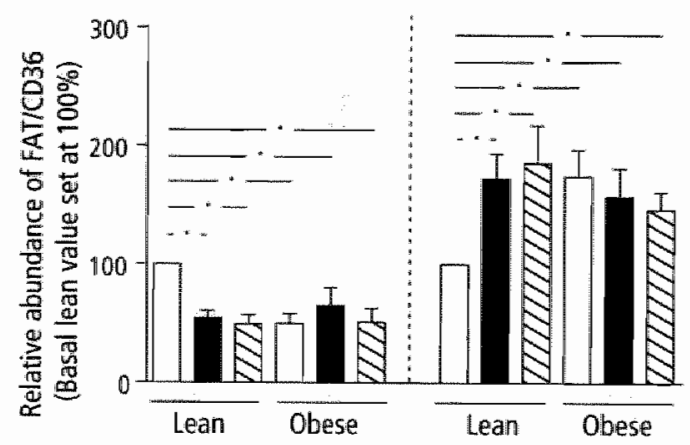

SL

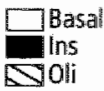

Figure 6.2: Effect of insulin and ollgomycin on total, intraceilular and sarcolemmal FAT/CD 36 protein content in cardiac myocytes from lean and obese Zucker rats.

Quantitation of the Western blots of the LCFA transporter FAT/CD36 in A) total heart homogenates, $n=6$ and B) low density microsonal (LDM) and sarcolemmal (SL) fractions prepared of cardiac myocytes from lean and obese

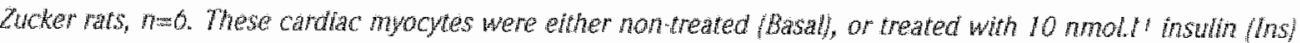
or 30 unol. 1 oligonycin /OIll. The BAT/CD 36 protein content was expressed as percentage of FAT/CD36 content the basal watues in cardiac myocytes from lean Zucker rats in the corresponding fractions. Data presented as means ¿ S.E.M. *Signtficantily different from basal values in lean Zucker rats, $p<0.05$.

\section{Myocardial LCFA oxidation rate}

Under basal conditions, myocardial LCFA oxidation rates were not significantly different in obese Zucker rats compared to lean control rats (Fig. 6.3). SSO reduced the myocardial LCFA oxidation to a similar extent in lean $(76 \%, \mathrm{p}<0.05)$ and in obese $(86 \%, \mathrm{p}<0.05)$ rats (Fig. 6.3). In vitro addition of insulin had no effect on the rates of LCFA oxidation in isolated cardiac myocytes obtained from lean and obese rats (Fig. 6.3). In contrast to the effects of insulin, oligomycin increased the LCFA oxidation rate in isolated cardiac myocytes from lean (2.6-fold, $p<0.05)$ and obese $(3.7 \cdot f \circ$ fold, $p<0.05)$ rats. The effect of oligomycin was greater in myocytes from obese compared to lean rats $(p<0.05$, Fig. 6.3). 


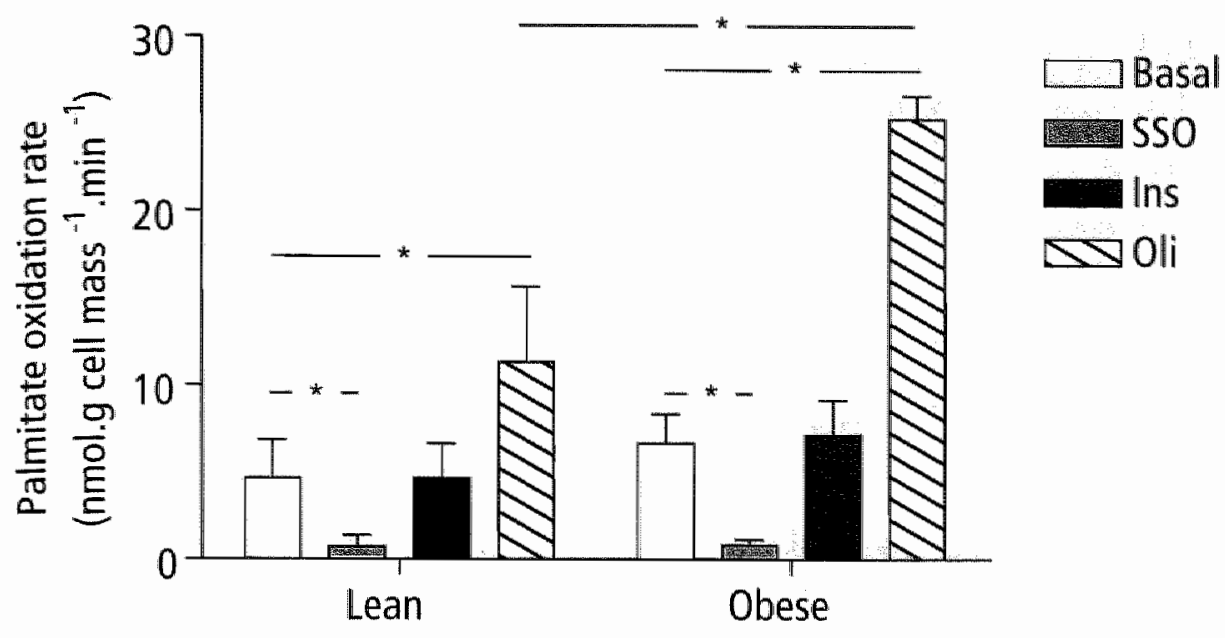

Figure 6.3: Inffuence of SSO, insulin and oligomycin on the patmitate oxidation rate in cardiac myocytes, from lean and obese Zucker rats.

Oxidation of " $\mathrm{C}$-palmitate was determined by the " $\mathrm{CO}_{2}$ production in 20 min by cardiac mocyles from lean and obese Zucker rats. These cardiac myocytes were either non treated (Basal) or treated with 0.4 mmol.M 550,10

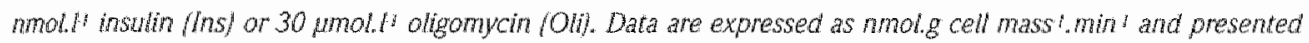
as means \pm S.E.M., $n=8$. Significantly different from each other, $p<0.05$.

\section{LCFA esterification rate into myocardial triacylglycerols and phospholipids, and the myocardial unesterified LCFA-pool}

The total TAG pool was 3-fold higher ( $p<0.05$ ) in heart homogenates of obese Zucker rats compared to lean rats (Fig. 6.4).

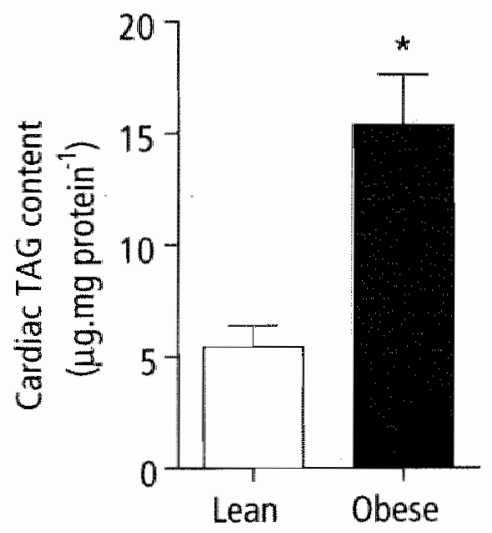

Figure 6.4: Cardiac triacylglycerol content in lean and obese Zucker rats.

The total triacyglycerol content was determined in heart homogenates by HPTLC. Data are expressed as fug.mg protein' and presented as means \pm S.EM. $n=\hbar$. Signiffantly different lean Zucker wais, p<0.05. 
A

Triacylglycerols

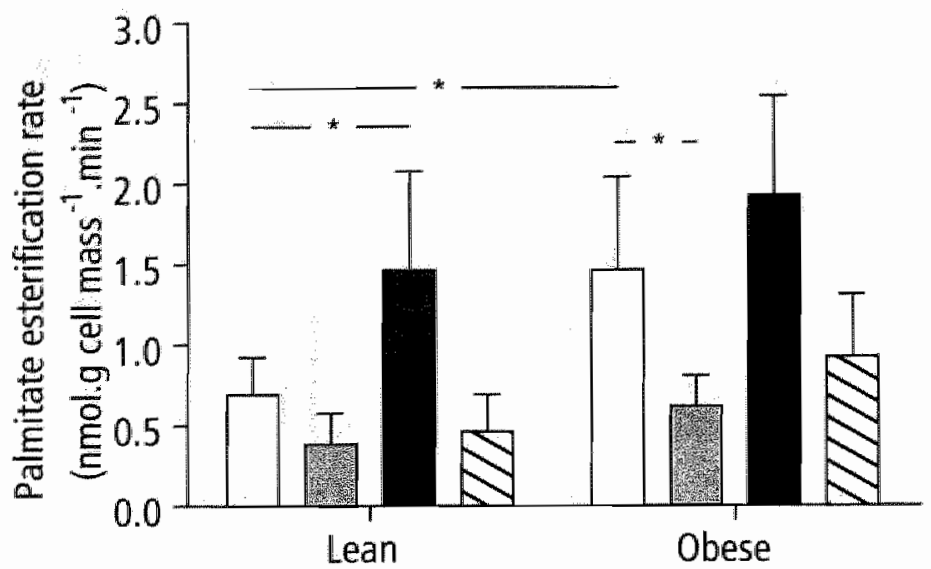

B

Phospholipids

Ins
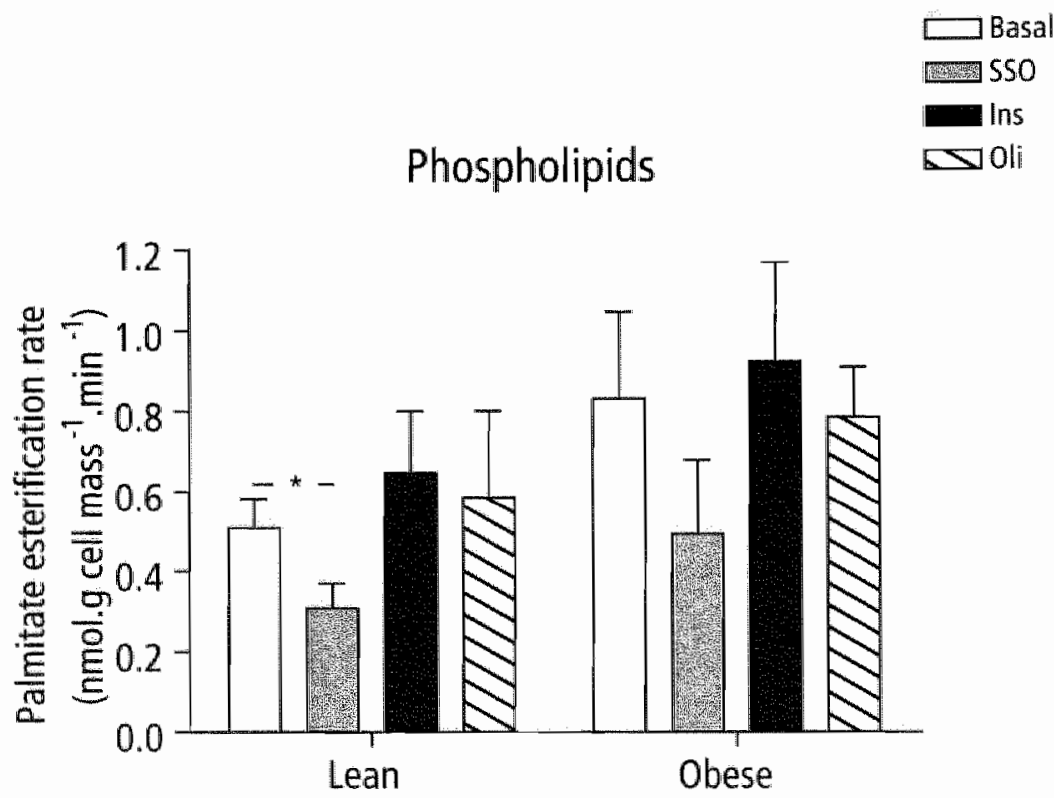

Figure 6.5: Infuence of $\$ 50$, insulin and oligomycin on palmitate esterification into triacytglycerols and phospholiplds in cardac myocytes from lean and obese Zucker rats.

Incorporation of "C patmitate into intracellutar Al tracylgicerols, or Bi phospholipids, was determined in 20 min

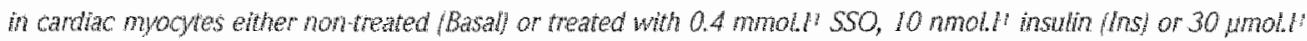
oligomicin (Oli. Data are expressed as nmolg cell mass? min and presented as means 4 S.E.M. $n=8$. *Significanty different from each other, $p<0.05$. 
Under basal conditions the rate of incorporation of extracellular LCFAs into intracellular TAGs in cardiac myocytes from obese rats was 2.3 fold higher $(0<0.05)$ than in cardiac myocytes from lean rats (Fig. 6.5A). SSO reduced the incorporation of LCFAs into intracellular TAGs in cardiac myocytes from lean rats, and significantly $(p<0.05)$ in cardiac myocytes from obese rats (Fig. 6.5A). In vitro insulin administration stimulated the incorporation of LCFAs into intracellular TAGs by 2.3 fold $(p<0.05)$ in cardiac myocytes isolated from lean rats. In contrast, in myocytes from obese rats, this hormone had no additional effect, over basal conditions, on the incorporation of LCFAs into the TAG pool (FIg. 6.5A). Oligomycin had no significant effect on the LCFA incorporation into intracellular TAGs in cardiac myocytes from lean and obese rats (FIg. 6.5A).

In non-treated cardiac myocytes, the rate of LCFA incorporation into PLS was not different in obese Zucker rats compared to lean rats (Fig. 6.5B). In myocytes from lean rats $\$ S O$ significantly reduced the rate of incorporation into the intracellular PI. pool by $42 \%(p<0.05)$, compared to the basal incorporation rate, but in myocytes from obese rats SSO had no significant effect on LCFA esterification into PLs. Insulin and oligomycin had no effect on the incorporation rate of LCFAs into PLs in myocytes from either lean or obese rats (Fig. 6.5B).

The rate of deposition of extracellular LCFAs into the intracellular, unesterified LCFA.pool in cardiac myocytes from obese Zucker rats was increased by more than 2-fold $(p<0.05)$ under basal conditions, compared to myocytes from lean rats. (Fig. 6.6). In cardiac myocytes from obese rats SSO reduced the LCFA deposition into the intracellular LCFA-pool to the same absolute level as in myocytes from lean rats under basal conditions (Fig. 6.6). In cardiac

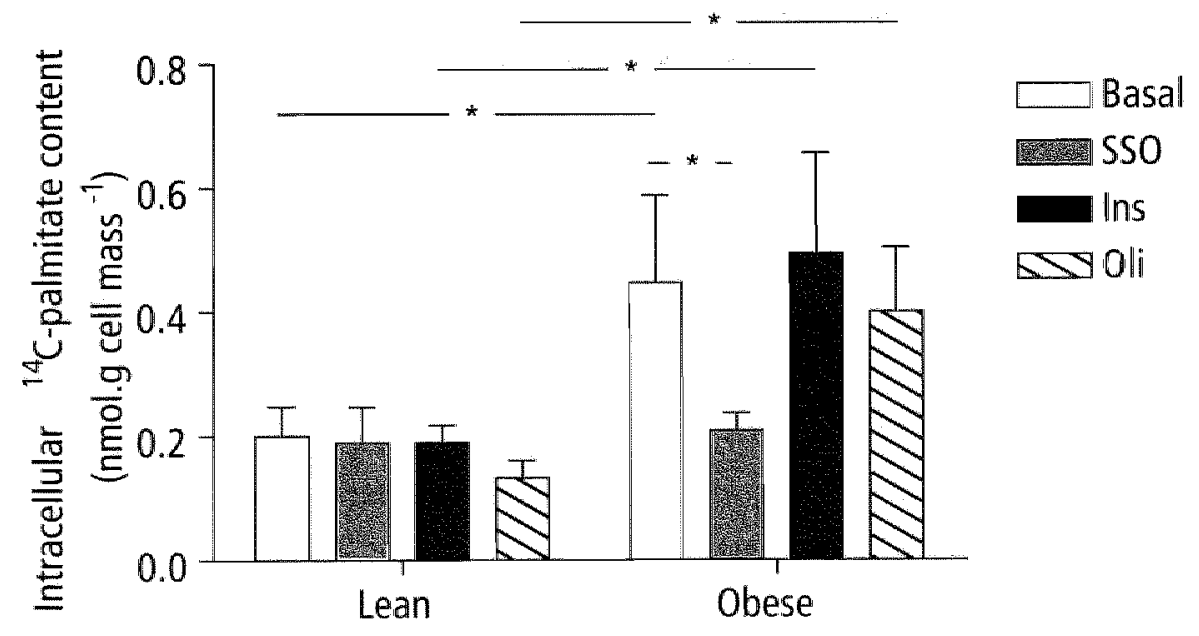

Figure 6.6: Influence of 550 , insulin and oligomycin on the intracellutar ${ }^{14} \mathrm{C}$.palmitate content in cardiac myocytes from lean and obese Zucker rats.

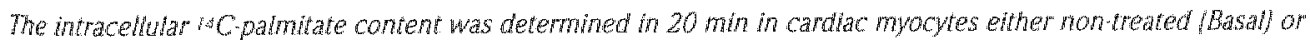

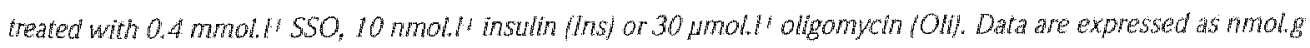
cell mass" and presented as means $\pm S . E . M, n=8$. "Significantly different from each other $p<0.05$. 
myocytes from lean rats SSO did not alter LCFA deposition into the LCFA-pool (Fig. 6.6). Insulin and oligomycin did not alter this parameter in cardiac myocytes from either lean or obese Zucker rats (Fig. 6.6).

\section{Discussion}

In the present study we investigated the regulation of the initial LCFA uptake rate, the subcellular localization of the LCFA transporter FAT/CD36, and the rates of LCFA oxidation and esterification into intracellular lipids in cardiac myocytes isolated from lean and obese Zucker rats. The following novel observations were made, (i) in cardiac myocytes isolated from obese Zucker rats, there was an increased LCFA uptake due to a permanent relocation of FAT/CD36 to the sarcolemma. In vitro, (ii) the stimulatory effect of insulin on LCFA uptake was lost in cardiac myocytes from obese rats, whereas the stimulatory effect of oligomycin was maintained, (iii) insulin as well as oligomycin lost their ability to induce FAT/CD36 translocation in cardiac myocytes from obese rats, [iv) the rate of LCFA esterification into intracellular TAGs was markediy elevated in cardiac myocytes from obese rats, which likely accounts for the increased cardiac TAG content, since rates of LCFA oxidation did not differ, and in vitro insulin failed to stimulate TAG esterification further, and (v) the FAT/CD36 inhibitor SSO was able to reduce the elevated incorporation of LCFAs into both the intracellular unesterified LCFA and the TAG pools in cardiac myocytes from obese rats to normal physiological levels as seen in those from lean littermates.

\section{Alterations in myocardial substrate uptake by obese Zucker rats}

The eleven-week old female obese Zucker rats were hyperinsulinemic and euglycemic, which indicates that these rats are insulin resistant. The rats were also hyperlipidemic, which is characterized by elevated TAG plasma concentrations (Table 6.1). Interestingly, deoxyglucose uptake by cardiac myocytes was under basal conditions not different between lean and obese rats. In both rats insulin and oligomycin were able to induce myocardial deoxyglucose uptake, suggesting that in obese Zucker rats the regulation of glucose uptake by cardiac myocytes is not altered.

In a previous study with eleven-week obese Zucker rats, we demonstrated, by using heart giant membrane vesicles, that obesity was associated with a marked elevation of the transsarcolemmal LCFA transport rate ${ }^{23}$. In the present study we were able to confirm in isolated cardiac myocytes the previously observed elevated uptake of LCFAs by giant membrane vesicles obtained from hearts of obese Zucker rats. The same previous study 23 also revealed that membranes from giant sarcolemmal vesicles displayed a higher content of FAT/CD36, while total cardiac tissue amounts of this protein were unaltered, suggesting that FAT/CD36 is permanently relocated to the sarcolemma in myocytes from obese rats. In the present study, the subcellular distribution of FAT/CD36 in cardiac myocytes was examined by subcellular fractionation (Figs. $6.2 \mathrm{~A}$ and $\mathrm{B}$ ). The findings demonstrate that the total protein content of FAT/CD36 in the obese heart is not altered, whereas its abundance in the sarcolemmal fraction is increased, coinciding with a decline in the intracellular pool of this 
transporter. Thus, these subcellular fractionation studies provide definitive evidence that a permanent relocation of FAT/CD36 from an intracellular compartment to the sarcolemma is responsible for the elevated myocardial LCFA uptake in obese Zucker rats. In the present study we also demonstrated that in myocytes isolated from obese rats and treated with $\mathrm{SSO}_{\text {, which }}$ specifically inhibits FAT/CD36-mediated LCFA uptake, LCFA uptake was markedly reduced to a level not significantiy different from that in SSO-treated cardiac myocytes from lean rats. This observation provides the causal link between chronically elevated sarcolemmal FAT/CD36 protein levels and enhanced myocardial LCFA uptake. Taken together, these findings show that in obesity, FAT/CD36 is permanently relocated to the sarcolemma, and increases the myocardial LCFA uptake rate. However, the mechanisms that maintain FAT/CD36 at the sarcolemma are incompletely understood.

Previously, we have established that there are two signalling pathways linked to the translocation of FAT/CD36 from an intracellular compartment to the sarcolemma, i.e., insulininduced $\mathrm{PI}_{3} \mathrm{~K}$-dependent signalling 13.15 and contraction-induced AMPK-dependent signalling ${ }^{18}$. Accordingly, in the present study we found that in vitro both insulin and oligomycin were effective in inducing FAT/CD36 translocation and stimulating LCFA uptake in cardiac myocytes from lean rats. In contrast, neither stimulus was able to further translocate FAT/CD36 in cardiac myocytes from obese Zucker rats. We specullate that FAT/CD36mediated LCFA uptake by cardiac myocytes from obese rats is already maximally stimulated due to physiologically high plasma insulin levels in vivo. Thus, the permanent relocation of FAT/CD36 seen in the myocytes from obese rats would then be a normal response to increased concentrations of circulating insulin. Importantly, the loss of insulin's ability to additionally induce FAT/CD36 translocation in cardiac myocytes from obese rats in vitro was paralleled by a loss in the ability of insulin to further stimulate LCFA uptake.

Oligomycin retained its ability to stimulate myocardial LCFA uptake in obese Zucker rats despite the lass of its ability to induce FAT/CD36 translocation. Apparently, oligomycin stimulates myocardial LCFA uptake in obese rats by a different mechanism than FAT/CD36 translocation. A possible explanation could be that oligomycin increases the intrinsic activity of FAT/CD36 by a signaling event that is not or only in part operative in cardiac myocytes from lean rats. In another study we gathered evidence that supports the fact that the intrinsic activity of FAT/CD36 in hearts of lean rats can be altered22.

\section{Alterations in myocardial LCFA metabolism by obese Zucker rats}

The increased FAT/CD36-mediated LCFA uptake by cardiac myocytes from obese Zucker rats will provide the intracellular metabolic machinery with a greater supply of LCFAs. Therefore, it was of interest to monitor the possible differences in metabolic fate of LCFAs taken up by cardiac myocytes from lean versus obese rats. When considering the main metabolic pathways that are involved in LCFA processing, it appeared that under basal conditions, the rate of esterification of LCFAs into intracellular TAGs is significantly elevated in myocytes from obese rats, whereas the rates of LCFA oxidation and esterification into PLs were not altered. We expect that the enhanced LCFA esterification rate into myocardial TAGs is causally related to the elevated intracellular TAG content found in hearts of obese Zucker rats. Another important 
metabolic alteration in cardiac myocytes from obese rats is that the intracellular concentration of unesterified LCFAs was significantly increased by more than 2 -fold. Previously, we have established that LCFAs taken up by cardiac myocytes are very rapidly equilibrated (in less than $30 \mathrm{sec}$ with the total intracellular unesterified LCFA pool12. Therefore, we can reasonably assume that a 2 -fold increase in deposition of radiolabel in the myocardial unesterified LCFA pool, when measured after $20 \mathrm{~min}$, reflects a 2 -fold increase in the LCFA pool size. Because intracelluiar unesterified LCFAs are highly disruptive to cellular membranes and to a great number of enzymes, the mammalian cell generally attempts to maintain a very low level of unesterified LCFAs ${ }^{19}$. As a result, the rise in intracellular unesterified LCFAs is a sensitive indicator of a mismatch berween LCFA uptake and subsequent LCFA metabolism ${ }^{34}$. Likely, esterification of LCFAs into TAGs provides an escape route to prevent a further rise in unesterified LCFAS. An intracellular TAG accumulation and an increased amount of intracellular unesterified LCFAs are considered to be critical steps in the development of cellular insulin resistance. These excess lipid depots will also result in an increased intracellular long-chain acyl $\mathrm{COA}$ pool, leading to cardiac lipotoxicity $4,7,35$. Our findings strengthen the relation between TAG storage and LCFA uptake and implicate that FAT/CD36 is involved in this process.

Insulin had no effect on the rates of LCFA oxidation and esterification into PLS, but stimulated the rate of esterification into TAGs in cardiac myocytes from lean rats. These observations are in line with our earlier observations 15 . However, in cardiac myocytes from obese rats, in vitro administration of insulin had no additional metabollic effects. The loss of insulin's ability to stimulate LCFA esterification is likely related to elevated basal levels of the LCFA esterification rate into intracellular TAGs. Analogous to the changes seen in the initial LCFA uptake rate, we speculate that insulin signalling is already maximally activated under basal conditions due to the high levels of insulin in wivo, so that insulin addition in vitro does not result in further activation of the rate of LCFA esterification into TAGs. This would indicate that the excess amount of LCFAs taken up under basal conditions is preferentially channeled into storage.

When examining the metabolic effects of contraction signalling, oligomycin strongly stimulates LCFA oxidation, and had no effect on esterification of LCFAs into TAGs and PLs in cardiac myocytes from lean rats. It was found that these metabolic actions of oligomycin are preserved in cardiac myacytes from obese Zucker rats and, strikingly, LCFA oxidation is even more sensitive to oligomycin in cardiac myocytes from obese compared to lean rats. This hypersensitivity of LCFA oxidation to oligomycin might be caused by a more potent activation of AMPK in cardiac myocytes from obese Zucker rats. In this respect, it should be noted that in skeletal muscle from both obese Zucker rats and type-2 diabetic patients AMPK activity is still highly inducible 30,37 .

A total blockade of FAT/CD 36-mediated LCFA uptake by SSO significantly reduced the rate of LCFA utilization by two major LCFA metabolic pathways, i.e., LCFA oxidation and esterification into intracellular TAGs, in cardiac myocytes from both lean and obese Zucker rats. This is in agreement with the notion that the inhibitory effects of SSO on LCFA metabolism are secondary to its inhibitory effect on the LCFA uptake process 12,16,25. Hence, 
SSO treatment proves to be an effective tool to normalize LCFA metabolism in cardiac myocytes from obese rats. Specifically, the normalization by SSO of the elevated esterification rate into TAGs in myocytes from obese rats suggests that increased sarcolemmal FAT/CD36 is responsible for TAG accumulation in the obese rat heart. Interestingly, and of potential therapeutic significance, is the observation that SSO is able to reduce the intracellular level of unesterified LCFAs, whereas the stimulatory effect of the AMPK activating agent oligomycin on LCFA oxidation failed to do so. This indicates that SSO is not only able to decrease LCFA esterification into TAGs, but also restores the balance between LCFA uptake and metabolism in obese cardiac myocytes. Therefore, SSO is possibly more suited as antidiabetic agent than currently used drugs, such as AICAR, that act via activation of AMPK ${ }^{36,38,39}$.

\section{Concluding remarks}

The present study indicates that in cardiac myocytes from obese Zucker rats a permanent translocation of FAT/CD36 to the sarcolemma results in enhanced extracellular LCFA uptake and channeling into TAGs, which is expected to lead to an accumulation of myocardial TAGs. Furthermore, these cardiac myocytes, while sensitive to contraction-like stimulation, are completely insensitive to insulin when administrated in vitro, since basal conditions in hyperinsulinemic, obese animals resemble the insulin-stimulated condition in lean littermates. Nonetheless, the action of insulin in these lean littermates will not lead to cardiac lipotoxicity as opposed to obese rats, because in vivo cardiac myocytes will only be exposed to insulin during a short postprandial insulin peak. Finally, the studies with SSO suggest that blocking FAT/CD36 would be an effective means to limit LCFA uptake and prevent myocardial TAG accumulation, which most likely will result in an improved function of the heart in obesity.

\section{ACKNOWLEDGEMENTS}

Antibody MO25 was kindly provided by Dr. N.N. Tandon, Otsuka America Pharmaceutical, Inc., Rockville, MD, USA. The authors would like to thank Ms. Inge van der Made for her excellent technical assistance. This study was supported by the Netherlands Heart Foundation, grant 2000.156, and by the Heart \& Stroke Foundation of Ontario and the Canadian Institutes of Health Research. Arend Bonen holds a Canada Research Chair in Metabolism and Health. Jan F.C. Glatz is Netherlands Heart Foundation Professor of Cardiac Metabolism. Joost J.F.P. Luiken is the recipient of a VIDI-Innovational Research grant from the Netherlands Organization for Scientific Reasearch (NWO-ZonMw grant nr. 016.036.305). 


\section{REFERENCES}

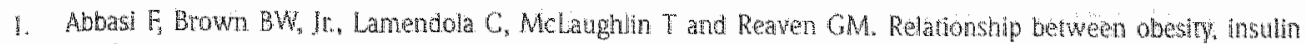
resictance, and coromary heart disease risk. I Am Coll Cardol. 2002:40:937-43.

2. Zhou YT, Graybum P, Karm A, Shinabukuro M, Higa M, Baetens D, Onci L and Unger RH. Lipotoxic heart disease in obese rats: impications for human obesity. Prot Nat Acá Sci U S.A. 2000,97:1784.Q.

3. Shuman G1. Cellular mechanisns of insulin resistance. J Clin /hvest: 2000;100:171.6.

A. Pan DA, Lilioja S, kriketos AD, Mitner MR, Baur LA, Bogardus G, Jenkins AB and Storlen LH. Skeletal muscle urgytreride lewets are inversely related to insulin action. Dlabetes. 1907;:46:983.8.

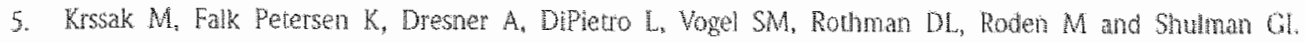
Intramyocelular lipid concentrations are correlated with insulin sensitivity in thumans: a 1 H MMR spectroscopy Suduly. Diabetologiz. 1990;42:113-6.

6. Turotle LP, Swenberger IR, Zavite Tucker $M$ and Yee AJ. Increased fatiy acid uptake and altered fatly acid metabolism in insulin resistant muscle of obese Zucker rats. Diateres. 2001;50:138900.

7. Young ME, Guthrie PH, Razeghi P, Leighion B, Abbasi S, Pati S, Youker KA and Taegimeyer H. Impared longr. chain fatty acid oxidation and coniactile dysfunction in the obese Zucker rat heart. Diaberes. 2002;51:2587,95.

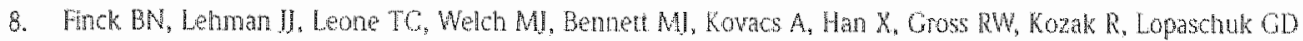
and Kelly DP. The candiac phenotype induced by PPARalpha overexpression mimics that caused by diabetes mellutus. J Clin Invest 2002;109:121-30.

9. Chi HC, Kovacs A, Ford DA, Hsu FF, Garcia R, Herrero P. Saffitz JE and Schaffer JE. A novel mouse model of lipotoxic cardiompopathy. I Clin Wwest $2001 ; 107: 81322$.

10. Luiken J], Schaap FG, van Nieuwenhoven FA, van der Vusse G., Bonen A and Glatz J1. Cellular latty acid transport in heart and sketetal muscle as faciliated by proteins. Lipids. 1999;34 Suppl:516075.

11. Luiken J, Turcote LP and Bonen A. Protennediated palmitate uptake and expression of fatry acid transport proteins in heart giant vesicles. J Lipid Res. 1999;40:1007 10.

12. Luiken J], van Nieuwenhoven FA, America G, van der Vusse Gl and Glatz IF. Uptake and me tabolism of pamitate by isolated cardiac myocytes from adult ats: involvement of sarcolemmal proteins. JLibd Res. 1697,38:745-58.

13. Bonen A, Luiken J), Arumugam X. Giatz If and Tandon WN, Acute regulaton of larty actd uprake inwolves the Celluar redistribution of faty acid translocase, f Biol Chem 2000,275:14501.8.

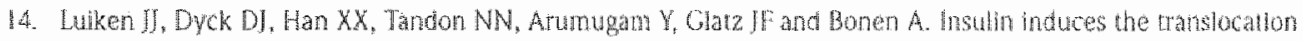
of the faty acid transporter FA/CD36 to the plasma membrane. Am / Physial Fndacinol Metab. 2002:282:E491.5.

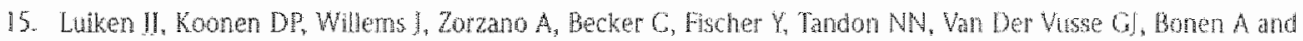

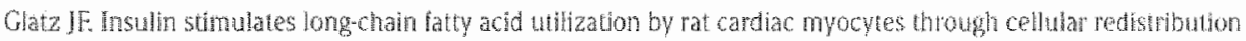
of FAT CD 30. Dabetes. 2002,51:31130.

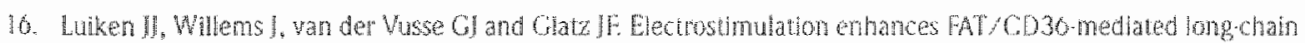

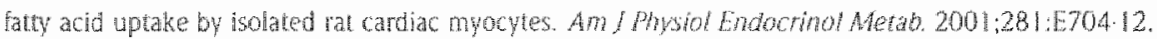

17. Kemp BE, Mitchelhili $X$, Stapleton D. Michel Bf, Chen $2 \mathrm{P}$ and Witers LA. Dealing with energy deriand: the AMP activated protein kinase. Trends Biochem Sch 1090:24:22.5.

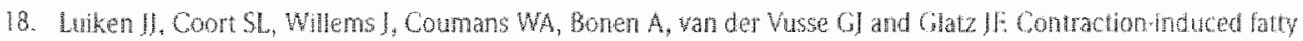
acid transiocase/CO30 translocation in rat cardiac myocytes is mediated through AMp acuvated protein kinase signaling. Diaberes. 2003;52:1627-34. 


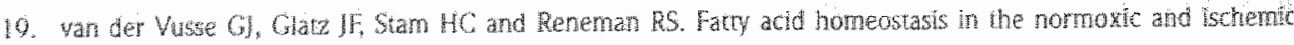
heart physol hew $1902,72.801 .940$

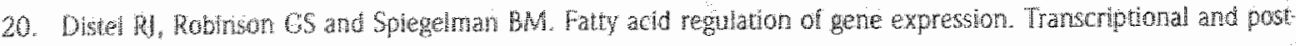

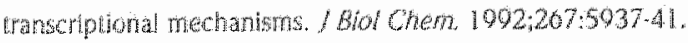

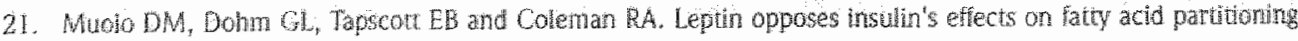

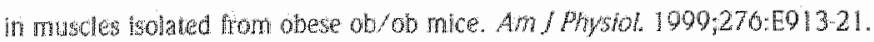

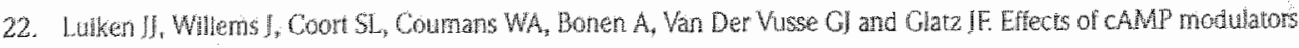

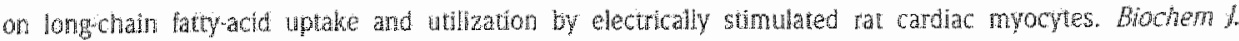
$2002 \times 367: 89: 7$

23. Lutken 11, Arumugan Y, Dyck DI, Bell RC, Pelsers MM, Turcote LP, Tandon NW, Gatz IF and Bonen A

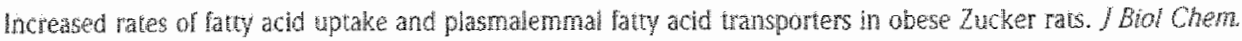
$2001,270: 40567.73$

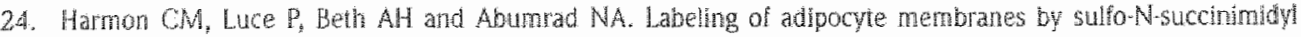

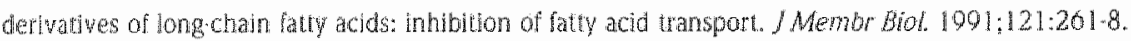

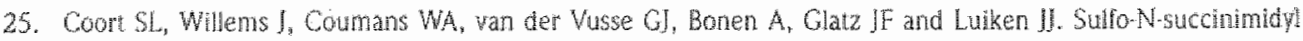

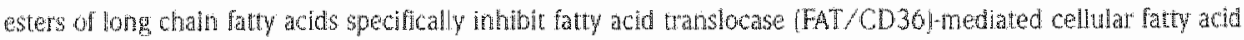
uptake. Mol Cell Bochen. $2002,2392139$.

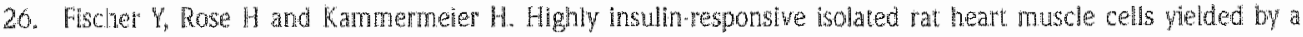

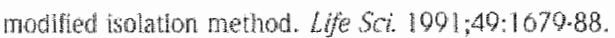

27. Arianeyutu RS and Stanos JV. Reactions of Nhydroxysulfosuccimimide active esters. Fre / Pept Protein Res. $1987,30: 117-24$

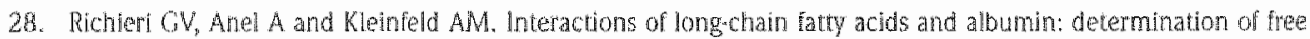
faty acid levels using the fluorescent probe ADHFB. Biochemstor. 1993:32:7574.80.

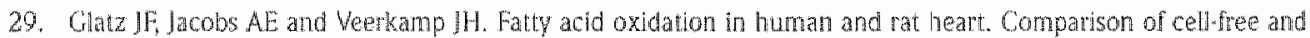
celular systems. Bochim Bophys Acta. 1984,704:454-65.

30. Wan det Vusse GI and Roemen TH. Protein acylation in nomoxic and ischemic/repertused cardiac tissue.

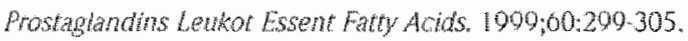

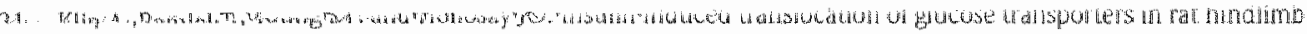
muscles. AFBS Let. 1987;224:22430.

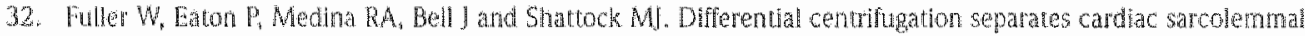

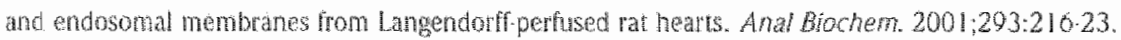

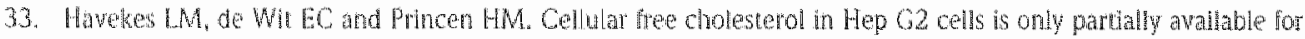

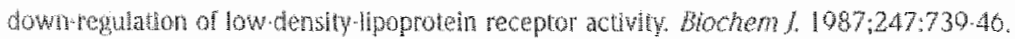

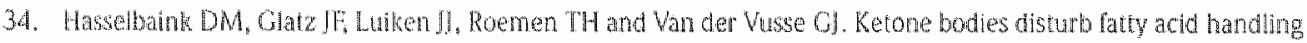
in isolated cantomyocyes dertwed from contol and dabetic rats. Bochem /.2003,371.753-60.

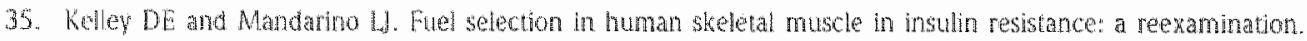
Drabetes: $2000,49: 67783$

30. Hergeron $R$, Previs SF, Che GW, Perre P, Russell RR, 3td, Young LH and Shuman GI. Effect of 5 m

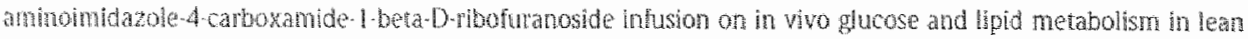
and obese zucher rais. Disteres. $2001,50,1076,82$

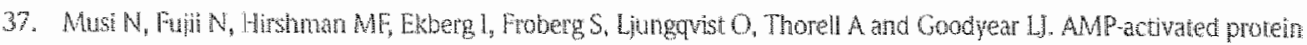

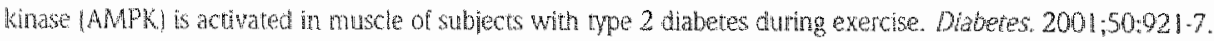




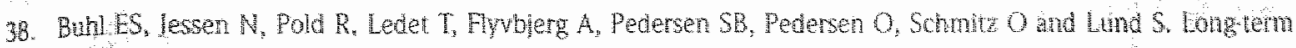
AGAR administration reduces metabolic disturbances and lower blood pressupe in ras displaying features of the insulin resistance syndrome. Diabetes $2002,51,2109200$.

39. Merill GF Kurth E, Hardie DG and Winder WW. AICA riboside increases AMPactivatad protein kinase, faty acid oxidation, and glucose uprake in rat muscle. Am J Physiol. 1907:273:E1107-12. 


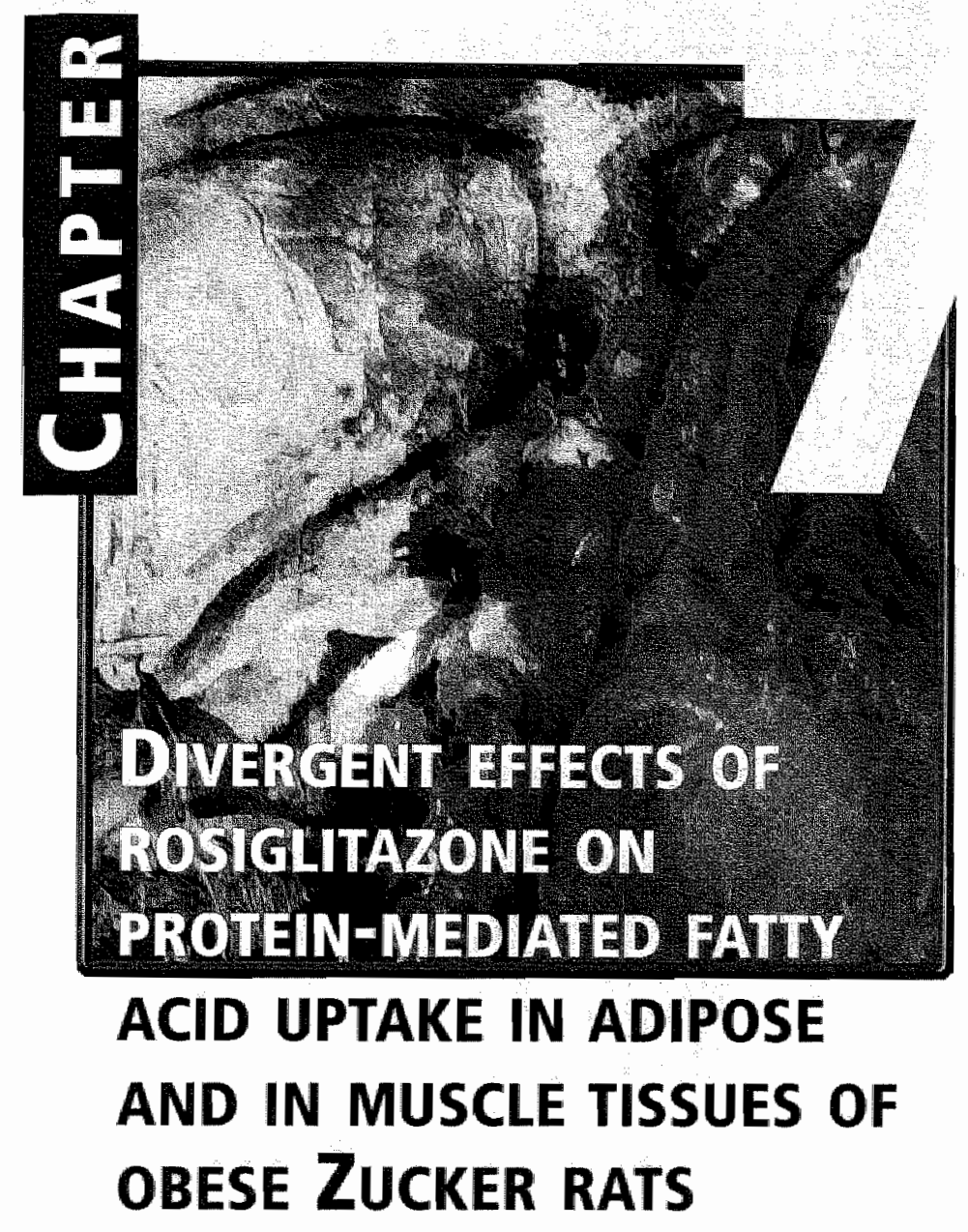

Susan L.M. Coort', Will A. Coumans', Arend Bonen², Ger J. van der Vusse ${ }^{3}$, Jan F.C. Glatz', and Joost J.F.P. Luiken ${ }^{1,4}$

\section{J. Lipid Res. $2005 ; 46: 1295-302$}

Departments of Molecular Genetics and aphysiology, Cardiovascular Research Institute Maastricht (CARIM), Maastricht University, Maastricht, the Netherlands.

2Department of Human Biology and Nutritional Sciences, University of Guelph, Guelph, Ontarto, Canada.

Deparment of Biochemical Physiology and Institute of Biomembranes, Utrecht University, Utrecht, the Netherlands. 


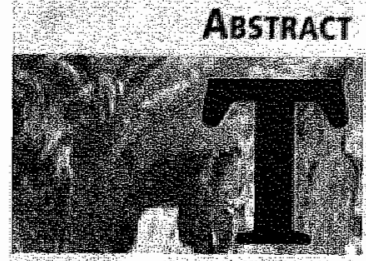

hiazolidinediones (TZDS) increase tissue insulin sensitivity in type-2 diabetes mellitus, and enhance long chain fatty acid (LCFA) deposition in adipocytes. Here, we hypothesize that, in adipose tissue, skeletal muscle and heart, alterations in the capacity to take up LCFAs and in the total and plasmalemmal contents of membrane associated LCFA transport proteins (FAT/CD36, FATPI and FABPpm) are involved in the insulin sensitizing effect of TZDs. As a model we used insulin-resistant, obese Zucker rats, orally treated for 16 days with rosiglitazone (Rgz). In adipose tissue from Rgz treated rats, LCFA uptake capacity increased by 2.0 fold, coinciding with increased total tissue contents of FAT/CD36 (2.3 fold) and FATPI $(1.7$ fold, but not of FABPpm, whereas only the plasmalemmal content of FAT/CD36 was changed (increase of 1.7 -fold). The increase in the LCFA uptake capacity of adipose tissue was associated with a decline in plasma FAs (-53\%) and triacylglycerols (TAGs, $56 \%$ ), suggesting that Rgz-treatment enhanced plasma LCFA extraction by adipocytes. In obese hearts, Rgz-treatment had no effect on the LCFA transport system, yet the total TAG content decreased by $36 \%$, suggesting enhanced cardiac insulin sensitivity. Also in skeletal muscle the LCFA transport system was not changed. However, the TAG content remained unaltered in skeletal muscle which coincided with increased cytoplasmic adipose-type FABP content, suggesting that increased extramyocellular TAGs mask the decline of intracellular TAGs in skeletal muscle. In conclusion, our study implicates FAT/CD 36 in the mechanism by which Rgz increases tissue insulin sensitivity. 


\section{INTRODUCTION}

Thiazolidinediones (TZDS) are a new class of insulin-sensitizing agents for the oral treatment of type.2 (non-insulin dependent) diabetes mellitus (T2DM). Several studies with insulinresistant rodent models and type-2 diabetic patients have demonstrated that TZD-treatment reduces both hyperinsulinemia and hyperlipidemia ${ }^{1-5}$. Another important effect of TZDs is the normalization of the insulin-stimulated whole-body glucase disposal, as reflected by an improved insulin action on skeletal muscle 2 and heart ${ }^{4}$. TZDs are agonists of the peroxisome proliferator activated receptor $\gamma$ (PPARy) ${ }^{6,7}$. PPAR $\gamma$, a nuclear hormone receptor, is predominantly expressed in adipocytes, but also, although at lower levels, in skeletal muscle and heart ${ }^{8}$.9. Together with the retinoid $X$ receptor $\alpha(R X R \alpha)$, PPAR $\gamma$ forms a heterodimer, and once activated this dimer modulates transcription patterns due to interaction with a peroxisome proliferator response element (PPRE) located in the promotor region of many genes ${ }^{6}$. One of the most potent members within the class of TZDs is rosiglitazone [Rgz), an agent which binds PPARY with a high affinity ${ }^{6}$. Activation of PPARY by TZDs regulates the transcription of genes involved in the differentiation of preadipocytes and the remodeling of adipose tissue, resulting in smaller, more insulin-sensitive adipocytes ${ }^{3,10}$. Moreover, TZDs have been proven to influence cellular long-chain fatty acid (LCFA) uptake by changing the mRNA expression levels of several key players in the protein-mediated LCFA uptake process $1,11$.

in most mammalian cells the majority of LCFAs are taken up via a protein-mediated transport system ${ }^{12}$. Until now three membrane-associated proteins have been identified as putative LCFA transport proteins, (i) a $43 \mathrm{kDa}$ plasmalemmal fatty acid-binding protein (FABPpm), a homologue of mitochondrial aspartate aminotransferase (mAspAT), (ii) a $63 \mathrm{kDa}$ fatty acid transport protein (FATP), a protein with very long-chain acyl-CoA synthetase (ACS) activity ${ }^{13}$, and (iii) an $88 \mathrm{kDa}$ highly glycosylated transmembrane protein, fatty acid translocase [FAT], the rat homologue of human CD3614. In muscle, FAT/CD36 is not only present at the plasma membrane, but also in an intracellular storage pool ${ }^{15}$. The membrane LCFA transport proteins are only involved in cellular LCFA transport when they are present at the plasma membrane. Intracellular $\mathbb{F A T} / \mathrm{CD} 36$ translocates to the plasma membrane upon a variety of stimuli, such as by contractile stimuli that activates AMP-activated kinase (AMPK]16 and by insulin via the activation of phosphatidylinositol -3 kinase $\left(\mathrm{PI}_{3} \mathrm{~K}\right)^{17}$. In addition to the membraneassociated proteins, a $15 \mathrm{kDa}$ soluble cytoplasmic fatty acid-binding protein $[\mathrm{FABPC}$ ) is also involved in cellular LCFA utilization 18 .

Studies on the insulin sensitizing effect of Rgz-treatment have been focusing on the effects in adipose tissue or on whole body level. Therefore, in the present study not only adipose tissue, but also other metabolically important tissues, i.e., skeletal muscle and heart, were investigated. We hypothesize that alterations in both the capacity to take up LCFAs and in the total and plasmalemmal amounts of LCFA transport proteins in metabolically important tissues play a pivotal role in the insulin sensitizing effect of TZDs. Evidence for a role of FAT/CD36 in the Rgz's insulin sensitizing effect has been given by a study performed in spontaneous hypertensive rats, which harbor a defective CD36 allele, and in which Rgz failed to improve glucose tolerance and hypertriglyceridemial?. Unfortunately, this particular study only investigated the whole-body effect of Rgz, and not 
possible tissue-specific effects. A proper model to investigate the tissue LCFA uptake capacity is giant membrane vesicles. These vesicles are oriented right side out and contain cytoplasmic LCFA binding proteins that serve as a LCFA sink, whereas LCFA metabolism has been entirely eliminated 20 (Fig. 7.1).

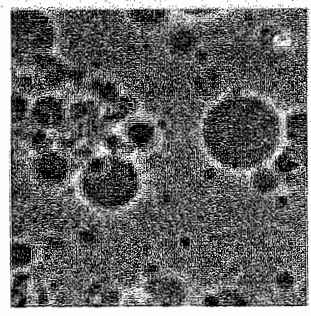

Figure 7.1: Giant membrane vesicles.

Gant membrane vesicles consist of a membrane of pure plasmatemal ongin and contain soluble cyroplasmic proteins, the cytoplasmic faty acid bindig protein IFABPC), which aCts as a sink for sequestered LCFAs. In addition, these vesicles lack intracellular structures like endoplasmatic reticulum, endosomes and mitochonditi, which latter absence implicates the inability of giant membrane vesicles to oxidize LCFASPI,2R.

In the present study, we advance the understanding of the in wivo action mechanism by which Rgz improves insulin sensitivity at three levels, the effects of Rgz on (i) LCFA transport capacity in separate tissues (adipose tissue, skeletal muscle and heart), (ii) protein levels of LCFA transport proteins (FAT/CD36, FABPpm and FATP1), whereas other studies measured only mRNA levels 23,24 , and (iii) the plasmalemmal localization of these LCFA transport proteins. The latter provides a superior indication of the functionality of the LCFA transport proteins, because changes in mRNA levels are not necessarily accompanied by alterations in protein content and function of the LCFA transport proteins. In addition, total tissue triacylglycerol (TAG) content was determined in skeletal. muscle and heart obtained from control and Rgz-treated obese animals. To discriminate between intramyocellular and extramyocellular lipids, we determined, in skeletal muscle and heart, cytoplasmic adipose-type $\mathrm{FABP}$ (A-FABPc), which is a marker of differentiated adipocytes ${ }^{25}$. The present study indicates that in obese Zucker rats an increased plasmalemmal protein content of FAT/CD36 in adipose tissue is implicated in the mechanism by which TZDs redirect the LCFA flux from muscle cells towards adipose tissue, causing plasma FA and TAG concentrations and intramyocellular TAG content to decline.

\section{EXPERIMENTAL DESIGN \& METHODS}

\section{Animals}

Eleven-week old lemale obese Zucker rats obtained from the Harlan laboratory (Horst, the Netherlands) were individually housed on a $12 \mathrm{~h}$ light/12 $\mathrm{h}$ dark cycle and divided into two groups of 8 animals each. The control group (control) was fed a standard rat chow, and the rosiglitazone (Rgz) treated group received standard rat chow supplemented with $5 \mathrm{mg}$ rosiglitazone (Avandia, GlaxoSmithKline, NC, USA) per $\mathrm{kg}$ body mass per day for 16 days. Body mass and food intake were monitored throughout the entire treatment period. The Experimental Animal Committee of Maastricht University gave approval for all experiments involving animals. Before tissue harvesting rats were anesthetized with Nembutal (sodium 
phentobarbital) injected intraperitoneally. We collected, (1) epididymal fat pads, (ii) the hindlimb muscle from the left leg, consisting of $\mathrm{m}$. gastronemius and $\mathrm{m}$. plantarius and (iii) the heart, thereby removing all the visible fat pads. After harvesting, tissues were separated in two parts, one part was used for the preparation of giant membrane vesicles and the other part was immediately frozen in liquid nitrogen.

\section{Materials}

${ }^{3} \mathrm{H}$-palmitate and ${ }^{14} \mathrm{C}$-mannitol were obtained from American Radiolabeled Chemicals Inc. 15 t. Louis, MO, USA.). Collagenase type II was obtained from Worthington Biochemical Co. (Lakewook, NJ, USA). Collagenase Ila, collagenase VII and bovine serum albumin (BSA, fraction $V$ fatty acid free) were obtained from Sigma Aldrich (St. Louis, MO, USA)

\section{Assays of plasma metabolites}

Blood samples were collected into 10-mi EDTA Vacutainer tubes Becton Dickinson, NJ, USA) immediately after anesthesia from fed control and Rgz-treated obese Zucker rats, and centrifuged at $10,000 \mathrm{~g}$ for $10 \mathrm{~min}$. Blood plasma was then separated from red blood cells and stored at $80^{\circ} \mathrm{C}$. Glucose (hexokinase method, Roche, Basel, Switzerland), fatty acids [Wako NEFA C test kit, Wako Chemicals, Neuss, Germany), and triacylglycerols (glycerol kinase-lipase method, Boehringer Mannheim, Mannheim, Germany) were analyzed in plasma on a COBAS BIO analyzer ICOBAS FARA semi-automatic analyzer, Roche, Basel, Switzerland). The distribution of cholesterol in the three lipopratein fractions (i.e., VLDL, LDL and HDL) in plasma was determined with an AKTABasic chromatography system with a Superose 6PC.

\section{Isolation of giant membrane vesicles}

Giant membrane vesicles from adipose tissue, skeletal muscle and heart derived from control and Rgz-treated obese Zucker rats were prepared as previously described 21,23 . Briefly, tissues were cut into thin layers $\left(1-3 \mathrm{~mm}\right.$ thick) and incubated for $1 \mathrm{~h}$ at $34^{\circ} \mathrm{C}$ in $140 \mathrm{mmol} .1 \mathrm{KCl}$, $10 \mathrm{mmol.}^{-1}$ MOPS (pH 7.4), aprotinin (10 $\mathrm{mg}^{-1} \mathrm{ml}^{-1}$, and collagenase under continuous shaking. Collagenase type VII (150 units. $\mathrm{ml}^{-1}$ ) was used for skeletal muscle, collagenase type II $|0.3 \%, w / v|$ for heart, and collagenase Ila $(0.05 \%, w / v)$ for adipose tissue. At the end of the incubation the supernatant fractions were collected and the remaining tissue was washed with $\mathrm{KCL} / \mathrm{MOPS}$ and $10 \mathrm{mmol} .1 . \mathrm{EDTA}$, which resulted in a second supernatant fraction. Both supernatant fractions were pooled and Percoll and aprotinin were added to a final concentration of $16 \%(\mathrm{~W} / \mathrm{v})$ and $10 \mathrm{mg} \cdot \mathrm{ml} / 1$, respectively. The resulting suspension was placed at the bottom of a density gradient consisting of a $3-\mathrm{ml}$ middle layer of $4 \%$ Nycodenz $(\mathrm{w} / \mathrm{v}$ ) and an $1 \mathrm{ml} \mathrm{KCV} / \mathrm{MOPS}$ upper layer. This sample was centrifuged at $60 \mathrm{~g}$ for $45 \mathrm{~min}$ at room temperature. Subsequently, the giant membrane vesicles were harvested from the interface of the upper and middle layers, diluted in $\mathrm{KCl} / \mathrm{MOPS}$, and recentrifuged at $900 \mathrm{~g}$ for $10 \mathrm{~min}$. In case of skeletal muscle, the pellet was resuspended in $\mathrm{KCl} / \mathrm{MOPS}$ to a protein concentration of $2-3 \mathrm{mg} \cdot \mathrm{ml}^{\mathrm{l}}$, in case of the other tissues the pellet was resuspended to a proteln concentration of $0.4-0.8 \mathrm{mg} \cdot \mathrm{ml}^{-1}$. 


\section{H-palmitate uptake by giant membrane vesicles}

Vesicular ${ }^{3} \mathrm{H}$-palmitate uptake was measured as previously described 21,23 . Briefly, $40 \mu \mathrm{l}$ of $0.1 \%$ $\mathrm{BSA}$ in $\mathrm{KCl} / \mathrm{MOPS}$ containing unlabeled $\left(15 \mu\right.$ mol.1.1) and radiolabeled ${ }^{3} \mathrm{H}$-palmitate $(0.3 \mu \mathrm{Ci})$ and ${ }^{14} \mathrm{C}$-mannitol $(0.06 \mu \mathrm{Ci})$ were added to a $40 \mu$ giant membrane vesicle suspension. Mannitol is used to correct for non-specific binding of palmitate The incubation was carried out for $15 \mathrm{~s}$. Vesicular ${ }^{3} \mathrm{H}$-palmitate uptake was terminated by the addition of $1.4 \mathrm{ml}$ ice-cold $\mathrm{KCl} / \mathrm{MOPS}, 2.5 \mathrm{mmol}^{-1} \mathrm{HgCl}_{2}$ and $0.1 \%$ bovine serum albumin. The suspension was then quickly centrifuged at $12,000 \mathrm{~g}$ for $1 \mathrm{~min}$. The supernatant fraction was discarded and radioactivity was determined in the tip of the tube. Nonspecific uptake was measured by adding the stop solution prior to addition of the radiolabeled palmitate solution.

\section{Tissue triacylglycerol content}

Total TAG content was determined in whole homogenates of skeletal muscle and heart derived from control and Rgz-treated obese Zucker rats. Lipids were extracted and separated by highperformance thin layer chromatography (HPTLC) as previously described ${ }^{20}$. Quantification was performed by scanning HPTLC plates and by integrating the density areas against an internal standard using Quantity One software.

\section{FAT/CD36, FABPpm and FATP1 protein determination in homogenates and giant membrane vesicles}

FAT/CD36, FABPpm and FATP1 protein contents were determined in homogenates and giant membrane vesicles derived from heart, skeletal muscle, and adipose tissue from control and Rgz-treated obese Zucker rats. Aliquots of these homogenates $(10 \mu \mathrm{g})$ and giant membrane vesicles ( $5 \mu \mathrm{g}$ ) were separated with a $12 \%$ SDS-polyacrylamide gel electrophoresis at $200 \mathrm{~V}$ for 55 min. Proteins were then transferred to a Trans-Blot pure nitrocellular membrane (Bio-rad Laboratorles, Hercules, CA, USA) at $100 \mathrm{~V}$ for $75 \mathrm{~min}$. After blotting the membrane was blocked for $1 \mathrm{~h}$ at room temperature with TBS-T (20 mmol..1-1 Tris-base, $137 \mathrm{mmol.1} \mathrm{H}^{-1} \mathrm{NaCl}, 0.1$ mol.1 $1 \mathrm{HCl}(\mathrm{pH}=7.5), 0.1 \%$ Tween-20) containing 7.5\% BSA for FAT/CD36 and 5\% non fat dry milk for FABPpm and FATP1. A monoclonal antibody $(\mathrm{MO} 25)(1: 20,000)$ directed against human $\mathrm{CD} 36$, a rabbit monoclonal anti-FABPpm antiserum $(1: 3,000)$ and a rabbit polyclonal $\lg \mathrm{G}$ antibody $(1: 1,000)$ directed against FATP1 (M-100, Santa Cruz Biotechnology, CA, USA) were used to detect FAT/CD36, FABPpm and FATP1, respectively. The primary antibody was incubated overnight at $4^{\circ} \mathrm{C}$ and then washed $5 \times 5$ min with TBS.T. After washing the membrane was incubated for $1 \mathrm{~h}$ at room temperature with the secondary antibody, rabbit antimouse polyclonal-horseradish peroxidase (HRP) $(1: 20,000)$ for FAT/CD36 and swine antirabbit polyclonal-HRP $(1: 3,000)$ for FABPpm and FATPI (DAKO, Glostrup, Denmark). Therealter, the membrane was washed $5 \times 5$ min with TBS-T and $2 \times 5$ min with TBS. Protein bands were visualized using enhanced chemiluminescence (ECL) and immunoblot intensities were analysed by densitometry using the computer program Scion Image. The antibody directed against FATP $\$ appeared not entirely specific and a few additional proteins bands were visible after using ECL. By using a molecular mass protein marker we identified the $63 \mathrm{kDa}$ protein band (= FATP1). 


\section{Assays of cytoplasmic FABP}

The contents of heart-type cytoplasmic FABP (H-FABPC) in homogenates of skeletal muscle and heart were determined by a sandwich-type enzyme-linked immunosorbent assay as previously described ${ }^{27}$. The content of adipose-type cytoplasmic FABP (A-FABPC) was measured in adipose tissue, skeletal muscle and heart homogenates by Western blotting using human anti A.FABPC (HyCult biotechnology bv, Uden, the Netherlands).

\section{Statistical analysis}

All data are presented as means \pm S.E.M. Differences between control and Rgz-treated obese Zucker rats were tested by ANOVA and appropriate post-hoc analysis between groups. $\mathrm{P}<0.05$ indicates statistical significance.

\section{RESULTS}

\section{Characteristics of control and rosiglitazone-treated obese Zucker rats}

Obese Zucker rats treated with $\mathrm{Rgz}$ gained significantly more body mass and had a higher food intake throughout the treatment period than their non-treated obese controls (Table 7.1 and Figs 7.2A and B). The calculated metabolic efficiency, i.e., the gain in body mass divided by the amount of food consumed after 16 days of treatment, was significantly higher in the $\mathrm{Rgz}$ group compared to the control group (Fig. 7.2C). Heart mass was significantly higher in the Rgz-treated animals, but after correction for body mass there was

\section{Parameter}

Body and organ mass

Body mass (g)

Body mass gain over 16 days (g)

Heart mass (g)

Heart/Body mass $\left(\times 10^{3}\right)$

Hindlimb mass (g)

Hindlimb/Body mass (x103)

\section{Control}

$453 \pm 23$

$45,6 \pm 15,6$

$1.07 \pm 0,0$

$0.24+0.02$

$260+0.16$

$0.57 \pm 0.02$

\section{Rosiglitazone}

$487 \pm 33^{*}$

$89.3 \pm 11.4^{*}$

$1.17 \pm 0.10 \%$

$0.24 \pm 0.02$

$2.44 \pm 0.17$

$0.50 \pm 0.04$

\section{Plasma metabolites (mmol.|-1)}

Glucose

$$
17.5 \pm 1.3
$$

$11.3 \pm 1.6^{*}$

Tracylglycerols

Fatty acids

Cholesterol

$2.49 \pm 0.57^{*}$

$0.17 \pm 0.03^{*}$

$3.3 \pm 0.1^{\star}$

Table 7.1: Characteristics of control and Rgz-treated" obese Zucker rats

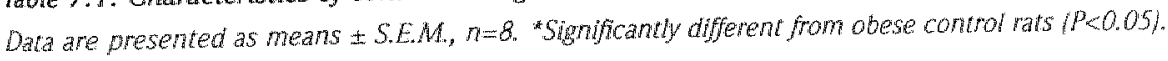




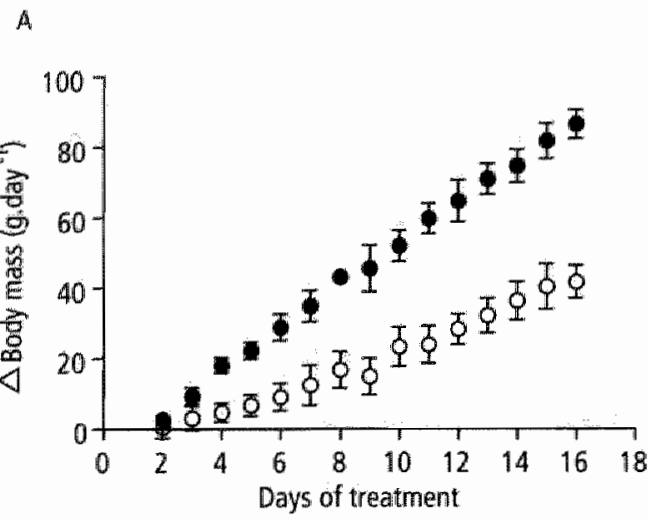

B

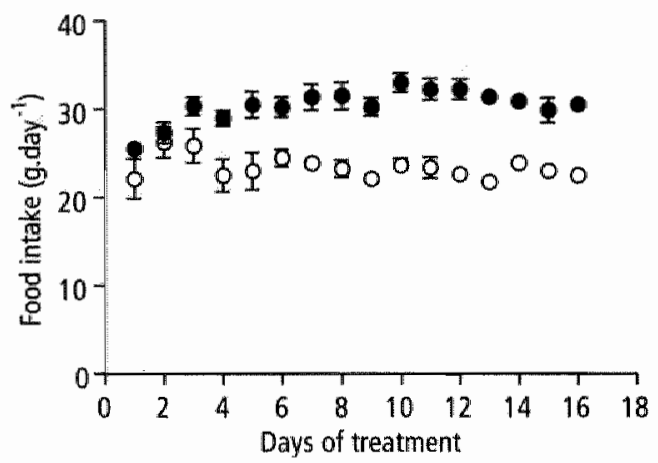

Control

- Rosiglitazone
C

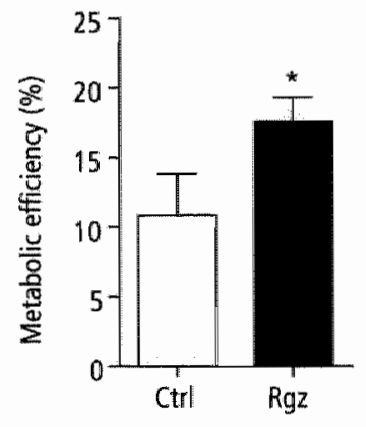

Figure 7.2: Effect of rosighitazone treatment on body mass, food intake and metabiolic efficiency in obese Zucker rats.

A) Change In body mass in the (g), B) Food intake in time (g), C) Metabolic efficiency ( = (total body mass gain/total amownt of food consumed) " $100 \%$ / were determined in (o) control or ( $\bullet$ Rgz-trealed abese Zucker rats. Data are presented as means \pm S.E.M, $n=8$. "Significantly different from control obese amimals (P<0.05).

no difference. In addition, plasma glucose, triacylglycerol (TAG), and fatty acid (FA) concentrations were significantly reduced, 1.e., by $35 \%, 53 \%$ and $56 \%$, in the Rgz-treated group compared to their controls $(p<0.05$, Table 7.1$)$. However, in response to the Rgztreatment plasma cholesterol levels significantly increased by 1.7-fold in obese Zucker rats $(p<0.05$, Table 7.1). This increased plasma cholesterol was equally distributed among the three different lipoprotein fractions (i.e., VLDL, LDL and HDL) (data not shown). The effects of $\mathrm{Rgz}$ are characteristic of the treatment of insulin resistance with PPARy agonists in rodent and human studies $2,3,28-30$. 
Whether the observed decline of plasma FA levels in obese Zucker rats upon Rgz-treatment results in a reduced LCFA availability for metabolically important tissues can be deduced from comparison between the estimation of the LCFA concentration and the apparent $\mathrm{Km}$ of these tissues for LCFAs. The driving force of cellular LCFA uptake is the non-protein-bound LCFA concentration, which is solely a function of the ratio of total LCFAs to albumin concentrations ${ }^{31}$. Corresponding with a decline of the total FA plasma levels from 0.4 to $0.2 \mathrm{mmol} . \mathrm{I}^{-1}$, the plasma non-protein-bound LCFA concentration decreases from 3.8 to $1.7 \mathrm{nmol} .^{-1}$ (calculated for a mixture of palmitate and oleate, the major LCFA species in plasma ${ }^{31}$. Because these LCFA concentrations are well below the apparent $\mathrm{Km}$ of $9.7 \mathrm{nmol} . .^{-1}$ for the LCFA transport system in cardiac myocytes ${ }^{21}$, a decrease in plasma LCFAs will result in a proportionally diminished cellular LCFA uptake rate, assuming that the albumin concentration did not change.

\section{Cellular fatty acid uptake capacity}

Giant membrane vesicles were used to investigate the capacity for LCFA uptake across the plasmalemma of adipose tissue, skeletal muscle and heart. These vesicles allow the measurement of LCFA uptake without confounding effects of LCFA metabolism ${ }^{32}$. These vesicles are oriented right-side-out and contain abundant quantities of $F A B P C$, which serves as a LCFA sink ${ }^{20}$. To be able to compare the LCFA uptake capacity among different tissues, the concentration of non-protein-bound $3 \mathrm{H}$-palmitate was equal in each experiment and set at 5.1 nmol..$^{1}$. This concentration is below the apparent $\mathrm{Km}\left(9.7 \mathrm{nmol} . \mathrm{r}^{1}\right)$ for the transport system in cardiac myocytes ${ }^{21}$ and likely also for that of adipocytes ${ }^{24}$, so that the in vivo LCFA uptake rates are a linear function of the (non-protein-bound) LCFA concentration, as explained above.

A

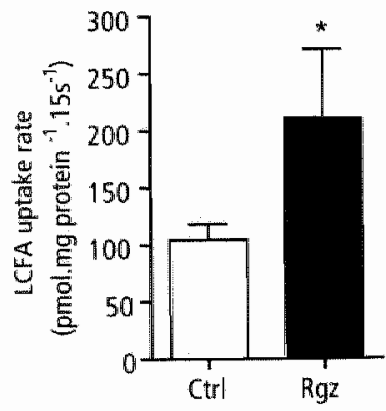

B Skeletal muscle

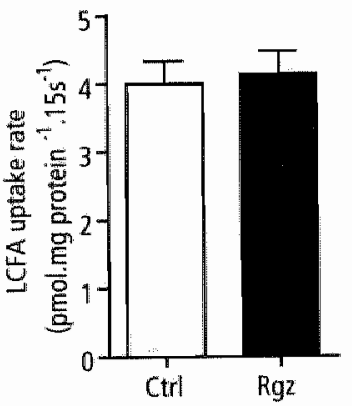

C Heart

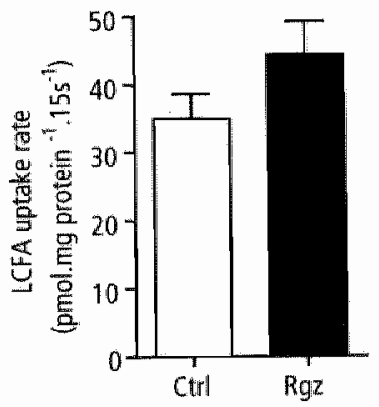

Figure 7.3: "H-palmitate uptake rate in giant membrane vesicles derived from metabollcally important tissules of obiese Zucker rats.

H.palmitate (LCFA) uptake in $15 \mathrm{~s}$ was measured in giant membrane vesicles from adipose tissue $(A)$, sketetal muscle (B) and heart (C) derived from ( $\square$ ) control or ( $D$ ) Rgz-treated obese Zucker rats and expressed as pmolmg protein" $155^{\prime}$. Data are presented as means $\pm S . E . M_{*}, n=8$. "Significantly different from control obese animals $1 P<0.05 \%$ 
A

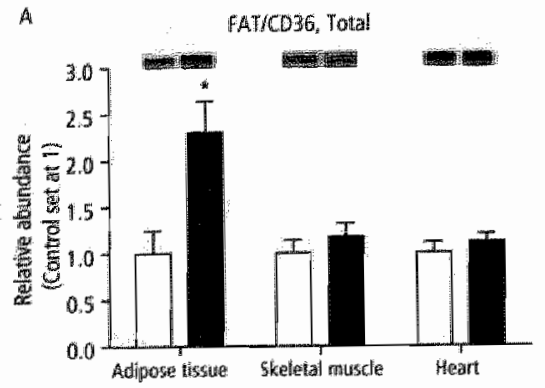

c

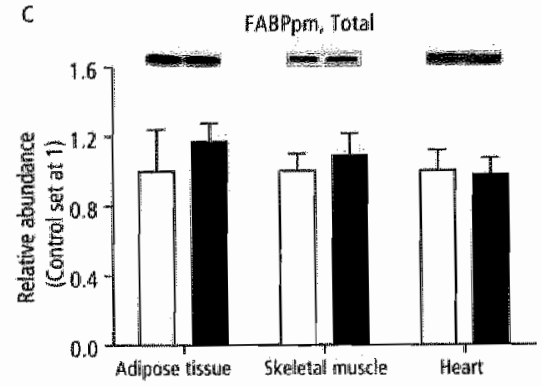

E

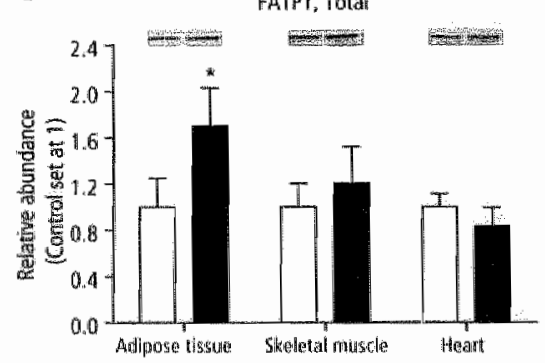

$B$
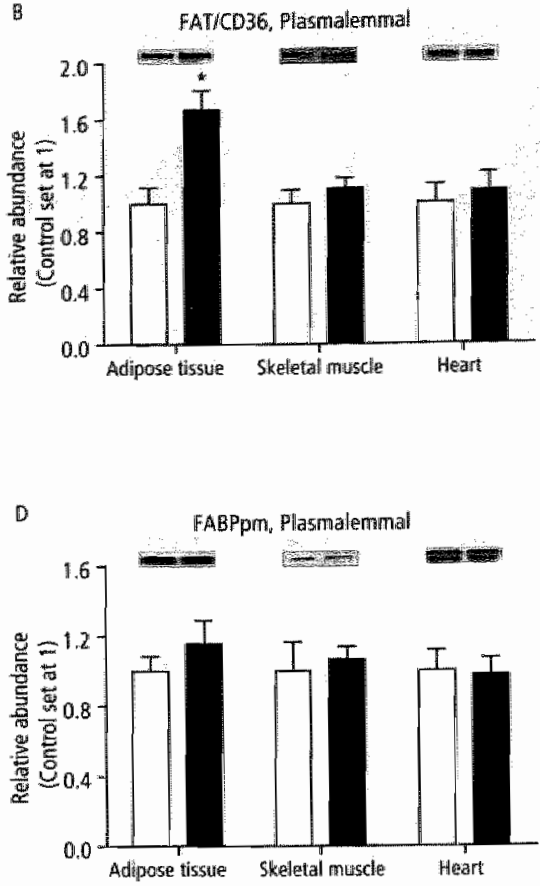

f

FATP ${ }_{\text {, }}$ Plasmialemmal

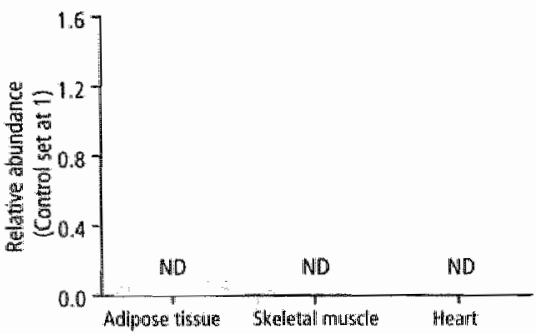

Figure 7. A: FAT/CD3O, FABPpom and FATPI protein content.

Westem bots and quantitation of FAT/CD30, EABPpm and FATPI in total homogenates (A, $C$ and Ely and in giant membrane vesicles ( $=$ plasmalemmal fraction/ $B$, $D$ and $P$ ) derwed from (U) control or ( 1 ) Rgz treated obese Zucker rats. Data are presented as means \pm S.E.M, relative to corresponding control values, which are set at $1, n=8$. "Significantly different from control obese anima"s $(P<0.05 \%$. ND $=$ not detectable.

After 16 days of Rgztreatment, the capacity to take up LCFAs was significantly increased, i.e., by 2.0-1old, in giant vesicles derived from adipose tissue (Fig. 7.3A). In contrast, Rgz-treatment had no effect on the LCFA uptake capacity in skeletal muscle and heart (Figs 7.3B and C]. 


\section{Total and plasmalemmal FAT/CD36, FABPpm and FATP1 protein contents}

In control and Rgz-treated obese Zucker rats, the total protein contents of FAT/CD36, FABPpm and FATP1 were measured in homogenates from adipose tissue, skeletal muscle and heart (Figs 7.4A, C and E), while plasmalemmal FAT/CD36, FABPpm and FATP1 protein contents were determined in the giant membrane vesicle preparations (Figs 7.4B, D and F). In skeletal muscle and heart neither total nor plasmalemmal amounts of FAT/CD36 and FABPpn were altered by Rgz-treatment of obese Zucker rats (Fig. 7.4). In contrast, Rgz-treatment increased the total amount of FAT /CD36 in adipose tissue by 2.3-fold $(p<0.05)$, with a concomitant increase in adipocyte plasmalemmal FAT/CD36 by 1.7-fold (Figs 7.4A and B). The total and plasmalemmal protein levels of FABPpm in adipose tissue were not altered by Rgz-treatment (Figs 7.4C and D). However, in adipose tissue the total amount of FATP1 increased by 1.7-fold after Rgz-treatment, whereas in skeletal muscle and heart FATP1 remained unaltered (Fig. 7.4E). In giant membrane vesicles from adipose tissue, skeletal muscle and heart, the content of FATP1 was below the detection level (Fig. 7.4F). In a previous study using a different antibody, FATP1 was also barely detectable in giant membrane vesicles from skeletal muscle and heart ${ }^{21}$.

\section{Total tissue triacylglyceral content}

The total tissue TAG content was measured in skeletal muscle and heart homogenates obtained from control and Rgz-treated obese Zucker rats. Rgz-treatment significantly lowered the total tissue amount of TAG in heart by $36 \%$. In skeletal muscle total tissue TAG content. was not significantly different between control and Rgztreated obese animals (Fig. 7.5).

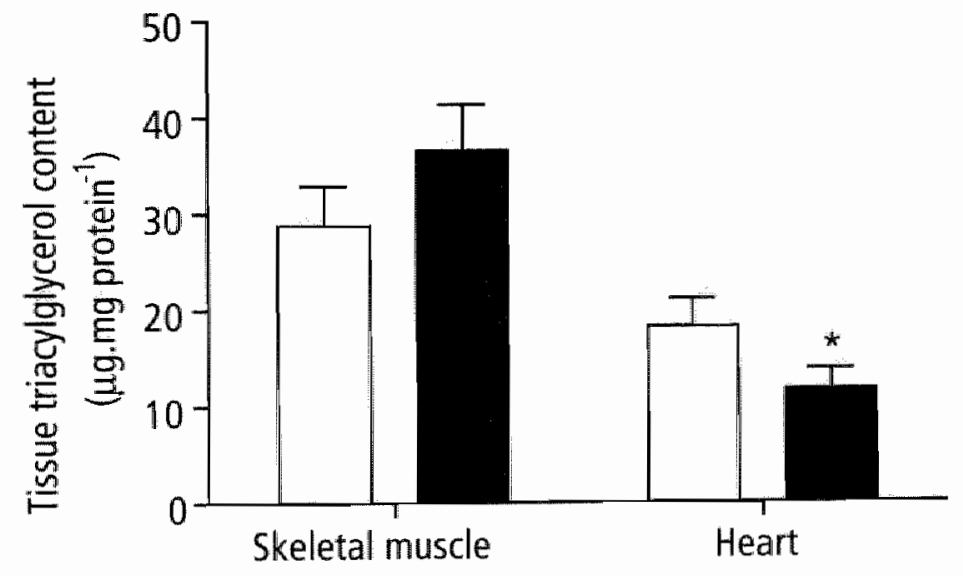

Figure 7.5: Effect of Rgz-treatment on TAG content in heart and skeletal muscle.

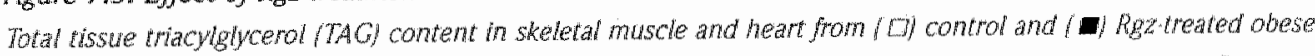
Zucker rats. Tissue TAG content was measured by using HPTLC and expressed as $\mu \mathrm{g}$.mg protein. Data are presented as means i S.E.M., $7=8$. *Significantly different from contral obese animals ( $P<0.05$ ). 


\section{Cytoplasmic heart-type and adipocyte-type FABP contents}

H.FABPC levels were measured in skeletal muscle and heart homogenates, and A-FABPC in adipose tissue, skeletal muscle and heart homogenates. Rgz-treatment resulted in a $48 \%$ decrease in H-FABPc content in skeletal muscle, but had no effect on the H-FABPC content in heart (Fig. 7.6).

In both adipose tissue and skeletal muscle from obese Zucker rats, Rgz administration significantly increased A.FABPC protein levels by 1.4 -fold and 1.2 -fold, respectively $(p<0.05$; Fig. 2.7). A.FABPC levels were almost undetectable in heart homogenates from both control and Rgz-treated obese rats (Fig. 7.7).

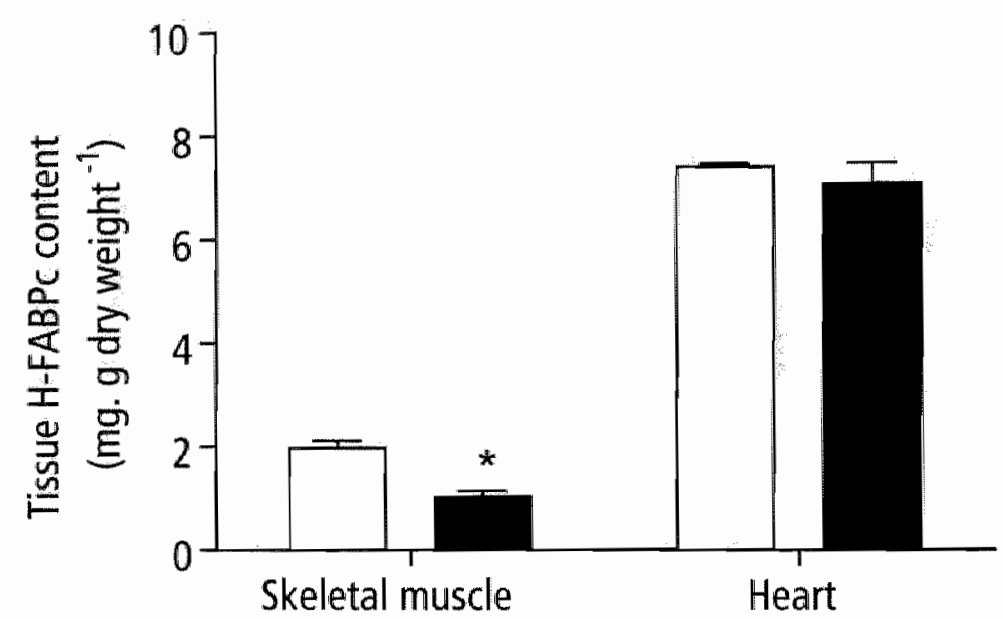

Flgure 7.6: Content of cytosplasmic heart(H)-type FABP in skeletal muscle and heart.

H.FABC levels in sketetal muscle and heart from (D) control and ( 1 ) Rgztreated obese Zucker rats. Data are presented as means s. S. EM, $n=8$, and expressed as ng.g dry weight * Significanty different from controt obese animals $(P<0.05 \%$

\section{Discussion}

The present study implicates FAT/CD36 in the insulin sensitizing action of Rgz in obese Zucker rats. Total and plasmalemmal FAT/CD36 protein content increased in adipose tissue, coinciding with an increased LCFA uptake capacity. Plasmalemmal protein contents of both FABPpm and FATP1 were unaltered in adipose tissue of Rgz-treated obese rats, suggesting no functional role for these putative LCFA transport proteins in the increased LCFA uptake capacity. Rgz-treatment decreased total cardiac TAG content, whereas in skeletal muscle the total TAG content remained unaltered. Interestingly, we demonstrated that in skeletal muscle 


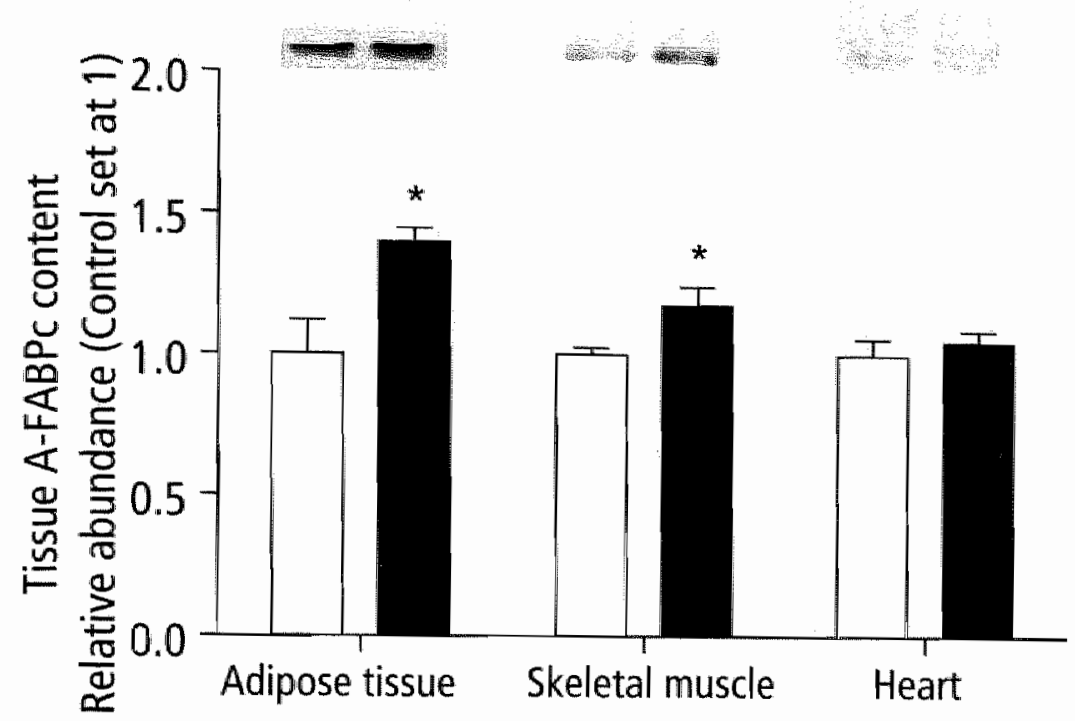

Figure 7.7: Content of cytoplasmic adipose (A)-type FABP in adipose tissue, skeletal muscle and heart. A. FABPC Western blots and quantitation in adipose tissue, skeletal muscle and heart from (O) control and ( 1 ) Rgz treated obese Zucker rats. Data are presented as means \pm S.E.M., relative to corresponding control values, which are set at $1, n=4$. ${ }^{\star}$ Significantly different from control obese animals $(P<0.05)$

of Rgz-treated rats the adipose-type (A)-FABPC content increased, indicating substantial extramyocellular deposition of differentiated adipocytes.

\section{Characteristics of control and Rgz-treated obese Zucker rats}

The present study and those of others 3,28 have demonstrated that Rgz-treated obese Zucker rats become metabolically more efficient. This resulted in significandly more body mass gain during the treatment period of 16 days compared to non-treated obese controls. Studies in T2DM patients and insulin-resistant rodents have demonstrated that this increase in total body mass is predominantly due to an increase in adipose tissue ${ }^{3,20}$. Subsequently, plasma glucose levels decrease during 16 days of Rgz-treatment suggesting that the whole body glucose disposal was increased as has been well documented by others 2,30 , and which is in line with the notion that Rgz improves the tissue insulin sensitivity. Moreover, obese Zucker rats treated with Rgz become less hyperlipidemic, which is reflected in a reduction of bath plasma TAG and FA concentrations. In addition, Rgz significantly increased plasma total cholesterol by 1.7 . fold, which is consistent with the increase of total cholesterol plasma levels seen in Rgz-treated T2DM patients ${ }^{33} \cdot 35$. Altogether, these findings show that in the present study Rgz elicited characteristic effects on body and plasma parameters in obese Zucker rats, that agree with the observations made in other rodent and human studies29,30. 


\section{Effect of Rgz-treatment on the cellular long-chain fatty acid uptake capacity}

Aiterations in cellular LCFA uptake have been proposed to play a prominent role in the insulin. sensitizing effect of TZDS in obesity and T2DM. Recently, we demonstrated that the LCFA uptake capacity is increased in adipose tissue, heart and skeletal muscle from insulin-resistant, obese Zucker rats, compared to lean control rats ${ }^{23}$. However, limited data is available on Rgz's effect on the cellular LCFA uptake capacity in these metabolically important tissues from obese rats. Therefore, in the present study we determined the LCFA uptake capacity in adipose tissue, skeletal muscle and heart by using giant membrane vesicles as a model. We are the first to demonstrate that the LCFA uptake capacity significantly increases by 2.0 -fold in adipose tissue from Rgztreated obese rats, compared to control abese rats. The present findings provide a mechanistic insight for findings from Oakes and coworkers ${ }^{3}$, who calculated, by using an in vivo tracer method, that darglitazone increases by 2.3 -fold the deposition of plasma LCFAs into adipose tissue from obese Zucker rats.

In contrast to adipose tissue, in skeletal muscle and heart the LCFA uptake capacity was unaffected by Rgz-treatment in obese rats. However, we calculated that by reducing the plasma FA and TAG levels, the availability of these substrates for nonadipose tissue, such as skeletal muscle and heart do not compensate the decline in plasma LCFA availability by increasing their LCFA uptake capacity.

\section{Alterations in membrane fatty acid transport protein levels after rosiglitazone- treatment}

In the present study, we showed that Rgz-treatment had differential effects on the LCFA uptake capacity in adipose and muscle tissues from obese rats. It is well documented that piasmalemmal LCFA uptake is predominantly mediated by LCFA transport proteins ${ }^{12}$, and several proteins have been identified to play a role in this transport system, i.e., FAT/CD36, FABPpm, and FATP14. Here, we demonstrated that in adipose tissue, total FAT/CD36 and FATP1 protein contents were significantly increased in Rgz-treated obese Zucker rats, whereas the total FABPpm protein content was unaltered. This is in agreement with the observation that both FAT/CD36 and FATPI have a PPRE. It is unknown whether a PPRE is present in the upstream regions of the FABPpm gene 36 . The fact that Rgz has an effect on FAT/CD36 and FATP, and not on FABPpm, suggests that such a PPRE is lacking in the FABPpm gene. Others already showed that mRNA levels of FAT/CD36 and FATP1 are upregulated in adipose tissue derived from TZD-treated, insulin resistant rodents 1.11. Apparently, changes in MRNA levels of FAT/CD36 and FATPI are in accordance with the respective total protein levels.

In addition to the amount of membrane-associated LCFA transport proteins, their subcellular localization is important for their function ${ }^{15}$. In earlier studies, we demonstrated that FAT/CD36 and FABPpn are present both at the plasma membrane and in intracellular storage compartments 15,37 . Moreover, we found a positive correlation between the amount of FAT/CD36 residing at the plasma membrane and the rate of cellular LCFA uptake21.

In the present study, we demonstrated that upon Rgz-treatment the plasmalemmal content of FAT/CD36 increased by 1.7 -fold, closely matching the increase of 2.3 -fold in its total expression and the 2.0-fold induction of the plasmalemmal capacity to take up LCFAs. In 
contrast to FAT/CD36, both the total and plasmalemmal amounts of FABPpm did not alter. Although the content of FATP1 in adipose tissue increased upon Rgz-treatment, FATP1 was undetectable in giant membrane vesicles from adipose tissue, skeletal muscle and heart. This latter finding suggests that FATPI plays quantitatively no prominent role in the transmembrane transport of LCFAS. Rather, FATP1 may function in the intracellular trapping of LCFAs, presumably by its acyl-CoA synthetase activity ${ }^{38}$. The Rgz-induced 1.4. fold increase of A-FABPC in adipose tissue relates to the presence of a PPRE also in the gene of this protein 14,36 . However, because FABPc's have a permissive and no regulatory role in cellular LCFA uptakel4, this increase will hardly influence the rate of LCFA uptake in adipose tissue. Therefore, these combined observations indicate that the rise in FAT/CD36 expression in adipose tissue is pivotal in explaining the increase in cellular LCFA uptake

In contrast to adipose tissue, Rgz-treatment had no effect on total and plasmalemmal protein contents of FAT/CD36, FABPpm and FATP1 in both skeletal muscle and heart from obese Zucker rats. These observations are in line with the unaltered LCFA uptake capacity in skeletal muscle and heart derived from Rgz-treated obese rats (present study) and with the low expression of PPAR $\gamma$ in these tissues ${ }^{39}$.

\section{Alterations in cytoplasmic fatty acid transport protein levels after rosiglitazone- treatment}

In addition to membrane-associated LCFA transport proteins, tissue-specific cytoplasmic FABP's play a role in intracellular LCFA transport. Once present inside the cell, LCFAs can bind to FABPC, which directs LCFAs towards their different sites of metabolism25. Several tissuespecific isoforms of FABPC have been identified, such as adipocyte-type (A)-FABPC in adipose tissue, and heart type $(H)-F A B P c$ in skeletal muscle and heart 40 . It has been demonstrated that after Rgz-treatment of obese rats mRNA and protein levels of A-FABPC in adipose tissue are significantly increased 11,41 . In contrast to upregulation of A.FABPC, H.FABPC levels were decreased in skeletal muscle and unaltered in heart derived from Rgz-treated obese Zucker rats.

A functional role of H-FABPC in LCFA uptake became evident when it was shown that in heart and skeletal muscle of homozygous H.FABPC knock-out mice plasmalemmal LCFA uptake is severely hampered. However, in heterozygous mice even a loss of $50 \%$ of H-FABPC in skeletal muscle had no effect on cellular LCFA uptake, suggesting a permissive rather than a rate-limiting role of H-FABPC in plasmalemmal LCFA uptake 2 . Therefore, the $48 \%$ decrease in H-FABPC in skeletal muscle of obese rats after Rgz-treatment most likely will not affect intracellular transport of LCFA in skeletal muscle.

\section{Effect of rosiglitazone on total TAG contents and A-FABPC protein levels in skeletal muscle and heart}

It is well documented that the accumulation of intramyocellular TAGs positively correlates with the development of tissue insulin resistance ${ }^{43,44}$. Recenty, we demonstrated that the total TAG content was threefold higher in hearts of obese Zucker rats than in their age-matched controls ${ }^{45}$. The present study showed that after Rgz-treatment the total cardiac TAG content of obese Zucker rats significantly declined, suggesting that the heart becomes more insulin 
sensitive. A reduction in intramyocellular TAGs is not only beneficial for the tissue sensitivity to insulin, but also for functioning of the heart. Young and coworkers 46 demonstrated in obese rats a positive correlation between contractile dysfunction and an increase in intramyocellular lipids. Moreover, an enhanced protection of the heart against ischemic injury after TZD. treatment was demonstrated by Sidell and coworkers 30 .

In contrast to heart, Rgztreatment had no effect on the total TAG content in skeletal muscle from obese rats. Puzzling findings were presented by the fact that Muurling and coworkers ${ }^{4}$ have shown an increased amount of TAGs in skeletal muscle from Rgz-treated $\mathrm{ob} / \mathrm{ob}$ mice, whereas the whole body insulin sensitivity improved. In our study and the one of Muurling and coworkers total TAG content was measured in total tissue homogenates making it impossible to discriminate between intramyocellular and extramyocellular TAGs. Therefore, the amount of $A-F A B P C$, an established marker of differentiated adipocytes 25 , was measured in tissue homogenates and demonstrated to be increased by 1.4-fold and 1.2-fold in adipose tissue and skeletal muscle, respectively, after Rgztreatment, whereas in heart A-FABPc was almost undetectable in Rgz-treated obese rats. In T2DM patients treated for 3 months with a TZD, it was indeed demonstrated that the extramyocellular TAG content in skeletal muscle increases by 1.4-fold $4 \%$. A.FABPc is expressed in differentiated adipocytes and not in skeletal muscle, thus adipose tissue deposition between muscle fibers increases. Because PPAR $\gamma$ activation elicits the differentiation of adipocytes ${ }^{10}$, we believe that the increase in muscular adipocytes is attributable to the differentiation of existing preadipocytes into adipocytes. Accordingly, an increased deposition of adipocytes between skeletal muscle fibers could mask a possible decline in intramyocellular TAGs in skeletal muscle cells after Rgz-treatment.

\section{Concluding remarks}

One of the hallmarks of obesity and T2DM is tissue insulin resistance ${ }^{48}$. It is well described that treatment of T2DM with TZDs improves insulin sensitivity 6,28 , exemplified by an increased cellular glucose uptake in both skeletal muscle and heart from TZD-treated obese Zucker rats 5,30 . Here, we show that an increased plasmalemmal protein content of FAT/CD36 in adipose tissue plays a pivotal role in the insulin sensitizing effect of Rgz-treatment in obese Zucker rats. As a result of Rgz-treatment, adipose tissue extracts LCFAs from the circulation thereby reducing the LCFA supply to non-adipose tissue such as skeletal muscle and heart. The decreased LCFA availability reduces the myocytal LCFA uptake rate and limits intramyocellular TAG accumulation, leading to an increased muscle insulin sensitivity. Thus, improvement of muscle insulin sensitivity can be considered secondary to the direct effect of $\mathrm{Rgz}$ on FAT/CD36-mediated LCFA uptake by adipose tissue.

\section{ACKNOWLEDGEMENTS}

The antibodies for FAT/CD36 and FABPpm were kindly provided by Dr N.N. Tandon (Otsuka Research Marryland, Besthesda, MD, USA) and Dr. J. Calles-Escandon (SmithKlineBeecham, Miami, FL, USA), respectively. The authors would like to thank Dr. M.M.A.L. Pelsers and Mrs. M. Minderhoud for their excellent technical assistance, and Dr. N.C. Schaper (Department of 
Internal Medicine/Endocrinology, University Hospital Maastricht, the Netheriands) for providing rosiglitazone (Avandia ${ }^{\circledR}$ ). This study was supported by the Netherlands Heart Foundation, grant 2000.156 , by the Heart \& Stroke Foundation of Ontario, and the Canadian Institutes of Health Research. Arend Bonen holds a Canada Research Chair in Metabolism and Health. Jan F.C. Glatz is Netherlands Heart Foundation Professor of Cardiac Metabolism. Joost J.F.P. Luiken is the recipient of a VIDI-Innovational Research grant from the Netherlands Organization for Scientific Research (NWO-ZonMw grant nr. 016.036.305). 


\section{References}

1. Martin $G$, Schoonians $\mathrm{K}$, Lefebre $\mathrm{AM}$, Staels $\mathrm{B}$ and Auwer I. Coordinate regulation of the expression of the fatty acid transport protein and achl-COA synthetase genes by PPARalpha and PPARgamma acrivators. I Btol Chems. 1997,272282107

2. Jucker BM, Schaeffer TR, Haimbach RE, Mctntosh TS, Chun D, Mayer M, Onlstein DH, Davis HN, Smitl SA; Cobizz AR and Sarkar SK. Nomalization of skeletal muscle gyycogen synthesis and glycolysis in rosiglitazone treated Zucker faty rais: an in wo nuclear magnetic resonance study. Drabetes. 2002; 51200073 .

3. Oalkes ND. Thaten PG, Jacinto SM and Lung B. Thiazolidnediones increase plasma-adipose lissue FFA exchange capacity and enhance insuln mediated control of spstemic FFA availlability. Diaberes. 2001,50:1158-65.

4. Muurling M, Mensink RP, Pijl H, Ronujn JA, Havekes LM and Voshol PJ. Rosiditazone improves musce insulin sensitivity, irrespective of increased trigyceride content, in obrob mice. Metabolsm, 2003,52:1078-83.

5. Kramer D, Shapiro R, Adler A, Bush E and Rondinone CM. Insulin-sensitzing effect of rosigliazone (BRL, 49653) by regulation of glucose transporters in muscle and fat of Zucker rats. Metabolism. 2001,50:1294300.

6. Berger I and Moller DE. The mechanisms of action of PPARS. Amu Rev Med. 2002,53:40935.

7. Lehmann IM, Moore LB, Smitholiver TA, Wilkson WO, Wilson TM and Kilewer SA. An andidabetic thiazoldinedione is a high aftunty hand for peroxisome proliferatoractivated neceptor ganma (PPaR gamma). I Biol Chen. 1995:270:12953-6.

8. Wilson TM, Brown P. Stentbach DD and Henke BR. The PPAR: from orphan receptors to drug discowery. Med Chen. 2000; $43: 527-50$.

9. Gilde Af, van der Lee KA, Willemsen PH, Chinetti $G$, van der Leij FR, van der Vusse GJ, Staels B and van Bilsen M. Peroxisone proifteratoractwated receptor (PPAR) alpha and PPARbeta/delta, but not PPARgamma, modulate the expression of genes inwolved in cardiac lipid melabolism. Cir Res. 2003,92.51824.

10. de Souza $\mathrm{Cl}$, Ecchardt M, Gagen $\mathrm{K}$, Dong $M$, Chen $W_{n}$ Laurent $D$ and Bukey BF Effects of piogliazone on adipase tisste remodeling within the setting of obesity and insulin resistance. Diabetes. $2001,50: 1803.71$.

11. Motoima K, Passiny P, Peies IM, Gonzalez Fl and Latruffe N. Expression of putative fatty acid transporter genes are tegulated by peroxisome proliferatorativated receptor apha and gamma aciwators in a tissue and inducerspecific mannet I Btol Cherr. 1908273:16710.4.

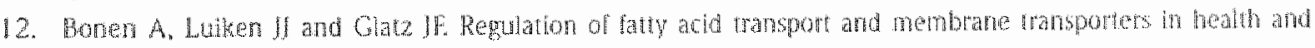
diserse. Mol Cel biochem 2002:239:181.02.

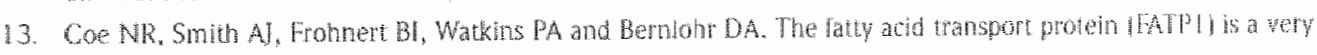
long chain acyl-CoA synthetase. J Bot Chen. 1099;274:363004.

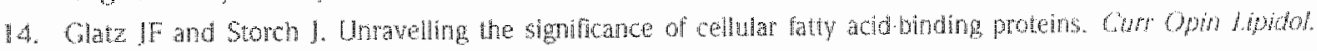
$2001: 12: 207.74$

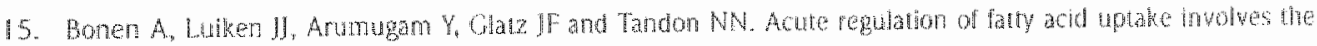

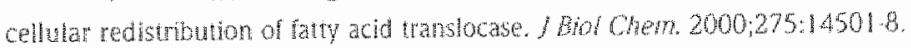

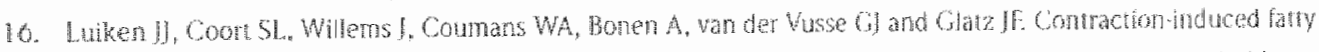

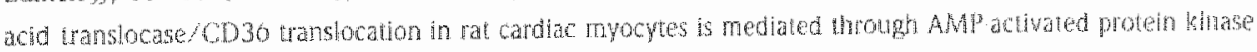
signaling. Dizberes. 2003,52162734

17. Luken I. Dyck DJ, Han XX, Tandon NN, Arumugam Y, Glaz JF and Bonen A Insulin induces the tranglocalion of the fatty acid transporter FAT/CD36 to the plasma membrane. Am I physhof Endochinol Merab. $2002 \cdot 282: E 4.45$ 


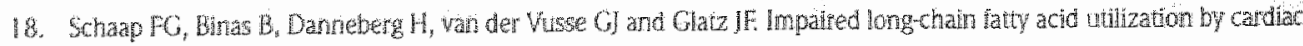

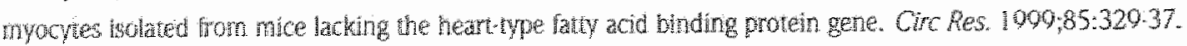

19. Seda $O$, Kardova 1. Krenova $D$ and Kren $V$. Rosigitazone falls to improve hypertighceridemia and gucose toletance in CD 30 deficint BN SHR congenic rat strain. Physiol Genomics, $2003 ; 1273-8$.

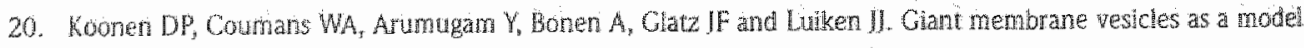
wh study celluar substrate uptake dissected from metabolsm. Mor Cell Bochem. 2002;230:121-30.

21. Luken If, Turcotie LP and Bonen A. Protein mediated palmitate uptake and expression of faty acid transpont proteins in heart giant vesicdes. J Lipid Res: 1900; $40: 1007$-16.

22. Luiken J), Schap FC, van Nieuwenhoven FA, van der Wusse GJ, Bonen A and Glaz: JE Cellutar fatty acid transport in heart and skeletal muscle as fachtated by proteins. Liphots. 1999;34 Suppl:5169.75.

23. Luken Ji, Anumugam Y, Dyck DI, Bell RC, Pelsers MM, Turcotte LF, Tandon NN, Glatz JF and Bonen A. increased rates of fatty acid uptake and plasmalemmal faty acid transponers in obese Zucker rats. IBor Chen. $2001: 270,40567-73$.

24. Luiken If, Arumugam Y, Bell RC, Calles Escandon !, Tardon NN, Gatz Jf and Bonen A. Changes in faty acid transport and transporters are related to the severity of insulin deficiency. Am / Physiof Endocrinol Metab. $2002 ; 283: 001221$.

25. Kaikaus RM, Bass MM and Ockner RK. Functions of faty acid binding protens. Experientia. 1090;46:617-30.

26. Havekes LW, de wit EC and Princen HM. Celluar free cholesterol in Hep G2 cells s only partially avaliable for down-regulation of low density lipoprotein receptor activity. Biochem /. 1987:247.739-40.

27. Vork MM, Glat IF, Surtel DA, Knubben HI and Van det Wusse OJ. A sandwch enzme linked immuno-sorbent assay for the determination of rat heart fatty acid binding protein using the streptandin biotin system. Application to tssue and effluent samples from normoxic rat heatt perfusion. Bhochim Biophys Acta. 1991:1075:199.205.

28. Larsen TM, Toubro 5 and Astrup A. PPARganma agonists in the treatment of ype ll diabetes: is increased faness comnensurate with long tem efficacy? Int J Obes Relat Metab Disord. 2003:27:147.61.

20. Miyazak Y, Gass L., Triplitt C, Matsuda M, Cusi K, Mahankali A, Mahankall S, Mandarino LJ and DeFronzo RA. Effect of rosiglitazone on glucose and nomesterfied fatty acid metabolism in Type Il diabetic patients. Diaketologia. 2001:44:22109.

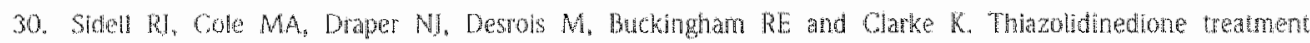
nomalizes insulin resistance and ischemic infury in the aucker Faty rat heart. Dhabes. 2002,51:11107.

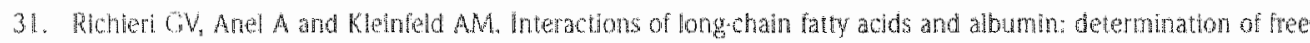
fatry actid levets using the fluorescent probe ADIAB. Biochemisty. 1093:32:7574.80.

32. Bonen A, Liken If. Lin S, Dyck DI, Kens B, Kristiansen S. Turcotte LP, Van Der Vusse G and Glaz JE. Pamitate

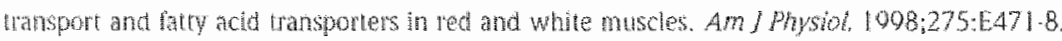

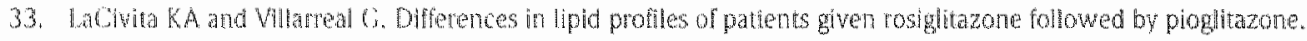
Gint Med Res Opon 2002,18:36\%70.

34. Meriden T. Progess with hizolidinediones in the management of type 2 diabetes melitus. Chin Ther $2004: 26: 177,90$

35. Peters Harmel AL, Kenda!l DM, Buse TE, Boyle PJ, Marchetti A and Lau H. Impact of adjunctive tharaldinedione therapy on blood lipid levels and glycemic control in patients with rype 2 diaberes. Curr Med Res oph 2004:20:21523.

30. Frohner BI, Hui TX and Bernola DA. Identification of a functional peroxisome proliferator responsive element in the murine fats acid transport protein gene. / Brol Chent 1099:274:30707. 
37. Chabowski A, Coort SL, Calles Escandon I, Tandon NN, Glaz IF, Luiken I] and Bonen A. Insulin stimulates fatty acid transport by regulating expression of FAT/CD30 but no FABPpr. An / Physiol Endowinot Metab. $2004287 \times 2781.9$

36. Hal AM, Smith AJ and Bernlohr DA. Characterization of the Acyl-CoA swnthelase activity of purified murne fatcy acid transport proten 1. J Biol Chern 2003;278:43008-13.

39. Tugwood JD and Montague CT. Biology and toxicology of PPARgarma ligands. Hum Exp Toxicol 2002;21:429-37.

40. Zimmerman AW and Veerkamp IH. New insights into the structure and lunction of fatty acid binding proteins. Cell Mol Life Sc: 2002:59:1090-110.

41. Yamauchi T, Kamon J, Waki $H_{x}$ Murakami K, Motojma R, Komeda K, lde T, Kuboia N, Terauchi $Y$, Tohe $K_{\text {, Miki }}$ $H$, Tsuchida A, Akanuma $Y$, Nagai $R$, Kimu:a $S$ and Kadowaki T. The mechanisms by which both heterozygous peroxisome prolferatoractwated receptor gamma IPPARgammal deficjency and PPARganma agonist improve insulin resistance. J Btol Chem, $2001 ; 270: 41245-54$.

42. Luken J, Koonen DP, Coumans WA, Pelsers MM, Bhas B, Bonen A and Glatz IF Longechan ratly acid uptake by skeletal muscle is impaired in homozygous, but nat heterozygous, hearthpe Fal $2003 ; 38: 491 \cdot 6$.

43. Pan DA, Lillioja S, Kriketos AD, Miner Mr, Baur LA, Bogardus C, Jenkins AB and Stortien LH. Skeletal muscle triglyceride levels are irversely related to insulin action. Diabetes. $1007 ; 460983-8$.

44. Young LH. Insulin resistance and the effecis of thiazolidinediones on cardiac metabolism. Am/ Med. 2003;115 Suppl BA:75s-80S.

45. Coort SL, Hasselbaink DM, Koonen DP, Willems J Coumans WA, Chabowksi A, varn der Vusse G, Bonen A, Glatz JF and Luiken J. Enhanced sarcolemmal FAT/CD36 content and triacylghtocerol storage in cardiac myocytes from obese Zucker rats. Diaberes. 2004;53:1655.03.

46. Young ME, Guthre PH, Razeghi P, Leighton B, Abbasi S, Patil S, Youker KA and Taegmeyer H. Impaired longchain fatty acid oxidation and contractile dystunction in the obese Zucker rat heart. Diaberes. 2002:51:2587-05.

47. Mayerson AE, Hundal RS, Dufour S, Lebon V, Befroy D, Cline GW, Enocksson S, Inzucchi SE, Shulman GI and Petersen KF. The effects of rosigitazone on insulin seinsitivity, lipolysis, and hepacic and stetetal muscle triglyceride content in patients with type 2 diabetes. Diabetes. 2002;51:797.802.

48. Shuman GI. Celluar mechansms of insulin resistance. / Cho /mest 2000;100:171.6. 


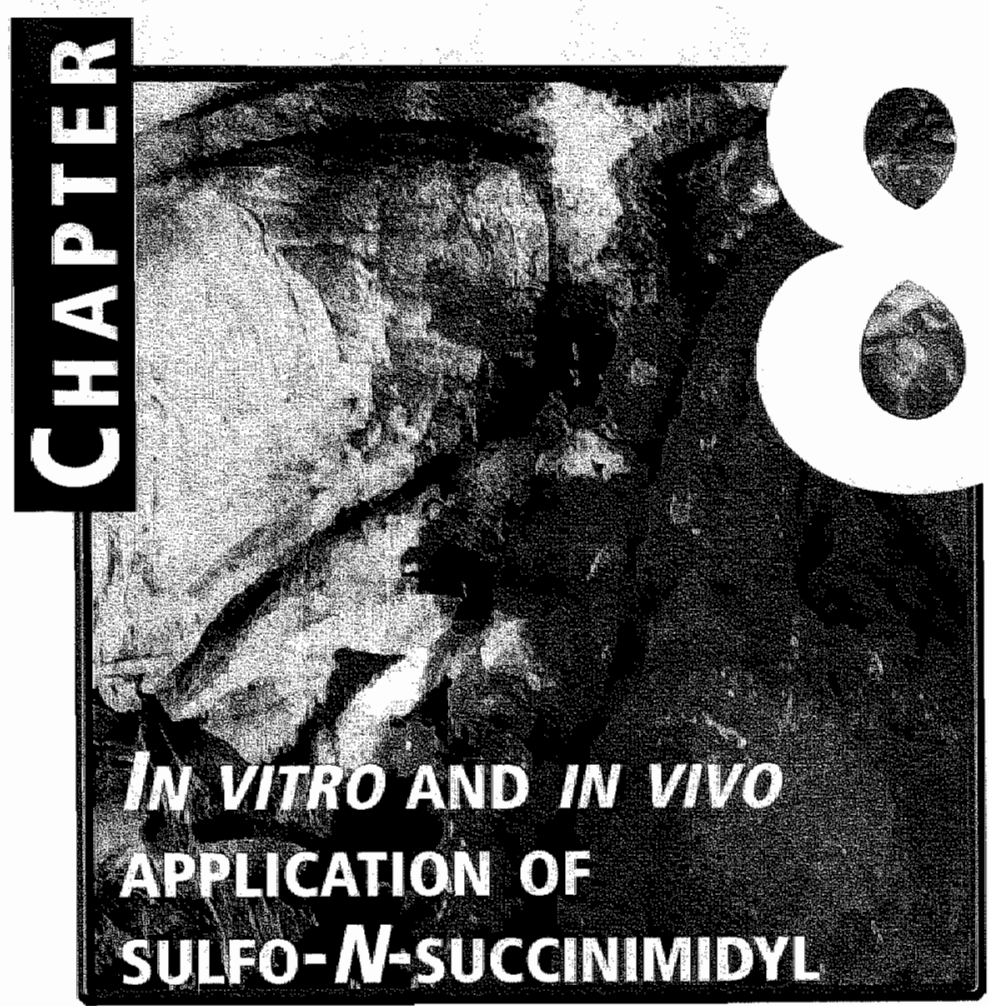

\section{ESTERS OF LONG-CHAIN \\ FATTY ACIDS}


Chapder 


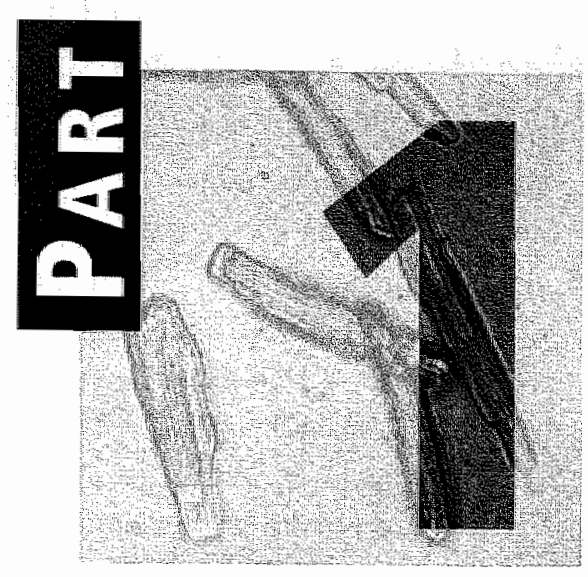

\section{SULFO-N-SUCCINIMIDYL} ESTERS OF LCFAS SPECIFICALLY INHIBIT FATTY ACID TRANSLOCASE (FAT)/CD36-MEDIATED CELLULAR FATTY ACID UPTAKE

Susan L.M. Coort', Jodil Willems', Will A. Coumansi, Ger J. van der Vusse", Arend Bonen $^{2}$, Jan F.C. Glatz', and Joost J.F.P. Luiken'.

Mol Cell Biochem. 2002; 239:213-9. (review)

Department of Physiology, Cardiowascular Research Institute Maastricht ICARIM, Maastutcht Uniwersity, Maastricht, the Netherlands.

2Department of Kinesiology, Waterloo University, Waterloo, ON, Canada 


\section{Abstract}

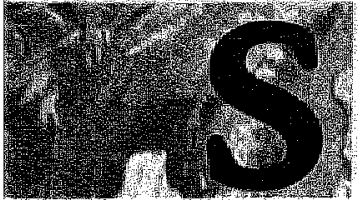

ulfo-Nsuccinimidyl esters of long chain fatg adids (LCFAs) are powerful lools to investigate the functional significance of membrane associated proteins involved in the LCFA uptake process. This notion is based on the following observations. First, sulfo-N-succinimidyl oleate (SSO) was found lo inhibit the bulk of LCFA uptake Into various cell types, 1,e, rat adipocyles, type 11 pneumocytes and cardiac myocytes. Second, ustrg giant membrane vesicles, in which LCFA uptake can be investigated dissected from its metabolism, SSO retained the ability to largely mhibit LCFA uptake. This indicates that the primary action of $S S O$ is the Inhibition of plasmalemmal LCFA transport. Third, SSO has no inhibitory effect on glucose and octanoate uptake into glant membrane vesicles derived from heart and skeletal muscle, indicating that its action is specific for cellular LCFA uptake. Finally, $\$ S O$ specifically inhibits the $88 \mathrm{kDa}$ plasmalemmal fatty acid transporter, FAT/CD36, which sesuls in an arrest of the transport function of this protein. In addition to its imhibltory action at the level of the plasma membrane, evidence is presented for the lack of a direct inhibitory effect on LCFA metabolism in intact cells. The relalive contribution of oxidation and esterification to LCFA uptake is nolaltered in the presence of SSO. As an example of its application we used SSP to study the role of TAT/CD36 in contraction and insulin-stimulated LCFA uptake by cardiac myocytes, showing that this transporter is the primary site of regulation of cellular LCFA utilization. 


\section{INTRODUCTION}

Long-chain fatty acids (LCFAS) are not only important substrates for energy production, but also function as precursors for signalling molecules, mediators of gene expression and constituents of membrane phospholipids 1 . In order to investigate the significance of membraneassociated proteins involved in the LCFA uptake process in mammalian cells, derivatives of LCFAs, which maintain the lipophilic properties of LCFAs but are able to crosslink with proteins, could be powerful tools. In particular, LCFAs have been coupled to N-hydroxysulfosuccinimides through an ester linkage. In general, sulfo- $N$-succinimidyl esters of carboxylic acids are used as acylating reagents for proteins and as crosslinkers 2 . These sulfo- $N$ succinimidyl esters were found to react at high yield with proteins present at the plasma membrane $e^{2,3}$.

Harmon and coworkers ${ }^{4}$ used sulfo $N$-succinimidyl esters of FAs with different chainlength in order to identify plasma membrane proteins that may be involved in the LCFA uptake process. They demonstrated that sulfo- $N$-succinimidyl oleate (SSO) labelled an $88 \mathrm{kDa}$ rat adipocyte membrane protein, which resulted in a decrease in LCFA uptake in isolated rat adipocytes. Moreover, they discovered that in isolated rat adipocytes pretreated with SSO the intracellular water space, glucose uptake and retinoic acid permeation were unaltered. These findings gave indirect evidence that SSO acts at the level of the plasma membrane. Furthermore, because of their membrane permeability intracellular processes are thought not to be directly affected by sulfo- $N$-succinimidyl esters of LCFAs.

In this review we discuss the use of sulfo- $N$-succinimidyl esters of LCFAs to examine cellular LCFA uptake in vitro. First, we investigated the possible role of an $88 \mathrm{kDa}$ plasma membrane protein, notably fatty acid translocase (FAT)/CD36, in the inhibitory action of SSO on LCFA uptake in heart and skeletal muscle. Second, evidence is presented that SSO specifically binds to FAT/CD36. Finally, examples of the application of sulfo- $N$-succinimidyl esters of LCFAs in studies on the regulation of cellular FAT/CD36-mediated LCFA uptake are discussed.

\section{Characterization and SYNTHESIS OF SULFo- $N$-SUCCINIMIDYl ESTERS OF LCFAS}

Sulfo-N-succinimidyl acyl esters are composed of a LCFA, such as palmitic acid or oleic acid, coupled to $N$-hydrosulfosuccinimide. These esters are synthesized in our laboratory by a procedure described by Harmon and coworkers ${ }^{4}$. Briefly, in this procedure the FA reacts with a N-hydrosulfosuccinimide in the presence of dicyclohexylcarbodiimide (DCC) under anhydrogenous conditions. In the upper part of figure 8.1 the general structure of a sulfo- $N$-succinimidyl ester of a $F A$ is given. In our laboratory we are able to synthesize sulfo- $N$ succinimidyl oleate (SSO) and palmitate (SSP). Moreover, by coupling either ${ }^{3} \mathrm{H}$-labeled or ${ }^{14} \mathrm{C}$-labeled palmitate to the $N$-hydrosulfosuccinimide we synthesized ${ }^{3} \mathrm{H}$ - and ${ }^{14} \mathrm{C}$ - SSP.

To identify the synthesized sulfo- $N$-succinimidyl esters of a specific LCFA, mass spectral analysis can be applied ${ }^{4}$ as well as infrared spectroscopy 5 . The latter is routinely used in our laboratory. It has been described that in an aqueous environment these ester hydrolyse after approximately two hours. A scheme for the hydrolysis of sulfo- $N$-succinimidyl acyl esters is given in figure 8.1. 

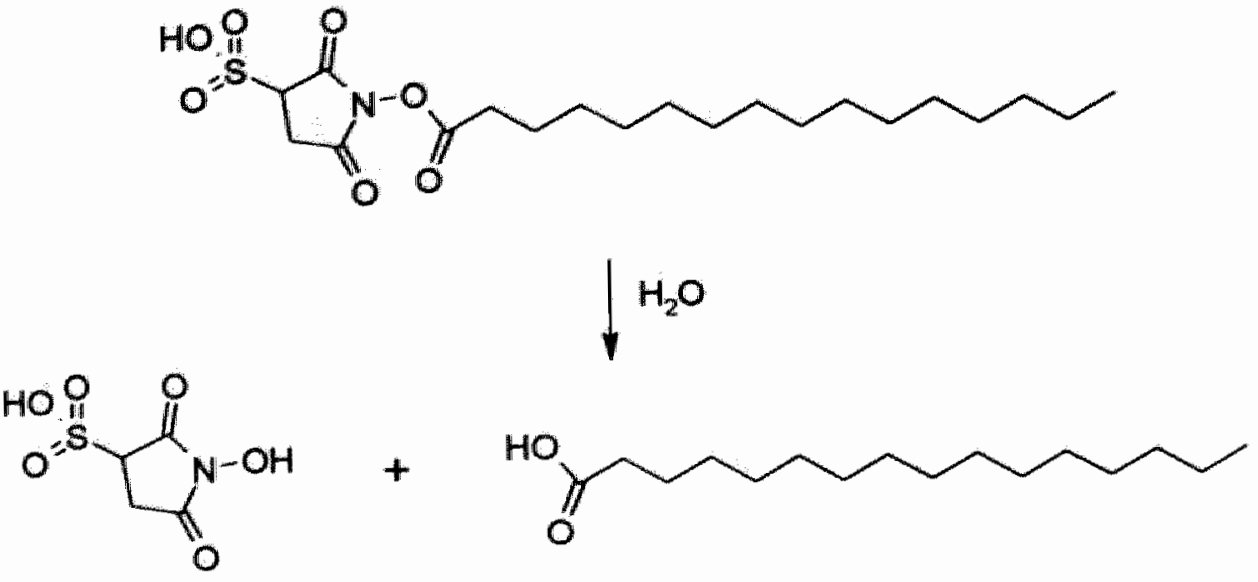

Figure 8.1: Hydrolysis of sulfo-N-succinimidyl esters of fatty acids.

The general structure of sulfo-N-succinimidyl esters of fatly acids is given in the upper panel. The molecule consists of a reactive sulfo $N$-succinimidyl head group and an acyl chain tail, such as myristate (C14:0), patmitate (C16:0) and oleate $(\mathrm{C} 1800)$. in the lower panel the hydrolysis products are given.

\section{EFFECTS OF SULFO- $\boldsymbol{N}$-SUCCINIMIDYL ACYL ESTERS ON UPTAKE OF LCFAS BY VARIOUS CELL TYPES}

The first study on the effect of sulfo- $N$-succinimidyl ester of LCFAs on substrate utilization was performed by Harmon and coworkers ${ }^{4}$. The uptake of oleate, linoleate and stearate into isolated rat adipocytes treated for $25 \mathrm{~min}$ with $0.2 \mathrm{mmol.1}{ }^{-1} \mathrm{SSO}$ was significantly reduced by approximately $65 \%$ in each case. These researchers also demonstrated that the length of the carbon chain of the acyl moiety chemically bound to the reactive sulfo- $N$ succinimidyl group was crucial for the function of the ester. Sulfo- $N$-succinimidyl propionate $(\mathrm{C} 3: 0)$ had no effect on the oleate uptake by rat adipocytes, while esters of oleate $(\mathrm{C} 18: 1)$, palmitate $(\mathrm{C} 16: 0)$ and myristate $[\mathrm{Cl}$ :0) had an inhibitory effect on the LCFA uptake by adipocytes. These findings indicate that only LCFAs coupled to a reactive sulfo- $N$-succinimidyl group influenced cellular LCFA uptake, which is in agreement with the notion that the transport system mediating uptake of oleate is specific for L.CFAs, and is not involved in uptake of short- and medium-chain latty acid4.

In rat type II pneumocytes, in which LCFAs are required for production of surfactant, uptake of palmitate was reduced upon pretreatment with $\mathrm{SSO}$, the maximal inhibition being $80 \%$ at 1 mmol. $\%$. In cardiac myocytes, for which LCFAs are the main source of energy ${ }^{7}$, incubation with 0.4 mmol.H SSO inhibited palmitate uptake by $50 \% 5$. Thus in rat adipocytes, type II pneumocytes and cardiac myocytes, SSO exerts an inhibitory effect of comparable magnitude on LCFA uptake, i.e., between 50 and 80\% (Fig. 8.2). 


\section{Adipocytes Pneumocytes Cardiomyocytes}

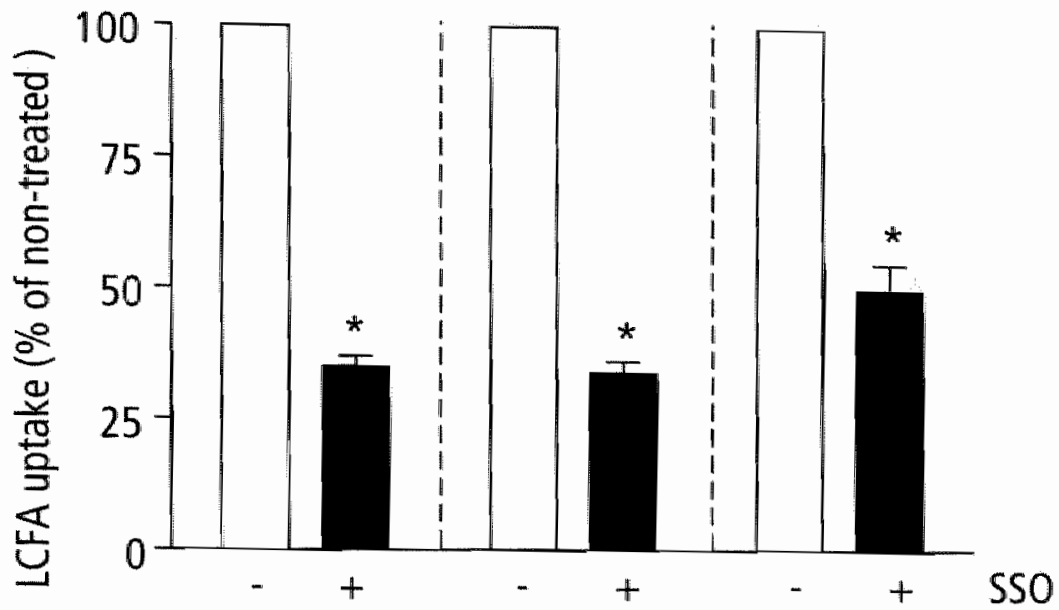

Figure 8.2: Effect of SSO on LCEA uptake by various cell types, i.e, rat adipocytes, type Il pneunnocytes and cardiac myocytes.

These various cell types were either non-treated ( $\square$ ) or pretreated with SSO ( $\quad$. Data are presented as percentage of non treated cells \pm S.EM. and were obtahed from Harmonet al." Guthman et al., Luikenet al.s. "Significanily different from non treated cells.

\section{EFFECT OF SULFo- $\boldsymbol{N}$-SUCCINIMIDYL ESTERS OF LCFAS ON MYOCARDIAL LCFA UPTAKE}

In yiew of the crucial role of LCFAs in cardiac energy production?, research with respect to the effect of sulfo-N-succinimidyl acyl esters on cellular LCFA uptake predominantly focuses on the heart. In this section we compare the effect of SSO/SSP on cardiac LCFA uptake in three different models. First, in isolated rat cardiac myocytes, in which LCFA uptake is functionally linked to its metabolism, SSO inhibited LCFA uptake by $50 \%, 8$, , as described in the previous section. Second, giant membrane vesicles derived from rat heart tissue were used to investigate myocardial LCFA uptake. Giant membrane vesicles are a model by which LCFA uptake can be investigated dissected from subsequent metabolism $\%, 10$. These vesicles consist of a membrane of pure sarcolemmal origin and contain soluble cytoplasmic proteins, like the cytoplasmic fatty acid bindig protein (FABPc) which acts as â sink for sequestered LCFAs. In addition, giant membrane vesicles lack intracellular structures like endoplasmatic reticulum, endosomes and mitochondria, which latter absence implicates the inability of giant membrane vesicles to oxidize LCFAS\%, Using giant membrane vesicles derived from heart, we discovered that inhibition of LCFA uptake 
by SSO occurs in the absence of mitochondrial $\beta$-oxidation. The comparable inhibitory effect of SSO on heart giant membrane vesicles $(-70 \%)$ and cardiac myocytes $(-50 \%)$, i.e., in the absence or presence of LCFA metabolism, indicates that inhibition of transsarcolemmal LCFA transport is the primary action of sulfo- $N$-succinimidyl esters of LCFAs. Third, the effect of SSP was investigated at total heart level by Tanaka and coworkers". They demonstrated that perfusing rat heart with $10 \mu$ mol.1" SSP resulted in a decrease in palmitate uptake by approximately $24 \%$. Thus not only at the cellular level, but also at total tissue level, sulfo- $N$-succinimidyl esters of LCFAs are able to inhibit cardiac LCFA uptake.

\section{INABILITY OF SULFO- $\boldsymbol{N}$-SUCCINIMIDYL ESTERS OF LCFAS TO INHIBIT CELLULAR UPTAKE OF SUBSTRATES OTHER THAN LCFAS}

In order to investigate whether SSO specifically inhibited LCFA uptake, we used giant membrane vesicles derived from rat heart and skeletal muscle to determine if SSO inhibits the

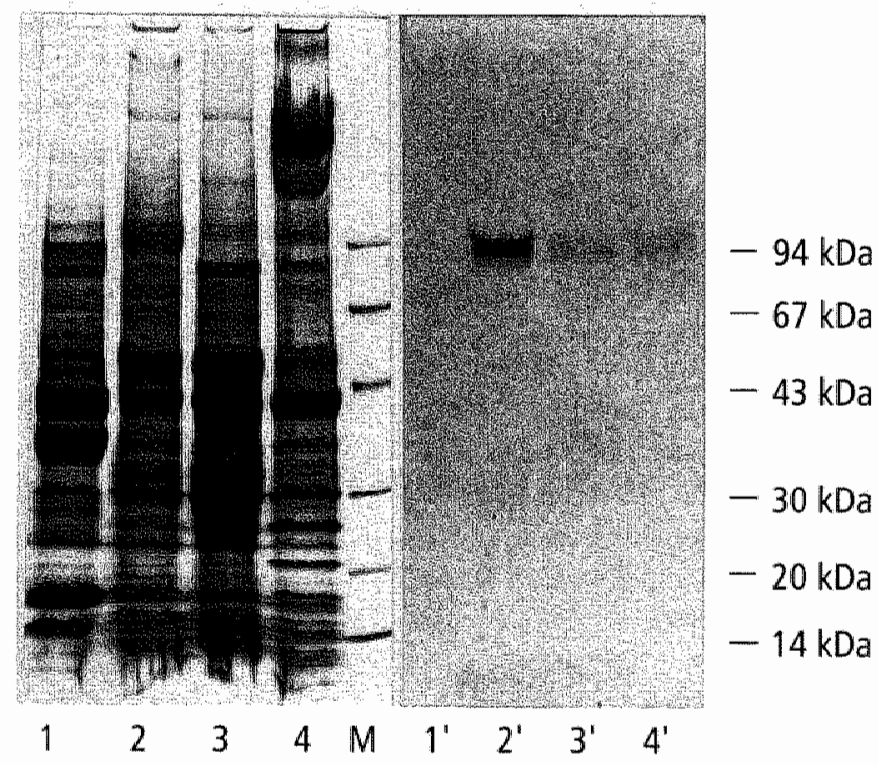

Figure 8.3: Presence of 3H-label in myocardial cell fractions obtained from 3 H-SSP perfused rat hearts.

SDS. PACE was perromed, followed by autoradiography. The molecular weight standards (lane M) were phosphorylase

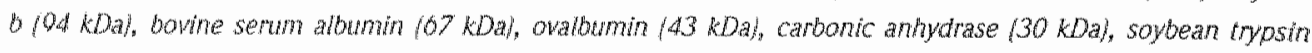
inhibitor $120.1 \mathrm{kDa}$ and $\mathrm{x}$ lactalbumin $14 \mathrm{kDal}$, Lanes $1-4$ and 1 "4" present rat heart fractions and autoradiographs, respectwely. Lane 1 and "': Cytosolic fraction, lames 2 and 2 : microsomal fraction, lanes 3 and 3': mitochondrial fraction, lanes 4 and 4 ': cell debris. These data are reproduced with permission of Dr. T. Tanaka, Japan!l. 
uptake of other substrates, such as glucose and medium chain FA, as well as LCFAs. SSO had no effect on the uptake of glucose into giant membrane vesicles derved from either heart ar skeletal muscle, whereas phloretin, a non-specific inhibitor of carriemediated transport, inhibited glucose uptake into these vesicles by more than $80 \% 9$. In contrast, in metabolically active cardiac myocytes ${ }^{5}$ and in the perfused heart' increase in glucose uptake by $40 \%$ and $31 \%$, respectively. We speculate that the 550 -induced inhibition of myocardial LCFA uptake lowers the intracellular levels of nonesterified LCFAs, Which might stimulate the uptake and cellular consumption of glucose. With respect to the medium-chain FAs, the uptake of octanoate in heart giant membrane vesicles was not inhibited by $\mathrm{SSO}^{9}$. Taken together, these findings indicate that the effect of sulfo- $N$-succinimidyl esters of LCFAs are restricted to the uptake of LCFAs.

\section{Specific binding of sulfo-N-succinimidyl esters of LCFAs to fatty acid translocase (FAT)/CD36}

At present three putative membrane associated proteins are described to be involved in transmembrane LCFA transport, each showing a characteristic tissue occurrence. These

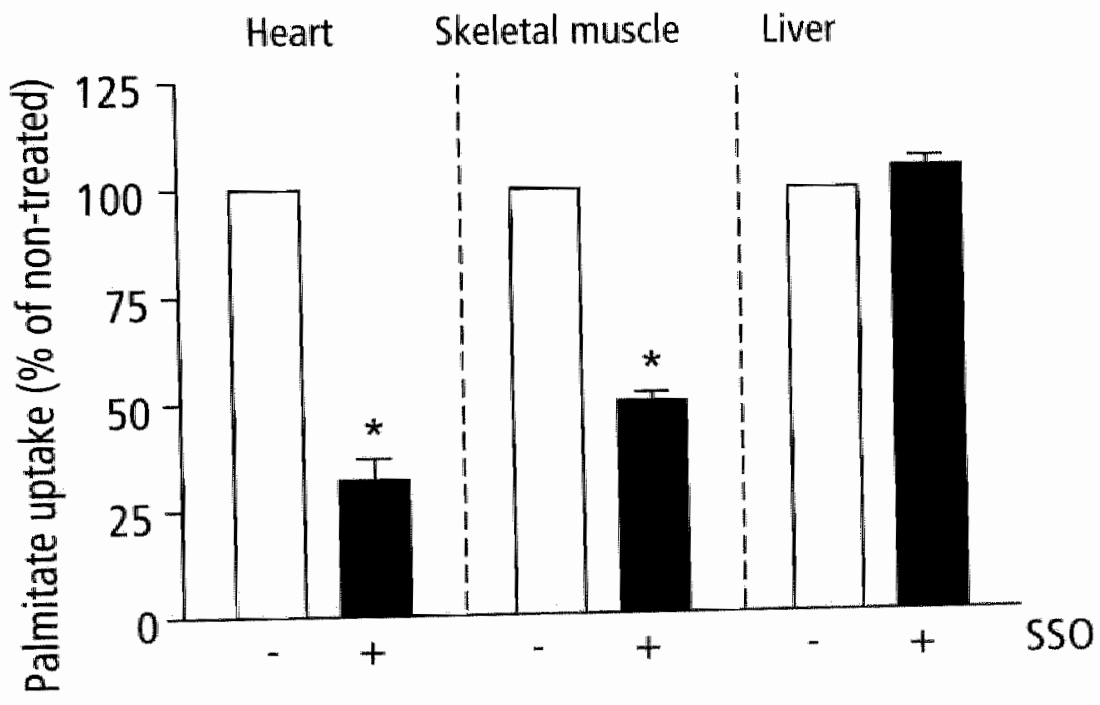

Figure 8.4: Effect of sulfo-N-Succinimidyl oleate (SSO) on the palmitate uptake rate in heart, skeletal muscle and liver giant membrane vesicles.

sH-Palmitate uptake in $15 \mathrm{sec}$ was measured in rat heart, skeletal muscle and liver giant membrame vesicles. Vesicles

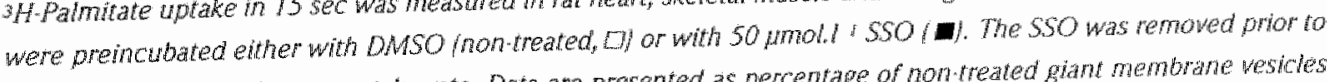
assessment of the palmitate uptake rate. Data are presented as percentage of nontreated giant membrane wesicies tS.EM. of 3 experiments carried out in different grant membrane preparations and published by Luken et al. wh. * Significandly different from non treated giant membrane vesicies, $p<0.05$. 
proteins are a $40 \mathrm{kDa}$ plasmalemmal fatty acid binding protein (FABPpm) 12 , an $88 \mathrm{kDa}$ highly glycosylated fatty acid translocase (FAT), the rat homologue of human CD36 13,14 , and a $62 \mathrm{kDa}$ fatty acid transport protein (FATP) 15 . Various cell types, in particular cardiac myocytes, are known to contain all three described plasma membrane-associated proteins.

There are two lines of evidence that sulfo- $N$-succinimidyl esters of LCFAs specifically bind to FAT/CD36, and in that manner inhibit the transport of LCFAs across the plasma membrane. First, in plasma membrane fractions of rat adipocytes, in which SSO reduced LCFA uptake by $65 \%$ (see earlier section), ${ }^{3} \mathrm{H}-\mathrm{SSO}$ specifically labelled an $88 \mathrm{kDa}$ rat adipocyte membrane protein which was identified as FAT"1. In addition, Tanaka and coworkers ${ }^{11}$ showed, using SDS-PAGE autoradiography, that in myocardial cell fractions from ${ }^{3} \mathrm{H}-\mathrm{SSP}$ perfused rat hearts a single microsomal protein of 80-90 kDa was labelled (Fig. 8.3).

Second, we discovered that, in contrast to giant membrane vesicles derived from heart and skeletal muscle, in which SSO inhibited LCFA uptake by 70 and $50 \%$, respectively, SSO had no effect on the LCFA uptake capacity in liver giant membrane vesicles (Fig. 8.4). In contrast to heart and skeletal muscle giant membrane vesicles, low levels of FAT/CD36 are present in liver giant membrane vesicles (Fig. 8.5). Moreover, Koonen et al. ${ }^{16}$ demonstrated that in giant membrane vesicles from liver, FATP and FABPpm are abundantly expressed. Therefore, a lack of inhibitory action of SSO on LCFA uptake in rat liver giant membrane vesicles suggests that SSO specifically interacts with FAT/CD36 (Fig. 8.5). The lesser inhibitory action of SSO in skeletal muscle compared to heart is related to the lower abundance of FAT/CD36 in the former tissue (Fig. 8.5). Thus, these two lines of evidence bolster the notion that SSO specifically inhibits the LCFA transport function of FAT/CD36.

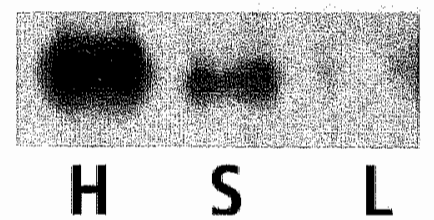

Figure 8.5: Protein content of FAT/CD36 in heart, skeletal muscle and itiver:

5 ug protein of giant membrane vesicles derived from heart (H), skeletal muscle (S) and liver (L/ was used to determine FAT/CD36 protein content. A representative westem blot is given.

\section{Metabolic effects of sulfo-N-succinimidyl esters of LCFAs}

In our studies we observed that SSO inhibited mitochondrial $\beta$-oxidation and esterification in intact cardiac myocytes (Fig. 8.6) ) $^{5}$ The maximal inhibition of initial palmitate uptake in cardiac myocytes pretreated with SSO was observed at a concentration of 0.4 mmol.1.1 or higher and amounted to 50\%. Mitochondrial $\beta$-oxidation and esterification were also inhibited by SSO, comparable with the amount of inhibition of palmitate uptake, $35 \%$ and $49 \%$, respectively5. Importantly, (i) the inhibitory effects of SSO on palmitate utilization (oxidation and esterification) are comparable to the $S S O$-induced inhibition of palmitate uptake across the sarcolemma, and (ii) the relative (\%) partitioning of LCFAs into oxidation and esterification was not changed by SSO. The observations, therefore, suggest that inhibition of LCFA oxidation and esterification are secondary to inhibition of LCFA uptake. 


\section{Application of sulfo-N-succinimidyl esters of LCFAs in studies on the regulation of cellular LCFA uptake}

Recently, we observed that LCFA uptake by heart and skeletal muscle is subject to short-term regulation by cellular contractions ${ }^{17,18}$, and by the hormone insulin 19 . For these studies sulfo$N$-succinimidyl esters of LCFAs were crucial tools to describe the involvement of FAT/CD36 in short-term inducible LCFA uptake. The first evidence that FAT/CD36 was involved in the regulation of LCFA uptake came from studies with giant membrane vesicles derived from rat hind limb muscle that had been electrically-stimulated. We demonstrated that the palmitate uptake rate was increased by $47 \%(p<0.05)^{20}$. However, the stimulatory effect on palmitate uptake, induced by electrostimulation, in these vesicles was completely inhibited by SSOH. Similarly, electrostimulation of cardiac myocytes increased the LCFA uptake by $49 \%$, an effect that could be completely inhibited by SSP (Fig. 8.7). Besides electrostimulation, insulin aiso had a stimulatory effect of LCFA uptake into cardiac myocytes, i.e., 1.4-fold induction at 10 nmol. $1^{-1}$ insulin. This insulin-mediated increase in LCFA uptake could be completely inhibited by SSP (Fig. 8.7).

These inhibitory actions of SSO indicate that the stimulatory effects of both electrical stimulation and insulin are mediated by alterations in the activity of sarcolemmal FAT/CD36.

Uptake Oxidation Esterification

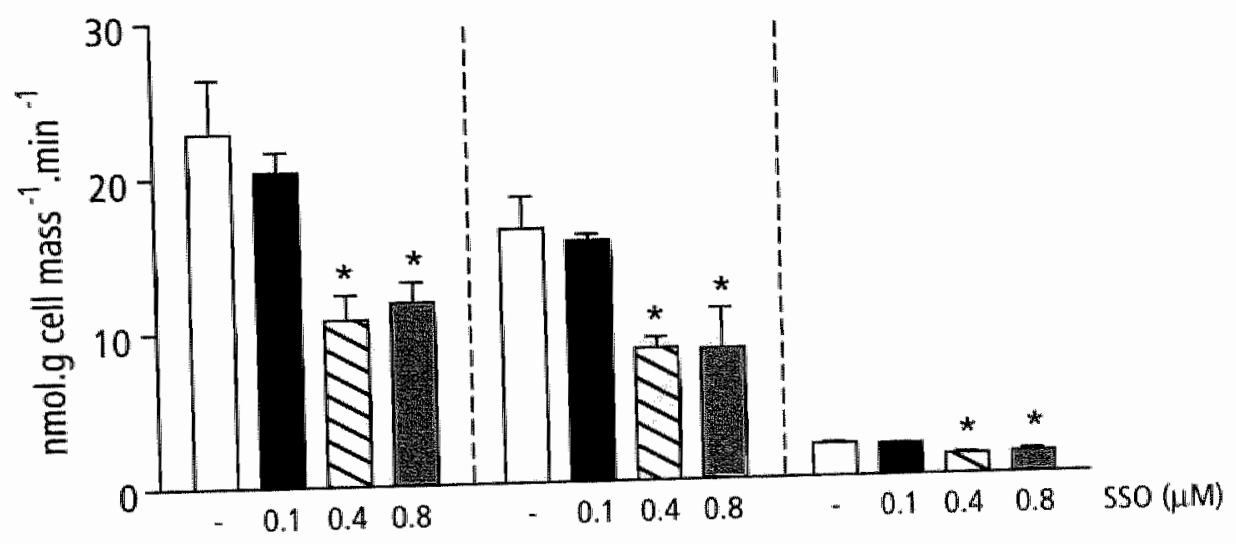

Figure 8.6: Myocardial palmitate uptake, oxidation and esterification as function of the concentration of suljo$\mathrm{N}$-succinimidyl oleate (SSO).

Uptake was measured in 3 min and " $\mathrm{CO}_{2}$ production, thus oxidation, and esterification in 20 min after "aC palmitate addition in isolated cardiac myocytes. These cardiac myocytes were pre incubated with ether $5 \%$ DMSO

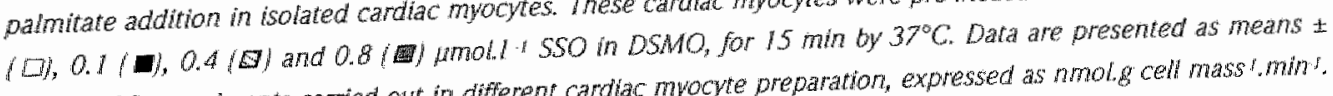
S.E.M. of 3 experiments carried out in different cardiac mocyte preparation, expressed as nomolg cell mass .mint. * Significantly different from nontreated cardiac myocytes. 
Subsequentiy, we demonstrated with subcellulaire fractionation experiments that the contraction- and insulin-stimulated LCFA uptake involved translocation of FAT/CD36 from intracellular storage pools towards the plasma membrane 17,21 .

\section{CONCLUDING REMARKS}

Sulfo-N-succinimidyl esters of LCFAs are useful compounds to study the mechanism and regulation of LCFA uptake by mammalian cells in vitro, because (i) they are specific in blocking uptake of LCFAs while having no direct effect on uptake of other substrates, and (ii) they do not directly interfere with the intracellular metabolic fate of LCFAs. Furthermore, there is convincing evidence that SSO and SSP specifically bind to FAT/CD36, and in doing so they inhibit its transport function. When cellular LCFA utilization is altered, sulfo-N-succinimidyl esters of LCFAs are useful tools to determine whether or not FAT/CD36 is involved. However, more insight is needed to identify the binding site of sulfo- $N$-succinimidyl esters of LCFAs to FAT/CD36 in order to unravel the molecular mechanism of their inhibitory action on LCFA uptake by this transporter.

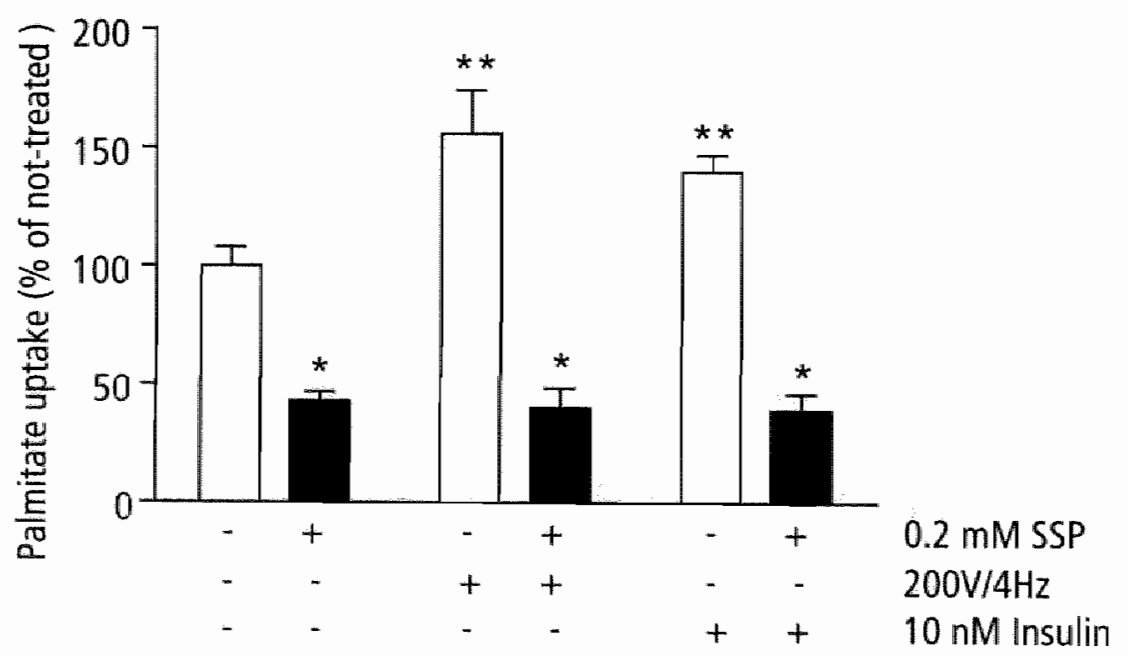

Figure 8.7: Effect of sulfo-N-succinimidyl palmitate (SSP) on the palmitate uptake rate in cardiac myocytes: either electrically stimulated or treated with insulin.

${ }^{4} \mathrm{C}$ patmitate uptake was measured in electrically-stimulated cardiac myocytes, or in cardiac mooctes treated with 10 nmoll: insulin, in the absence or presence of SSP. Data are presented as percentage of non-treated cardiac myocytes \pm S.EM. "Significantly different from cardiac myocytes not treated with SSP (p<0.05)" "Significantly" different from non treated cardiac myocytes (p<0.05). 


\section{ACKNOWLEDGEMENTS}

We wish to thank Dr. T. Tanaka, Osaka, Japan, for providing the SDS.PAGE autoradiography blot presented in figure 8.3. Our studies were supported by the Netherlands Heart Foundation, grants D98.012 and 2000.156, the Canadian Institutes of Health Research, and the Heart and Stroke Foundation of Ontario. 


\section{REFERENCES}

1. Van der Vusse GI, van Bilsen $M$ and Gatz JF. Cardiac fatty acid uptake and tanspont in health and disease. Cardiovasc Res. 2000; 45,27993 .

2. Anjaneyulu PS and Staros IV Reactions of Nhydroxysulfosuccinimide active esters. Int f tapt Proten Res. $1987,30: 11724$

3. Giedroc DP, Puett D, Ling $N$ and Staros W Demonstation by covalent cross-linking of a specife interacton between beta-endorphin and calmodulin. I Biod Chem. 1983;258:16-9.

4. Hamon CM, Luce P, Beth AH and Abumatad NA. Labeling of adipocyte membranes by sulto N.succinimidy? derivatives of longechain fatty acids: inhibion of faty acid transport. Membr Bol. 1095121.261.8\%.

5. Lujken J, wan Nieuwenhoven FA, America G, van der Vusse GJ and Gatz JF. Upalke and meabolism of paimitate by isolated cardiac myochtes from adult rats involwement of sarcolemmal proteins. fliph hes. $1907 ; 38: 745.58$.

6. Guthmann F; Haup R, Looman AC, Spener F and Rustow P. Fatty acd translocase/CD 30 mediates the uptake of palmitate by ryte II pneumocytes. Am f Physol. 1009;277.L191.0.

7. wan def Vusse G], Glaiz $\mathrm{JF}_{4}$ Stam HC and Reneman RS. Fatty acid homeosiasis in the nomoxic and ischemic heart. Physiol Rev 1992:72:881940.

8. Gatz JF and Storth I. Unwavelling the significance of cellutar fatty acid-binding proteins. Curr Oph Lipiod. $2001 ; 1226774$.

9. Luiken J], Tutotte LP and Bonen A, Protein-mediated palmitate uptake and expression of fatty acid transport protens in heart gian wesicles. / Lipid Res 1909,40:100\%-16.

10. Luiken UJ, Schap FG, van Niewwenhowen FA, van der Vusse G, Bonen A and Glatz fF Celular fatiy acld tramsport in heart and skeletal muscle as faciliated by proteins. Liplds. 1909;34 Suppl:S160-75.

11. Tanaka $T$ and Kawamura K. Isolation of myocardia! membrane longchan fatty acidbinding protein: homology with a rat membrane protein implicated in the binding or transport of longchain faty acids. 1 Mol Cefl Cardiol. $1095 ; 27: 101322$.

12. Isola LM, Zhou SL, Kiang CL, Stump DD, Bradbury MW and Berk PD. 3T3 fibroblasts Utansfected with a CDNA for mitochondrial aspariate aminotransferase express plama membrane faty acid binding protein and saturable fatry acid uptake. Proc Nall Acad So U 5 A $1905,92086070$.

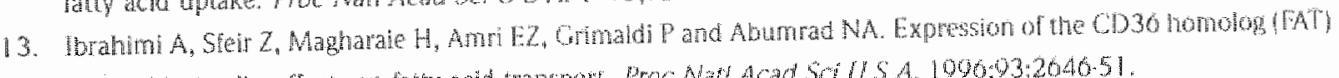

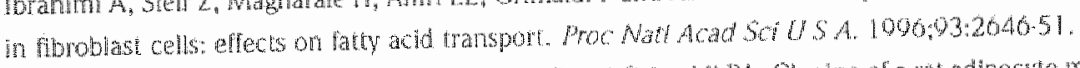

14. Abumad MA, Gaghrabi MR, Amr E2. Lopez E and Crimaldi PA. Conting of a lat adipocyle membrane protein implicated in binding of transport of longechain fatty acids that is induced during preadipocyte differentiation. Homology with human CD36. J Bol Chem 1903;268:17665.8.

15. Schaffer IE and Lodish HE. Expression cioning and charactenkation of a nowet adipocyta long chan faty acid Uanspori protein. Cell 1994,79:42730.

16. Koonen DP. Coumans WA, Arumugarn X, Bonen A, Glatz If and Luken If. Giant membrane vesicles as a model to study celluar substrate uptake dissected fron metabolism. Mor Cetl Biochem. 2002230:12130.

17. Bonen A, Luken I. Arumugam $Y$, Gaz IF and Tandon NN Acute repulaton of haty acid uptake intolves the cellular redistribution of taly acid uansiocase. / Bol Chen $2000 ; 275: 14501-8$.

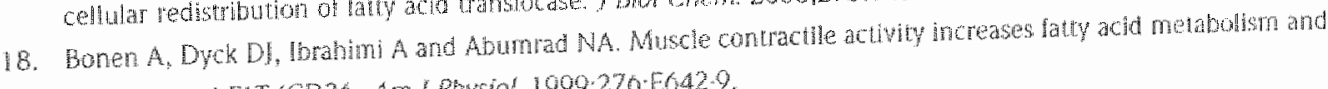
transport and EAT/CD36. Am J Physiol 1090,270:E0429. 
19. Dyck DJ, Stemberg $\mathrm{G}$ and Bonen A. Insullin increases FA uptake and esterfification but reduces hipd usilization in isolated coniracing muscle. An / Physiol Endacinol Metab 2001;281:E0007.

20. Luiken II, Wilems I, van der Vusse G) and Gatz IF Blectrostimulation emhances FAT/CD36-mediated long chain faty actd untake by isolated rat cawlac myocytes. Am I Physiol Endocrinol Metab 200 /,281:E704-12.

21. Lutken If, Dyck DJ, Han X.X, Tandon NR, Arumugan Y, Glatz JF and Bonen A. Insulin induces the translocation of the faty atid transponter EAT/CD36 to the plasma membrane. Am / Physiol Endochinol Metab. $2002 ; 282.64915$ 


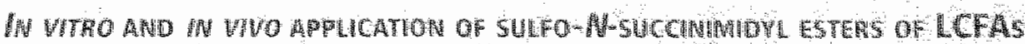




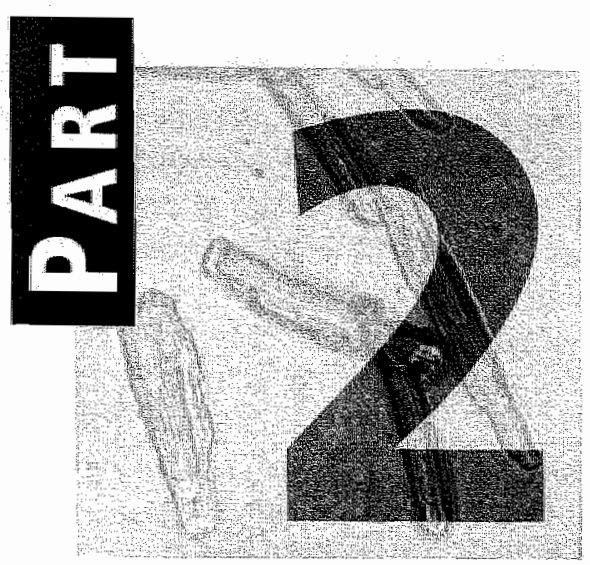

\section{IN VIVO ADMINISTRATION OF SULFO- $\boldsymbol{N}$-SUCCINIMIDYL ESTERS OF LONG-CHAIN FATTY ACIDS}




\section{INTRODUCTION}

In vitro administration of sulfo-N-succinimidyl esters of long-chain fatty acids (LCFAs) has been proven to be an important tool to specifically inhibit cellular FAT/CD36-mediated LCFA uptake (part 1 of this chapter). The aim of the present study was to verify the in vitro effects of these esters of LCFAs with respect to the inhibition of cellular LCFA uptake in rats in vivo. First, the tissue distribution in time after one intraperitoneal (i.p.) injection of $3 \mathrm{H}-$ sulfo- $N$-succinimidyl palmitate (SSP) was monitored in rats. Second, the LCFA uptake capacity in adipose tissue, heart, skeletal muscle and liver was determined after chronic i.p. administration of sulfo- $N$ succinimidyl oleate (SSO) in rats.

\section{Pharmacokinetics of ${ }^{3} \mathbf{H}$-SULFo- $\boldsymbol{N}$-sucCinimidyl palmitate (SSP)}

Male lewis rats $1200-250 \mathrm{~g})$ were given one i.p. injection of $3 \mathrm{mg} 3 \mathrm{H}$-SSP dissolved in $2.2 \%$ DMSO $/ 0.9 \% \mathrm{NaCl}$ ( $3 \mathrm{mg}{ }^{3 \mathrm{H}-S S P} \cong 1.9 * 10 \% \mathrm{DPM}$ ). Thereafter, the appearance of ${ }^{3} \mathrm{H}$-label in blood, heart, skeletal muscle, liver and epididymal adipose tissue, was determined at 4 different time-points, i.e., 8, 24, 72 and 96 hours. At all time-points one rat was sacrificed and blood samples, and heart, skeletal muscle, liver and epididymal white adipose tissue were harvested and immediately frozen in liquid nitrogen.

The amount of ${ }^{3} \mathrm{H}$-label was determined in heart, skeletal muscle, liver and adipose tissue homogenates. To this end, $2 \mathrm{ml}$ of $20 \%$ tissue homogenates were digested in $3 \mathrm{ml}$ Solvent ${ }^{3}$

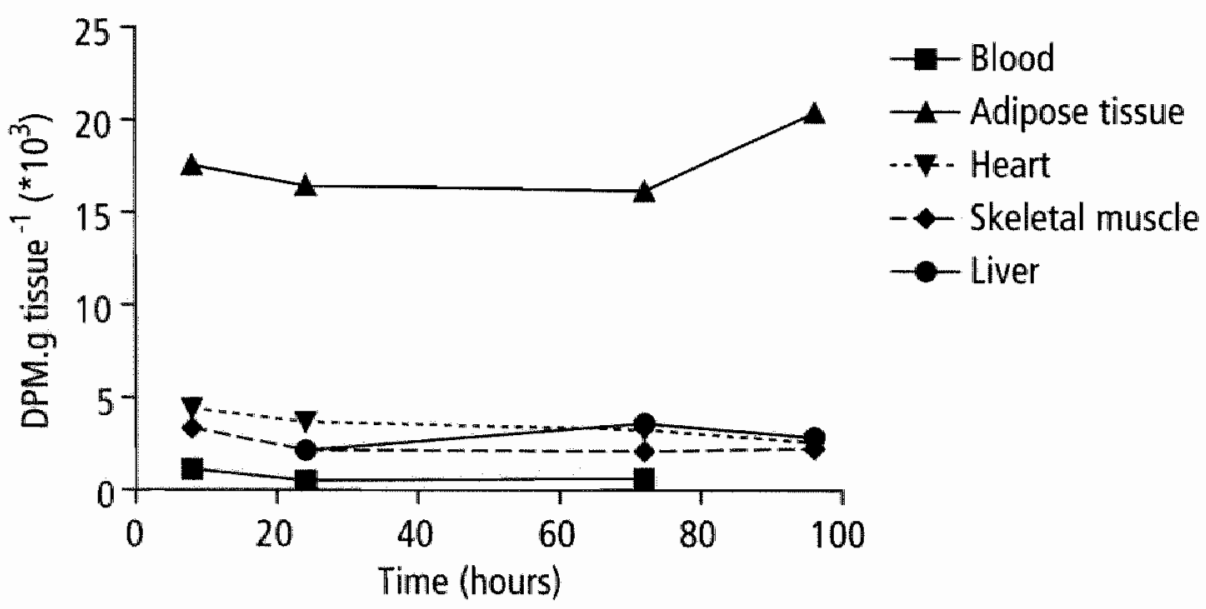

Figure 8.8: Rat tissue distribution of 3 H-label after an intraperitoneal bolus injection of 3 H-sulfo-N-succinimidyl patmitate ( 3 H.SSP).

Rats were given a bolus injection of $3 \mathrm{mg}{ }^{3} \mathrm{HSSP}$ dissolved in $2.2 \%$ DMSO $0.0 \% \mathrm{NaCl}$. Thereafter, the appearance of 3 Habet in blood, heart, skeletal muscle, ther and adipose tissue, was determined at 4 different time points, i.e.; $8,24,72$ and of hours. The data are expressed as disintegrations per minute $(d p m)$ g tissue $l^{*} 103$. 
(Perkin Elmer) at $60^{\circ} \mathrm{C}$ for 6 hours. Cooled solutions were well mixed with $15 \mathrm{ml}$ HionicFluor $^{\text {is }}$ (Perkin Elmer) and counted by a scintillation counter.

Figure 8.8 shows that ${ }^{3} \mathrm{H}$-label mainly accumulates in adipose tissue after one i.p. injection of ${ }^{3} \mathrm{H} \cdot \mathrm{SSP}$. Conversely, only minor amounts of ${ }^{3} \mathrm{H}-1 \mathrm{abel}$ could be retrieved from the blood, heart, skeletal muscle and liver (Fig. 8.8).

\section{Chronic Intraperitoneal administration OF SUlfo- $\boldsymbol{N}$-SUCCINIMIDYL OLEaTE (SSO) TO RATS}

As mentioned in the previous paragraph, after one i.p. injection of ${ }^{3} \mathrm{H}-\mathrm{SSP},{ }^{3} \mathrm{H}$-label accumulates in epididymal white adipose tissue, whereas substantially lesser amounts of ${ }^{3} \mathrm{H}$-label were present in blood samples, heart, skeletal muscle or liver. Therefore, we hypothesize that by injecting sulfo- $N$-succinimidyl esters of LCFAs i.p. the cellular LCFA uptake capacity will be inhibited only in adipose tissue, but not in skeletal muscle, heart and liver.

The in vivo effect of sulfo- $N$-succinimidyl oleate (SSO), when administrated by i.p. injection, on the cellular LCFA uptake capacity in heart, skeletal muscle, liver and adipose tissue was. measured in male Lewis rats $(200-250 \mathrm{~g})$. These rats were divided in two groups of 6 animals each, and they were twice a week for 12 weeks injected i.p. with, (i] $2.2 \% \mathrm{DMSO} / 0.9 \% \mathrm{NaCl}$ [control) or (ii) $20 \mathrm{mg} \mathrm{SSO} / \mathrm{kg}$ body mass dissolved in $2.2 \% \mathrm{DMSO} / 0.9 \% \mathrm{NaCl}$ (SSO-treated). Body mass was measured at the begin and the end of the treatment period. Moreover, at 12 weeks organ mass of heart, skeletal muscle (hindlimb), liver and adipose tissue, and also plasma glucose, FA and cholesterol concentrations were determined.

\section{Parameter}

Body and organ mass

Body mass (start)

Body mass (end)

Heart mass

Hindlimb mass

Liver mass

Epididymal adipose tissue pads

Plasma metabolites (mmol. $\left.\mathrm{I}^{-1}\right)$

Glucose

Fatty acids

Cholesterol

\section{Control}

$149 \pm 5$

$389 \pm 18$

$1.43 \pm 0.06$

$13.6 \pm 0.8$

$6.52 \pm 0.27$

$11.0 \pm 1.4$

$9.52 \pm 0.83$

$0.36 \pm 0.05$

$1.43 \pm 0.04$
S5O

$143 \pm 2$

$394 \pm 9$

$1.46 \pm 0.04$

$13.8 \pm 0.4$

$6.42 \pm 0.25$

$12.9 \pm 1.3$

$7.23 \pm 0.16^{*}$

$0.39 \pm 0.04$

$1.50 \pm 0.04$

Table 8.1: Characteristics of control and SSO-treated rats; intraperitoneal injection. Data are presented as means $\pm S E M, n=0$. ${ }^{*}$ Significantly different from control rats. 


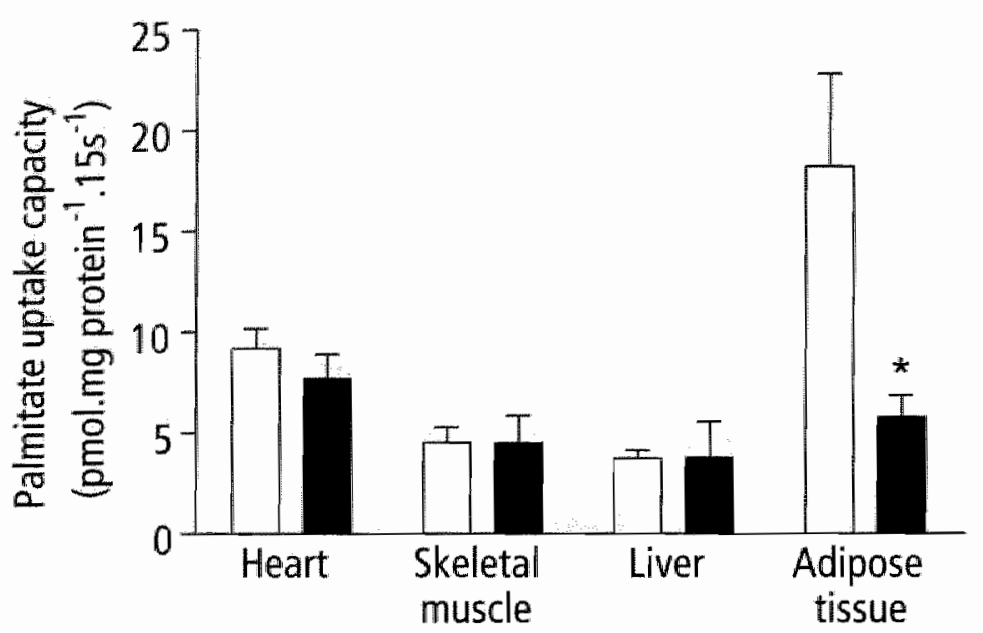

Figure 8.9: Effect of chronic intraperitoneal sulfo-N-succinimidyl oleate (SSO) administration on the cellular palmitate uptake capacity.

In ghant membrane vesicles prepared from heart, skeletal muscle, liver and adpose tissue of DMSO /non-treated, (D) and SSO-treated ( 1 rats, the palmitate uptake capacity was determined. Data are presented as means \pm S.EM. and expressed as pmolmg protein".155', n=6. *Significantly different from giant membrane vesicles obtained from non. 550 treated rats.

After treating rats for 12 weeks twice a week with SSO, plasma glucose concentrations significantly decrease by $24 \%$, whereas plasma FA and total cholesterol concentrations were unaltered compared to control rats (Table 8.1). in addition, body, heart, skeletal muscle (hindlimb), liver and epididymal adipose tissue mass were unaltered after 550 -treatment (Table 8.1).

The celiular LCFA uptake capacity in adipose tissue was significantly inhibited by $68 \%$ in SSO-treated rats, whereas in skeletal muscle, heart and liver the capacity was unattered (Fig. 8.9]. The inhibited cellular LCFA uptake capacity in adipose tissue is in agreement with the accumulation of ${ }^{3 H}$-SSP in this organ after one i.p. injection.

\section{CONCLUDING REMARKS}

Since the LCFA uptake capacity decreases only in adipose tissue and not in heart and skeletal muscle, it is believed that SSO when given i.p. does not reach muscle tissues. Therefore, a manner to improve the bioavailability of SSO should be investigated in future studies. In addition, long-term i.p. administration of $S S O$ to rats may lead to increased cellular glucose utilization, which is secondary to a decreased FAT/CD36-mediated LCFA uptake by adipose tissue. 


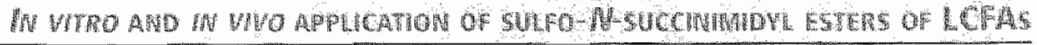




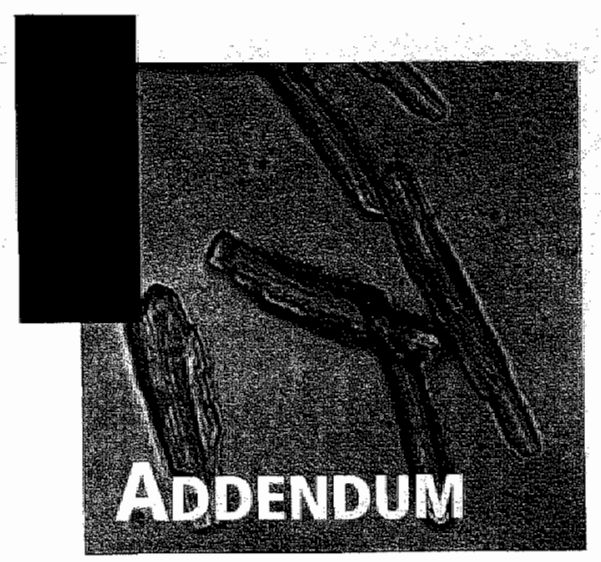




\section{ADMINISTRATION OF SULLO- $N$-SUCCINIMIDYL ESTERS OF LONG-CHAIN FATTY ACIDS TO RATS BY OSMOTIC MINIPUMPS (ALZET)}

To investigate the whole body effect of sulfo $N$-succinimidyl esters of LCFAs they have to reach metabolically important tissues. We demonstrated that when injected i,p. these esters accumulate in adipose tissue and only a small amount reaches the circulation and non-adipose tissues. In the present study we investigated whether $1 \mathrm{C}$-SSP, when administrated to rats by Alzet osmotic minipumps, reaches heart, skeletal muscle, liver, adipose tissue and kidney. By using osmotic minipumps a continuous rate of $14 \mathrm{C}-\mathrm{SSP}$ can be given for one week.

Tissue distribution of ${ }^{14} \mathrm{C}$-SSP given by osmotic minipumps was determined in SpragueDawley rats. These rats were anesthetised by halothane and the osmotic minipumps (Alzets) were subcutaneously positioned at the back of the rat via a small incisjon. Here, we used osmotic minipumps with a total volume of $200 \mu$, that delivered, with a continuous flow, 1.2 mg ${ }^{14} \mathrm{C}$-SSP dissolved in DMSO per day for 7 days (1 mg ${ }^{14} \mathrm{C}-S S P \equiv 1.1{ }^{*} 106$ DPM). After 7 days of ${ }^{4} \mathrm{C}$-SSP administration, red \& white muscle, soleus, heart, kidney, liver, tissue surrounding the pump and edipidymal adipose tissue were harvested and immediately frozen

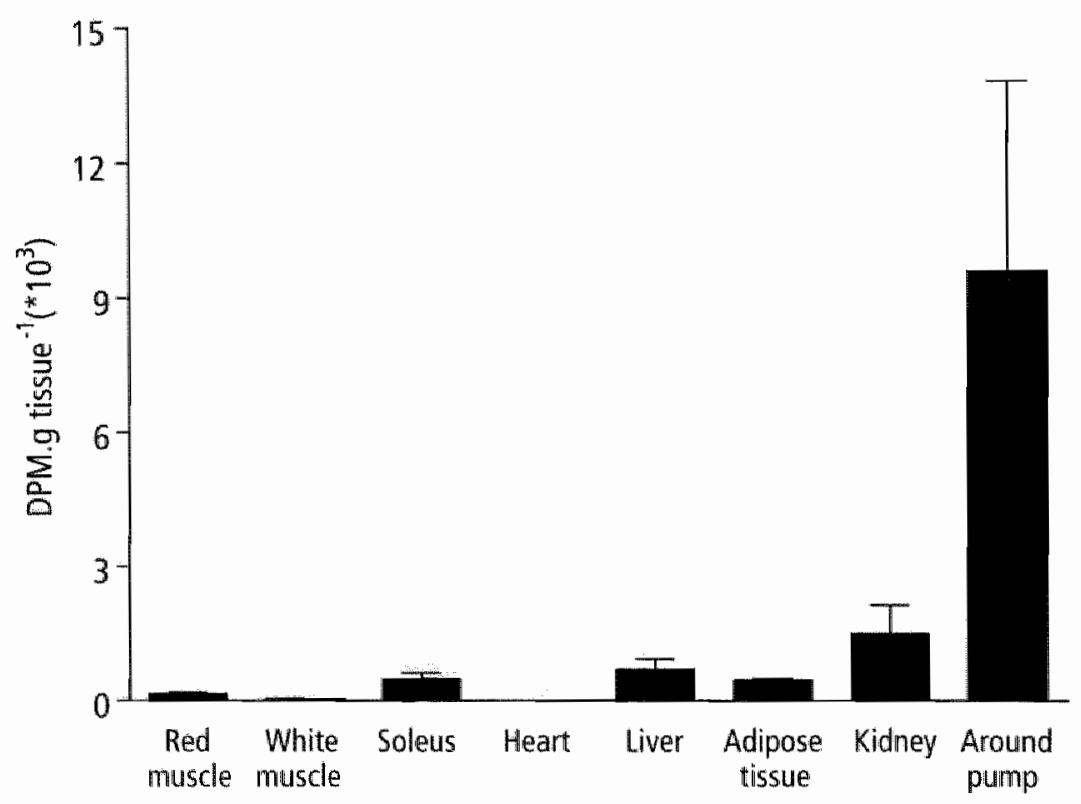

Figure 8.10: Tissue distribution of 14 C-label after one week of ${ }^{4} \mathrm{CSSP}$ administration by osmotic minipumps. "CSSP dissolved in 22\% DMSO/0.9\% NaCl was administered to rats by osmotic mimipumps for one week Thereater, the appearance of th Clabel in red $B$ white muscle, soleus, heart, liver, epididymal adipose tissue, kidney and the tissue surrounding the pump was determined. The data are expressed as disintegrattons per minute ldom.g tissue: ${ }^{*} 10 \%$ in,$n=4$ 
in liquid nitrogen. To digest these tissues, approximately $100 \mathrm{mg}$ of frozen tissue was incubated in 20 $\mathrm{ml}^{4}$ scintillation wials with $1 \mathrm{ml}$ Soluen 350 (Perkin Elmer) for 6 hours at $60^{\circ} \mathrm{C}$. After the solution cooled down, $10 \mathrm{ml}$ Hionic Fluor ${ }^{\text {tal }}$ (Perkin Elmer) was added, mixed well and counted on a scintillation counter.

After 7 days of treatment with 14C-SSP administrated by osmotic minipumps, 14C-Label was predominantly present in the tissue surrounding the pump (Fig. 8.10). In addition, $14 \mathrm{C}$ label was also, although at small amounts, present in soleus, liver, adipose tissue and kidney $\{$ Fig. 8.10$\}$.

The present study demonstrated that after administration of ${ }^{14} \mathrm{C}$-SSP by means of osmotic minipumps the majority accumulated in the tissue surrounding the pump. In conclusion, osmotic minipumps positioned at the back of the rat are not suitable for measuring whole body effects of sulfo- $N$-succinimidyl esters of LCFAs.

\section{Procedure to apply a Catheter into the Rat Jugular vein CONNECted to an OSMOTIC MINIPUMP}

Since both i.p. injections and osmotic minipumps were not suitable for the measurement of the whole body effects of sulfo- $N$-succinimidyl esters of LCFAs, we developed a new method to directly administrate agents into the circulation with a contimuous flow. The materials needed and the surgical procedure are mentioned here.

\section{Materials:}

PE-tubing:

Intramedic ${ }^{1}$, Clay Adams , Becton Dickinson Primary Care Diagnostics,

Becton Dickinson Company, MD, USA.

- PE-50, internal diameter $=0.58 \mathrm{~mm}$ and outer diameter $=0.965 \mathrm{~mm}$

- PE- 1.60 , internal diameter $=1.4 \mathrm{~mm}$ and outer diameter $=1.57 \mathrm{~mm}$

Alzet osmotic minipumps

Somnotol (sodium phentobarbital injection):

MTC Pharmaceuticals, Cambridge, ON, Canada.

Buprenex Injectable (buprenorphine hydrochloride):

Reckitt \& Colman, Pharmaceuticals Inc., Richmond, VA, USA.

\section{Surgical procedure}

Sprague-Dawley rats were anesthesized by an intravenous injection of Somnotol and were given Buprenex Injectable for painkilling and eye augment to prevent drying of the eye. Thereafter, the back in between the shoulder blades, the right side of the shoulder and from the neck to the top peak of the arm, were shaven. After disinfecting the shaven areas with betadine and $70 \%$ ethanol, a small incision was made at the back near the neck of the rat, where after by using scissors, a small pocket was made at the back of the rat. A asmotic minpump filled with saline connected to a catheter was gently positioned in this pocket. The catheter was made of a large piece of PE-50 with a loop and the end which enters the jugular 
vein was connected to a small piece of PE-160. After placing the osmotic minipump, a small pocket was made at the right side of the animal from the neck at the back to the front. Than, the external jugular vein was exposed and side-branches were tight up. Ones the external jugular vein was exposed the catheter was placed in the vein and tight up so it will not move. Thereafter, the incisions were closed by stapling and the rat was monitored for four hours.

\section{CONCLUDING REMARKS}

The combined use of a catheter and an osmotic minipump is a promising method to apply agents straight into the circulation with a continuous flow. In future studies effects of sulfo- $N$. succinimidyl esters of LCFAs on substrate metabolism when administered in this manner should be investigated. 


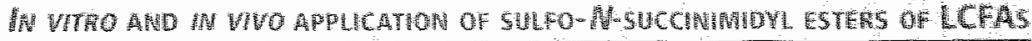




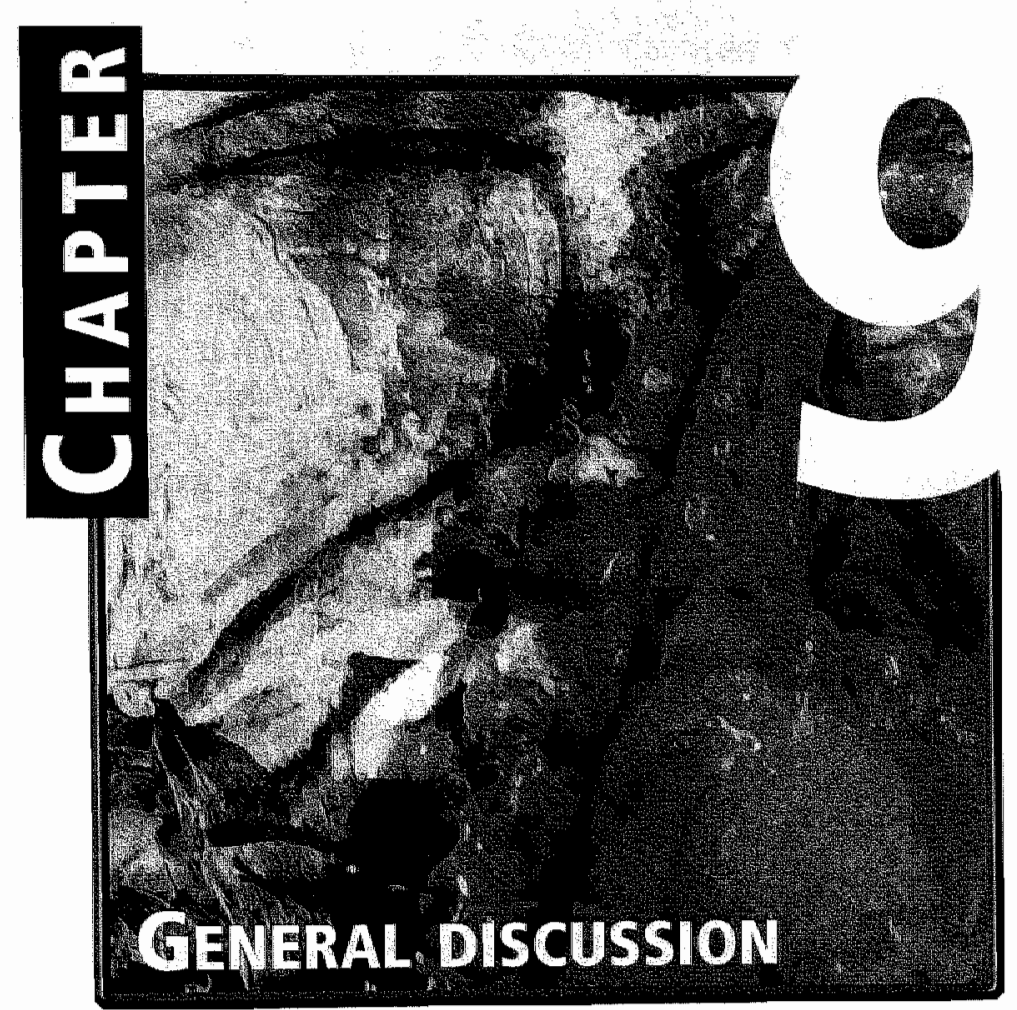




\section{INTRODUCTION}

In this chapter a selection of the most important findings of this thesis will be discussed in relation to the newest literature. Because in our studies we used the obese Zucker rat as a model of obesity-induced type-2 diabetes mellitus (T2DM) to study substrate utilization, it is discussed whether the obese Zucker rat is a model that adequately reflects the human situation. Our studies in these rats showed that a sarcolemmal presence of FAT/CD36 plays a pivotal role in the development of cardiac insulin resistance. Hence it is of interest to discuss this finding in relation to published data and new insights in the (tissue) insulin sensitivity in CD36-deficient rodents and humans. Apart from the fact that translocation of FAT/CD 36 appears very important in the regulation of its activity, also other ways to alter the amount and activity of sarcolemmal FAT/CD36 have recently been unveiled and may open additional opportunities for future studies. Finally, normalizing LCFA uptake by cardiac myocytes during insulin resistance and obesity is believed to be beneficial for cardiac function. Therefore, two possible strategies to reduce FAT/CD36-mediated LCFA uptake will be discussed.

\section{Obese (fA/FA) ZuCKer RATS A SUITABLE MOdEL TO REFLECT THE OBESITY-INDUCED T2DM?}

To investigate substrate uptake and utilization and subcellular distribution of FAT/CD36 in obesity-induced T2DM we used eleven-week old insulin resistant obese Zucker rats. The genetically obese (fa/fa) Zucker rat, first described by Zucker \& Zucker ${ }^{1}$, carries an autosomal recessive mutation, the fa-mutation, in the gene encoding for the leptin receptor, which in homozygous $(\mathrm{fa} / \mathrm{fa})$ rats results in the development of obesity, insulin resistance, hyperinsullinemia, and hyperlipidemial,2. In eleven-week old Zucker rats plasma insulin, fatty acid (FA) and triacylglycerol (TAG) concentrations are markedly increased, whereas the plasma glucose level is unaltered, indicating that these rats are insulin resistant, but not type2 diabetic (see Chapters 6 and 7). It can be questioned whether these obese (fa/fa) Zucker rats are the rodent model that best reflects obesity-induced T2DM in humans. One of the major concerns is that obese Zucker rats, when fed a regular diet, do not develop T2DM and hyperinsulinemia persists throughout life. Moreover, in humans a defect in the leptin receptor is very sare ${ }^{3}$.

A different rat model for obesity and insulin resistance can be generated by feeding rats a western-type (high-fat ( $[\mathrm{FF}$-containing) diet. In several ways this rodent model resembles the human situation better than insulin resistant, obese Zucker rats. Rats excessively fed alimentary fat for 7 weeks developed T2DM, whereas obese Zucker rats do not develop T2DM4. Also, most patients with obesity will eventually develop type-2 diabetes mellitus (T2DM). Moreover, in humans environmental factors such as a western-type diet and a sedentary lifestyle, even more than genetic factors result in the development of obesity. Therefore, in future studies it is worthwhile to investigate subcellular localization and function of FAT/CD36 in isolated cardiac myocytes from rats with a HF versus a low-fat (LF) diet intervention. 


\section{FAT/CD36 AND INSULIN RESISTANCE}

It has been demonstrated that the development of insulin resistance and the accumulation of TAGs are positively correlated in muscle tissues. 8 and it is believed that enhanced plasmalemmal FAT/CD36 content contributes to the development of insulin resistance. In insulin resistant, obese Zucker rats we showed that the amount of CD36 present at the sacrolemma of cardiac myocytes is increased, which coincided with enhanced rates of LCFA uptake and LCFA. incorporation in the TAG pool, 10 (see for more detail Chapter 6 ). In addition, Bonen et al." demonstrated that in human skeletal muscle the intracellular amount of TAGs correlates positively with the plasmalemmal FAT/CD36 protein content. Several studies in CD36 null mice and CD36-deficient humans investigated the relation between CD36-deficiency and (tissue) insulin resistance. On the basis of our observations it would follow that CD36 null mice and CD36-deficient humans become more insulin sensitive while overexpression of CD36 in skeletal muscle would make this tissue insulin resistant.

\section{CD36 null mice and mice overexpressing CD36 in muscle}

In 1999 Febbraio et al.12 generated a mouse null for CD36 by homologues recombination. Upon fasting these CD36 null mice showed significantly increased plasma FA and TAG concentrations, whereas the plasma glucose levels were significantly decreased 12. In heart and skeletal muscle of $\operatorname{CD} 36$ null mice LCFA uptake and oxidation were significantly decreased by approximately $40-80 \%$, and also the LCFA incorporation into intramyocellular TAGs was reduced ${ }^{3}$. In addition, muscle tissues from CD36 null mice exhibited a compensatory increase in the glucose oxidation rate ${ }^{14}$. These findings suggest that CD36 null mice become more sensitive to insulin. Indeed it was shown that whole-body insulinmediated glucose uptake was increased in CD36 null mice ${ }^{15}$. This effect is attributed to the increased insulin sensitivity in muscle tissues, whereas the liver, which tissue normally hardly expresses CD36, was insulin resistant in CD36 null mice ${ }^{15}$. Due to the decreased LCFA uptake by muscle and adipose tissues, LCFAs in the circulation are directed towards the liver leading to an increased accumulation of TAGs that results in hepatic insulin resistancels. Collectively, these findings indicated that in mice, CD36 deficiency results in an increased muscle tissue insulin sensitivity.

In addition, a mice was generated by lbrahimi et a.1.6 that overexpresses CD36 in muscle tissue. These transgenic mice exhibited an opposite lipid profile to the one observed in CD36 null mice, i.e., plasma TAG and FA concentrations were significantly decreased ${ }^{16}$. Whereas the concentration of glucose in plasma was increased at 20 weeks of age the glucose tolerance was not different between control and transgenic mice, suggesting that the whole body insulin sensitivity remains unaltered 10 . Whether at this age the insulin sensitivity of muscle tissues is altered and if the transgenic mice will develop glucose intolerance later in life remains to be determined.

Taken together these findings are in line with the hypothetical model for the development of cardiac insulin resistance presented in Chapter 2 , which suggests that an elevated sarcolemmal FAT/CD36 content plays a pivotal role in the development of cardiac insulin resistance. 


\section{Human CD36 deficiency}

The prevalence of human $\mathrm{CD} 36$ deficiency is $3.11 \%$ in Asian and African populations, whereas It is only $0.3 \%$ in the US population ${ }^{17,18}$. In humans the relation between CD36 deficiency and the sensitivity of insulin is controversial. Several studies demonstrated a correlation between insulin resistance and $\mathrm{CD} 36$ deficiency 19,20. However, these studies are performed in a fairly small population of CD36-deficient subjects $2 \Downarrow, 22$ and are therefore difficult to interpret. In contrast, a study in which a large CD36-deficient population demonstrated no relation between the development of insulin resistance and CD36 deficiency23. Thus CD36 may contribute to the development of insulin resistance, but it is certainly not the only factor causing insulin resistance.

\section{REGLILATION OF THE AMOUNT AND ACTIVITY OF SARCOLEMMAL FAT/CD36}

Since FAT/CD36 can only exert its function as a LCFA transport protein at the sarcolemma, the subcellular localization is important. in agreement, the sarcolemmal amount of FAT/CD36 has been found to correlate with the LCFA uptake rate 24,25 . Besides induction of existing endosomal FAT/CD36 translocation to the sarcolemma, the amount and activity of sarcolemmal FAT/CD36 may also be regulated in other ways (Fig. 9.1). The machinery involved in the intracellular vesicular trafficking of FAT/CD36 between the intracellular storage compartments and the sarcolemma remains to be elucidated.

Once present at the sarcolemma, localization of FAT/CD36 in specific domains of the membrane is important for its function. Stremmel et al. ${ }^{26}$ suggested a possible role for caveolae in the EAT/CD36-mediated LCFA uptake process. These caveolae are invaginations of the sarcolemma consisting of caveolin, cholesterol, and glycosphingolipids, and are enriched with membrane receptors and signalling molecules ${ }^{27}$. Indeed it has been demonstrated that in human skeletal muscle, FAT/CD36 colocalizes with caveolin-328,29, which is predominantly expressed in myocytes, but it is unknown whether FAT/CD36 interacts directly with caveolin3. In contrast to FAT/CD36, FABPpm is not present in the caveolae. The importance of this plasmalemmal localization of FAT/CD30 was presented by Pohl and coworkers ${ }^{30}$, who showed that a proper organization of caveolae is necessary for FAT/CD36-mediated LCFA uptake by adipocytes. Thus in addition to translocation of FAT/CD36, its sarcolemmal localization is another levels of regulation. Therefore, caveolea-disrupting agents could have therapeutic potential.

Recently, we demonstrated that myocardial LCFA uptake can be regulated without changes in the total amount and subcellular localization of FAT/CD 3631, suggesting that the sarcolemmal FAT/CD36 activity can be increased without changing its content. In fact, several post-translational modifications of the FAT/CD36 molecule, i.e., phosphorylation, glycosylation and palmitoylation, could alter the intrinsic activity of $\mathrm{FAT} / \mathrm{CD} 36^{32,33}$. In human platelets it has been shown that FAT/CD36 can be phosphorylated by a kinase present at the outer leaflet of the sacrolemma ${ }^{34}$. Here, phosphorylation of FAT/CD36 was paralleled by a significant decrease in initial palmitate uptake by intact human platelets ${ }^{35}$. These data suggest that also in cardiac myocytes phosphorylation of FAT/CD30 could influence its intrinsic activity. However, it should 


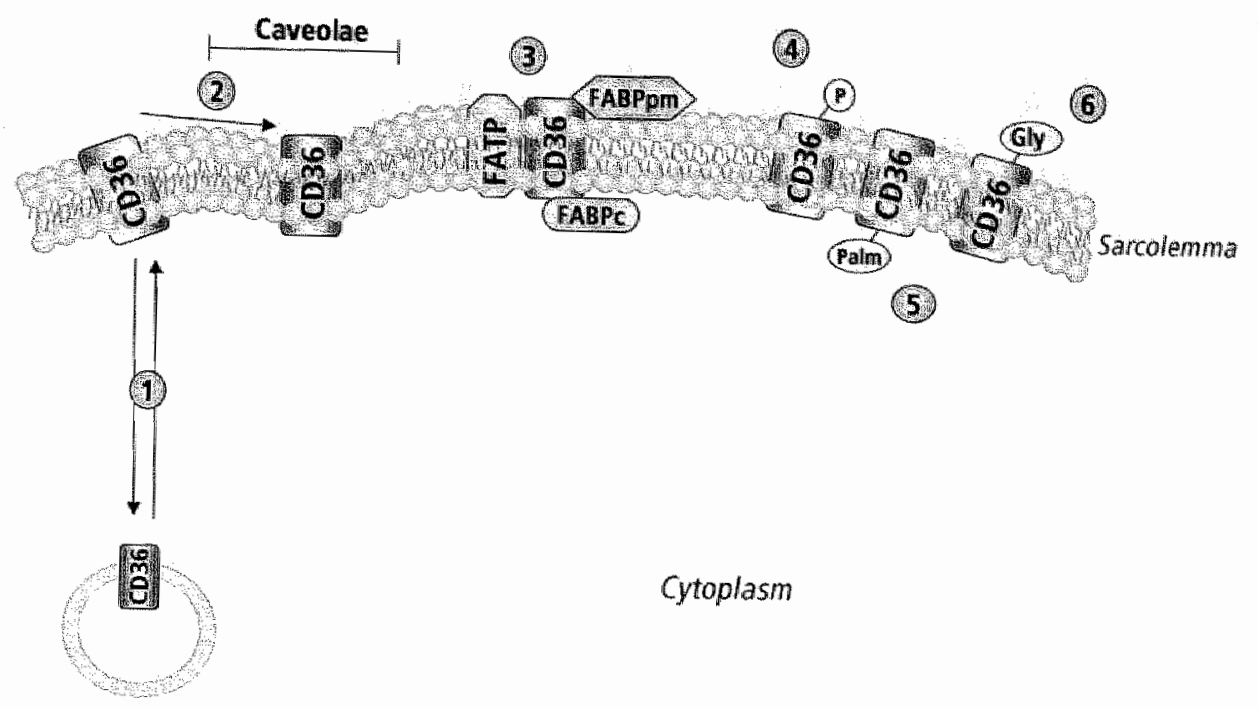

Figure 9.1: Regulation of the amount and activity of sarcolemmal FAT/CD36.

Possible levels of regulation are: If Intracellular vesicular trafficking 2) Membrane domain localtzation, 3) Interaction with plasmalemmal fatty acid binding protein (FABPpm, fatty acid transport protein (FATP) or cytoplasmic FABP (FABPC), 4) Phosphorylation (P), 5) Palmitoylation (Palm), and of Gycosylation (CWy).

be realized that several tissue-specific functions of FAT/CD36 have been revealed. Whereas, in myocytes and adipocytes. FAT/CD36 has been demonstrated to function as a putative LCFA transport protein, in platelets it is a receptor for collagen and thrombospondin, and in monocytes and macrophages it serves as a scavenger receptor for oxidized low-density lipoproteins $36-39$. Since FAT/CD36 is a highly glycosylated protein the degree of glycosylation could influence its function in different tissues. Thereiore, studies which simultaneously investigated the various post-translational modifications of FAT/CD36 and their effect on its function in different tissue could shed more light on the whole-bady effect of FAT/CD36.

\section{Possible strategies to Reduce the sarcolemmal FAT/CD36 amount or activity}

One of the main conclusions of this thesis is that an increased sarcolemmal FAT/CD 36 content plays a pivotal role in the accumulation of intracellular TAGs in cardiac myocytes from insulin resistant rodents. Because intracellular TAG accumulation is associated with the development of cardiac insulin resistance and dysfunction, a reduced sarcolernmal content and/or activity of FAT/CD36 should help prevent TAG accumulation. Therefore, manners to reduce the sarcolemmal FAT/CD36 localization and activity are suggested as new strategies to normalize cardiac insulin sensitivity and function. 
A manner to inhibit the activity of FAT/CD36 is by blocking the binding site of LCFAs at the PAT/CD36 molecule. As demonstrated in Chapter 8, in vitro FAT/CD36-mediated cellular LCFA uptake can be inhibited by sulfo- $N$-succinimidyl oleate (SSO), which covalently binds to FAT/CD36. However, when SSO is given in wivo it must be realized that FAT/CD36 is not only expressed in muscle tissue, but also in adipose tissue, monocytes, macrophages and platelets ${ }^{37}$.39. As a result, in vivo administration of SSO has more effects than inhibiting LCFA uptake and TAG accumulation in muscle tissues. Other disadvantages of administrating SSO in vivo are that in an aqueous environment SSO hydrolyses in approximately 2 hours, and SSO is very hydrophobic making it almost impossible to dissolve it in a vehicle that is not toxic for rodents and humans. Therefore, an agent should be developed that, II specifically inhibits FAT/CD36 in muscle tissue, (ii) is stable in an aqueous environment and (iii) dissolves easily in a non-toxic vehicle. Moreover, it should be considered that when specifically inhibiting the activity of muscle FAT/CD36 in vivo it is likely that plasma LCFA levels will rise. In line with results obtained in studies with CD36 null mice, it is expected that this rise in LCFA levels will result in accumulation of TAGs in the liver, causing hepatic insulin resistance. A manner to reduce hepatic TAG content is to induce hepatic LCFA oxidation by activating the nuclear receptor, peroxisome proliferatoractivated receptol $\alpha$ (PPAR $\alpha$ ). PPAR $\alpha$ agonists are known to Increase the expression of genes in LCFA oxidation in liver and skeletal muscle40. A combination therapy of a muscle-specific EAT/CD36 inhibitor and a PPARo agonist could be a suitable strategy to prevent accumulation of intracellular TAGs in muscle tissues and liver. Therefore, in future studies the effect of such a combination therapy should be investigate on tissue insulin sensitivity, intracellular TAG accumulation and subcellular FAT/CD 36 localization.

The sarcolemmal amount of FAT/CD36 can be reduced by specifically inhibiting the recruitment of FAT/CD36 to the sarcolemma, without affecting GLUT4 translocation. As demonstrated in Chapter 4, it is possible to selectively induce FAT/CD36 translocation in a contraction-like manner, suggesting that beyond AMPK the signal branches off into two separate ways to mobilize GLUT4 and FAT/CD36. However, these downstream targets of AMPK remain to be identilied in future studies. But once the FAT/CD36-mobilizing branch is identified and can be blocked it is possible to enhance mitochondrial LCFA oxidation by actiwating AMPK without inducing recruitment of FAT/CD36. This could be a new strategy to reduce the elevated intracellular "TAG content in cardiac mycoytes in a prediabetic state.

Besides these two strategles there is a whole range of possibilities to influence the sarcolemmal FAT/CD36 amount and/or activity. Agents that influence membrane domain localization of FAT/CD30, intracellular vesicular trafficking, interaction of FAT/CD36 with either FABPpm, FATP or FABPC, or phosphorylation/palmitoylation/glycosylation of FAT/CD36, each may alter FAT/CD36 funcional activity and hence the cellular LCFA uptake rate.

Although an agent that reduces. FAT/CD 36-mediated LCFA uptake by cardiac myocytes in vivo remains to be designed and developed, such an inhibitor could be of great value in the fight against diabetic cardiomyopathy. 


\section{REFERENCES}

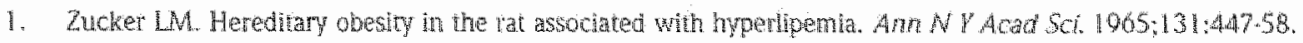

2. White $\mathrm{BD}$ and Martin RJ. Evidence for a central mechamism of obesity in the Zucker rat: role of neuropeptide $Y$ and leptin. Proc Soc Exp Biol Med. 1997,214:222-32

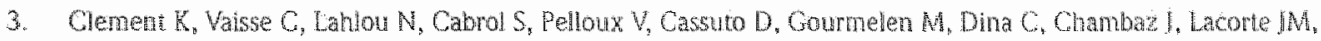

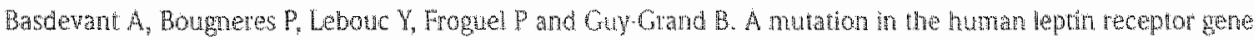
causes obesiry and pituitary dysfuncion. Nature. 1998;392:398-401.

4. Owwen DM, Boer C, Fodor M, de Galan P, Heine R, Massen IA and Diamant M. High hat dier induced cardiac dystunction 5 associated with altered myocandial insulin signaling in rats. Diabetologia. 2005;

5. Zhou YT, Grapurn P, Karim A, Shinabuturo M, Higa M, Baelens D, Orci L and Unger RH. Lipotowic heart aisease in obese rats: implications for human obesity. Proc Natl Acad SCi US A. 2000:07:1784.

6. Pan DA, Lilioja S. Kriketos AD, Miner MR, Baur LA, Bogardus G, lenkins AB and Storlten LH. Skeletai muscle triglyceride levels are inversely related to insulin action. Dabetes. 1907,46:983.8.

7. Krssak M, Fak Petersen K, Dresner A, DiPtetro L, Vogel SM, Rohmain DL, Roden M and Shulman CA. Intramyocellular lipid concentrations are correlated with insulin sensidity in humans; a IH NMR spectrowcopy study. Diabetologta 1999,42:1136.

8. Young ME, Guthrie PH, Razeghi P. Leighton B, Abwast S, Patil S. Youker RA and Taeguneyer H. Impaired longchain fatcy acid oxidation and contratile dysfunction in the obese Zucker rat heart. Diwetes 2002;51:2587-05.

9. Coort Sl, Hassebaink DM, Koonen DP, Willems I, Coumans WA, Chabowski $A$, van der Wusse Gl, Bonen A, Glatz JF and Luiken J]. Enhanced sarcolemmal EAT/CD30 content and thiachlycerol storage in cardiac myocytes from obese zucker rans. Diabetes. 2004,53:1655-63.

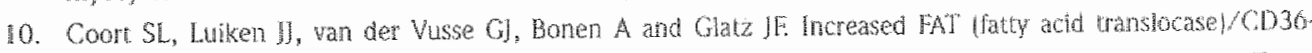
mediated long chain fatly acid uptake in cardiac myocytes from obese Zucker mats. Biochen Soc Thans 2004;32:83.5.

11. Bonen A, Parolin ML, Steimberg GR, Calles Escandon J, Tandon NN, Clatz IF, Luiken J, Heigenhauser Gl and Dyck DJ. Tracylglycerol accumulation in human obesily and the 2 diabeles is ascocialed with incrasted rates of skeletal muscle faty acld transpont and increased sarcolemmal FAT/CD 36. Faseb /. 2004;18:11.440.

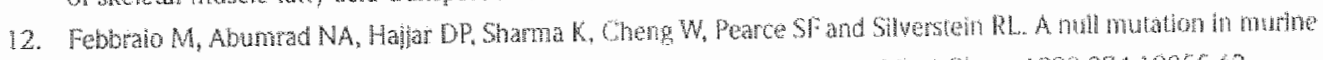
CD30 reveals an important role in falty acid and lipopotein metabolism. J bot chem. 1990;274:10055.62.

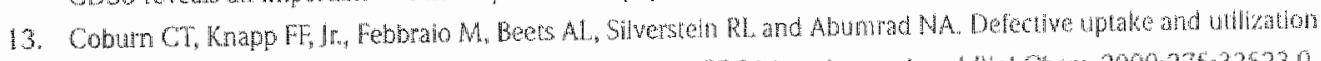
of long chain faty acids in muscle and adpose tisues of CD 30 knockour wice. J Bot Chen. $2000,275,32523.0$.

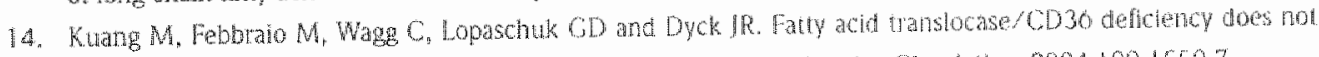
energetically or functionally compromise hearts belore or ater ischemia, Croculation. 2004; 109:15507.

15. Goudrian IR. Dahlmans VE, Teusink B, Ouwens DM, Feboraio M, Massen IA, Fomien IA, Havekes LM and Voshor PJ. CD36 deficiency increases insuin sensitivity in musche, but induces insulin restatance th the liwa in mice.J Liph Res. 2003:44:22707.

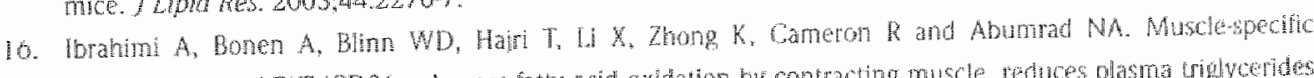

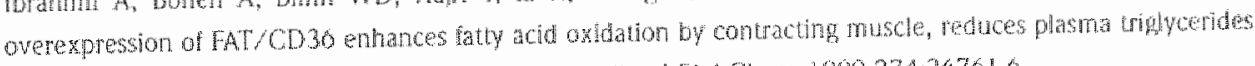
and fary acids, and increases plasma glucose and insuin. / Bot Chen. 1999,274:20761\%.

17. Lkeda H. Mitani T, Onmuma M, Haga H, Onzuka S, Kato T, Nakase T and Sekiguch S. M, new platelet specific antigen, Naka, invalved in the refractoriness of HLA mathed placele trancusion. Wox Sang. $1089,572137$. 


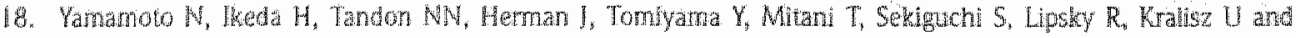
Jameson CA. A platetet membrang glycoprotein (GP) deficency in healthy blood donors: Naka platefets lack detectable GPV (CO36). Blood. 1990;70:1699.703.

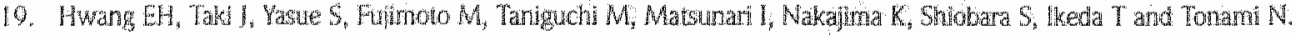

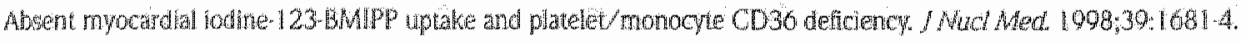

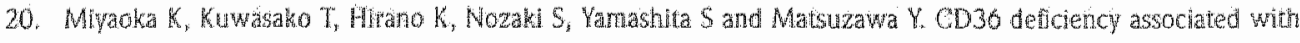
insulin resistance. Lancet. $2001,357: 0807$.

21. Tanaka T, Sohniy $K$ and Kawamuta $K$. Is CD36 deficiency an etology of hereditary hypertiophic cardonyopathy? I Mol Cell Cardol 1997:29:1217.

22. Nakata T, Nakahara N, Sohmiya K, Okamolo F, Tanaka T, Kawamura K and Shimamoto K. Scintigraphic evidence lot a specific longchain fatty acid transporting system deficit and the genetic background in a patent with hypertrophic cardiomwopathy. fon Circ \& 1999;03:319.22.

23. Furuhach $M$, Ura $N$, Nakata $T$ and Shimamoto $K$. Insulin sensitivity and lipid meiabolism in buman $C D 36$ deficiency. Daberes Catre. 2003:20:471-4.

24. Luken Jf, Willems J, van der Wusse GI and GlatZ JF. Electrostimulation enhances FAT/CD36-mediated long-chain latiy acid uptake by isolated rat cardide myocyes. Am J Physiol Endocinol Metab. 2001;281:E704-12.

25. Luiken JJ, Dyck DI, Han XX, Tandon NN, Arumugam Y, Glatz JF and Bonen A. Insulin induces the translocation of the latty acid transporter $\mathrm{AA} / \mathrm{CD} 30$ to the plasma membrane. An / Physiol Endocrinol Metab. 2002:282:E491-5.

26. Stremme W, Pohl L, Ring A and Hermann T. A new concept of cellular uptake and intracellular trafficking of long chain farty acids. Lipids. $2001,36081.9$.

27. Hnasko R and Lisant MP. The biology ol caveotae: lessons from caveolin knockour mice and implications, far human disease. Mol Inter 2003;3:445-64.

28. Vistisen B, Roepstorfl $K$, Roepstorf $C$, Bonen A, van Deurs B and Kiens B. Sarcolemmal FAT/CD30 in human skeletall muscle colocalizes with caveolin -3 and is mote abundant in type 1 than in type 2 fibers. $J$ Lipid Res. $2004,45: 003-9$.

29. Keizer HA, Schaart $G$, Tandon NN, Glatz J and Luiken JJ. Subcellular immunolocalisation of faty acid transiocase (KATV/CD 30 in thuman trpe 1 and rype 2 skeletal muscle fibres. Histochem Cell Bol 2004:121:101-7.

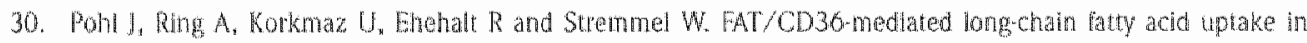
adpocytes requires plasma metnbrane rafts. Mol Biol Cell 2005;16:24-31.

31. Luiken II. Willems I, Coon SL, Coumans WA, Bonen A, Van Der Vusse Gl and Glaz JF. Effects of cAMP modulators on tongchairy tatryacid uptake and wtlization by electrally stimulated rat cardiac myocyles. Blochem 1. 2002; 307.8817.

32. Asch AS, Liul, Brccetu FM, Banwell JW, kwakye Berko F, Dokun A, Goldberger and Pernambuco M. Analysis of CD30 binding domains: ligand specificity controlled by dephosphorylation of an ectodoman. Science. $1003 ; 202: 1436-40$.

33. Tho $\mathrm{N}$, Wagner $\mathrm{SI}$ and Lublin DM. CD30 is palmitoylated on both $\mathrm{N}$ - and C-terminal cyoplasnic tails. J Biol Crem. 1096:271:22315:20.

34. Hatmi M. Gavart JM, Elatamy I, vargattig BB and Jacquemin C. Evidence for CAMPdependent plarelet ectoprotein kinase activity that phosphorytates platelet glycoptotein IV (CD36). / Biol Chern. 1996;271:24770.80.

35. Guthmann F, Maenl P. Preiss I, Kolleck I and Ruslow B. Ectoprotein kinase-mediated phosphorylation of FAT/CD30 regulates patmitate uptake by human platelets. Cell Mol Lfe Sci. 2002:50:1990-2003. 
36. Abumad NA, el Maghrahi MR, Amri E2, Lopez $\mathbb{E}$ and Grimaldi PA. Cloning of a rat adipochte membane protein implicated in binding or transport of long chan fatty acids that is induced during preadipocyte differentation. Homology with human CD30. J ERol Chem 1993268:17605-8.

37. Tandon WN, Kralisz U and Jamieson GA. Identfication of giycoprotein IV (CD36) as a primary receptor for plateletcollagen adhesion. / Biol Chem. 1989;264:7576-83.

38. Asch AS; Barnwell J, Silverstein RL and Nachman RL. Isolation of the thrombospondin membrane receptor / Chn Invest. $1987 ; 79: 105461$.

39. Endemann G, Stanton LW, Madden KS, Bryant CM, White RT and Protter AA. OD36 is a receptor for oxidized low derisity lipoprotein. I bial Chem. 1993;268:118116.

40. Kim H, Haluzik M, Asghar 2 , Yau D, Joseph IW, Femandez AM, Reitman ML Yakar S, Stannard B, Heron Mithavet $L$, Wheeler MB and LeRoith D. Peroxisome prolferatoractivated receptoratpha agonist treatment in a transgenic model of type 2 diabetes reverses the lipotoxic state and improves glicose honestasis. Diabetes. 2003:52:1770-8. 


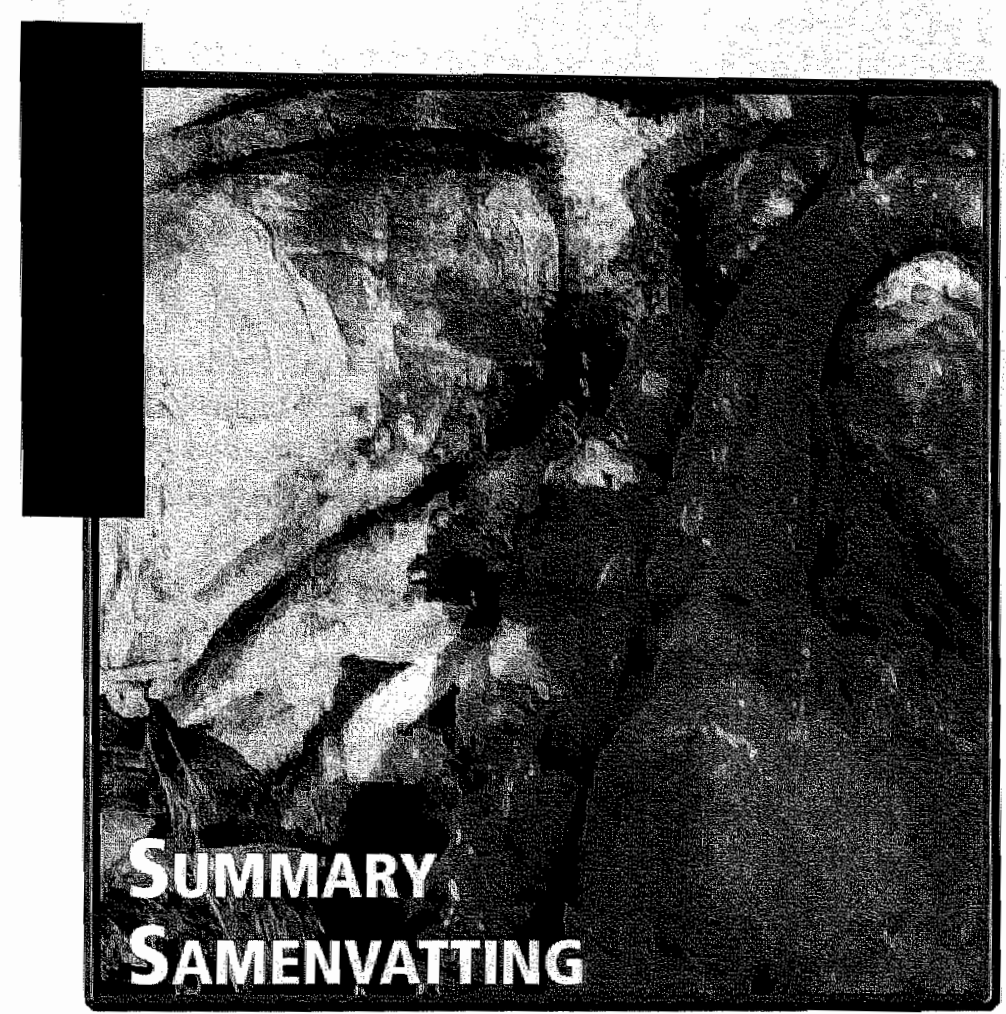




\section{SUMMARY}

The heart predominantly consists of specialized muscle cells, cardiac myocytes, which perform contractions in a coordinated fashion. These contractions require large amounts of energy in the form of ATP which is generated by oxidation of substrates. Under normal physiological conditions cardiac myocytes predominantly utilize long-chain fatty acids (LCFAs, 60-70\%), with the remainder covered by carbohydrates, i.e., glucose $(20 \%)$ and lactate (10\%). The cellular uptake of these substrates is regulated by the sarcolemmai content and activity of specific transport proteins. GLUT4 is the main glucose transport protein in the heart and is not only present at the sarcolemma, but also in intracellular compartment stores from where it can translocate to the sarcolemma. It has been well described that both the hormone insulin and an increased workload induce translocation of GLUT4 from the intracellular stores to the sarcolemma resulting in an increased glucose uptake by cardiac myocytes. Although both stimuli increase glucose uptake different signalling pathways are activated. Insulin acts via the activation of phosphatidylinositol-3 kinase $\left(\mathrm{PI}_{3} \mathrm{~K}\right)$, whereas cellular contractions induced adenosine monophosphate kinase (AMPK) activity. Several putative transport proteins are involved in the LCFA uptake process; (i) fatty acid translocase (FAT), the rat homolog of human CD36, (ii) plasmalemmal fatty acid binding protein (FABPpm) and (iii) fatty acid transport protein (FATP). There is evidence that the amount of FAT/CD36 at the sacrolemma is the ratelimiting step in the LCFA uptake process. Like GLUT4, FAT/CD36 is located both at the sarcolemma and in intracellular storage compartments. Recently, we demonstrated that insulin is also able to increase myocardial LCFA uptake by inducing FAT/CD36 translocation via activation of $\mathrm{PI}_{3} \mathrm{~K}$. However, whether the regulation of FAT/CD36-mediated LCFA uptake by an increased workload resembles that of GLUT4-mediated glucose uptake was unknown.

Several studies presented in this thesis give new insights into the effect of cellular contractions in rat cardiac myocytes on, (i) FAT/CD36-mediated LCFA uptake and (ii) the intracellular signalling pathway affecting LCFA utilization. We were the first to demonstrate that upon cellular contractions FAT/CD36 translocates to the sarcolemma resulting in an increased uptake of LCFAs. Interestingly, we showed that activation of AMPK is involved in this contraction-induced translocation of FAT/CD36 (Chapter 3). Although the manner in which cellullar contractions induce glucose uptake resembles that of LCFA uptake, we showed that it is possible to recruit FAT/CD36 to the sarcolemma without affecting the subcellular localization of GLUT4. The universal phosphodiesterase-inhibitor, dipyridamole, is able to induce FAT/CD36-mediated LCFA uptake in a contraction-like manner, but has no effect on glucose uptake (Chapter 4). This latter study suggests that beyond AMPK the contractioninduced signalling pathway branches off into separate mobilizations of GLUT4 and of FAT/CD36.

Besides AMPK, we were also interested in other kinases that could be involved in the contraction-induced increase in LCFA uptake. Attractive candidates are members of the protein kinase C (PKC) family. The PKC family consists of three subfamilies, conventional, novel and atypical PKCs. Conventional and novel PKCs can be activated by phorbol myristate acetate (PMA), a diacylglycerol (DAG) analog. The activation of AMPK during cellular contractions can be pharmacologically mimicked by oligomycin, a mitochondrial $F_{1} / F_{0}$ ATPase inhibitor 
which elevates that intracellular AMP/ATP ratio. We indeed demonstrated that PKCs are involved in oligomycin-induced LCFA uptake (Chapter 5). Moreover, we showed that the effect of oligomycin and PMA are non-additive suggesting that the activated PKC should have a DAG-binding domain. However, additional studies are needed to disclose which specific PKC isoform is actiwated in the contraction signalling resulting in an increased LCFA uptake.

After identifying that both insulin and cellular contractions stimulate FAT/CD36-mediated LCFA uptake by cardiac myocytes we were interested in whether the effects of these stimuli are altered during obesity and insulin resistance. It is believed that alterations in myocardial LCFA utilization in obesity and type-2 diabetes mellitus (T2DM) can contribute to the development of cardiac dysfunction. The incidence of obesity and T2DM is drastically increasing worldwide and heart failure is one of the main causes of morbidity and death in these patients. Therefore, identifying the mechanism involved in the alterations in LCFA utilization in these conditions will contribute to finding new therapeutically approach to prevent or treat cardiac dysfunction.

We demonstrated that in cardiac myocytes from obese, insulin resistant rats, under basal conditions, FAT/CD36 was to a large extent relocated to the sarcolemma at the expense of intracellular stores resulting in an increased LCFA uptake rate (Chapter 6). Whereas insulin stimulated the FAT/CD36-mediated LCFA uptake by cardiac myocytes in lean rats it failed to do so in obese rats. Oligomycin was able to induce the myocardial LCFA uptake rate in both lean and obese rats, but only in lean rats more FAT/CD36 was recruited to the sarcolemma. In cardiac myocytes from obese rats the intracellular amount of triacylglycerols (TAGS) and non-esterified LCFAs, and the intracellular incorporation rate of LCFA into TAGs were markedly elevated already under basal conditions. It should be mentioned that insulin directs the intracellular LCFAs towards storage and cellular contractions directs them into the mitochondrial oxidation. In vitro insulin-treatment of cardiac myocytes from obese rats does not further induce the incorporation rate into TAGs. In obese rats oligomycin was still able to induce the myocardial LCFA oxidation rate. Thus in vitro cardiac myocytes from obese rats, while sensitive to contraction-like stimulation, are completely insensitive to insulin. Thus, the basal condition in hyperinsulinemic, obese rats resembles the insulin-stimulated condition in lean rats. Finally, it was found that each the metabolic processes altered under basal conditions in cardiac myocytes from obese rats were normalized by specific inhibition of FAT/CD30, indicating the involvement of this transport protein.

A new class of insulin sensitising agents, i.e., thiazolidinediones (TZDs) are commonly used to treat insulin resistance in obesity and T2DM. TZDs are peroxisome proliferator activated receptor y (PPARy) agonists. PPARy is a nuclear hormone receptor predominantly expressed in adipose tissue, but which is also present, although in lower levels, in skeletal muscle and heart. We investigated whether in the insulin-sensitizing effect of rosglitazone (Rgz), a member of the TZD family, alterations in (i) the capacity to take up LCFAs and (ii) the total and plasmalemmal protein content of membrane-associated LCFA transport proteins, i.e., FAT/CD36, FABPpm and FATP1, in adipose tissue, heart and skeletal muscle are involved [Chapter 7]. In adipose tissue from obese, insulin resistant rats treated for 16 days with Rgz, the LCFA uptake capacity increased coinciding with increased total tissue contents of 
FAT/CD36 and FATP1, but not of FABPpm, whereas only the protein content of FAT/CD36 plasma membrane was elevated. The increase in the LCFA uptake capacity in adipose tissue was associated with a decline in plasma FAs and TAGs, suggesting that Rgz-treatment enhanced plasma FA extraction by adipocytes. In obese heart, Rgz-treatment had no effect on the LCFA transport system, yet the total TAG content decreased, suggesting enhanced cardiac insulin sensitivity. Although in skeletal muscle, the LCFA transport system also remained unaltered, the tissue TAG content did not change. However, the skeletal muscle content of cytoplasmic adipose-type FABP, a marker of differentiated adipocytes increased, indicating that the extramyocellular TAG increased. In conclusion, this study implicates. FAT/CD36 in the mechanism by which Rgz, in obese rats, redirects the FA flux towards adipose tissue, causing plasma FA and TAG concentrations to decline, and reducing intramyocellular lipid overload, which most likely results in increased muscle insulin sensitivity.

FAT/CD36 is believed to play a pivotal. role in the development of cardiac dysfunction in obesity and T2DM. We showed that in vitro sulfo- $N$-succinimidyl esters of LCFAs inhibit FAT/CD36-mediated LCFA uptake by cardiac myocytes without directly affecting its metabolism (Chapter 8). However, the in wivo effect of these acyl esters on cardiac LCFA utilization remains to be elucidated. Several strategies for future studies to improve cardiac function and insulin sensitivity during obesity and T2DM are discussed in Chapter 9 . We believe that an agent that specifically reduces FAT/CD36-mediated LCFA uptake by cardiac myocytes could be of great value in the fight against the development of diabetic cardiomyopathy. 


\section{Samenvatting}

Het hart bestaat voornamelijk uit spiercellen die gecoördineerd contraheren. De energie die nodig is om te contraheren wordt gegenereerd uit het verbranden van voedingstoffen. Onder fysiologische omstandigheden verbranden hartspiercellen voomamelijk langketenige vetzuren $(60-70 \%)$. De overige energie wordt gehaald uit de verbranding van koolhydraten, glucose $(20 \%)$ en melkzuur (10\%). Voordat glucose en vetzuren verbrand kunnen worden passeren ze eerst het ominulsel van de hartspiercel, de zogenaamde plasmamembraan. In de plasmamembraan bevinden zich transporteiwitten die de opname van glucose en vetzuren reguleren. GLUT4 is het voornaamste glucose transporteiwit in het hart en is niet alleen aanwezig in de plasmamembraan maar ook in intracellulaire opslagruimtes. In hartspiercellen wordt een verplaatsing van GLUT4 van de intracellulaire opslagruimtes naar de plasmamembraan geïnduceerd door zowel het hormoon insuline als door contracties. Ondanks dat beide stimuli de opname van glucose verhogen worden er verschillende intracellulaire signaaltransductieroutes geactiveerd. Insuline activeert phosphatidylionositol-3 kinase $\left(\mathrm{PI}_{3} \mathrm{~K}\right)$ en contracties stimuleren adenosine monofosfaat kinase (AMPK). Bij de opname van vetzuren zijn meerdere transporteiwitten betrokken; (i) vetzuur translocase (FAT), de rathomoloog van het humane CD36, (ii) plasmalemmaal vetzuurbindend eiwit (FABPpm) en (iii) vetzuurtransporteiwit (FATP). De hoeveeilheid FAT/CD36 aanwezig in de plasmamembraan wordt gezien als de snelheidsbepalende stap in de opname van vetzuren. FAT/CD36 is net als GLUT4 aanwezig in zowel de plasmamembraan als in intracelluaire opslagruimtes. Eerder is aangetoond dat in hartspiercellen onder de invloed van insuline ook FAT/CD36 verplaatst van de opslagruimtes naar de plasmamembraan. Doordat er meer FAT/CD36 aanwezig is in de plasmamembraan neemt de vetzuuropname in deze cellen toe. Of de regulatie van FAT/CD36-gemedieerde vetzuuropname tijdens contracties gelijk is aan die van de GLUT4-gemedieerde glucose opname is een van de bevindingen die voortvloeien uit dit proefschrift.

Studies die gepresenteerd worden in dit proefschrift geven nieuwe inzichten in het effect van contracties in hartspiercellen van ratten op, (i) de FAT/CD36-gemedieerde vetzuuropname en (ii) de intracelluiaire signaaltransductieroute die betrokken is bij het verbruik van vetzuren. Wij hebben aangetoond dat onder invloed van contracties FAT/CD36 naar de plasmembraan verplaatst waardoor de opname van vetzuren toeneemt (Hoofdstuk 3). Tevens is gebleken dat een verhoogde AMPK activiteit betrokken is bij de stimulatie van de vetzuuropname tijdens contracties. De manier waarop contracties de opname van glucose stimuleert vertoont een grote gelijkenis met de manier waarop de vetzuuropname toeneemt. Wij hebben echter laten zien dat het mogelijk is om FAT/CD36 naar de plasmembraan te rekruteren zonder dat de subcellulaire lokalisatie wan GLUT4 verandert. De universele fosfodiesterase-remmer, dipyridamole, is in staat om de FAT/CD36-gemedieerde vetzuuropiame te verhogen op een wijze die lijkt op de verhoging bij contracties, maar die geen effect heeft op de opname van glucose (Hoofdstuk 4). Deze studie suggereert dat de contractiegeinduceerde signaaltrans. ductieroute na AMPK afsplits in twee verschillende routes om GLUTA en FAT/CD36 te mobiliseren.

Naast AMPK waren we ook geïnteresseerd in andere kinases die betrokken zijn bij de contractiegeinduceerde verhoging van de vetzuuropname door hartspiercellen. Attractieve 
kandidaten zijn leden van de proteïne kinase C (PKC) familie. De PKC familie bestaat uit drie subfamilies, conventionele, nieuwe en atypische PKCs. Conventionele en nieuwe PKCs kunnen geactiveerd worden door phorbol myristaat acetaat (PMA), een diacylglycerol (DAG) analoog. Activatie van AMPK tijdens contracties kan farmacologisch nagebootst worden door oligomycine, een remmer van het mitochondriële $F_{1} / F_{0}$ ATPase. Door het tot in zekere mate remmen van $F_{1} / F_{0}$ ATPase stijgt de AMP/ATP ratio en wordt AMPK geactiveerd. We hebben aangetoond dat PMA de vetzuuropname in hartspiercellen verhoogt. (Hoofdstuk 5). Tevens hebben we laten zien dat dit effect van PMA niet additief is aan het stimulerende effect van oligomycine. Deze bevindingen suggereren dat een PKC met een DAG-bindend domein betrokken is bij de oligomycine-geinnduceerde vetzuuropname in hartspiercellen. Additionele studies zuilen moeten uitwiizen welke specifieke PKC isoform geactiveerd wordt.

Nadat gebleken is dat zowel insuline als ook contracties de FAT/CD36-gemedieerde vetzuuropname in hartspiercellen verhogen, waren we geinteresseerd in het effect van deze twee stimuli tijdens abesitas en insulineresistentie. Veranderingen in het vetzuurverbruik door hartspiercellen tijdens type-2 diabetes mellitus (T2DM) zouden kunnen bijdragen aan de ontwikkeling van diabete cardiomyopathie. De incidentie van obesitas en T2DM stijgt wereldwijd gestaag en hartfalen is een van de voornaamste oorzaken van morbiditeit en mortaliteit in deze patiëntengroepen. Door het ontrafelen van het mechanisme dat betrokken is bij veranderingen in vetzuurverbruik zou er mogelijk gerichter gezocht kunnen worden naar manieren voor de preventie en behandeling van diabete cardiomyopathie.

Wij hebben aangetoond dat onder basale condities significant meer FAT/CD36 aanwezig is in de plasmamembraan van hartspiercellen wan obese ratten (Hoofdstuk 6). Aangezien de totale hoeveelheid FAT/CD36 niet verandert en de intracellulaire hoeveelheid is afgenomen, lijkt het erop dat FAT/CD36 permanent verplaatst is naar de plasmamembraan. Deze verplaatsing van FAT/CD36 zorgt voor een chronische toename van de vetzuuropname. Terwijl insuline de FAT/CD36-gemedieerde vetzuuropname door hartspiercellen stimuleert in slanke ratten is het hormoon hiertoe niet in staat in obese ratten. Daarentegen stimuleert oligonycine de vetzuuropname in hartspiercellen van zowel slanke als van obese ratten, maar alleen in slanke ratten is er meer FAT/CD36 naar de plasmamembraan verplaatst. Al onder basale condities is de totale hoeveelheid triacylglycerolen (TAGs) en vetzuren in hartspiercellen van obese ratten hoger dan in slanke ratten. Tevens stijgt in hartspiercellen van obese ratten de snelheid waarmee extracellulaire vetzuren worden ingebouwd in intramyocellulaire TAGs. Onder fysiologische condities stimuleert insuline de opslag van extracellulaire vetzuren en stimuleren contracties de verbranding van deze vetzuren. In vitro behandeling van hartspiercellen van obese ratten met insuline laat de snelheid waarmee vetzuren worden ingebouwd in TAGs niet verder toenemen. In deze cellen is oligomycine nog steeds in staat om de snelheid warmee vetzuren worden verbrand te laten toenemen. Concluderend, in vitro zijn hartspiercellen van obese ratten gevoelig voor contractie-achtige stimulatie, maar ze zijn volledig ongevoelig voor insuline. De basale conditie in obese ratten lijkt dus op de insulinegestimuleerde conditie in slanke ratten. Tot slot hebben we in deze studie aangetoond dat elk van de metabole processen die veranderd zijn onder basale omstandigheden in hartspiercellen van obese ratten genormaliseerd kunnen worden door de specifieke remming 
van de activiteit van FAT/CD36. Deze bevindingen suggereren de betrokkenheid van FAT/CD36 in de veranderingen van het vetzuurverbruik die plaatsvinden in hartspiencellen tijdens obesitas en insulineresistentie.

Een nieuwe groep van medicijnen die de insulinegevoeligheid tijdens obesitas en T2DM verhogen zijn de thiazolidinediones (TZDs). TZDs zijn agonisten van peroxisoom proliferaton geactiveerde receptor $y$ (PPARY). PPAR $\gamma$ is een hormoonreceptor die aanwezig in de cekern. PPARy komt voornamelijk tot expressie in vetcellen, maar is in lagere hoeveetheden ook aanwezig in hart en skeletspier. We hebben onderzocht of rosiglitazone (Rgz), een lid van de TZD familie, invloed heeft op de eiwit-gemedieerde opname in vet-en spierweefsel van obese ratten (Hoofdstuk 7). In vetweefsel van obese, insulineresistente ratten die 16 dagen behandeld zijn met Rgz neemt de capaciteit waarmee vetzuren worden opgenomen toe. Dit gat samen met een verhoogde totale hoeveelheld van FAT/CD36 en FATP1, terwijl de totale hoeveelheid van FABPpm onveranderd is. Tevens is in de plasmamembraan alleen de hoeveelheid van FAT/CD36 verhoogd. De toegenomen vetzuuropnamecapaciteit in vetweefsel wordt geassocieerd met een verlaging van de concentratie vetzuren en TAGs in het bloedplasma. Dit suggereert dat door de behandeling met Rgz het vetweefsel meer vetzuren uit het plasma extraheert. In het hart van obese ratten heeft de Rgz behandeling geen effect op het vetzuurtransportsysteem, maar de totale hoeveelheid TAGs is verlaagd. Dit suggereert dat de insulinegevoeligheid van het hart toeneemt. In de skeletspier blikt dat naast het vetzuurtransportsysteem ook de totale TAG hoeveelheid onveranderd blift. De hoeveelheid van cytoplasmatisch adipose type FABP (A-FABPC), een marker voor gedifferentieerde vetcellen, neemt echter toe. Deze toename in A.FABPC toont aan dat de extramyocellulaire hoeveelheid TAG toeneemt. Concluderend, deze studie laat zien dat FAT/CD36 in obese ratten een belangrijke rol speelt in het mechanisme waarop $\operatorname{Rgz}$ de insulinegevoeligheid in spierweefsel verhoogt.

FAT/CD36 wordt gezien als een eiwit dat betrokken is bij de ontwikkeling van diabete cardiomyopathie. We hebben aangetoond dat in vitro de FAT/CD 36-gemedieerde vetzuuropname door hartspiercellen specifiek geremd kan worden middels sulfo-N-succinimidyl esters van langketenige vetzuren (Hoofdstuk 8). Het in vivo eflect van deze acyl esters op het vetzuur. verbruilk door het hart moet echter nog onderzocht worden. Verschillende strategieën voor verder onderzoek naar het verbeteren van de functie van het hart en de insulnegevoeligheid tijdens obesitas en T2DM worden bediscussieerd in Hoofdstuk 9. Wij denken dat specifieke remming van de FAT/CD36-gemedieerde vetzunopname doot hartspiercellen van grote waarde kan zijn in het gevecht tegen de ontwikkeling van diabete cardiomyopathie. 


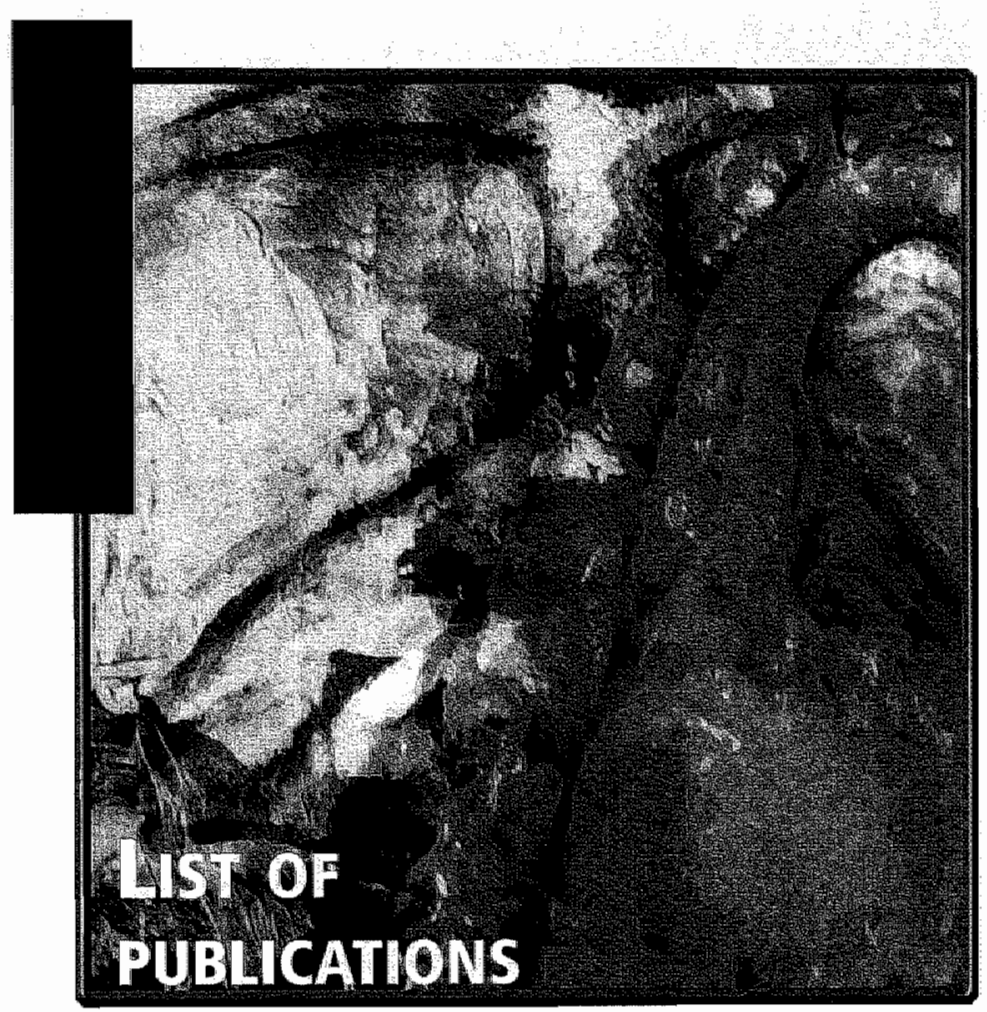




\section{LIST OF PUBLICATIONS}

1. Coort SLM, Bonen A, van dew Vusse GJ, Glatz IFC, Luken JIP. Cardiac substrate uptake and metabolism in obesity and type-2 diabetes: Role of substrate transport proteins. Mol Cell Biochem. (accepted).

2. Coort SLM, Coumans WA, Bonen A, van der Vusse CI, Glatz JFC, Luiken JIFP. Divergent effects of rosiglitazone protein-mediated fatiy acid uptake in adipose and muscle ussues of Zucker rats. Lipid Res. 2005:46:1295-302.

3. Chabowski A, Coort SLM, Calles-Escandon J, Tandon NN, GlaL2 LFC, Luiken JJP, Bonen A. The subcelluar comparmentation of faty acid transporters is regulated differenty by insulin and ACAR. FEBS letters 2005;579:2428-32.

4. Coort SLM, Hasselbaink DM, Koonen DPY, Wilems I, Coumans WA, Chabowski A, wan der Vusse GJ, Bonen A, Glatz JFC, Luiken JJFP. Enhanced sarcolemmal FAT/CD36 content and triacylglycerols storage in cardiac myocytes from obese Zucker rats. Diabetes 2004;53:1655-63.

5. Chabowski A, Coont SLM, Calles Escandon I, Tandon NN, Glatz IFC, Luiken JJFP, Bonen. A. Insulin stimulates fatty acid transport by regulating the expression of FAT/CD30 but not of FABPpm. Am J Physiol. 2004;287:-1:781-9.

6. Luiken JJF, Coort SLM, Koonen DPY, Bonen A, Glatz JFC. Signalling components involved in contraction-inducible substrate uptake into cardiac myocytes. Proc Nutr Soc. $2004 ; 63: 251-8$.

7. Bonem A, Campell SE, Benton CR, Chabowski A, Coort SLM, Han XX, Koonen DPY, Glatz JFC, Luiken JJPP. Regulation of fatty acid transport by fatty acid translocase/CD36. Proc Nutr Soc. $2004,63: 2459$.

8. Luiken J]FP, Coort SLM, Koomen DPY, van der Horst DI, Bonen A, Zorzano A, Clatz JFC. Regulation of cardiac long-chain faty acid and glucose upake by translocation of substrate twansporters. Pfugers Arch 2004;448:1-15.

9. Luiken JIPP, Coort SLM, Willems I, Coumans WA, Bonen A, Gatz IFC. Dipvridamole alters cardiac substrate preference by inducing translocation of FAT/CD30, bult not of GLUT4. Mol Phatmacol. 2004;65:039-45.

10. Coort SLM, Luken JIPP, van der Vusse G], Bonen A, Glatz JFC. Increased FAT (fatty acid translocase/CD36-mediated long-chain fatty acid uptake in cardiac myocytes from obese Zucker rats. Biochem Soc Trans. 2004;32:83.5. 
11. Schrauwen P, Hoeks J, Schaart G, Kornips E, Binas B, van der Vusse GI, van Bilsen M, Luken JJFP, Coort SLM, Glatz JFC, Saris WH, Hesselink MK. Uncoupling protein 3 as a mitochondrial farty acid anion transporter. FASEB J. 2003;17:2272-4.

12. Luiken JIFP, Coort SLM, Willems J, Coumans WA, Bonen A, wan der Vusse GJ, Glatz JFC. Contraction induced fatty acid translocase/CD 36 translocation in rat cardiac myocytes is mediated by AMPactivated protein kinase signalling. 2003;52:1627-34.

13. Coort SLM, Willems I, Coumans WA, wan der Vusse GI, Bonen A, Glatz JFC, Luiken IJFP. Sulfo N-succinimidyl esters of long.chain fatty acids specifically inhibit fatty acid translocase (FAT)/CD36-mediated cellular fatty acid uptake. Mol. Cell Biochern. $2002 ; 239: 213-9$. (review)

14. Luiken JJFP, Willems J, Coort SLM, Coumans WA, Bonen A, van der Vusse GJ, Glatz JFC. Effects of CAMP modulators on long chain fatty acid uptake and utilization by electrically stimulated rat cardiac myocytes. Blochem J. 2002;367:881.7.

\section{AwARDS}

1. Poster award at the $27^{\text {th }}$ Arnual Meeting of the European Lipoprotein Club at Tüzing, Germany, 2004.

2. Poster award at the $45^{\text {th }}$ Intermational Conference on the Bioscience of Lipids (ICBL), a special FEBS meeting at Ioànnina, Greece, 2004.

3. Poster award for innovative research at the Euregional Life Sciences Conference, Cells at Work at Maastricht, the Netherlands, 2002. 


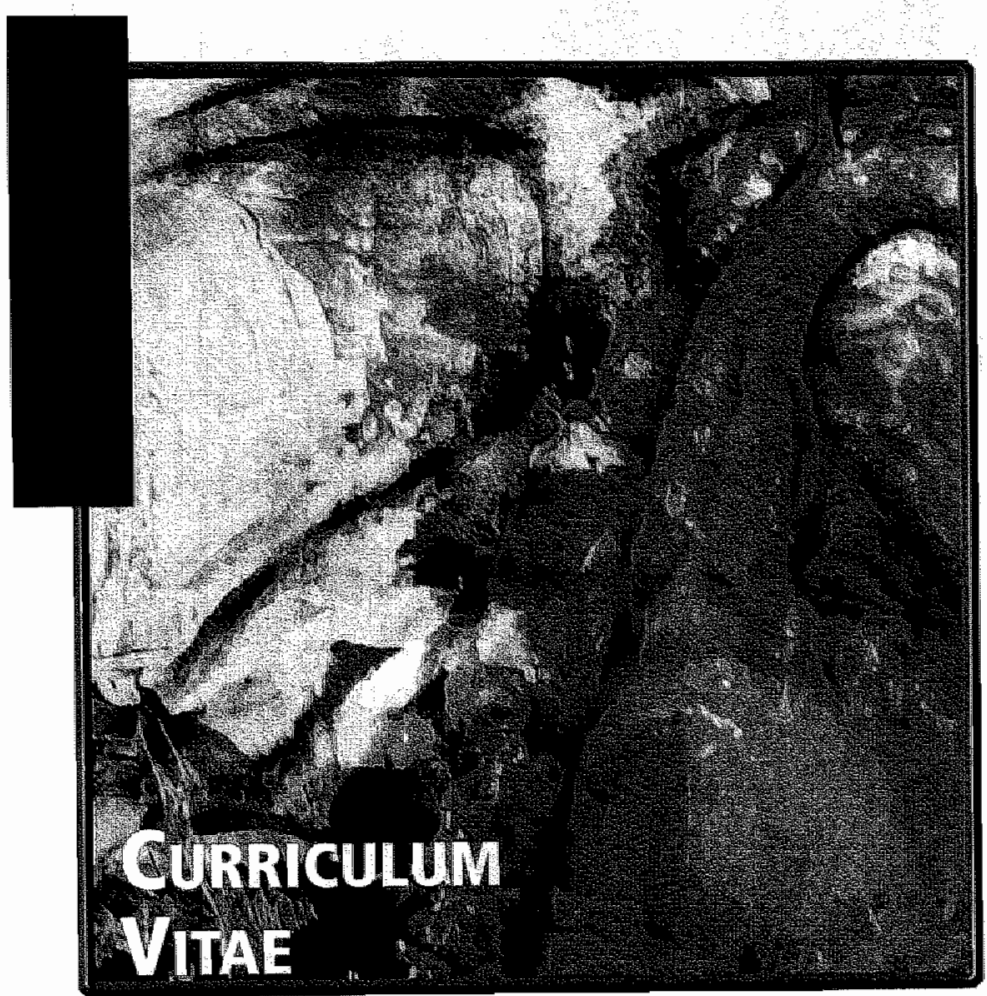


$\begin{array}{ll}\text { Surname } & \text { Coort } \\ \text { First names } & \text { Susan Leonie Marie } \\ \text { Date of birth } & \text { February 9, 1978 } \\ \text { Place of birth } & \text { Limbricht, the Netherlands }\end{array}$

Education

1990-1996 Athenaeum, Stelia Maris College, Meerssen, the Netherlands.

1990-2000 Biological Health Sciences, Maastricht University, the Netherlands.

$2000 \quad$ Licence of working with laboratory animals.

Certificate: "Artikel 9 functionaris"

2001-2004 Ph.D.-course programme of the Cardiovascular Research Institute Maastricht (CARIM).

2002

Course on radiation protection and health physics.

Certificate: "Deskundigheidsniveau 5b"

Research

2000

Internship for 6 months at the department of Pharmacology \& Toxicology, Maastricht University, Maastricht, the Netherlands, under the supervision of Dr. ir. C.T.A. Evelo.

2000 Internship for 3 months at the Research Institute of Toxicology (RITOX), Utrecht University, Utrecht, the Netherlands, under the supervision of Dr. R.H. Pietersen.

2001-2005 Ph.D. student at the departments of Genetics \& Cell Biology and Physiology, Cardiovascular Research Institute Maastricht (CARIM), Maastricht University, Maastricht, the Netherlands, under the supervision of Prof. dr. J.F.C. Glatz, Prof. dr. G.J. van der Vusse and Dr. J.J.F.P. Luiken.

2002

Working visit of 4 months at the department of Kinesiology, Waterloo University, Waterloo, Ontario, Canada, under the supervision of Prof. dr. A. Bonen. This visit was financed by "de Stichting De Gelderfonds" of the Netherlands Heart Foundation.

2005

ICP post-doctoral fellowship at the department of Hormone and Metabolic Research Unit, Université Catholique de Louvain, Brussels, Belgium, under the supervision of Prof. dr. L. Hue, Prof. dr. M.H. Rider and Dr. D. Vertommen. 


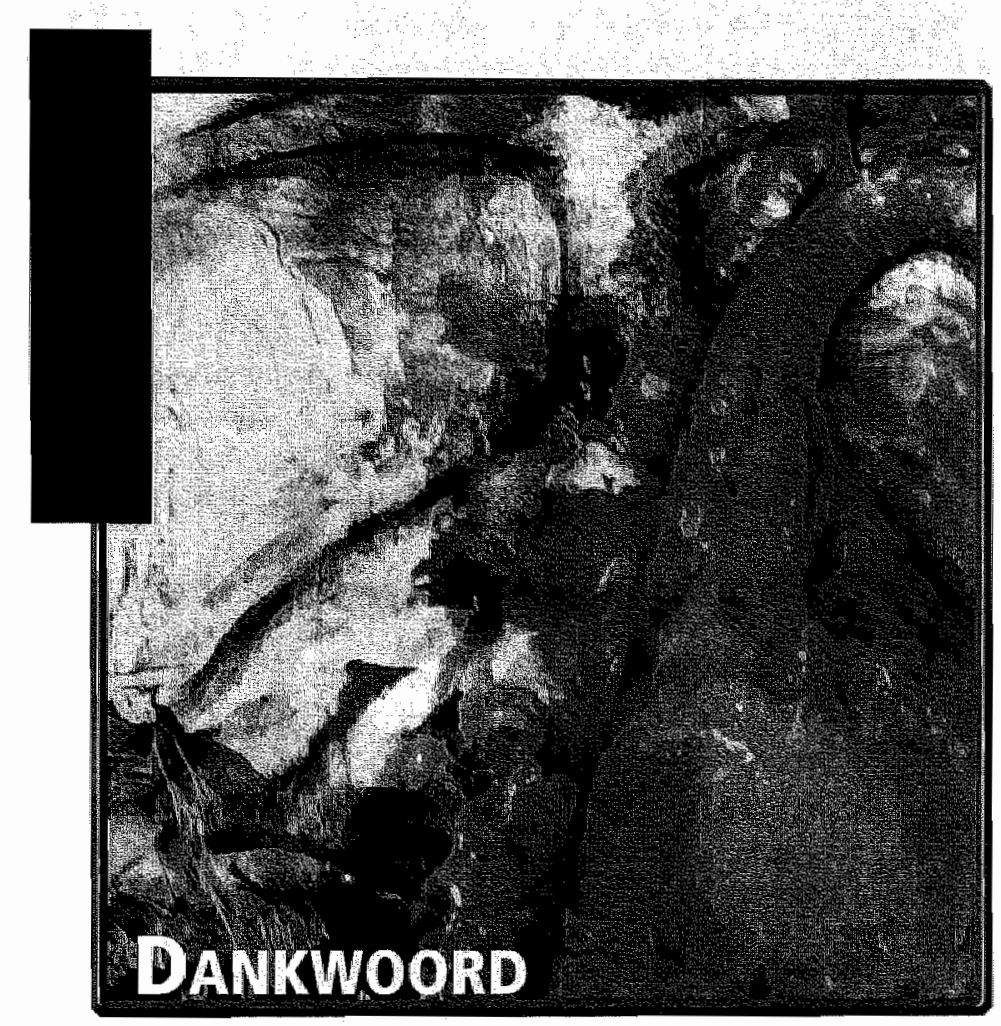


Na vier jaar met veel plezier aan mijn promotieonderzoek te hebben gewerkt, is het nu toch echt zover: het proefschrift is af. Het tot stand komen van dit proefschrift zou niet zijn gelukt zonder cle hulp en steun van anderen. Nu is het dan ook tijd om de mensen te bedanken die hebben biggedragen aan een succesvolle promotieperiode.

Allereerst wil ik mijn promotieteam, bestaande uit mijn twee promotores Prof. dr. J.F.C. Glatz en Prof. dr. G.J. van der Vusse en co-promoter Dr. J.J.F.P. Luiken, bedanken.

Beste Jan, ten eerste bedankt dat je me de mogelijkheid hebt gegeven om mijn promotieonderzoek bij jouw groep uit te voeren. Je deskundigheid, toewijding en optimisme maakten deze AlO-periode een waardevolle tijd waarin ik veel algemene en specifieke vaardigheden heb opgedaan. Als ik het even niet meer zag zitten wist je me weer te motiveren om door te gaan. De uitspraak "de aanhouder wint" is geheel op jou van toepassing.

Beste Ger, ondanks je drukke agenda maakte je altijd tijd voor mij vrij, zowel voor als tijdens de afronding van het proefschrift. Ik wil je bedanken woor je kritische en deskundige beoordeling van de manuscripten.

Beste Joost, jij bent degene die me wegwijs heeft gemaakt in de wereld van de geïsoleerde hartspiercellen. Ik heb veel van je geleerd. Je betrokkenheid bij mijn dagelijkse werkzaamheden en je enthousiasme heb ik zeer gewaardeerd. Af en toe verschilden we van mening wat betreft aanpak en interpretatie, maar de daaruit volgende discussies zijn het eindresultaat alleen maar ten goede gekomen.

Gedurende mijn AIO-periode heb ik de mogelijkheid gehad om een deel van het onderzoek uit te voeren in het laboratorium van Prof. dr. A. Bonen in Waterloo, Canada. Dear Arend, it was a pleasure to work with an expert in the field of muscle substrate metabolism and many thaniks for your hospitality. Even after my stay in Canada you stayed involved in my project, which I appreciated very much.

I also want to thank Adrian, Dave, Lisa, Miriam, Ted \& Marieke, Shannon \& Ben, Ruth, XiaoXia and Yoga, all (old) members of the Bonen-lab who each contributed to an unforgettable stay in Canada. A special thanks to Carley, you became a true friend. Your visits to Maastricht and the Keystone meeting in Alberta were wonderful. Good luck. with finishing your thesis and who knows maybe one day we will become colleagues again.

Een speciaal woord van dank gaat uit naar mijn twee paranimfen.

Beste Barbara, samen VWo en samen op kamers tijdens de studietijd. We hebben lief en leed gedeeld en je bent mijn beste vriendin. Het is vanzelfsprekend, geruststellend en zeer prettig dat je mijn paranimf bent.

Beste Hanneke, als zusje van Petra heb ik je leren kennen en nadat ik je als student heb mogen begeleiden, werd je uiteindelijk een collega AlO en kamergenootje. Bij jou kan ik altijd terecht en dat waardeer ik zeer. Ik vind het fantastisch dat jij mijn paranimf bent. 
Beste Jodil, de keren dat we samen de klok hebben rondgeteld zijn ontelbaar. Mede dankzij jouw inzet is de Zucker studie een succes geworden. Bedankt voor alle hulp bij de werkzaamheden op het lab en voor de eerste huip bij computerproblemen.

Beste Will, met een stralend humeur gaf je aan het werken op het lab iets speciaals. Jouw uitspraken zoals "het briesend paard" en "ho, ho..." staan al bekend als echte klassiekers. Bedankt voor het aanleren van de isolatie van vesicles en al je hulp op het lab.

Beste Maurice \& Daniëlle vd V, bedankt voor alle gezelligheid op en buiten het lab. Nog eventjes wachten en dan zijn jullie met z'n vijven, spannend!

Beste Debby, Masja en Daphna, geïsoleerde hartspiercellen zijn jullie allen niet vreemd. Debby, jij was al een jaartje bezig toen ik begon. Samen hebben we heel wat congressen en cursussen bezocht. Nu werk je als Post-doc in Canada en ik wens je veel succes toe. Masja en Daphna, veel succes met het afronden van jullie promotieonderzoek.

Gedurende mijn promotieonderzoek heb ik het genoegen gehad om bij twee verschillende capaciteitsgroepen binnen de Universiteit Maastricht te mogen werken.

Het begon allemaal bij Fysiologie. Ik wil dan ook de collega's van Fysiologie, Andries, Ben, Claire, Danny (bedankt voor al het krabwerk!), Frans, Geertje, Hans, Joep, Jos, Karin, Kristel, Luc, Marc, Mirjam, Pascal, Peter, Richard, Roy (jij bent de eerstvolgende van ons groepje, succes met de laatste loodjes), Theo en Viviane, bedanken woor een onvergetelijke tijd.

Mijn tweede thuisbasis werd Moleculaire Genetica. Arjen, Claudia, Daniëlle C, Guilaumme, Inge (wielrennen \& kolonisten, wanneer \& waar?), Iris (bedankt voor je interesse), Kristiaan, Le, Marion, Marten, Mathys, Menno, Mohammed (zorg je goed voor mijn oude plekje?), Monique \& Patrick, Petra \& Sander (bedankt voor de gezellige (kolonisten) avondjes), Ronit, Stjjn, Vivian, Willem, Wilma en Yana, bedankt voor alle leerzame en gezellige momenten. Mijn collega AlO's wens ik heel veel succes met het afronden van hun promotieanderzoek.

Beste Fysiologie-kamergenoten, lieve Anita, Veerle \& Miriam, we konden lief en leed samen delen. Ik wil jullie bedanken voor een geweldige tijd. Het kameruitje naar de Efteling was zeer geslaagd en is zeker voor herhaling vatbaar. Anita: heel veel succes met de laatste loodjes, het gaat je zeker lukken!

Dear Molgen-roommates, dear Céline, Frank, Hanneke \& Sofia, after a warm welcome l felt at home immediately. You each were a real help during the last stressful months of my Ph.D. project.

Alle medewerkers van de Centrale Proefdier Voorzieningen wil ik bedanken voor hun expertise bij het uitwoeren van diverse experimenten.

John \& Eric, bedankt voor de creatieve bijdrage aan dit proefschrift. 
Dr. Ir. C.T.A. Evelo, beste Chris, bedankt dat je me hebt gestimuleerd om door te gaan in het onderzoek. Mijn afstudeerstage heb ik als zeer leerzaam en prettig ervaren.

Beste Paul en llia, ik heb jullie adviezen en interesse voor en tijdens mijn AlO-periode altijd zeer op prijs gesteld.

Alle vrienden en in het bijzonder Jannie \& Maarten [de vakantie in Canada was geweldig!!, Barbara \& Owen, Linda \& Gaston, Fabiënne \& Raoul, Ingrid \& Geert en Anouk \& Johan wil ik bedanken voor de nodige ontspanning naast het werk en voor het medeleven tijdens het afronden van mijn proefschrift.

De familie Steinbusch; Harrie \& Fieny, Wilbert, Annegien, Jan \& Rik, Maurice, Tanja, Linde, Lara \& Tom bedankt voor al hun getoonde interesse. Wilbert nog bedankt voor het redden van mijn gecrashte memory stick!

Beste oma Mia en oma Mieke, bedankt dat jullie me al wan kleins af aan hebben bijgestaan. Jullie hebben altijd veel voor me betekend en ik hoop nog lang van jullie te mogen genieten.

Lieve Piep \& Miem, bedankt voor jullie steun, belangstelling en liefde. Jullie staan altijd voor me klaar. Alle adviezen die jullie me geven over belangrijke zaken in het leven stel ik zeer op prijs. Heel erg bedankt voor alles!

Lieve Erik, samen met jou ben ik begonnen aan het AIO-avontuur. Dat het niet altijd van een leien dakje gaat heb je van dichtbij meegemaakt. Bedankt dat je er onvoorwaardelijk voor me bent. Samen gaan we een mooie toekomst tegemoet.

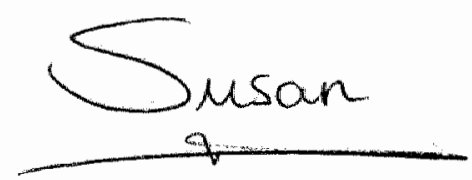


